UNIVERSIDADE DE SÃO PAULO

INSTITUTO DE QUÍMICA DE SÃO CARLOS

\title{
ESTUDO QUÍMICO E ESPECTROSCÓPICO DA DINÂMICA DA VERMICOMPOSTAGEM DE RESÍDUOS AGROINDUSTRIAIS PARA MANEJO SUSTENTÁVEL EM AGRICULTURA ORGÂNICA
}





\section{UNIVERSIDADE DE SÃO PAULO}

INSTITUTO DE QUÍMICA DE SÃO CARLOS

\section{ESTUDO QUÍMICO E ESPECTROSCÓPICO DA DINÂMICA DA VERMICOMPOSTAGEM DE RESÍDUOS AGROINDUSTRIAIS PARA MANEJO SUSTENTÁVEL EM AGRICULTURA ORGÂNICA}

Lívia Botacini Favoretto Pigatin

Tese apresentada ao Instituto de Química de São Carlos da Universidade de São Paulo como parte dos requisitos para a obtenção do título de Doutor em Ciências.

Área de concentração: Química Analítica e Inorgânica Orientadora: Maria Olímpia de Oliveira Rezende

São Carlos, SP

Março de 2017 

Stop wishing and start doing.

Chande you thoughts and you change your world. 



\section{A Deus}

Pela inspiração, força e sabedoria.

\section{OFEREÇO}

Aos meus pais Reinaldo e Goreti, meus exemplos de vida, caráter e determinação, por todo sacrifício que fizeram a vida toda, para que hoje eu chegasse aqui;

À minha avó e madrinha Helena, por sua força e fé inabalável, por todas as orações que sempre faz por mim. Em memória dos meus amados avós Isaura, Cido e João que tanta falta fazem, mas que em algum lugar devem estar vibrando por essa conquista;

Ao meu querido esposo Paulo, meu companheiro de todas as horas, por estar sempre ao meu lado, me apoiando em cada etapa de minha vida acadêmica. Pela ajuda com os experimentos de campo e por me aguentar nos meus momentos de ansiedade e estresse por causa da Tese;

À minha amada filhinha Ana Elisa, que acompanhou boa parte das minhas "aventuras" neste Doutorado, desde a minha barriga, até o último congresso juntas;

Ao meu pequeno príncipe Gabriel, que também vem acompanhando as últimas etapas desta jornada. 



\section{AGRADECIMENTOS}

À Dra. Maria Olímpia de Oliveira Rezende pela orientação, confiança, amizade e diversas oportunidades durante a realização deste trabalho. Meus sinceros agradecimentos.

À FAPESP, pela grande oportunidade e pela bolsa concedida (Processo 2011/132947).

À Usina Raízen Energia S/A (unidade de Ibaté, SP), à Indústria de Alimentos Fruthil do Grupo Hildebrand e à Fazenda Pigatin pela concessão dos resíduos orgânicos para estudo. E ainda à Fazenda Pigatin e Sítio São Pedro pela infraestrutura para montagem do experimento de vermicompostagem.

Ao Dr. Aurélio Vinicius Borsato, meu coorientador e à Embrapa Pantanal, pelo auxílio na montagem dos experimentos agronômicos e pelo seu atencioso acompanhamento durante todo o trabalho. À Dra Maria Diva Landgraf e ao Dr. Marcelo Luiz Simões, pela valiosa colaboração na realização deste trabalho.

Ao Instituto de Química de São Carlos da Universidade de São Paulo e à Embrapa Instrumentação pela infraestrutura e pelo excelente ambiente de trabalho.

Ao Dr. Ladislau Martin-Neto, meu orientador no Mestrado e ao Dr. Wilson Tadeu Lopes da Silva por terem me deixado "as portas abertas" na Embrapa Instrumentação. À Dra Debora Milori e ao Dr. Eduardo Bessa Azevedo pela colaboração na pesquisa. À querida Profa. Dra. Eny Maria Vieira, pela amizade, companheirismo e oportunidades.

À Dra. Magali Benjamin de Araújo, minha orientadora de Iniciação Científica na UnifalMG. Meus sinceros agradecimentos por ter sido minha primeira orientadora nesta vida acadêmica.

Ao meu marido Paulo, pelo amor, cumplicidade e total apoio durante todos esses anos. Aos meus pais, pelas sábias palavras, pelos incansáveis conselhos em todos os momentos e pela valiosa ajuda com os cuidados de meus filhos, para que eu 
pudesse finalizar o doutorado da melhor forma possível. Ao meu irmão André e toda minha família pelo apoio e carinho.

Aos amigos do Laboratório de Química Ambiental, Fernanda, Andressa, Rut, Rachide, Leandro e Darlan, meus agradecimentos pela agradável convivência e amizade.

Ao amigo nigeriano Idowo, pela amizade e pelo valioso auxílio nas análises estatísticas.

Aos amigos da Embrapa, Lilian, Bruno, Cleber, Joana, Fernanda, Ursula, Larissa e Poliana, pela companhia, conversas e risadas, aprendi muito com cada um de vocês desde o início do estágio na Embrapa em 2008.

Às minhas amigas de faculdade e de infância, Danianne (Danão), Dani Semedo, Saionara, Lívia (Livinha), Tatiana (Tatão), Polyana, Giovana, Taís, Ana Lívia, Flaísa e Marina, meus agradecimentos pelo incentivo e amizade de sempre. 


\section{RESUMO}

A destinação dos resíduos sólidos constitui um sério problema ambiental para a humanidade. Por meio do processo de vermicompostagem, pode-se obter a reciclagem dos resíduos orgânicos, resultando em um material mais humificado, de grande potencial agrícola e de sequestro de carbono atmosférico quando aplicado ao solo. Para que se tenha segurança agronômica quando da utilização de resíduos é necessário que se conheçam os mecanismos de incorporação, mineralização e liberação de nutrientes, ou seja, a dinâmica da matéria orgânica no solo. Dessa forma, contribui-se para a manutenção do ciclo da matéria orgânica (devolvendo ao solo parte da matéria orgânica que Ihe é tirada), e também para uma destinação ambientalmente adequada de resíduos orgânicos. Esta é a orientação geral deste estudo. Compilando os resultados obtidos por métodos convencionais e técnicas espectroscópicas para caracterização das amostras coletadas durante a vermicompostagem dos ácidos húmicos extraídos, foi possível fazer o monitoramento contínuo do processo de degradação de diferentes resíduos orgânicos (bagaço de laranja, torta de filtro e esterco bovino). Para execução dos experimentos foram montadas 9 pilhas $(\mathrm{P})$ de compostagem de bagaço de laranja + esterco bovino, torta de filtro + esterco bovino e esterco bovino (100\%). Após a estabilização da temperatura os compostos foram tranferidos aos vermicompostores. O monitoramento foi realizado por 135 dias com medidas diárias de temperatura, controle semanal de umidade e coletas quinzenais das amostras para caracterização química e extração de ácidos húmicos. Observaram-se três fases de temperatura durante a primeira etapa da vermicompostagem (compostagem). Primeira fase: mesofílica, em que houve um aumento na temperatura, a qual alcançou valores superiores a $30^{\circ} \mathrm{C}$; segunda fase: termofílica, em que a temperatura atingiu valores máximos, superiores a $60^{\circ} \mathrm{C}$ para as pilhas P1, P2 e P3 (bagaço de laranja + esterco bovino), as quais apresentaram as temperaturas mais altas dentre os tratamentos; terceira fase: esfriamento e maturação. Foi possível acompanhar a dinâmica do processo de vermicompostagem química e espectroscopicamente. A caracterização química dos vermicompostos (teor de $\mathrm{C} \mathrm{e} \mathrm{N}, \mathrm{C} / \mathrm{N}, \mathrm{pH}, \mathrm{CTC}$, macro e micronutrientes) está de acordo com o que é exigido pela Instrução Normativa $n^{\circ} 25$, do Ministério de Agricultura, Pecuária e Abastecimento. Estas análises evidenciaram o potencial fertilizante dos vermicompostos produzidos. A análise das características estruturais dos ácidos húmicos revelou diferenças entre os ácidos húmicos estudados. Os espectros de FTIR referentes a todos os tratamentos apresentaram bandas típicas de substâncias húmicas indicando algumas transformações a nível molecular como a perda de estruturas mais lábeis devido ao processo de biodegração. A presença de sistemas aromáticos foi observada por meio da técnica de UV-Vis, principalmente por meio das baixas razões $E_{2} / E_{4}$, o que é indicativo da presença de estruturas porfirínicas relacionadas à lignina. Assim como os resultados apresentados por FTIR os espectros de $\mathrm{RMN}$ de ${ }^{13} \mathrm{C}$ apresentam picos correspondentes à degradação de carboidratos. Houve aumento do teor de aromaticidade e diminuição do teor de alifaticidade dos $\mathrm{AH}$ com o tempo de vermicompostagem, exceto para os referentes ao tratamento com torta de filtro que apresentou comportamento contrário. Em geral o desenvolvimento das plantas que receberam adubação orgânica foi similar ao 
desenvolvimento das plantas que receberam adubação mineral comercialmente recomendada e significativamente superior ao das plantas referente ao tratamento testemunha. Para o vertissolo o efeito dos vermicompostos sobre os atributos altura e biomassa das plantas foi mascarado, possivelmente pelo alto teor de matéria orgânica naturalmente existente naquele solo. A análise cromatográfica do óleo essencial extraído do Manjericão mostrou que a adubação orgânica influenciou positivamente a produção do principal componente do óleo essencial, o linalol, havendo aumento de seu teor com o aumento da dosagem de vermicomposto aplicado, nos dois solos estudados (latossolo e vertissolo). Dos tratamentos analisados, o referente à adubação com vermicomposto de torta de filtro + esterco bovino $30 \mathrm{t} \mathrm{ha}^{-1}$, em vertissolo, apresentou o maior teor de linalol (34,90 \%). De modo geral constata-se a viabilidade do uso de vermicompostos de misturas de bagaço de laranja e torta de filtro com esterco bovino como alternativa ao uso de fertilizantes minerais, contudo o manejo e as implicações na nutrição de plantas e a plena produtividade das culturas ainda representa desafio importante para as pesquisas. Dentre as doses dos vermicompostos avaliadas, em geral a aplicação da dosagem intermediária (30 t ha ${ }^{-1}$ ou 3,0\%) apresenta resultados superiores em termos de qualidade nutricional e da MOS, sendo dessa forma a melhor opção para manejo do solo para cultivo de Manjericão. Em estudos futuros, a dosagem $30 \mathrm{t} \mathrm{ha}^{-1}$ poderia ser adotada como dosagem agronômica recomendada, bem como a mistura de resíduos orgânicos agroindustriais para produção do vermicomposto. 


\section{ABSTRACT}

The disposal of solid waste is a serious environmental problem for humanity. By means of the vermicomposting process, one can get the recycling of organic waste, resulting in a humified material of great agricultural potential and atmospheric carbon sequestration when applied to soil. To have agronomic security when using waste is necessary to know the mechanisms of incorporation, mineralization and release of nutrients, or the dynamics of soil organic matter. Thus, it contributes to maintaining the organic matter cycle (returning to the ground of the organic matter that is taken away), and for an environmentally proper disposal of organic waste. This is the general direction of this study. Compiling the results obtained by conventional methods and spectroscopic techniques for characterization of samples collected during vermicomposting of extracted humic acids, it was possible the continuous monitoring of the degradation process of different organic waste (orange bagasse, filter cake and manure). For execution of the experiments were set 9 cells $(P)$ composting orange peel + cattle manure, filter cake + cattle manure and manure. After temperature stabilization compounds were tranferidos to vermicompostores. The monitoring was held for 135 days with daily measurements of temperature, humidity and weekly control fortnightly collections of samples for chemical and extraction of humic acids. They observed three stages of temperature for the first stage of vermicomposting (composting). First stage: mesophilic, wherein an increase in temperature, which reached values higher than $30^{\circ} \mathrm{C}$; second phase: Thermophilic, wherein the maximum temperature reached values higher than $60^{\circ} \mathrm{C}$ for stacks $\mathrm{P} 1, \mathrm{P} 2$ and $\mathrm{P} 3$ (orange peel + cattle manure), which had the highest temperature among treatments; third phase: cooling and maturation. It was possible to follow the dynamics of the process of chemical and spectroscopically vermicomposting. The chemical characterization of vermicompost ( $\mathrm{C}$ and $\mathrm{N}$ content, $\mathrm{C} / \mathrm{N}, \mathrm{pH}, \mathrm{CEC}$, macro and micronutrients) is in line with what is required by the Normative Instruction 25, the Ministry of Agriculture, Livestock and Supply. These analyzes showed the fertilizer potential of the vermicomposts. The analysis of the structural characteristics of humic acids showed differences between the studied humic acids. FTIR spectra for all of the treatments showed typical bands of humic substances indicating some changes at the molecular level as the loss of more labile structures due to the biodegradation process. The presence of aromatic systems was observed by UV-Vis technique mainly through the lower ratios $E_{2} / E_{4}$, which is indicative of the presence of porfirínicas structures related to lignin. As the results presented by FTIR the ${ }^{13} \mathrm{C}$ NMR spectra show peaks corresponding to the degradation of carbohydrates. There was an increase of aromaticity content and decreased alifaticidade content of $\mathrm{AH}$ with a time of vermicomposting, except for those related to treatment with filter cake which showed opposite behavior. In general the development of the plants that received organic fertilization was similar to the development of the plants that received commercially recommended mineral fertilization and significantly higher than the plants referring to the control treatment. For the vertisol the effect of the vermicompost on the height and biomass attributes of the plants was masked, possibly due to the high content of organic matter naturally present in that soil. The chromatographic analysis of the essential oil extracted from Manjericão showed that the organic fertilization positively 
influenced the production of the main component of the essential oil, linalol, increasing its content with the increase of the applied vermicompost dosage, in the two studied soils. Of the analyzed treatments, the one referring to the fertilization with vermicompost of filter cake + bovine manure $30 \mathrm{t} \mathrm{ha}^{-1}$, in vertisol, presented the highest content of linalool (34.90\%). In general, it is possible to verify the viability of the use of vermicompostos of mixtures of orange bagasse and filter cake with bovine manure as an alternative to the use of mineral fertilizers, however the management and the implications in plant nutrition and the full productivity of the crops still represents an important research challenge. Among the doses of vermicompost evaluated, in general the application of the intermediate dosage (30 $\mathrm{t} \mathrm{ha}^{-1}$ or $3.0 \%$ ) presents superior results in terms of nutritional quality and MOS, being thus the best option for soil management for cultivation Of Basil. In future studies, the $30 \mathrm{t} \mathrm{ha}^{-1}$ dosage could be adopted as the recommended agronomic dosage, as well as the mixture of agroindustrial organic residues for vermicompost production. 


\section{SUMÁRIO}

RESUMO

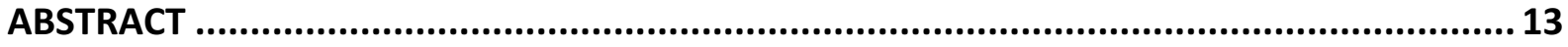

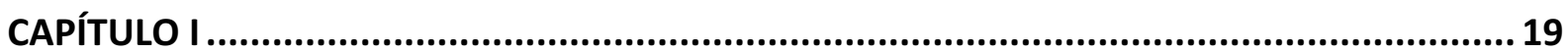

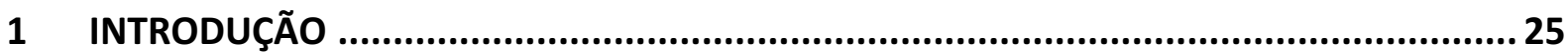

1.1 Resíduos Orgânicos: Produção e Potencial Agronômico .............................................25

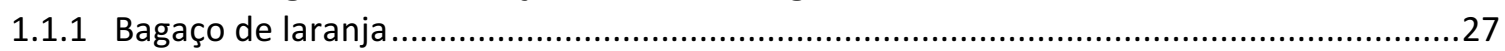

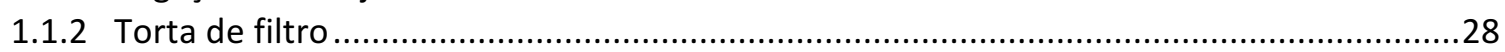

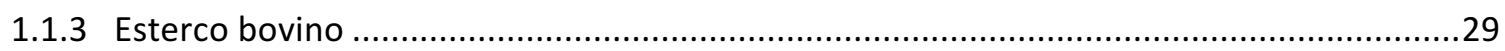

1.2 Reciclagem de Resíduos Orgânicos: Vermicompostagem...........................................29

1.3 A Importância do Incremento de Matéria Orgânica no Solo ..........................................31

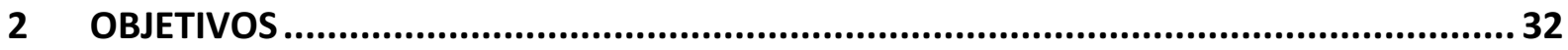

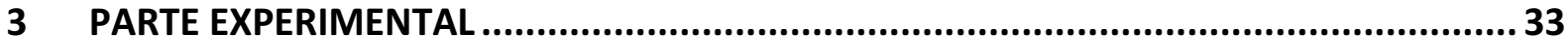

3.1 Caracterização dos Resíduos Orgânicos Agroindustriais ...............................................33

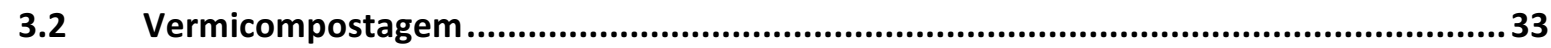

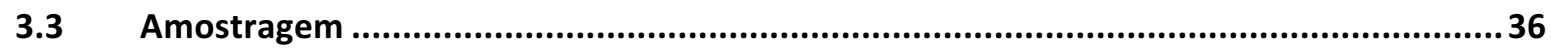

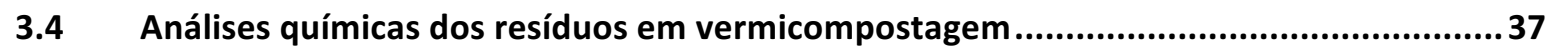

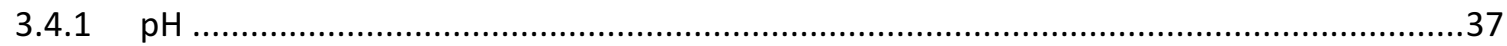

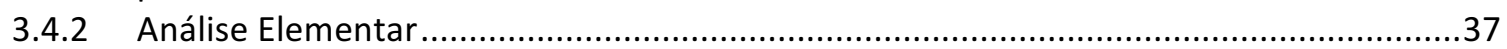

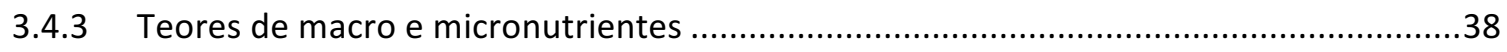

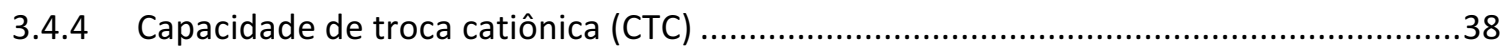

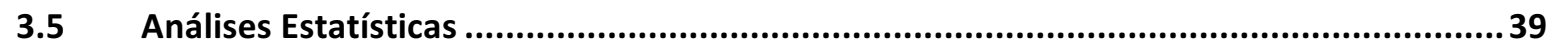

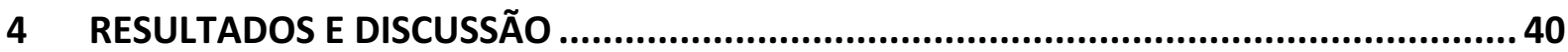

4.1 Caracterização Química dos Resíduos Frescos e Observações Experimentais ..................40

4.2 Monitoramento Físico e Químico do Processo de Vermicompostagem .............................41

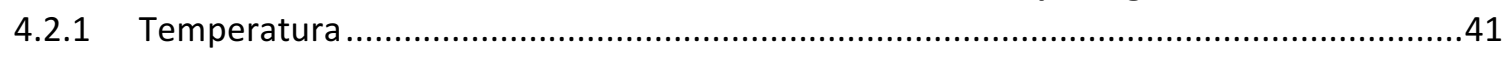

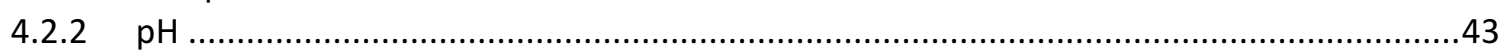

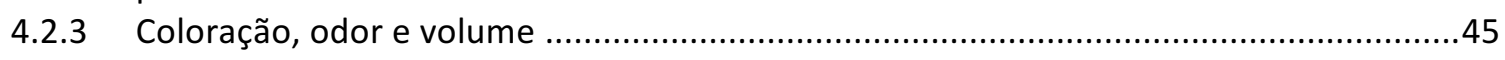

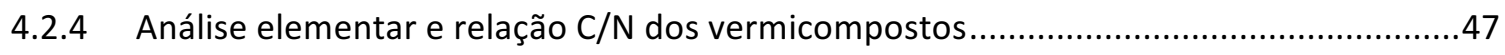

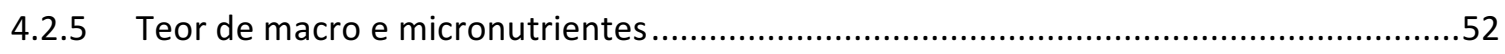

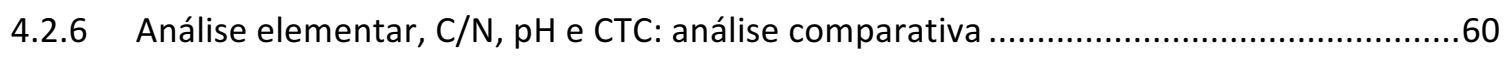

4.2.7 Correlações: macro e micronutrientes, análise elementar, $\mathrm{C} / \mathrm{N}, \mathrm{pH}$ e CTC .......................65

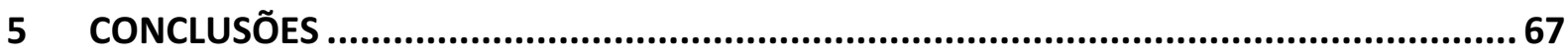

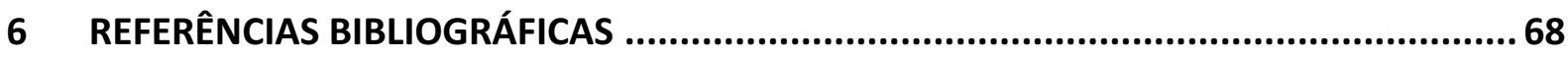

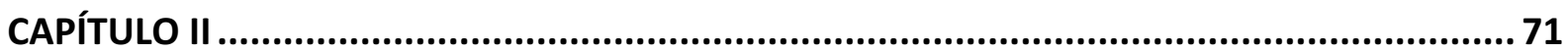

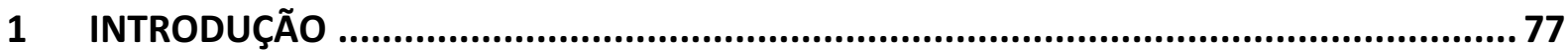

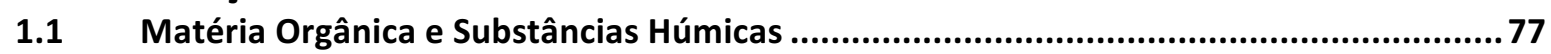

1.2 Caracterização dos Ácidos Húmicos.....................................................................78

1.2.1 Espectroscopia na região do infravermelho médio com transformada de Fourier

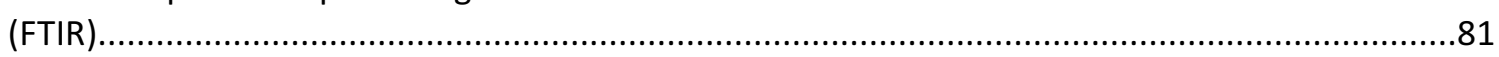

1.2.2 Espectroscopia de ressonância magnética nuclear de ${ }^{13} \mathrm{C}\left({ }^{13} \mathrm{C} R M N\right)$ - técnica de polarização cruzada com amplitude variável ( ${ }^{13} \mathrm{C}$ RMN VACP-MAS) ...........................................8.

1.2.3 Pirolisador acoplado à cromatógrafo à gás com detector de massas (P-CG/EM) ...........89 
1.2.4 Espectroscopia de absorção na região do UV-Visível ................................................91

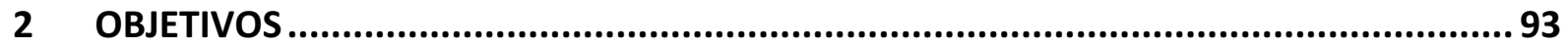

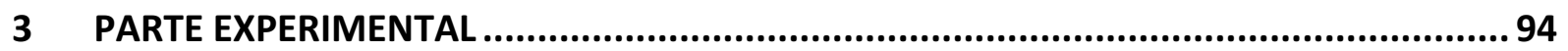

3.1 Extração, Isolamento e Purificação das Substâncias Húmicas ........................................94

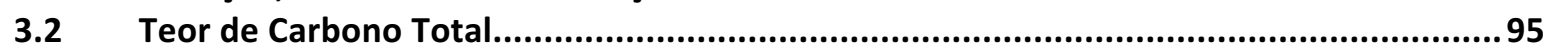

3.3 Espectroscopia na Região do Infravermelho com Transformada de Fourier (FTIR) ..........96

3.4 Espectroscopia de Absorção na Região do UV-Visível (UV-Vis) ...................................96

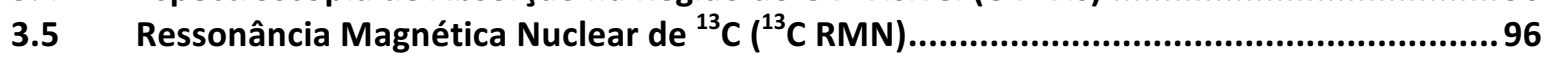

3.6 Pirólise acoplada à Cromatografia Gasosa com Detector de Espectrometria de Massas (P-

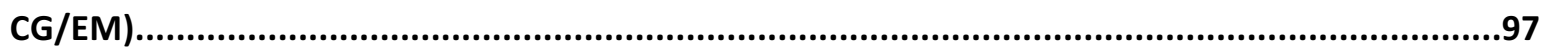

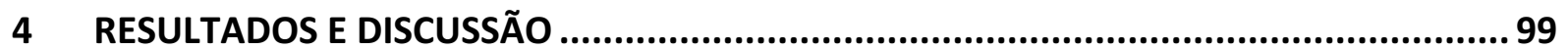

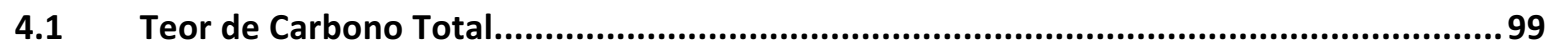

4.2 Espectroscopia na Região do Infravermelho com Transformada de Fourier (FTIR) ....... 100

4.3 Espectroscopia de Absorção na Região do UV-Visível (UV-Vis) ..................................... 103

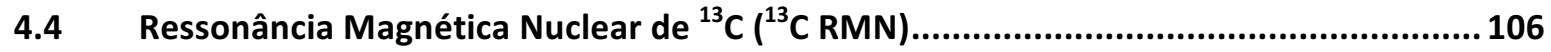

4.5 Pirólise Acoplada à Cromatografia Gasosa e Espectroscopia de Massas (P-CG/EM) ..... 111

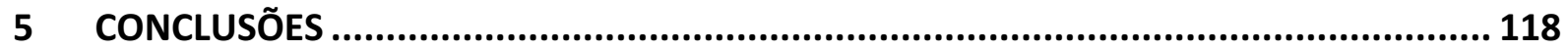

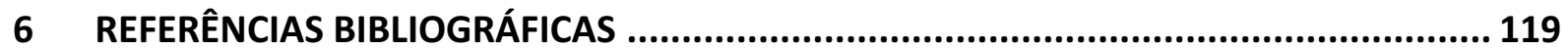

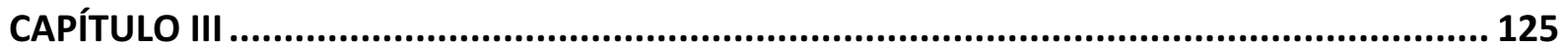

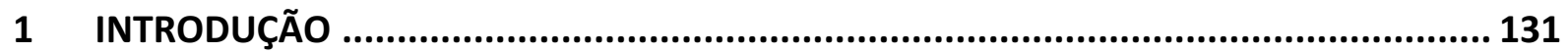

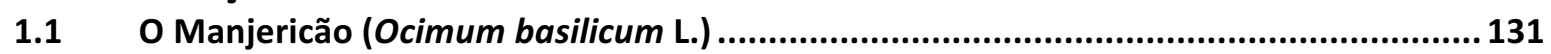

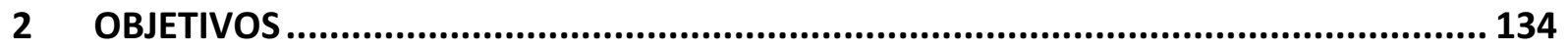

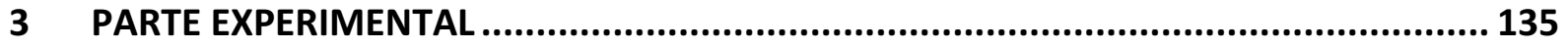

3.1 Cultivo de Manjericão (Ocimum basilicum L.), Análise Biométrica e Determinação da

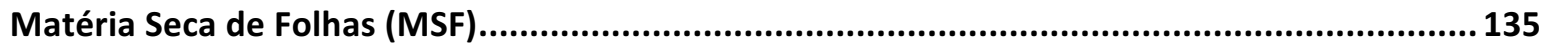

3.2 Determinação da Composição e Avaliação da Qualidade do Óleo Essencial Extraído das

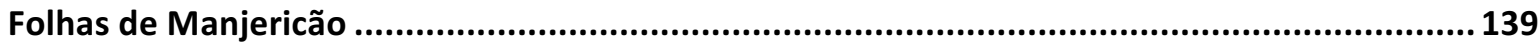

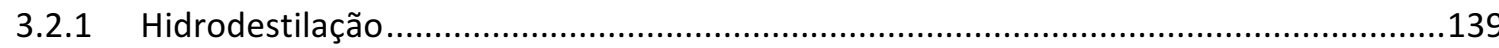

3.2.2 Determinação da composição e avaliação da qualidade do óleo essencial extraído das

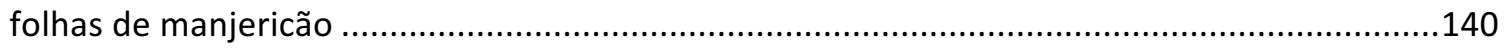

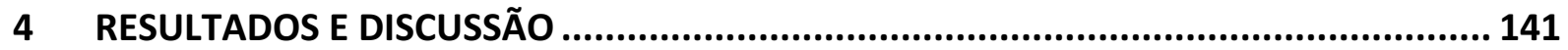

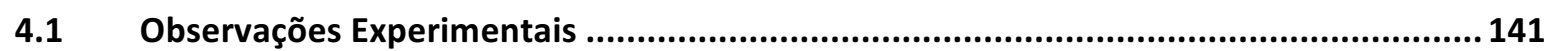

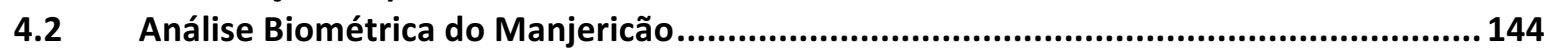

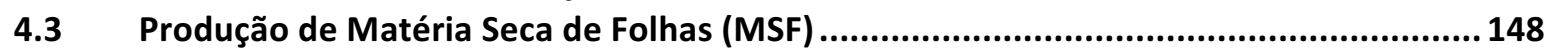

4.5 Determinação da Composição do Óleo Essencial Extraído das Folhas de Manjericão... 150

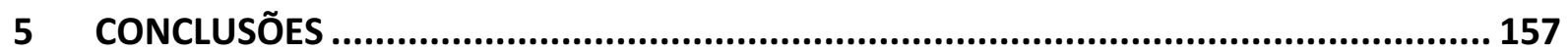

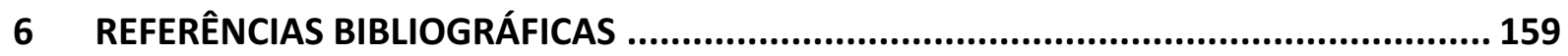

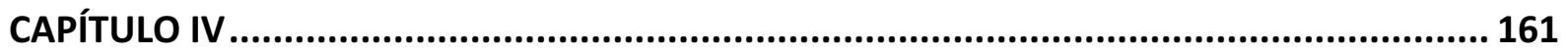

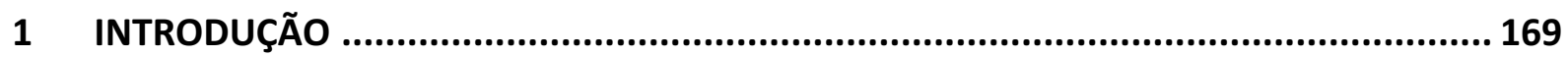

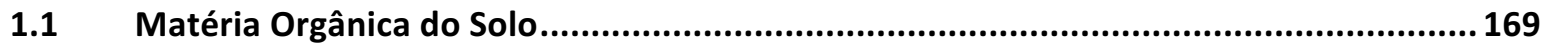

1.2 Conceito e Classificação da Matéria Orgânica do Solo .................................................. 170

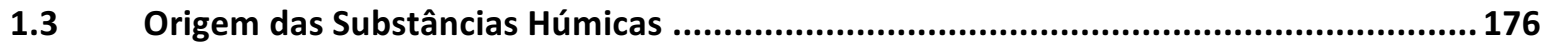

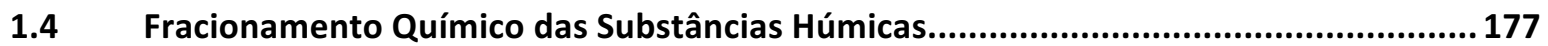

1.5 Caracterização de Substâncias Húmicas.................................................................. 180 
1.5.1 Espectroscopia na região do infravermelho próximo (NIRS) .........................................182

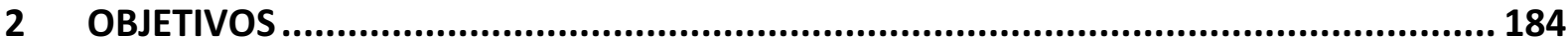

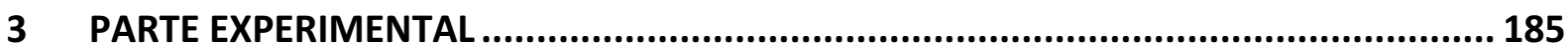

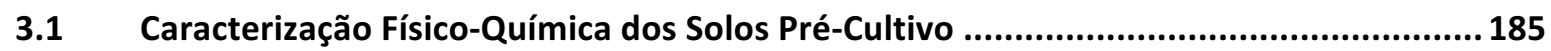

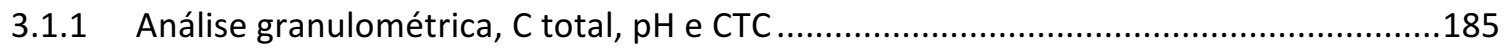

3.2 Caracterização Química e Espectroscópica dos Solos Pós-Cultivo ................................186

3.2.1 Determinação do teor de macro e micronutrientes e $C$ total ......................................186

3.2.3 Espectroscopia na região do Infravermelho Próximo (NIRS)........................... 187

3.3 Caracterização Química e Espectroscópica dos Ácidos Húmicos Extraídos dos Solos Pós-

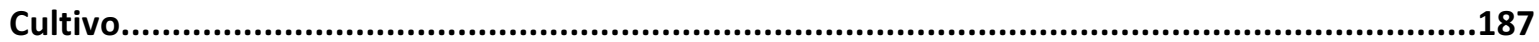

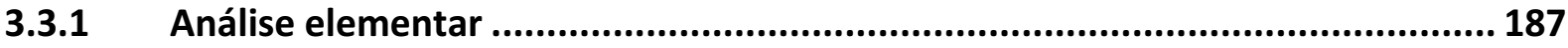

3.3.2 Espectroscopia na região do infravermelho médio com transformada de Fourier

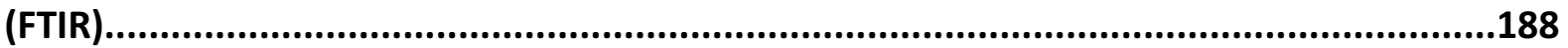

3.3.4 Espectroscopia de absorção na região do UV-Vis .......................................... 188

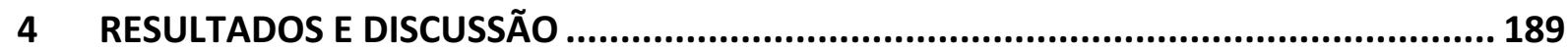

4.1 Caracterização Física e Química dos Solos Pré-Cultivo: Análise Granulométrica, C Total,

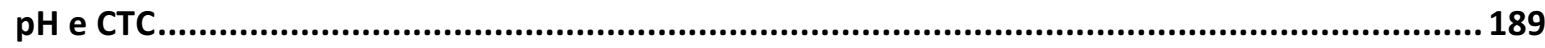

4.2 Caracterização Química dos Solos Pós-Cultivo: C Total e Teor de Macro e

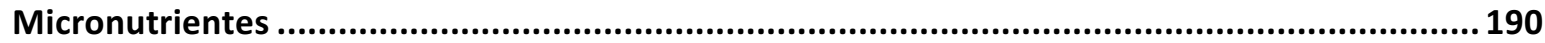

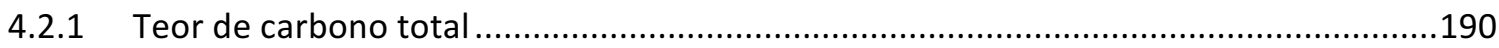

4.2.2 Teor de macro e micronutrientes dos solos pós-cultivo: análise das componentes

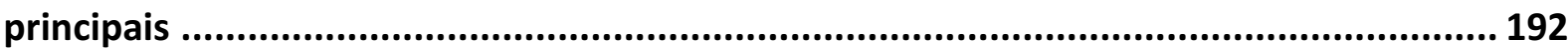

4.3 Caracterização Espectroscópica da MOS Pós-Cultivo Orgânico de Manjericão ............. 205

4.3.1 Espectroscopia na região do infravermelho próximo (NIRS) .......................................205

4.4 Caracterização Química e Espectroscópica dos Ácidos Húmicos Extraídos dos Solos Pós-Cultivo: Teores de C e N, Relação C/N, FTIR e Absorção no UV-Vis ......................... 215

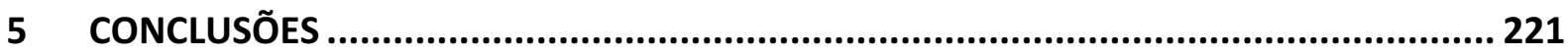

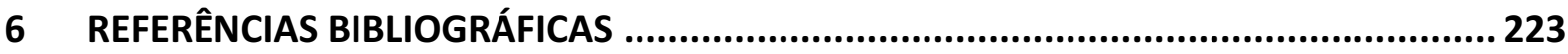



CAPÍTULO I

\section{VERMICOMPOSTAGEM DE MISTURAS DE ESTERCO BOVINO COM BAGAÇO DE LARANJA E TORTA DE FILTRO}

ESTUDO FÍSICO-QUÍMICO DO PROCESSO 



\section{LISTA DE FIGURAS}

Figura 1 - I. Primeira fase do experimento: pilhas de compostagem, sendo pilhas 1, 2 e 3 formadas de bagaço de laranja + esterco bovino $(2: 1 \mathrm{~m} / \mathrm{m})$; pilhas 4,5 e 6 formadas de torta de filtro + esterco bovino $(3: 1 \mathrm{~m} / \mathrm{m})$ e pilhas 7 , 8 e 9 formadas de esterco bovino (ordem de 1 a 9 da esquerda para direita)

Figura 2 - I. Segunda fase do experimento: vermicompostagem, sendo vermicompostores 1, 2 e 3 formadas de bagaço de laranja + esterco bovino $(2: 1 \mathrm{~m} / \mathrm{m})$; 4, 5 e 6 formadas de torta de filtro + esterco bovino $(3: 1 \mathrm{~m} / \mathrm{m})$ e 7 , 8 e 9 formadas de esterco bovino (ordem de 1 a 9 da direita para esquerda) (a) e minhocas Eisenia fetida utilizadas para a vermicompostagem (b)

Figura 3 - I. Variação média da temperatura nas pilhas de compostagem durante 60 dias do processo. Onde $(\mathrm{P} 1+\mathrm{P} 2+\mathrm{P} 3)$ : bagaço de laranja + esterco bovino; (P4+P5+P6): torta de filtro + esterco bovino; (P7+P8+P9): esterco bovino

Figura 4 - I. Variação média da temperatura por tratamento no centro das pilhas de compostagem durante 60 dias do processo. Onde (P1+P2+P3): bagaço de laranja + esterco bovino; (P4+P5+P6): torta de filtro + esterco bovino; (P7+P8+P9): esterco bovino

Figura 5 - I. Variação média do pH em função do tempo de vermicompostagem. $\mathrm{BL}+\mathrm{EB}$ : bagaço de laranja + esterco bovino (composta de P1+P2+P3); TF+EB: torta de filtro + esterco bovino (composta de P4+P5+P6); EB: esterco bovino (composta de $\mathrm{P} 7+\mathrm{P} 8+\mathrm{P9}$ ). $\mathrm{T}_{0}$ a $\mathrm{T}_{135}$ representam as amostragens no diferentes tempos

Figura 6 - I. Amostras coletadas no tempo zero (à esquerda) e após 135 dias (à direita) de vermicompostagem: bagaço de laranja + esterco bovino (a), torta de filtro + esterco bovino (b) e esterco bovino (c) 46 
Figura 7 - I. Variação média da relação $C / N$ em função do tempo de vermicompostagem. BL+EB: bagaço de laranja + esterco bovino; TF+EB: torta de filtro + esterco bovino; EB: esterco bovino 


\section{LISTA DE TABELAS}

Tabela 1 - I. Propriedades químicas dos resíduos orgânicos usados para vermicompostagem

Tabela 2 - I. Teores de N, C, H e S e relação $\mathrm{C} / \mathrm{N}$ durante o processo de vermicompostagem

Tabela 3 - I. Macro e micronutrientes no início e no final do processo de vermicompostagem de acordo com os diferentes tratamentos.

Tabela 4 - I. O efeito do tempo de vermicompostagem nos teores de macro e micronutrientes independente dos diferentes tratamentos .56

Tabela 5 - I. Macro e micronutrientes no final do processo de vermicompostagem de acordo com os diferentes tratamentos

Tabela 6 - I. Teores de N, C, H e S, C/N e pH no início e final do processo de vermicompostagem e CTC no final do processo de acordo com os diferentes tratamentos

Tabela 7 - I. O efeito do tempo de vermicompostagem na Análise Elementar, $\mathrm{C} / \mathrm{N}$ e $\mathrm{pH}$ independente dos diferentes tratamentos

Tabela 8 - I. Análise Elementar, C/N, pH e CTC no final do processo de vermicompostagem de acordo com os diferentes tratamentos. .64

Tabela 9 - I. Correlações entre as propriedades químicas dos vermicompostos produzidos. 66 



\section{INTRODUÇÃO}

\subsection{Resíduos Orgânicos: Produção e Potencial Agronômico}

A geração de resíduos sólidos acontece em todo mundo, principalmente nos países mais desenvolvidos onde o consumo de insumos é mais elevado. Nas cidades brasileiras o cenário não é diferente, e a produção de resíduos sólidos ocorre diariamente em quantidades e composições variáveis de acordo com seu nível de desenvolvimento econômico e social. Sendo assim, um importante desafio a ser enfrentado não só por cientistas, mas também pelos políticos, é assegurar o acesso e o uso sustentável dos recursos para o bem-estar do homem.

Para assegurar a sustentabilidade e minimizar os impactos ambientais devemse adotar importantes estratégias tais como: eliminação do desperdício, uso racional dos recursos renováveis, busca de alternativas corretas para substituição ou minimização do uso de fontes não renováveis, como aquelas derivadas do petróleo.

Segundo Goedert \& Oliveira (2007), não se trata de interromper o crescimento e sim eleger um caminho que garanta o desenvolvimento integrado e participativo da sociedade, considerando a base dos recursos naturais e seus ciclos de produção e regeneração. Particularmente, no que se refere às atividades agroindustriais, ainda segundo os autores, o crescimento da atividade agrícola e a conservação ambiental têm sido frequentemente considerados objetivos antagônicos. Embora a expansão da agricultura cause desequilíbrio em biomas naturais, um novo equilíbrio pode ser alcançado com o uso de práticas que respeitem a capacidade de recomposição desses recursos. Assim, a questão ambiental não deve ser necessariamente entendida dentro dessa contradição, mas, sim, dentro de um contexto que concilie as diversas vertentes do desenvolvimento sustentável. A agricultura deveria integrar perfeitamente as estratégias de manejo do solo e a busca da sustentabilidade. 
A reciclagem dos resíduos orgânicos gerados pelas atividades agrícolas, de pecuária e agroindustriais para uso na própria agricultura, caracteriza-se como uma forma adequada de reaproveitamento desses resíduos, minimizando os impactos ambientais que seriam gerados pela sua disposição final. Devido ao elevado teor de carbono, hidrogênio e oxigênio que armazenam em suas moléculas constituintes, os resíduos orgânicos podem ser utilizados na fabricação de adubos orgânicos, na alimentação animal, como substrato para fermentações, como cobertura do solo e como matérias-primas para a agroindústria. $\mathrm{O}$ aporte adequado desses materiais orgânicos no solo tem efeito condicionador, melhorando as características químicas (capacidade de troca de cátions, complexação de elementos tóxicos etc.), físicas (estrutura, retenção de água, densidade etc.) e biológicas desse solo (microfauna e microflora). Em adição, agrega-se valor a resíduos, antes indesejáveis, e agora transformados em insumos.

Segundo o MAPA, na agricultura orgânica não é permitido o uso de substâncias que coloquem em risco a saúde humana e o meio ambiente. Não são utilizados fertilizantes sintéticos solúveis, agrotóxicos e transgênicos. O Brasil, em função de possuir diferentes tipos de solo e clima, uma biodiversidade incrível aliada a uma grande diversidade cultural, é, sem dúvida, um dos países com maior potencial para o crescimento da produção orgânica. Para ser considerado orgânico, o produto tem que ser produzido em um ambiente de produção orgânica, onde se utilizam como base do processo produtivo os princípios agroecológicos que contemplam o uso responsável do solo, da água, do ar e dos demais recursos naturais, respeitando as relações sociais e culturais (MAPA, 2009).

Neste trabalho os resíduos orgânicos escolhidos foram o bagaço de laranja, a torta de filtro e o esterco bovino. Neste contexto, o adjetivo orgânico refere-se à estrutura química dos resíduos. Embora a definição do MAPA seja bastante generalista, não é possível atestar que os resíduos avaliados possam se enquadrar na definição de orgânico (segundo o MAPA). Trata-se de uma reflexão químicofilosófica: quais resíduos obedeceriam aos critérios do MAPA? Pensando no esterco bovino, como exemplo, para que esse resíduo pudesse ser classificado como orgânico, deveria ser proveniente de uma vaca orgânica. O mesmo vale para a laranja 
e a cana-de-açúcar: toda a produção deveria ser orgânica (segundo o MAPA). Dessa forma talvez não houvesse agricultura orgânica no nosso planeta!!! Assim, tomamos a liberdade de alcunhar de orgânicos os vermicompostos produzidos a partir desses resíduos, independentemente de sua origem.

É importante salientar que alguns resíduos necessitam de uma decomposição prévia antes de serem incorporados ao solo, a fim de reduzir possíveis efeitos adversos à saúde humana, às plantas e ao solo. Dentre estes efeitos, citam-se: a contaminação com organismos patogênicos (fungos, bactérias, vírus e helmintos), a imobilização de $\mathrm{N}$ decorrente da elevada relação $\mathrm{C} / \mathrm{N}$ de alguns materiais, as possíveis alterações no $\mathrm{pH}$ do solo decorrentes da elevada acidez ou alcalinidade dos resíduos (CASTILHOS \& DICK, 2008).

A região administrativa central, na qual se encontra o município de São Carlos, caracteriza-se pelo forte crescimento da produção da cana-de-açúcar. Também é tradição na região a produção de laranja e intensa atividade agropastoril, em que a pecuária bovina de confinamento e extensiva tem papel destacado. Essas atividades geram resíduos orgânicos que podem ser aproveitados como matéria-prima para compostagem e/ou vermicompostagem, obtendo-se produtos finais com distintas características químicas.

Devido à disponibilidade, baixo custo, e à possibilidade de propor uma alternativa ambientalmente mais viável a alguns resíduos gerados na região de São Carlos, SP, os resíduos orgânicos utilizados no presente estudo foram: bagaço de laranja (BL), torta de filtro (TF) e esterco bovino (EB).

\subsubsection{Bagaço de laranja}

A laranja está entre as frutas mais produzidas e consumidas no mundo, sendo que sua produção ultrapassa 80 milhões de toneladas/ano. Em média, 34\% da produção é transformada em suco, mas em grandes países produtores (Brasil e Estados Unidos), esta percentagem chega a 96\%, o que gera grande quantidade de 
resíduos. O bagaço de laranja é o principal subproduto da indústria de processamento de citrus, correspondendo a cerca de $45 \%$ da massa total da fruta e pode se tornar um grande problema para indústria, pois se deteriora muito rápido durante a estocagem (ABECITRUS, 2006). Atualmente o uso principal dos resíduos da laranja é como complemento para a ração animal. Algumas limitações fazem com que estes resíduos tenham uma utilização restrita, entre elas a grande quantidade de água que contêm o que acarreta problemas de coleta, transporte e armazenamento. Vários estudos têm proposto outros usos para os resíduos da laranja, incluindo a obtenção de fertilizantes orgânicos, pectina, óleos essenciais, compostos com atividade antioxidante e várias enzimas, incluindo pectinases e amilases (PETRY, 2011).

\subsubsection{Torta de filtro}

A torta de filtro é um subproduto da agroindústria canavieira, obtida nos filtros rotativos após extração da sacarose residual da borra. Sua composição é variável, em função da variedade da cana, tipo de solo, maturação da cana, processo de clarificação do caldo e outros. Durante o processo de clarificação do caldo, a adição de produtos que auxiliam na floculação das impurezas pode aumentar o teor de alguns minerais, principalmente fósforo e cálcio. Cerca de $30 \%$ do conteúdo total de fósforo aparece na forma orgânica e o nitrogênio predomina na forma proteica, propiciando lenta liberação desses elementos e, consequentemente, alto aproveitamento pelas plantas. A torta de filtro possui também elevada quantidade de matéria orgânica. Deve-se salientar os grandes investimentos e o incentivo que a produção de biocombustíveis proporcionou um grande aumento na escala produtiva da cana em todo o território nacional. Desta forma, configura-se um cenário com grande volume gerado de resíduo sem destino certo, além de impactos ambientais decorrentes do uso de insumos agrícolas bem como os impactos oriundos da queimada, técnica recorrente no Brasil para se efetuar o corte da cana. 


\subsubsection{Esterco bovino}

O desenvolvimento da pecuária em confinamento, com elevada concentração de animais tem causado danos aos recursos hídricos em geral e aos solos uma vez que origina grandes quantidades de estrumes e chorumes, sendo que o destino final desses resíduos tem mostrado um problema extremamente preocupante. Esta situação piora em pastagens com áreas relativamente pequenas onde a disponibilidade de terras é insuficiente e não consegue assimilar a quantidade de dejetos recebidos. A criação de bovinos em sistemas de confinamento gera diariamente um grande volume de dejetos e o manejo inadequado destes, que são ricos em matéria orgânicas e agentes patogênicos, pode ser responsável pela poluição de águas superficiais e subterrâneas, devido ao arraste desse material pela ação das chuvas. O esterco bovino já é um resíduo amplamente usado in natura como adubo orgânico, no entanto, por meio do processo de compostagem e/ou vermicompostagem suas propriedades fertilizantes são otimizadas.

\subsection{Reciclagem de Resíduos Orgânicos: Vermicompostagem}

Como alternativa para o acúmulo de resíduos orgânicos, os processos de compostagem e vermicompostagem apresentam uma dinâmica ambientalmente econômica e vantajosa. A vermicompostagem é uma variante do processo de compostagem, cuja técnica de decomposição consiste na biooxidação e estabilização da matéria orgânica, resultante da ação combinada das minhocas, da microflora que vive em seu trato digestivo e dos microrganismos do próprio meio, em ambiente úmido propício. É um método relativamente novo comparado à compostagem (SINGH et al, 2010). As minhocas exercem função mecânica de triturar o material, e os microrganismos presentes naturalmente em seus intestinos são responsáveis pela ação bioquímica sobre o resíduo (BIDONE; POVINELLI, 1999). As minhocas ingerem rapidamente a matéria orgânica fresca, transformando-a em um 
material de melhor qualidade que o composto gerado pelo método convencional de compostagem (pilhas ou leiras), rico em elementos essenciais para as plantas (nitrogênio, fósforo, magnésio, enxofre e potássio), além de conter bactérias fixadoras de nitrogênio. A esse material produzido pelas minhocas dá-se o nome de húmus de minhoca ou vermicomposto (KIEHL, 1985; SUTHAR, 2009). De acordo com DoresSilva et al. (2015), por sua ação transformadora as minhocas podem ser denominadas de microbiorreatores.

ATIYEH et al. (2000) reportaram que compostos tem maior concentração de íons amônio enquanto que vermicompostos tem maiores concentrações de nitratos que é a forma mais assimilável de nitrogênio pelas plantas. HAMMERMEISTER et al. (2004) afirmam que esterco vermicompostado tem maior concentração de nitrogênio disponível do que estercos puramente compostados.

A maturidade ou humificação do composto está relacionada com o grau de estabilidade das propriedades físicas, químicas e biológicas do material de origem. A adição de um resíduo fresco ao solo pode provocar desequilíbrio devido à possível emissão de gases do efeito estufa em função da atividade da microfauna para degradá-lo e diminuição da CTC do solo, entre outras consequências. Muitos testes têm sido propostos para avaliar a maturidade e estabilidade do material resultante da vermicompostagem, sendo necessário o uso de técnicas complementares para a compreensão desse processo.

Para o pleno êxito do uso agrícola dos resíduos orgânicos destaca-se a necessidade de pesquisas específicas para cada tipo de resíduo, solo e cultura, a fim de subsidiar futuras políticas públicas sobre a normatização do uso agrícola de resíduos orgânicos. Nesse contexto, fica evidente a necessidade de estabelecer uma norma regulamentar específica para as condições de clima e solos do Brasil, visando a garantir que o uso dos resíduos orgânicos seja realmente benéfico e ambientalmente seguro, pois o uso de resíduos orgânicos nos solos com fim de produção agrícola de forma não criteriosa pode acarretar prejuízos ao sistema soloplanta-atmosfera. 


\subsection{A Importância do Incremento de Matéria Orgânica no Solo}

A matéria orgânica tem influência em quase todas as propriedades do solo, atuando de maneira marcante no crescimento dos vegetais. Sua presença caracteriza os solos de boa fertilidade, aos quais proporciona uma estruturação favorável à vida das plantas. É, praticamente, a principal fonte de nitrogênio para as plantas sendo, ainda, fornecedora de elementos como o fósforo e o enxofre, bem como de vários micronutrientes (REZENDE; LANDGRAF; MESSIAS, 2005).

A vermicompostagem pode ser uma tecnologia alternativa adequada para o gerenciamento dos resíduos orgânicos visto que o produto final é livre de patógenos, inodoro e rico em nutrientes para as plantas, em comparação com o composto convencional. A utilização agrícola de vermicomposto melhora as propriedades físicas, químicas e biológicas do solo. O vermicomposto ajuda na reciclagem dos nutrientes para o solo e também evita sua degradação. Além do benefício econômico da utilização agrícola de vermicomposto, reduzindo a carga de fertilizantes inorgânicos aplicada, esta atividade propicia a manutenção da sustentabilidade do ecossistema (SINGH et al, 2010).

A escassez de matéria orgânica (MO) faz com que os solos tendam a ficar compactados, impedindo a permeação da água. A adição frequente de MO facilita a síntese de combinações orgânicas complexas que ligam partículas de solo em unidades estruturais chamadas agregados moleculares. Esses agregados moleculares ajudam a manter o solo solto, em condição granular, facilitando a absorção da água pelas raízes e facilitando a provisão ininterrupta de $\mathrm{O}_{2}$, pois permitem uma melhor troca de gases com a atmosfera. Assim, a MO melhora a aeração, a retenção de umidade e a proteção do solo. Deve ser enfatizado, contudo, que a importância de um determinado fator varia de um solo para outro e depende das condições ambientais, como clima, agricultura e do próprio manejo desse solo (REZENDE; LANDGRAF; MESSIAS, 2005). 


\section{OBJETIVOS}

O objetivo geral deste capítulo foi avaliar as características físico-químicas de resíduos orgânicos em processo de vermicompostostagem oriundos da mistura de esterco bovino com bagaço de laranja e torta de filtro, visando que o uso de resíduos orgânicos seja realmente benéfico e ambientalmente seguro.

Os objetivos específicos são:

a) Aquisição, secagem, trituração, e caracterização inicial $(\mathrm{pH}$ e $\mathrm{C} / \mathrm{N})$ dos resíduos orgânicos agroindustriais: esterco bovino, bagaço de laranja e torta de filtro;

b) Compostagem das diferentes misturas dos resíduos orgânicos agroindustriais até estabilização da temperatura seguida da vermicompostagem utilizando minhocas Eisenia fetida;

c) Monitoramento das propriedades físicas (temperatura e umidade) durante o processo de vermicompostagem;

d) Amostragem nos tempos 0, 7, 15, 30, 45, 60, 75, 90, 105, 120 e 135 dias de vermicompostagem e preparo das amostras (secagem à temperatura ambiente, moagem e peneiramento);

e) Monitoramento das propriedades químicas durante 0 processo de vermicompostagem: $\mathrm{pH}$, teor de $\mathrm{C}$, teor de $\mathrm{N}$ e razão $\mathrm{C} / \mathrm{N}$ e

f) Determinação da CTC e teor de macro e micronutrientes das amostras coletadas no tempo zero e após 135 dias de vermicompostagem. 


\section{PARTE EXPERIMENTAL}

\subsection{Caracterização dos Resíduos Orgânicos Agroindustriais}

O esterco bovino utilizado no experimento foi coletado em uma propriedade rural na região de São Carlos, SP. A torta de filtro foi concedida pela Usina Raízen de Açúcar e Álcool (Grupo Shell), localizada em Ibaté, SP. O bagaço de laranja foi concedido pela Fruthil Indústria de Suco de Laranja, localizada em São Carlos, SP.

Amostras dos resíduos frescos (foram secas em estufa à temperatura de aproximadamente $50{ }^{\circ} \mathrm{C}$, maceradas com auxílio almofariz e pistilo e peneiradas em peneira de 2,5 $\mathrm{mm}$ de abertura de malha. Os resíduos foram caracterizados quanto ao $\mathrm{pH}$ em solução de $\mathrm{CaCl}_{2}$ 0,01 mol L-1 e ao teor de $\mathrm{C}$ e N. Em função desses dados e da quantidade disponível de cada material foram determinadas as proporções dos resíduos a serem misturadas para montagem das pilhas de compostagem ( $1^{\text {a }}$ etapa do processo de vermicompostagem). As diferentes proporções foram feitas a fim de que as misturas obtivessem relação C/N inicial entre 20 e 30.

\subsection{Vermicompostagem}

O experimento foi conduzido em plataforma de cerâmica coberta e bem arejada (para evitar excesso de umidade nos períodos chuvosos), em uma fazenda localizada na região de São Carlos. Teve início em setembro de 2011 e durou 135 dias. Os resíduos in natura foram secos à temperatura ambiente e triturados em moinho de facas para homogeneização das partículas. O processo de vermicompostagem consistiu em duas etapas: a compostagem no formato de pilhas aeradas para estabilização prévia dos resíduos e a vermicompostagem (adição das minhocas Eisenia fetida, vulgarmente conhecidas como californianas) após estabilização da temperatura das pilhas. 
O volume das pilhas foi de 2,25 $\mathrm{m}^{3}$, com dimensões de $1,5 \mathrm{~m}$ de comprimento $x 1,5 \mathrm{~m}$ de largura $\times 1,0 \mathrm{~m}$ de altura. Ao todo foram três tratamentos e os experimentos foram conduzidos em triplicata. Foram montadas nove pilhas de compostagem (Figura 1 - I). As composições das pilhas estão descritas a seguir:

i. Pilha 1, Pilha 2 e Pilha 3. (P1, P2 e P3): 300 kg de bagaço de laranja + 150 de $\mathrm{kg}$ esterco bovino $(2: 1 \mathrm{~m} / \mathrm{m})$;

ii. Pilha 4, Pilha 5 e Pilha 6. (P4, P5 e P6): $450 \mathrm{~kg}$ de torta de filtro $+150 \mathrm{~kg}$ de esterco bovino $(3: 1 \mathrm{~m} / \mathrm{m})$;

iii. Pilha 7, Pilha 8 e Pilha 9. (P7, P8 e P9): 400 kg de esterco bovino.

Figura 1 - I. Primeira fase do experimento: pilhas de compostagem, sendo pilhas 1, 2 e 3 formadas de bagaço de laranja + esterco bovino $(2: 1 \mathrm{~m} / \mathrm{m})$; pilhas 4,5 e 6 formadas de torta de filtro + esterco bovino (3:1 m/m) e pilhas 7, 8 e 9 formadas de esterco bovino (ordem de 1 a 9 da esquerda para direita)

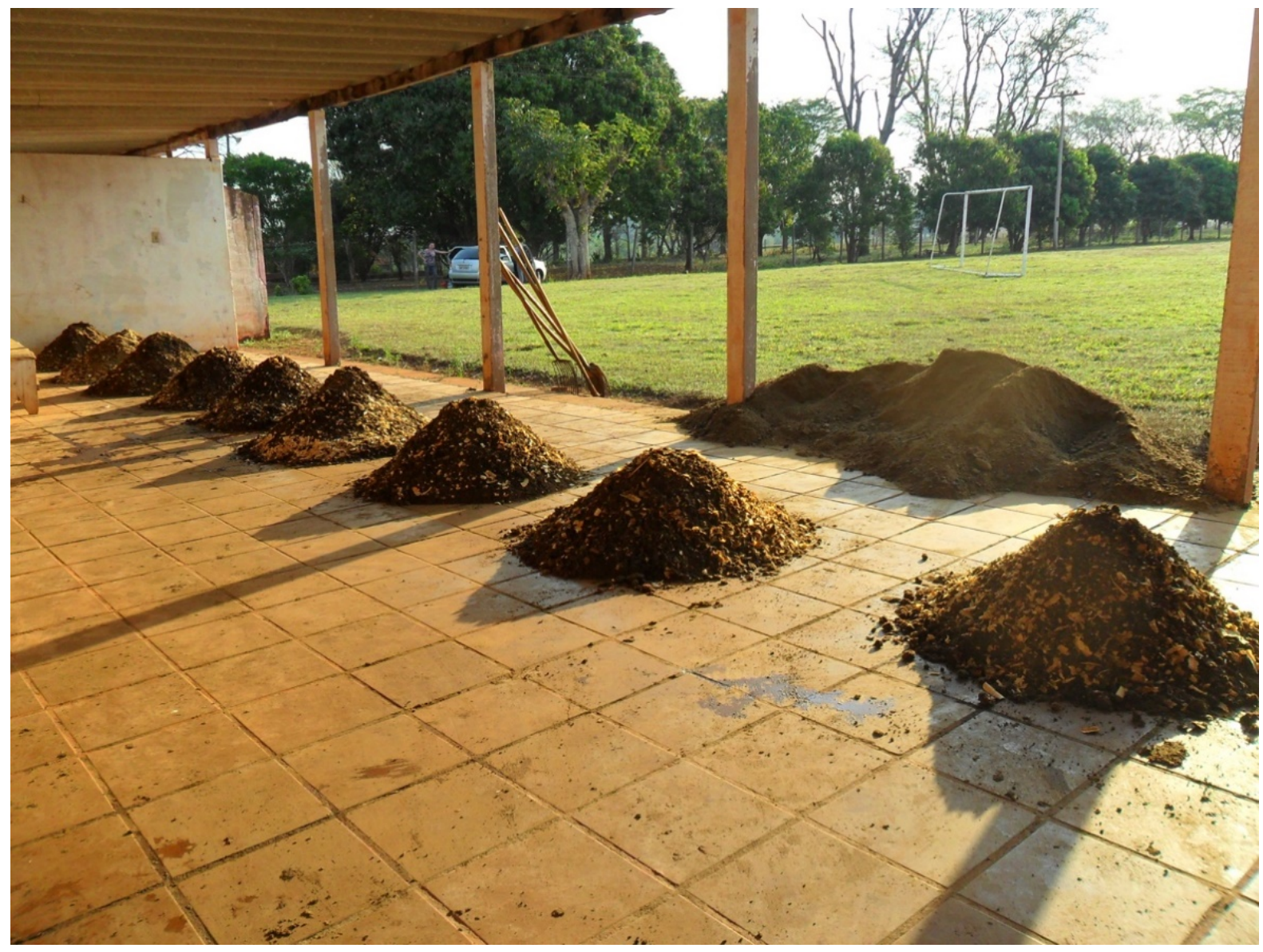

A serragem foi utilizada em pequena quantidade apenas como agente estruturante e para melhorar a aeração do meio. As proporções das misturas dos 
resíduos com esterco bovino foram determinadas de acordo com a quantidade de material disponível e para se obter uma razão $\mathrm{C} / \mathrm{N}$ entre 20-30. Uma razão $\mathrm{C} / \mathrm{N}$ adequada promove a atividade dos microrganismos no processo de degradação dos resíduos orgânicos. Uma razão $\mathrm{C} / \mathrm{N}$ entre 20-30 é considerada apropriada para o início do processo de co-vermicompostagem, permitindo a produção de vermicomposto em menor tempo. Ao final do processo de degradação, o composto/vermicomposto humificado deve ter uma razão $\mathrm{C} / \mathrm{N}$ em torno de 10:1.

As pilhas foram montadas camada por camada, tendo cada camada, aproximadamente $20 \mathrm{~cm}$ de altura, independente da massa. As camadas foram montadas na seguinte ordem: serragem - esterco bovino - bagaço de laranja ou torta de filtro, e assim sucessivamente. A umidade das pilhas foi mantida em torno de $60 \%$ e o revolvimento das mesmas foi feito semanalmente nas duas primeiras semanas e quinzenalmente no restante do processo.

A aferição da temperatura das pilhas foi feita diariamente, no período da manhã (entre 6 - 8 horas) com o auxílio de um termômetro de haste. As medidas foram feitas no interior das pilhas em três pontos distintos (topo, centro e base), simetricamente distribuídos e desses três pontos foi feita a média. Ao final da $6^{a}$ semana de compostagem a temperatura retornou para a fase mesofílica, e então os compostos foram transferidos para aos vermicompostores (Figura 2a - I). Foram adicionadas 500 minhocas jovens (Eisenia fetida) em cada vermicompostor (minhocas jovens são minhocas que não apresentam clitelo) (Figura 2b - II). 
Figura 2 - I. Segunda fase do experimento: vermicompostagem, sendo vermicompostores 1, 2 e 3 formadas de bagaço de laranja + esterco bovino $(2: 1 \mathrm{~m} / \mathrm{m}) ; 4,5$ e 6 formadas de torta de filtro + esterco bovino (3:1 m/m) e 7, 8 e 9 formadas de esterco bovino (ordem de 1 a 9 da direita para esquerda) (a) e minhocas Eisenia fetida utilizadas para a vermicompostagem (b)

(a)

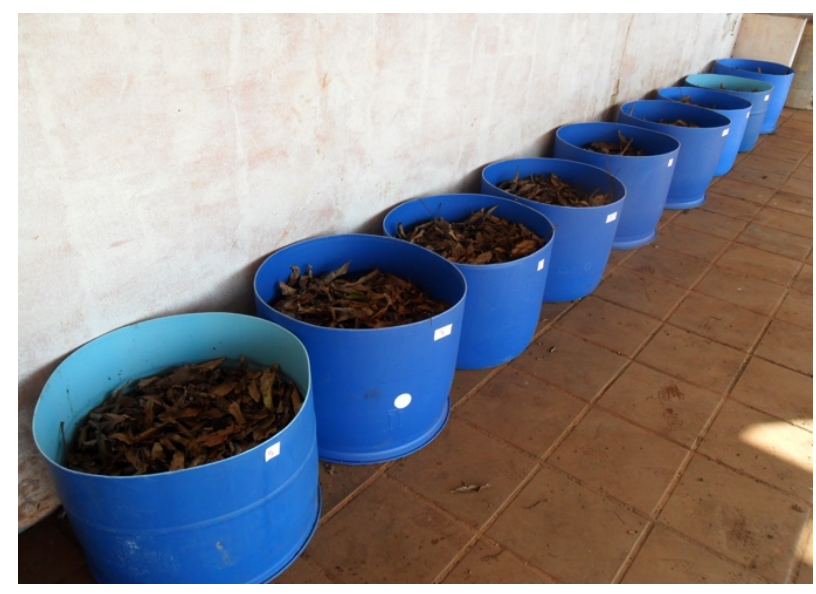

(b)

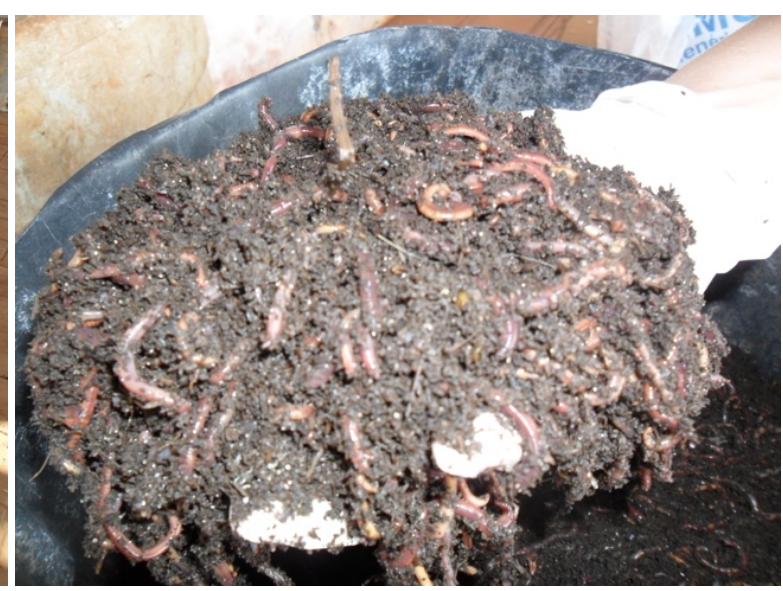

A massa de cada minhoca era em torno de $10 \mathrm{~g}$ e a massa total de minhocas adicionadas por vermicompostor foi de 5,0 kg. A superfície dos vermicompostores foi recoberta com folhagens secas para manutenção da sombra, ambiente propício para as minhocas. O conteúdo dos vermicompostores foi revolvido a cada 15 dias até o final do processo.

\subsection{Amostragem}

Para o monitoramento químico e espectroscópico da dinâmica da matéria orgânica em processo de vermicompostagem, coletou-se em pontos aleatórios, aproximadamente, $1,0 \mathrm{~kg}$ de amostra de cada tratamento, nos tempos $0,7,15,30$, $45,60,75,90,105,120,135$ dias. As amostras foram secas a $60^{\circ} \mathrm{C}$, maceradas com auxílio de almofariz e pistilo e passadas por peneira de $0,5 \mathrm{~mm}$ de abertura de malha. 


\subsection{Análises químicas dos resíduos em vermicompostagem}

\subsection{1 $\mathrm{pH}$}

Pesou-se 0,5 g de cada amostra (resíduos in natura e vermicompostos nos diferentes tempos de vermicompostagem) seca e peneirada e em seguida adicionaram-se $5,0 \mathrm{~mL}$ de solução $\mathrm{CaCl}_{2}, 0,01 \mathrm{~mol} \mathrm{~L}^{-1}$. A mistura foi agitada por 30 minutos em agitador orbital e a leitura de $\mathrm{pH}$ foi feita em pHmetro Tecnal (TEC-2) eletrônico com eletrodo combinado de vidro (RAIJ et al., 2001). As determinações foram conduzidas em triplicata.

\subsubsection{Análise Elementar}

Por meio da análise elementar das amostras dos resíduos e vermicompostos coletados durante o processo de vermicompostagem foram determinados os teores de $\mathrm{C}, \mathrm{N}, \mathrm{H}$ e S total. As determinações, conduzidas em triplicata, foram feitas de uma mistura eluída, separada por uma coluna cromatográfica e detectada na sequência $\mathrm{N}_{2}, \mathrm{CO}_{2}, \mathrm{H}_{2} \mathrm{O}$ e $\mathrm{SO}_{2}$. O equipamento utilizado foi um CHNS-O da CE Instruments EA1110, pertencente à Central de Análises Químicas Instrumentais (CAQI) do Instituto de Química de São Carlos, USP.

A relação $\mathrm{C} / \mathrm{N}$ foi calculada a partir da razão do teor de $\mathrm{C}$ total dividido pela massa atômica do carbono pelo teor de $\mathrm{N}$ total dividido pela massa atômica do nitrogênio. 


\subsubsection{Teores de macro e micronutrientes}

Os teores de macronutrientes ( $\mathrm{N}, \mathrm{P}, \mathrm{K}$ ) e micronutrientes ( $\mathrm{Fe}, \mathrm{Mn}, \mathrm{Cu}, \mathrm{Zn}, \mathrm{Cr}$, Ca e $\mathrm{Mg}$ ) foram determinados para as amostras coletadas no tempo zero e após 135 dias de vermicompostagem. As amostras foram digeridas usando micro-ondas (BERGHOF Speed Wave Four). Para as determinações de Fe, Mn, Cu, Zn, K, Cr, Ca e Mg as amostras foram digeridas em ácido nítrico (MALAVOLTA et al, 1989), e as leituras feitas por Espectroscopia de Absorção Atômica. Para a determinação dos teores de nitrogênio Kjeldahl total (NKT) e de fósforo a digestão das amostras foi feita em ácido sulfúrico (MALAVOLTA, 1989) e as leituras no Espectrofotômetro UV-Vis Hach, modelo DR 6000, operando em modo absorbância para NKT (método 399) e em modo concentração para fosfato que via cálculos foi convertido em fósforo (método 480). O espectrofotômetro possui lâmpada de deutério (UV) e de halogênio (visível), atuando na faixa de comprimento de onda de $200-900 \mathrm{~nm}$, com resolução de $0,1 \mathrm{~nm}$.

\subsubsection{Capacidade de troca catiônica (CTC)}

A determinação da CTC foi baseada na metodologia de Rodella e Alcarde (1994) adaptada da metodologia da Association of Official Analytical Chemists empregada para análise de CTC de turfa (WILIAMS, 1984; Fialho, 2007).

Foram pesados, aproximadamente, 2,0 $\mathrm{g}$ de composto e 1,0 $\mathrm{g}$ de carvão ativado e transferidos juntamente com $100 \mathrm{~mL}$ de $\mathrm{HCl} 0,5 \mathrm{~mol} \mathrm{~L}^{-1}$ para um balão de $250 \mathrm{~mL}$. Esta mistura foi agitada durante 30 minutos em agitador orbital.

Montou-se o sistema de filtração a vácuo, colocando sobre o funil de Büchner um disco de papel faixa azul. O papel foi umedecido, aplicou-se sucção moderada e transferiu a mistura lavando com pequenas porções de água destilada. Procederamse sucessivas lavagens do material orgânico retido no funil, desagregando-o com 
jatos provenientes de uma pisseta e enchendo o funil até $1 \mathrm{~cm}$ de sua borda. A próxima lavagem era realizada após todo líquido da lavagem anterior ter sido drenado. Fez-se um número de lavagens suficiente para obter um volume de $350 \mathrm{~mL}$ no kitassato.

Após a fase das lavagens, trocou-se o kitassato por outro de igual capacidade e foram transferidas 10 alíquotas de $10 \mathrm{~mL}$ de solução de acetato de cálcio $0,5 \mathrm{~mol}$ $\mathrm{L}^{-1}$ com $\mathrm{pH} 7,0$, sendo distribuídas sobre toda superfície do material orgânico sob vácuo reduzido, para permitir uma lenta percolação. Uma nova porção de solução de acetato de cálcio apenas era adicionada, após a porção anterior ter sido drenada para o kitassato. Após a adição dos $100 \mathrm{~mL}$ da solução de acetato de cálcio o material orgânico foi lavado com porções de água destilada até totalizar um volume de, aproximadamente, $300 \mathrm{~mL}$ no kitassato. Esta solução foi transferida para um erlenmeyer de $500 \mathrm{~mL}$ e titulada com solução de $\mathrm{NaOH} \mathrm{0,1} \mathrm{mol} \mathrm{L}^{-1}$, previamente padronizada. Utilizou-se fenolftaleína como indicador.

Foi conduzida uma determinação, empregando-se o carvão ativado e omitindo a presença da amostra. A seguinte equação foi utilizada para o cálculo da CTC:

$$
C T C=\frac{(V a-V b) x C}{m_{\text {amostra }}} \quad \mathrm{mmol}_{\mathrm{c}} \mathrm{kg}^{-1}
$$

Sendo $\mathrm{Va}$ e $\mathrm{Vb}$ os volumes de solução de $\mathrm{NaOH}$ gastos nas titulações das amostras e da titulação da mistura dos reagentes sem a amostra, respectivamente, (em $\mathrm{mL}$ ); C é a concentração da solução de $\mathrm{NaOH}$ padronizada (em $\mathrm{mol} \mathrm{L}^{-1}$ ), e m é a massa de vermicomposto utilizada (em kg).

\subsection{Análises Estatísticas}

Os dados gerados de todas as análises químicas foram submetidos à análise de variância (ANOVA) e as médias foram separadas usando teste de Tukey $(p<0,05)$. Para as análises foi utilizado o programa SAS 9.0 Software (SAS Institute 2004). 


\section{RESULTADOS E DISCUSSÃO}

\subsection{Caracterização Química dos Resíduos Frescos e Observações Experimentais}

Na Tabela 1 - I estão apresentados os resultados da caracterização preliminar dos resíduos orgânicos: $\mathrm{pH}$, teores de nitrogênio total e carbono total determinados por análise elementar. Esta caracterização permitiu estimar as razões $\mathrm{C} / \mathrm{N}$ apropriadas para o início do processo de vermicompostagem.

Em geral, a relação $\mathrm{C} / \mathrm{N}$ do resíduo determina a capacidade de degradação microbiana do material, mas alguns resíduos orgânicos como os provenientes de plantas podem ter relação $\mathrm{C} / \mathrm{N}$ ótima e conter uma elevada proporção de lignina, um componente que é difícil de degradar.

Tabela 1 - I. Propriedades químicas dos resíduos orgânicos usados para vermicompostagem

\begin{tabular}{lccc}
\hline Atributos & Bagaço de Laranja & Torta de Filtro & Esterco Bovino \\
\hline $\mathbf{C}_{\text {total }}$ a & $41,95 \pm 5,28$ & $37,97 \pm 0,38$ & $32,11 \pm 4,32$ \\
$\mathbf{N}_{\text {total }}{ }^{a}$ & $1,34 \pm 0,00$ & $1,73 \pm 0,00$ & $1,73 \pm 0,00$ \\
$\mathbf{C} / \mathbf{N}$ & 36,63 & 25,66 & 26,11 \\
$\mathbf{p H}^{\mathbf{b}}$ & $2,40 \pm 0,40$ & $7,30 \pm 0,00$ & $8,00 \pm 0,10$ \\
\hline
\end{tabular}

${ }^{a}$ Resultados apresentados em \% de matéria seca.

${ }^{b}$ Medido em $\mathrm{CaCl}_{2} 0.01 \mathrm{~mol} \mathrm{~L}^{-1}(1: 10, \mathrm{~m} / \mathrm{v})$.

Observou-se para P4, P5 e P6 (torta de filtro + esterco bovino) que o processo de vermicompostagem perdurou por mais tempo do que os demais tratamentos. Este fato foi observado pela presença ou ausência das minhocas nos vermicompostores. Mantendo-se as condições de umidade e aeração adequadas no decorrer do 
processo, quando o material orgânico fresco já havia sido todo consumido/ degradado, pode-se observar um decaimento da atividade das minhocas, as quais se apresentaram mais lentas até morrerem. Para P1, P2 e P3 (bagaço de laranja + esterco bovino), P7, P8 e P9 (esterco bovino) já não se encontravam minhocas após 105 dias do início do processo. Para certificar-se de que o processo havia cessado, foram adicionadas 100 minhocas em cada um dos recipientes contendo o vermicomposto supostamente maturado. Após sete dias, não havia minhocas. Visto que a umidade foi mantida constante e que a solução estava levemente básica, possivelmente as minhocas fugiram em busca de alimento ou morreram pela ausência de material fresco a ser degradado. Para P4, P5 e P6 (torta de filtro + esterco bovino) após 135 dias não foram mais encontradas minhocas nas vermicomposteiras.

\subsection{Monitoramento Físico e Químico do Processo de Vermicompostagem}

\subsubsection{Temperatura}

Pode-se dizer que a vermicompostagem foi dividida em duas partes. A primeira parte foi a compostagem dos resíduos até a estabilização da temperatura. Observaram-se três fases de temperatura (Figuras $3-$ I e $4-I$ ) $-1^{\circ}$ fase: mesofílica, em que houve um aumento na temperatura, a qual alcançou valores superiores a 30 ${ }^{\circ} \mathrm{C}$; $2^{\mathrm{a}}$ fase: termofílica, em que a temperatura atingiu valores máximos, superiores a $60{ }^{\circ} \mathrm{C}$ para as pilhas P1, P2 e P3 (bagaço de laranja + esterco bovino), as quais apresentaram as temperaturas mais altas dentre os tratamentos; $3^{\circ}$ fase: esfriamento e maturação. Após 15 dias, a temperatura diminuiu chegando à aproximadamente $25^{\circ} \mathrm{C}$. 
Figura 3 - I. Variação média da temperatura nas pilhas de compostagem durante 60 dias do processo. Onde (P1+P2+P3): bagaço de laranja + esterco bovino; $(\mathrm{P} 4+\mathrm{P} 5+\mathrm{P} 6)$ : torta de filtro + esterco bovino; (P7+P8+P9): esterco bovino

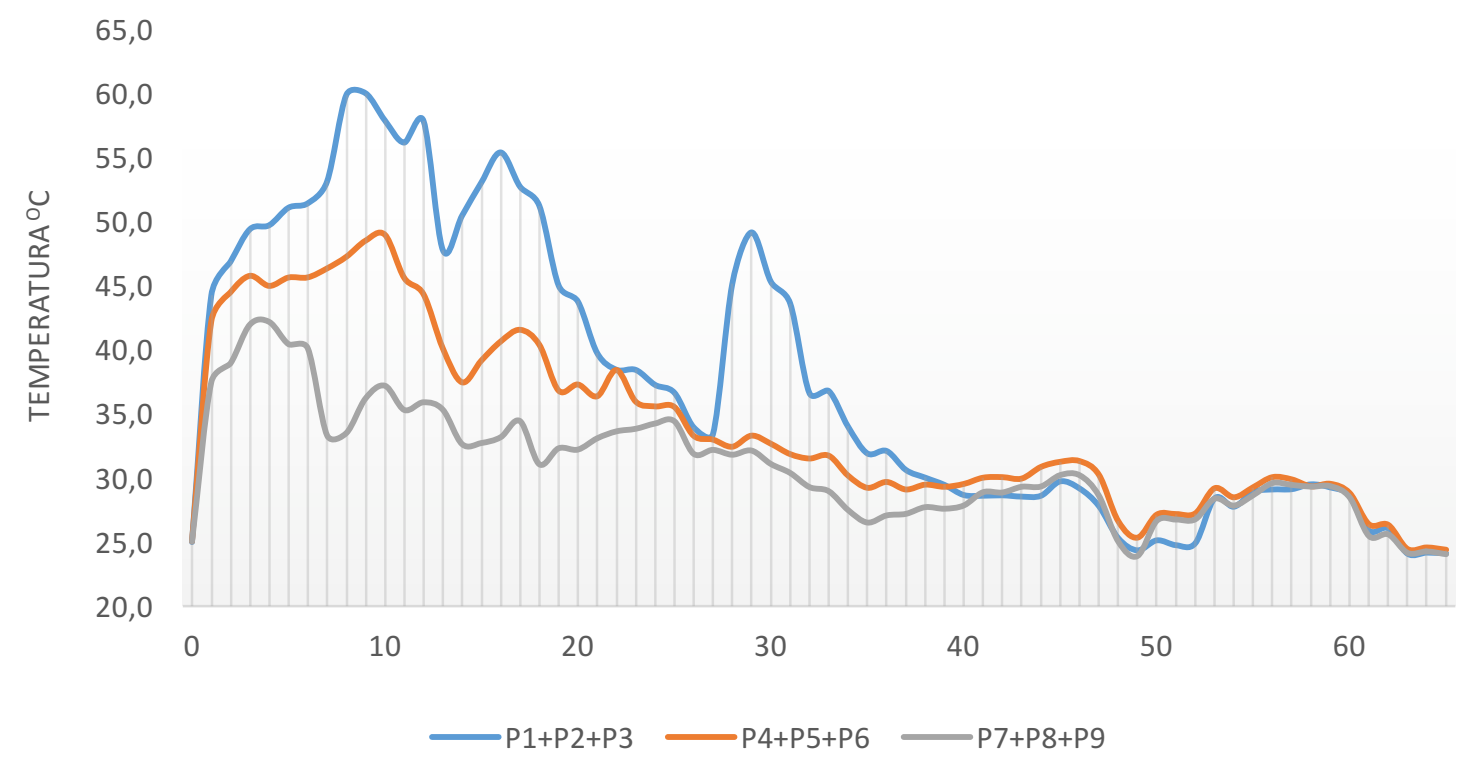

Figura 4 - I. Variação média da temperatura por tratamento no centro das pilhas de compostagem durante 60 dias do processo. Onde (P1+P2+P3): bagaço de laranja + esterco bovino; (P4+P5+P6): torta de filtro + esterco bovino; $(P 7+P 8+P 9)$ : esterco bovino

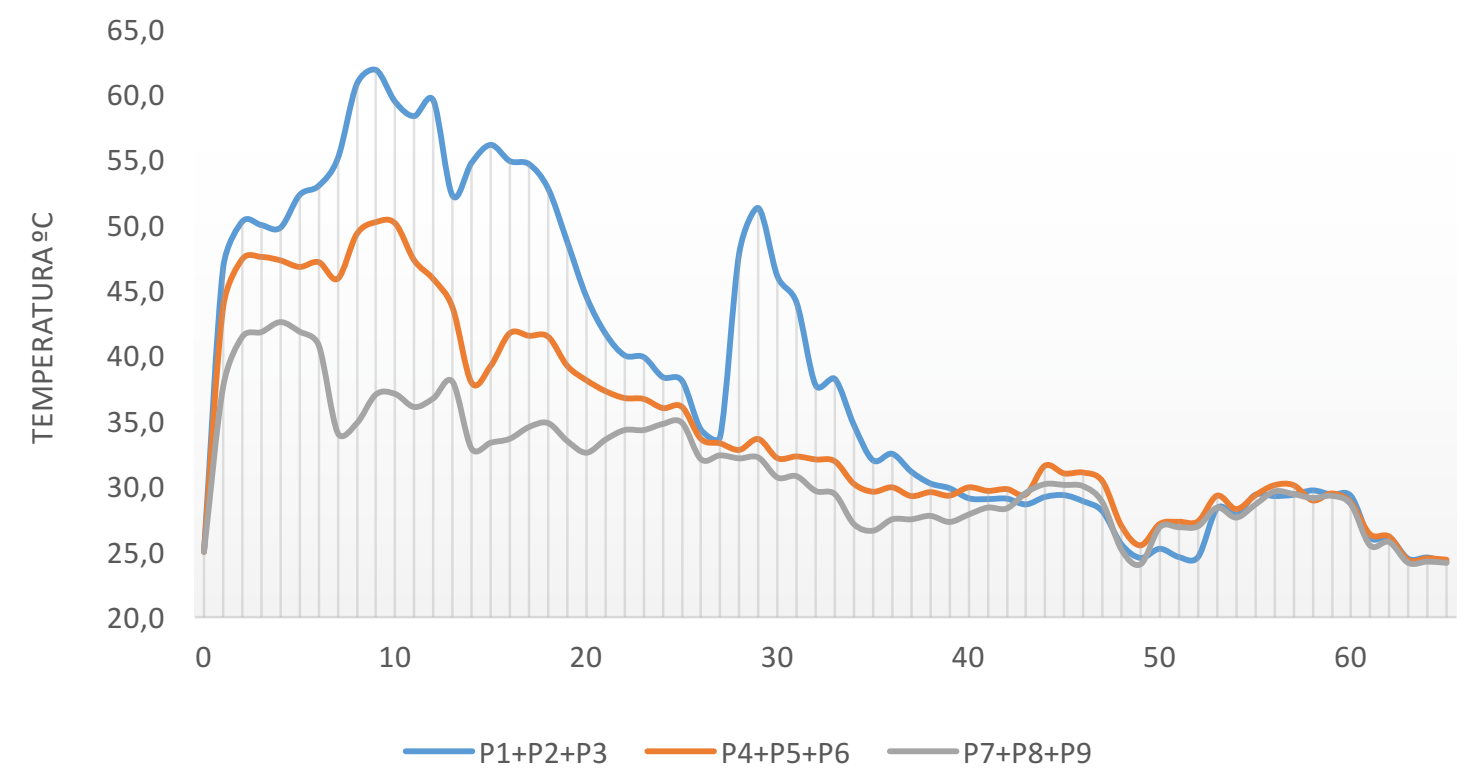


O clima da região é tropical, com temperaturas médias entre $16^{\circ} \mathrm{C}$ e $27^{\circ} \mathrm{C}$. De acordo com Fialho et al. (2010), esses comportamentos são consequência da atividade de microrganismos na decomposição dos resíduos e também da dinâmica das populações microbianas, uma vez que para a decomposição máxima dos resíduos, a temperatura deve atingir valores entre 50 e $60{ }^{\circ} \mathrm{C}$. Esta foi a gama de temperaturas atingidas para a fase termofílica dos compostos de P1, P2 e P3 (bagaço de laranja + esterco bovino) e P4, P5 e P6 (torta de filtro + esterco bovino). Nas pilhas P7, P8 e P9 (esterco bovino) a temperatura não atingiu $50^{\circ} \mathrm{C}$, o que, de acordo com Fialho et al. (2010), sugere o crescimento microbiano lento em comparação com outras pilhas além de que a eficiência do processo de compostagem depende do tipo de substrato.

\section{$4.2 .2 \mathrm{pH}$}

Pode-se observar que durante o processo de compostagem houve ligeira variação do $\mathrm{pH}$ das pilhas em todos os tratamentos (Figura 5 - I). 
Figura 5 - I. Variação média do pH em função do tempo de vermicompostagem. $B L+E B$ : bagaço de laranja + esterco bovino (composta de P1+P2+P3); TF+EB: torta de filtro + esterco bovino (composta de P4+P5+P6); EB: esterco bovino (composta de P7+P8+P9). $\mathrm{T}_{0}$ a $\mathrm{T}_{135}$ representam as amostragens no diferentes tempos

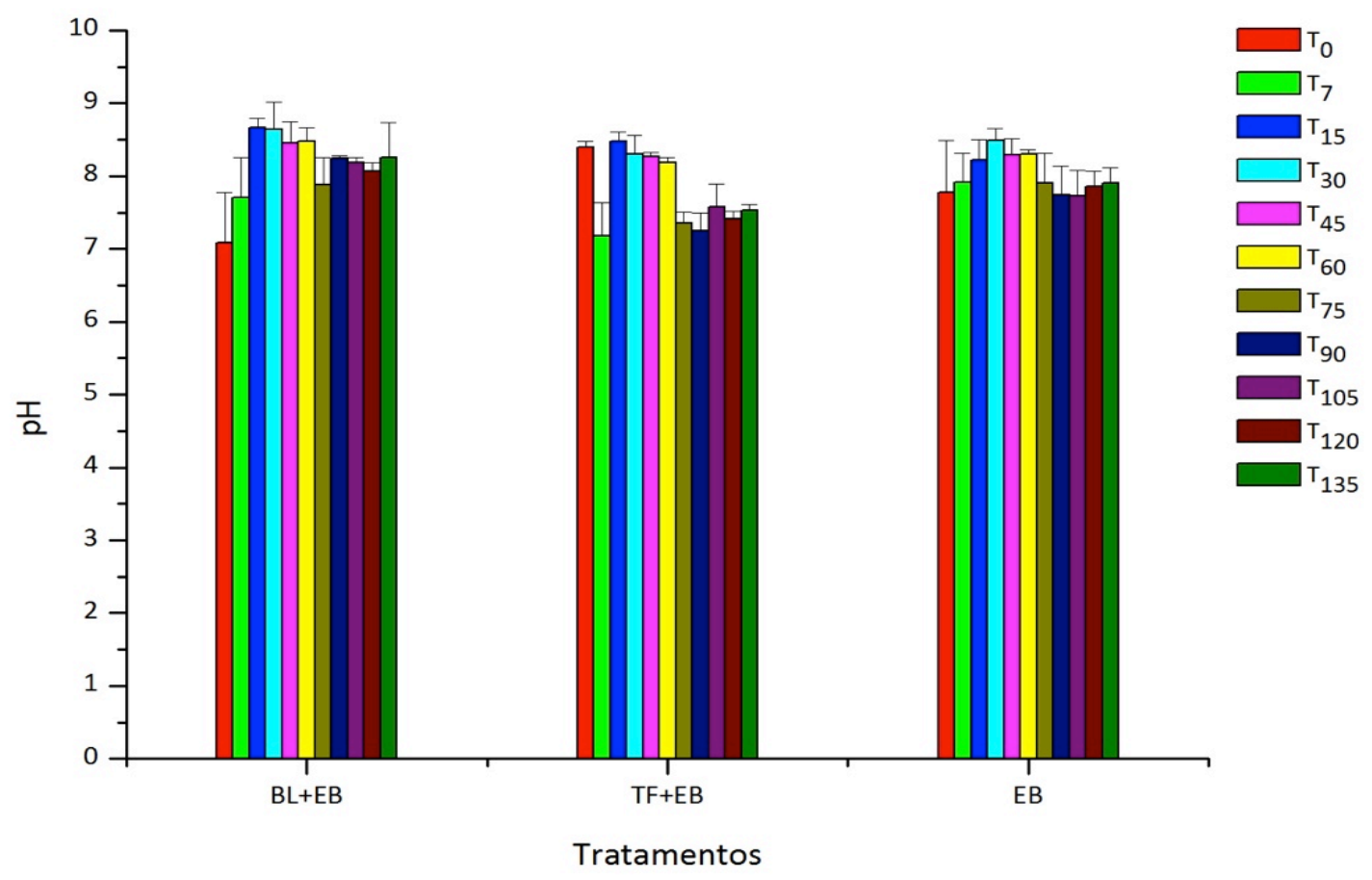

Para o tratamento $\mathrm{BL}+\mathrm{EB}$, houve um aumento do $\mathrm{pH}$ de 7,09 para 8,26, enquanto para o tratamento TF+EB houve um decréscimo do $\mathrm{pH}(8,40-7,55)$ e para o tratamento EB, o $\mathrm{pH}$ permaneceu praticamente o mesmo no início e no final do processo $(7,8)$. Os valores de $\mathrm{pH}$ dos tratamentos foram próximos a neutralidade ou ligeiramente alcalinos no final do processo. Isso indica a condição esperada de composto estabilizado. Quarenta e cinco dias após a adição das minhocas às misturas, os valores de $\mathrm{pH}$ tenderam a decrescer 1 unidade, ou seja, tendendo à neutralidade. Bhat et al. (2015) também observaram um decréscimo no pH durante o processo de vermicompostagem de misturas de bagaço de cana de açúcar e esterco bovino. Os autores explicam que o declínio do pH durante a vermicompostagem é devido à mineralização de compostos de nitrogênio e fósforo e à produção de ácidos húmicos e fúlvicos.

É notável que o tratamento $\mathrm{BL}+\mathrm{EB}$ apenas atingiu valores de $\mathrm{pH}$ próximos à neutralidade, no início do processo, devido à adição de esterco bovino, visto que o 
$\mathrm{pH}$ do bagaço de laranja puro é $2,5 \pm 0,4$. A primeira etapa do processo de vermicompostagem foi a de compostagem em pilhas, permitindo a pré-estabilização dos materiais, e em seguida a segunda etapa com a adição das minhocas (vermicompostagem).

4.2.3 Coloração, odor e volume

Observou-se uma mudança significativa na coloração dos vermicompostos em função do tempo de vermicompostagem (Figura 6 - I). A cor inicial sem brilho, com o decorrer do processo de vermicompostagem passou a se tornar cada vez mais escura e brilhante, quando úmida. 
Figura 6 - I. Amostras coletadas no tempo zero (à esquerda) e após 135 dias (à direita) de vermicompostagem: bagaço de laranja + esterco bovino (a), torta de filtro + esterco bovino (b) e esterco bovino (c)

(a)
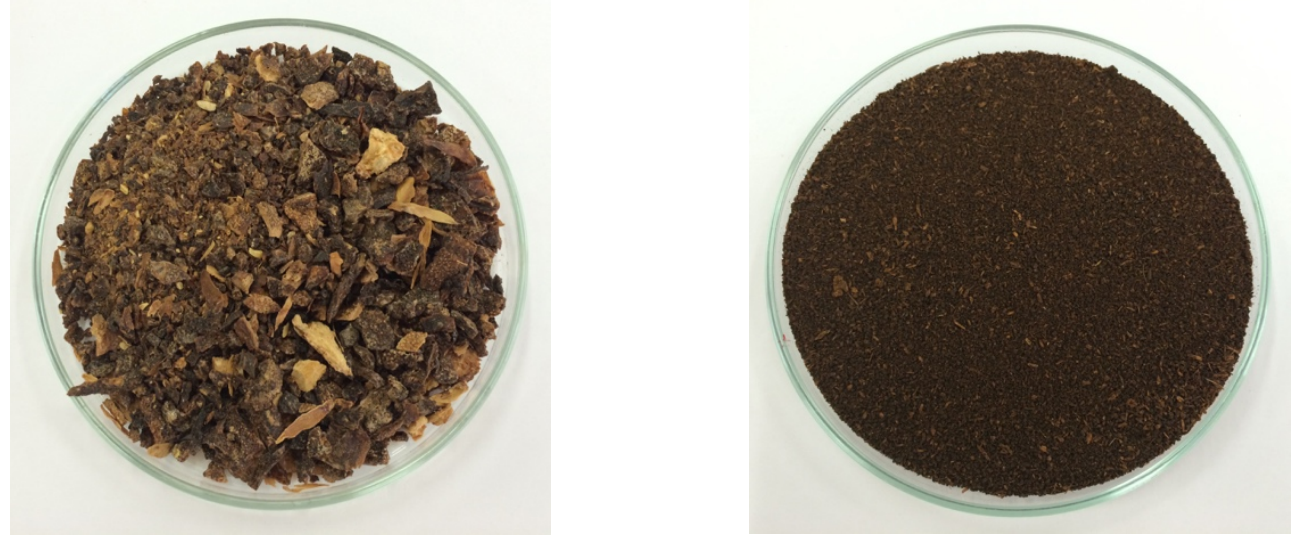

(b)
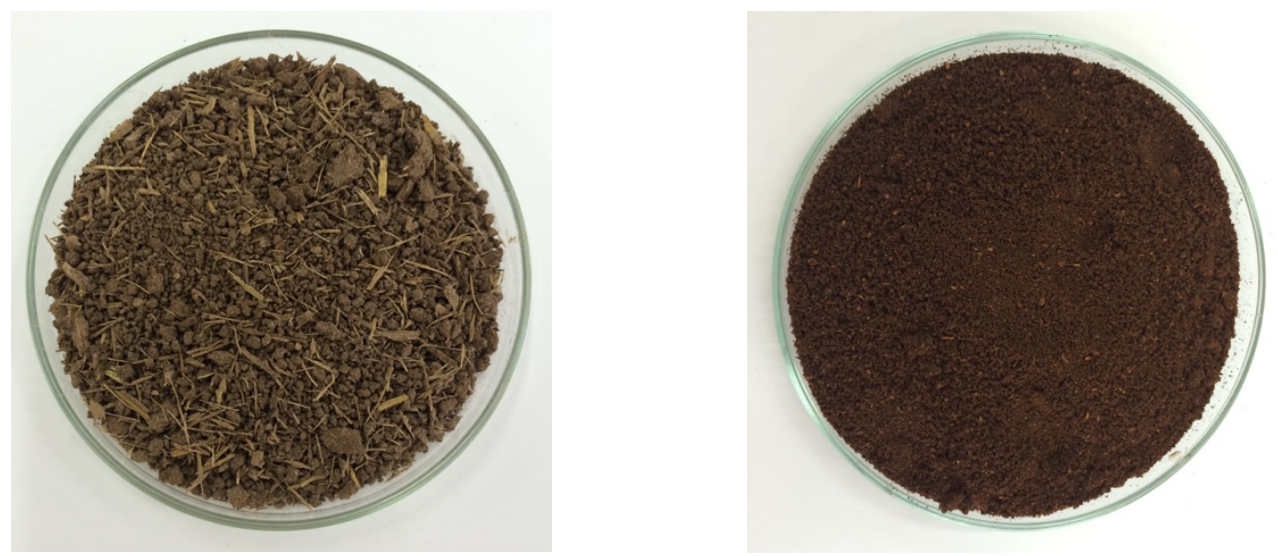

(c)
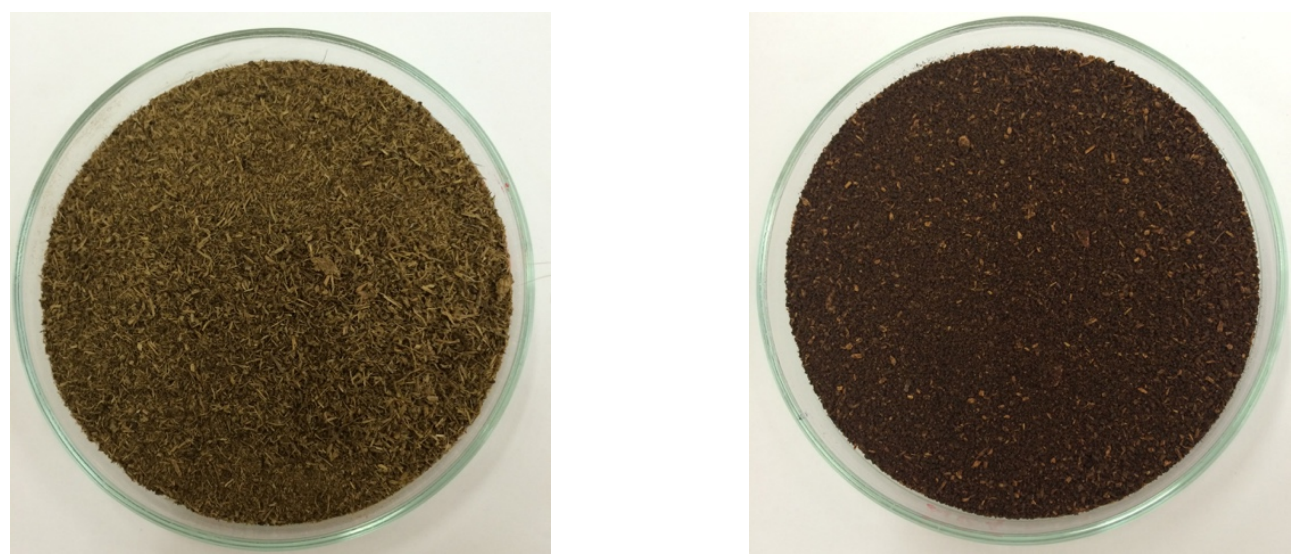
Segundo Kiehl (1985), a partir destas alterações nas características visuais durante o processo de compostagem pode-se inferir sobre o grau de maturação do composto. O húmus tem coloração negra e devido à acentuada decomposição, a maior parte da mistura original de resíduos não mais permite ser identificada e tornase uma massa moldável, quando úmida. O odor penetrante característico de cada resíduo, com a vermicompostagem, passou a um cheiro de terra molhada perfeitamente tolerável e a redução do volume da massa inicial foi nítida.

\subsubsection{Análise elementar e relação $\mathrm{C} / \mathrm{N}$ dos vermicompostos}

No final do processo de vermicompostagem pode-se observar uma diminuição no teor de $C$ nos três diferentes tratamentos (Tabela 1), resultado da mineralização da matéria orgânica pelos microrganismos. A diminuição do teor de $C$ já havia sido relatada por Huang et al. (2006) durante a compostagem de esterco de porco com serragem. Bhat et al. (2015) também relataram uma diminuição do teor de carbono orgânico em todos os produtos finais da vermicompostagem de misturas de resíduos de bagaço de cana e esterco bovino. O conteúdo $C$ dos tratamentos EB e TF+EB diminuiu $58 \%$, enquanto que para o tratamento $B L+E B$ a redução foi de $53 \%$. Isto pode ser devido às características do bagaço de laranja, uma vez que contém mais lignina que não é facilmente degradada. A taxa de mineralização da MO diminuiu nos três tratamentos após 105 dias e não foram observadas diminuições adicionais significativas.

$\mathrm{O}$ teor de $\mathrm{N}$ total nos três tratamentos, no início e no final do processo de vermicompostagem, não foi significativamente diferente. Após 90 dias, o teor de $\mathrm{N}$ total dos três tratamentos aumentou 152, 19,5 e 99\% para BL+EB, TF+EB e EB respectivamente (Tabela 2 - I). De acordo com Bernal et al. (2009), a perda de $\mathrm{N}$ durante a compostagem ocorre por volatilização de amônio, tornando, assim, o N total reduzido, no final do processo. É também possível que a perda de nitrogênio tenha ocorrido por desnitrificação. 
Tabela 2 - I. Teores de N, C, H e S e relação C/N durante o processo de vermicompostagem

\begin{tabular}{|c|c|c|c|c|c|c|}
\hline Tratamentos & $\begin{array}{c}\text { Tempo } \\
\text { (dias) }\end{array}$ & $\mathbf{N}$ & C & H & $\mathbf{s}$ & $\mathrm{C} / \mathrm{N}$ \\
\hline \multirow[t]{11}{*}{$\mathrm{BL}+\mathrm{EB}$} & 0 & $1,57 \mathrm{e}$ & $34,75 a$ & $4,90 a$ & $0,85 a$ & $25,96 a$ \\
\hline & 7 & $2,62 e$ & $33,02 a b$ & $4,65 a b$ & $0,80 a$ & $24,27 a$ \\
\hline & 15 & $2,01 \mathrm{de}$ & $34,28 a$ & $4,60 a b$ & $0,73 a$ & $20,06 \mathrm{~b}$ \\
\hline & 30 & $2,66 c$ & $32,72 \mathrm{abc}$ & $4,19 a b c$ & $0,70 a$ & $14,36 \mathrm{c}$ \\
\hline & 45 & $2,54 \mathrm{c}$ & $33,09 a b$ & $4,29 a b$ & $0,68 a$ & $15,22 \mathrm{c}$ \\
\hline & 60 & $2,67 c$ & $32,12 \mathrm{abc}$ & $4,35 a b$ & $0,89 a$ & $14,36 \mathrm{c}$ \\
\hline & 75 & $2,42 \mathrm{~cd}$ & $26,96 c$ & $3,64 \mathrm{bc}$ & $0,77 a$ & $12,96 \mathrm{~cd}$ \\
\hline & 90 & $3,97 a$ & $27,71 \mathrm{bc}$ & $5,06 a$ & $0,00 b$ & $8,14 \mathrm{e}$ \\
\hline & 105 & $3,37 b$ & $19,23 d$ & $4,18 a b c$ & $0,00 b$ & $6,65 \mathrm{e}$ \\
\hline & 120 & $2,33 \mathrm{~cd}$ & $19,80 d$ & $3,29 b$ & $0,95 a$ & $9,88 \mathrm{de}$ \\
\hline & 135 & $2,00 \mathrm{de}$ & $16,34 d$ & $2,37 d$ & $1,05 a$ & $9,51 \mathrm{de}$ \\
\hline \multirow[t]{11}{*}{$\mathrm{TF}+\mathrm{EB}$} & 0 & $2,71 \mathrm{~cd}$ & $27,12 \mathrm{abc}$ & $4,22 a$ & $0,89 a$ & $18,39 a b$ \\
\hline & 7 & $1,65 \mathrm{~cd}$ & $29,41 a b$ & $4,12 \mathrm{a}$ & $0,74 a$ & $20,94 a$ \\
\hline & 15 & $2,17 \mathrm{c}$ & $30,57 a$ & $4,39 a$ & $0,69 a$ & $16,59 \mathrm{abc}$ \\
\hline & 30 & $2,24 b c$ & $28,13 a b$ & $4,06 a$ & $2,07 a$ & $14,64 \mathrm{bcd}$ \\
\hline & 45 & $2,20 c$ & $27,07 a b$ & $3,99 a$ & $0,66 a$ & $14,82 \mathrm{bcd}$ \\
\hline & 60 & $2,13 c$ & $26,77 a b c$ & $3,91 a$ & $0,71 a$ & $14,72 \mathrm{bcd}$ \\
\hline & 75 & $2,24 b c$ & $25,02 \mathrm{abc}$ & $3,69 a$ & $0,64 a$ & $13,07 \mathrm{bcde}$ \\
\hline & 90 & $3,24 a$ & $20,56 \mathrm{abcd}$ & $4,45 a$ & $0,00 a$ & $7,22 \mathrm{ef}$ \\
\hline & 105 & $2,95 a b$ & $16,91 \mathrm{~cd}$ & $3,48 a$ & $0,00 a$ & $6,62 f$ \\
\hline & 120 & $2,05 \mathrm{~cd}$ & $19,73 \mathrm{~cd}$ & $3,28 a$ & $0,83 a$ & $11,22 \mathrm{cdef}$ \\
\hline & 135 & $1,38 d$ & $11,36 d$ & $2,03 b$ & $1,15 a$ & 9,62def \\
\hline \multirow[t]{11}{*}{ EB } & 0 & $1,50 c$ & $29,63 a b$ & $4,23 a$ & $0,79 a b c$ & $23,08 a$ \\
\hline & 7 & $1,88 \mathrm{bc}$ & $33,76 c$ & $4,72 a$ & $0,81 a b$ & $20,71 a b$ \\
\hline & 15 & $1,82 \mathrm{bc}$ & $30,41 a b$ & $4,21 a$ & $0,70 \mathrm{bcd}$ & $9,68 a b$ \\
\hline & 30 & $1,84 \mathrm{bc}$ & $30,39 a b$ & $4,13 a$ & $0,65 \mathrm{~cd}$ & $19,28 a b$ \\
\hline & 45 & $1,77 \mathrm{bc}$ & $25,59 a b c$ & $3,57 a$ & $0,63 d$ & $17,04 \mathrm{bc}$ \\
\hline & 60 & $1,89 \mathrm{bc}$ & $27,03 \mathrm{abc}$ & $3,77 a$ & $0,66 \mathrm{bcd}$ & $16,70 \mathrm{bc}$ \\
\hline & 75 & $1,61 b c$ & $21,78 \mathrm{abcd}$ & $3,04 a$ & $0,67 \mathrm{bcd}$ & $15,81 \mathrm{~cd}$ \\
\hline & 90 & $2,99 a$ & $18,96 \mathrm{bcd}$ & $4,14 a$ & $0,00 e$ & $7,38 \mathrm{e}$ \\
\hline & 105 & $2,81 a$ & $14,74 \mathrm{~cd}$ & $3,31 a$ & $0,00 e$ & $6,10 \mathrm{e}$ \\
\hline & 120 & $2,18 b$ & $24,61 \mathrm{abcd}$ & $3,70 a$ & $0,86 a$ & $13,22 \mathrm{~cd}$ \\
\hline & 135 & $1,31 \mathrm{c}$ & $12,43 d$ & $1,92 b$ & $0,58 d$ & $11,03 \mathrm{ed}$ \\
\hline
\end{tabular}

$\overline{\mathrm{BL}+\mathrm{EB} B a g a c ̧ o ~ d e ~ l a r a n j a ~+~ E s t e r c o ~ B o v i n o ; ~}{ }^{\mathrm{TF}+\mathrm{EB}}$ Torta de filtro + Esterco Bovino; ${ }^{\mathrm{EB}}$ Esterco bovino.

*De acordo com o teste de Tukey, valores seguidos pela mesma letra na mesma coluna não são significantemente diferentes $(p<0,05)$. 
A Figura 7 - I mostra a relação $\mathrm{C} / \mathrm{N}$ em função do tempo para os três tratamentos. A relação $\mathrm{C} / \mathrm{N}$ é muitas vezes utilizada para avaliar a evolução do processo de degradação. Houve uma diminuição na relação $\mathrm{C} / \mathrm{N}$ do tratamento BL+EB a partir do valor inicial de 25,96 para 14,36 após 30 dias de compostagem, e este continuou diminuindo gradualmente para 6,65 em 105 dias. Para o tratamento $\mathrm{TF}+\mathrm{EB}$, a relação C/N diminuiu gradualmente até um mínimo de 6,62 em 105 dias de processo, enquanto para o tratamento $\mathrm{EB}$, o valor mínimo de relação $\mathrm{C} / \mathrm{N}$ foi de 6,10 após 105 dias. Isto foi devido à perda contínua de $\mathrm{C}$ através da respiração microbiana durante o processo. Este comportamento foi semelhante ao relatado por Juarez et al. (2011). No final de 90 dias, as relações $\mathrm{C} / \mathrm{N}$ dos três tratamentos foram inferiores a 8,14. De acordo com Bernal et al. (1998) a relação $C / N$ inferior a 12 indica a maturidade do composto e sua adequação para aplicação no solo. Pode-se concluir que a maturação do composto foi atingida após 90 dias. Tem sido sugerido que a relação $\mathrm{C} / \mathrm{N}$ deve ser considerada juntamente com outros parâmetros para monitoramento da estabilização de compostos (FIALHO et al. 2010). Os autores também observaram que, em algumas pilhas de compostagem, embora a relação $\mathrm{C} / \mathrm{N}$ se estabilizasse, a temperatura ainda estava na fase termofílica, o que é uma indicação de que os compostos não estavam estabilizados naquele momento. $A$ evolução do processo depende fortemente da natureza do material utilizado no composto e/ou vermicompostagem e a relação $\mathrm{C} / \mathrm{N}$ afeta a taxa a qual o material está estabilizado em termos da atividade microbiológica. Resultados similares foram observados por Bhat et al. (2015). No final do processo de vermicompostagem, as relações $\mathrm{C} / \mathrm{N}$ dos tratamentos $\mathrm{BL}+\mathrm{EB}, \mathrm{TF}+\mathrm{EB}$ e $\mathrm{EB}$ foram 9,51; 9,62 e 11,03, respectivamente. Esses valores indicam baixa atividade microbiana e a possibilidade de estabilização do material, como também sugerido por Provenzano et al. (2001), Bernal et al. (1998) e Chefetz et al. (1996). A diminuição na relação C/N em função do tempo de vermicompostagem é indicativo de aumento da humificação da $\mathrm{MO}$, o que está diretamente relacionado à qualidade e maturidade do vermicomposto. A relação $\mathrm{C} / \mathrm{N}$ também é indicativo do grau de incorporação de $\mathrm{N}$ na estrutura húmica. $\mathrm{A}$ Tabela 2 - I apresenta o aumento do teor de $\mathrm{N}$ até 120 dias para vermicompostos de TF+EB, $\mathrm{BL}+\mathrm{EB}$ e EB. A incorporação de $\mathrm{N}$ proporciona um aumento do potencial fertilizante 
deste material, porque o $\mathrm{N}$ é libertado para as raízes das plantas sob a forma de $\mathrm{NO}_{3}{ }^{-}$ por meio de vários mecanismos de mineralização da matéria orgânica do solo.

O processo de vermicompostagem do tratamento TF+EB durou mais tempo do que os demais. Isto pode ser devido às características da torta de filtro, a qual contém mais lignina, composto muito recalcitrante. Em geral, a relação $\mathrm{C} / \mathrm{N}$ determina a capacidade de degradação microbiana dos resíduos, mas alguns resíduos orgânicos, tais como os derivados de plantas, apesar de atingirem relação $\mathrm{C} / \mathrm{N}$ adequada, podem conter uma elevada proporção de lignina, dificultando o processo de degradação. Após 105 dias de processo, não foram mais observadas minhocas em atividade nos vermicompostores referentes aos tratamentos $B L+E B$ e $E B$, enquanto sua atividade continuou a ser observada nos vermicompostores de TF+EB. Como colocado anteriormente, para confirmar que os vermicompostos estavam prontos, mais 100 minhocas foram adicionadas a cada vermicompostor. Após sete dias, não havia mais minhocas em BL+EB e em EB. Uma vez que a umidade foi mantida constante e o meio permanecia ligeiramente básico, pode-se constatar que não havia mais substrato (matéria orgânica fresca) para as minhocas se alimentarem. No entanto, para o tratamento $T F+E B$, a atividade das minhocas cessou apenas com 135 dias de vermicompostagem.

Para o teor de $C$ total observa-se uma tendência de diminuição principalmente após adição das minhocas ao processo (segunda etapa do processo). Foi constatado um aumento do teor de $\mathrm{N}$ total no decorrer da primeira etapa do processo (compostagem), ou seja, nos primeiros 90 dias. A partir disso pode-se notar uma diminuição dos teores devido ao acréscimo das minhocas na segunda etapa do processo (vermicompostagem). Dessa forma, pode-se considerar parar o processo aos 90 dias, visto que nesse tempo há um teor adequado de $\mathrm{N}$ e a partir de 105 dias começa haver perda de de C (para todos os tratamentos). 
Figura 7 - I. Variação média da relação $\mathrm{C} / \mathrm{N}$ em função do tempo de vermicompostagem. $\mathrm{BL}+\mathrm{EB}$ : bagaço de laranja + esterco bovino; TF+EB: torta de filtro + esterco bovino; EB: esterco bovino

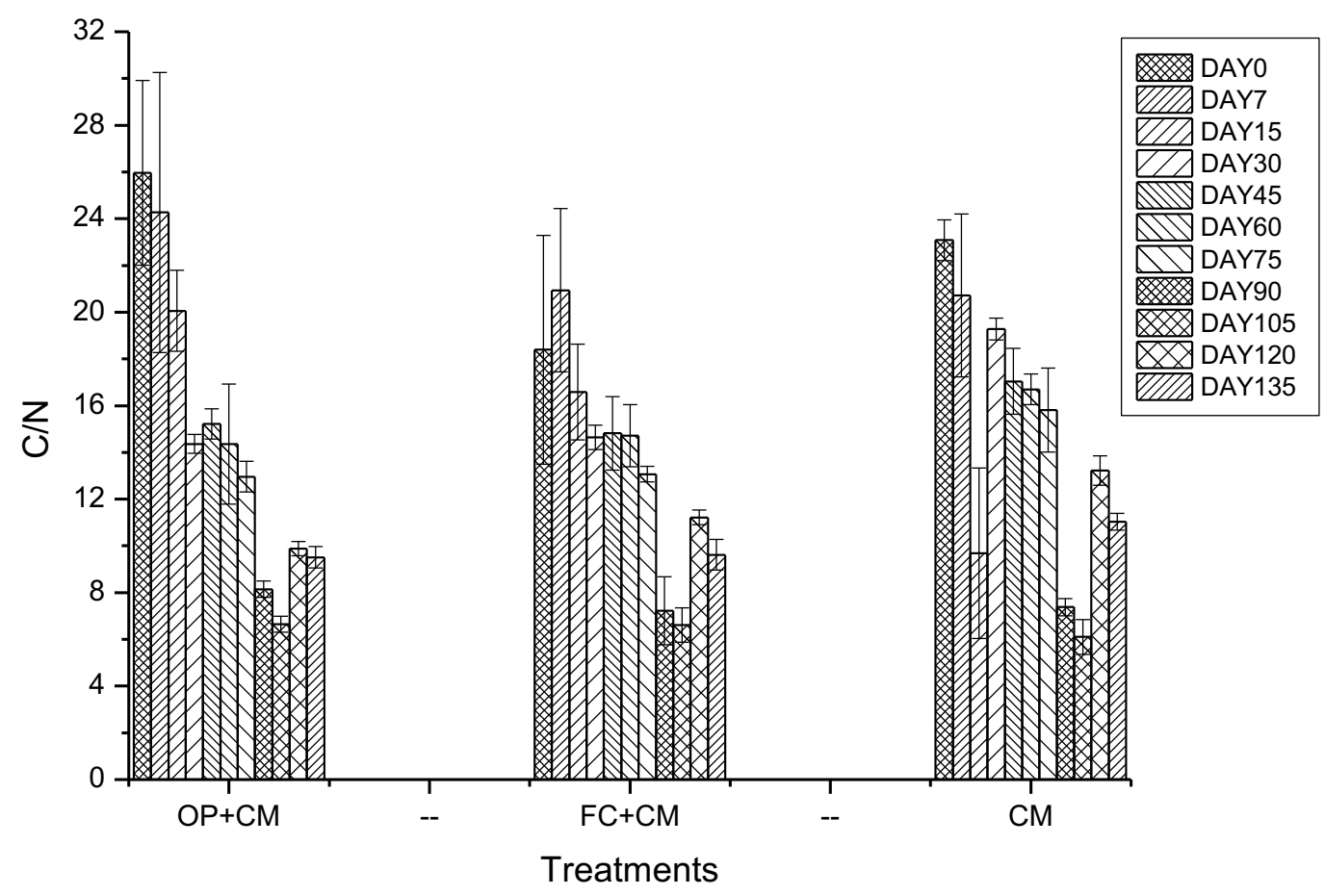

Entre os três tratamentos, $\mathrm{BL}+\mathrm{EB}$ apresentou o maior teor de $\mathrm{N}$ no final do processo de vermicompostagem. Os teores de $N$ de TF+EB e EB não foram significativamente diferentes $(p<0,05)$. Não houve diferença significativa no conteúdo de $\mathrm{C}, \mathrm{H}$ e $\mathrm{S}$ de todos os vermicompostos. Além disso, embora as relações $\mathrm{C} / \mathrm{N}$ dos tratamentos $\mathrm{BL}+\mathrm{EB}$ e TF+EB não tenham sido significativamente diferentes, elas foram significativamente mais baixas do que a do EB. Isto mostra que os tratamentos $\mathrm{BL}+\mathrm{EB}$ e TF+EB atingiram um nível mais elevado de condensação molecular o que significa que esses tratamentos apresentaram-se em uma fase mais avançada de humificação do que que o tratamento EB (BERNAL et al., 1998). O decréscimo na relação $\mathrm{C} / \mathrm{N}$ foi devido à maior perda de carbono através da respiração microbiana na forma de $\mathrm{CO}_{2}$, juntamente com um aumento do teor de nitrogênio e estabilização de resíduos pela ação das minhocas (HAIT \& TARE, 2011). 


\subsubsection{Teor de macro e micronutrientes}

Os dados coletados, juntamente com os dados de $\mathrm{N}$ e $\mathrm{P}$, foram analisados usando a técnica de Análise de Variância (ANOVA) e as médias foram separadas usando Teste de Tukey $(p<0,05)$ por meio do programa SAS 9.4 Software Package. A Tabela 3 - I apresenta os resultados de macro e micronutrientes no início e final do processo de vermicompostagem de acordo com os diferentes tratamentos. Para análise multivariada, neste caso, foram levados em consideração dois fatores: os diferentes tratamentos (origem dos resíduos) e os diferentes tempos de processo (início e final).

Pode-se observar na Tabela 3 - I que TF+EB 11 possui maior teor de fósforo e EB 1 o menor teor (os índices 1 e 11 representam os tempos 0 e 135 dias de vermicompostagem respectivamente). $O$ teor de $P$ de TF+EB 11 não é significativamente diferente de BL+EB 11 e TF+EB 1. Para TF+EB 11, o teor de $P$ é significantemente maior do que para $B L+E B$ 1, EB 1 e EB 11, entretanto não é significativamente diferente de TF+EB 1 e $B L+E B 11$. O significativo $(p \leq 0,05)$ maior teor de $\mathrm{P}$ no vermicomposto TF+EB 11 possivelmente é devido ao maior conteúdo de $\mathrm{P}$ no resíduo torta de filtro (FIALHO et al., 2010).

Os vermicompostos oriundos das misturas de esterco bovino com bagaço de laranja ou com torta de filtro (BL+EB 11 e TF+EB 11) apresentam maior conteúdo de $P$ do que o vermicomposto de esterco bovino puro (EB 11) no final do processo. Analisando-se isoladamente este macronutriente, de acordo com a demanda de $\mathrm{P}$ pela cultura, pode-se recomendar a não utilização do esterco bovino isolado para vermicompostagem, visto que para as misturas de EB com os demais resíduos agroindustriais estudados, os resultados são significativamente diferentes $(p \leq 0,05)$. 
Tabela 3 - I. Macro e micronutrientes no início e no final do processo de vermicompostagem de acordo com os diferentes tratamentos

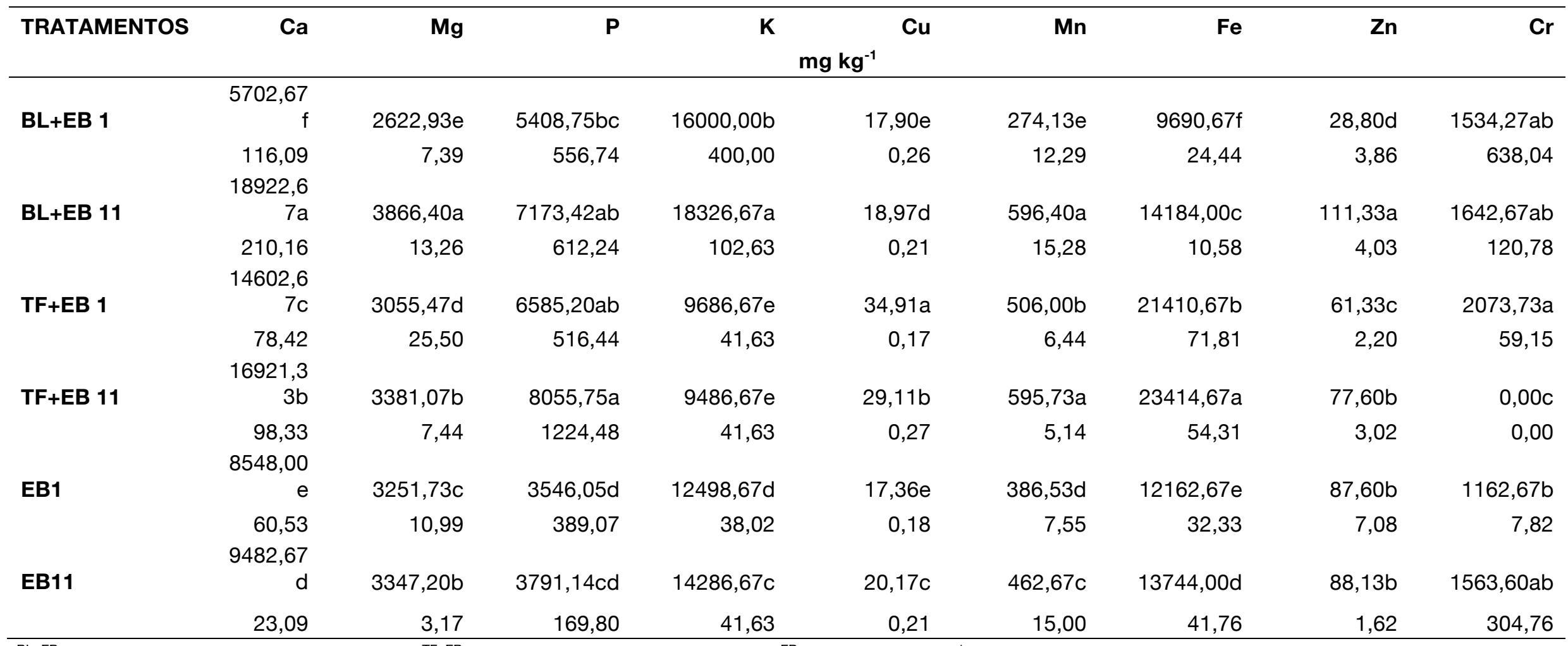

${ }^{\mathrm{BL}+\mathrm{EB} B}$ Bagaço de laranja + Esterco Bovino; ${ }^{\mathrm{TF}+\mathrm{EB}}$ Torta de filtro + Esterco Bovino; ${ }^{\mathrm{EB}}$ Esterco bovino. ${ }^{1}$ Coleta tempo

${ }^{0 ; 11}$ Coleta após 135 dias. ${ }^{\text {a, b, }}$ Valores médios seguidos de seus desvios padrões de três réplicas laboratoriais.

Valores seguidos pela mesma letra em uma mesma coluna não são significativamente diferentes em $p<0.05$ pelo Teste de Tukey. 
Analisando-se o teor de K, pode-se observar na Tabela 3 - I que o vermicomposto oriundo da mistura de esterco bovino com bagaço de laranja, $B L+E B$ 11, apresenta o maior teor deste elemento, sendo significativamente diferente de todos os demais $(p \leq 0,05)$. Os valores para todos os tratamentos nos diferentes tempos de vermicompostagem são significativamente diferentes entre si $(p \leq 0,05)$ e seguem a ordem: $\mathrm{BL}+\mathrm{EB} 11>\mathrm{BL}+\mathrm{EB} 1>\mathrm{EB} 11>\mathrm{EB} 1>\mathrm{TF}+\mathrm{EB} 11>\mathrm{TF}+\mathrm{EB} 1$. Analisando-se isoladamente este macronutriente $(\mathrm{K})$ e a demanda de determinada cultura por este nutriente, recomendar-se-ia a utilização do vermicomposto oriundo da mistura dos resíduos bagaço de laranja e esterco bovino. A mistura de esterco bovino, neste caso, com o resíduo bagaço de laranja, proporcionou um aumento no teor do macronutriente no vermicomposto final comparado ao vermicomposto de esterco bovino puro.

Quanto aos teores dos macronutrientes Ca e Mg, BL+EB 11 apresenta valores significativamente maiores $(p \leq 0,05)$ que os demais tratamentos nos diferentes tempos de vermicompostagem. Para ambos os elementos todos os tratamentos nos diferentes tempos de vermicompostagem são significativamente diferentes entre si $(p \leq 0,05)$ e seguem a ordem para o teor de $\mathrm{Ca}$ : $\mathrm{BL}+\mathrm{EB} 11>\mathrm{TF}+\mathrm{EB} 11>\mathrm{TF}+\mathrm{EB} 1>$ EB $11>$ EB $1>\mathrm{BL}+\mathrm{EB} 1$; e seguem a ordem para Mg: $\mathrm{BL}+\mathrm{EB} 11>\mathrm{TF}+\mathrm{EB} 11>\mathrm{EB}$ $11>\mathrm{EB} 1>\mathrm{TF}+\mathrm{EB} 1>\mathrm{BL}+\mathrm{EB} 1$.

Com relação aos teores dos micronutrientes $\mathrm{Cu}, \mathrm{Mn}$, Fe e $\mathrm{Zn}$, em geral, os vermicompostos $\mathrm{BL}+\mathrm{EB} 11$, TF+EB 11 e TF+EB 1 apresentam os maiores teores. Para o cobre, TF+EB 1 apresenta o maior teor deste micronutriente, sendo significativamente maior $(p \leq 0,05)$ que todos os demais tratamentos nos diferentes tempos de vermicompostagem. Os demais também são significativamente diferentes entre si $(p \leq 0,05)$, exceto $B L+E B ~ 1$ e EB 1, e seguem a ordem: TF+EB $11>$ EB $11>$ $\mathrm{BL}+\mathrm{EB} 11>\mathrm{BL}+\mathrm{EB} 1$ = EB1. Para o Mn, BL+EB 11 e TF+EB 11 apresentam os maiores teores, sendo iguais entre si e significativamente diferentes $(p \leq 0,05)$ dos demais tratamentos nos diferentes tempos de vermicompostagem. Os demais tratamentos são significativamente diferentes entre si $(p \leq 0,05)$ e seguem a ordem: $\mathrm{TF}+\mathrm{EB} 1>\mathrm{EB} 11>\mathrm{EB} 1>\mathrm{BL}+\mathrm{EB} 1$. O vermicomposto TF+EB 11 apresenta o teor 
mais alto de Fe, sendo significativamente diferente de todos os demais $(p \leq 0,05)$. Todos os tratamentos são significativamente diferentes entre si $(p \leq 0,05)$ e seguem a seguinte ordem para o teor de Fe: TF+EB $11>\mathrm{TF}+\mathrm{EB} 1>\mathrm{BL}+\mathrm{EB} 11>\mathrm{EB} 11>\mathrm{EB}$ $1>\mathrm{BL}+\mathrm{EB}$ 1. Quanto ao teor de $\mathrm{Zn}, \mathrm{BL}+\mathrm{EB}$ apresenta significativamente o maior valor $(p \leq 0,05)$, seguido de EB 11, EB 1 e TF+EB 11 que são estatisticamente iguais e significativamente diferentes $(p \leq 0,05)$ de TF+EB 1 e BL+EB 1 (TF+BL $1>B L+E B$ 1) (Tabela $3-1)$.

Foi incluído nesta análise a determinação do teor de cromo o qual se presente em grande quantidade, pode ter caráter tóxico. Pode-se observar na Tabela 3 - I que TF+EB 11 possui maior teor $\mathrm{Cr}$ e TF+EB 1 o menor teor. O teor de $\mathrm{Cr}$ de TF+EB 11 não é significativamente diferente de $B L+E B$ 11, BL+EB 1 e EB 11. Para TF+EB 11, o teor de P é significantemente maior do que para TF+EB 11 e EB 1.

A Tabela 4 - I apresenta uma análise estatística dos dados de macro e micronutrientes, levando-se em consideração apenas um fator, o tempo de vermicompostagem, independente dos tratamentos (origem dos resíduos). Pode-se observar, que houve um incremento no teor de macro e micronutrientes com o tempo de vermicompostagem, exceto os teores de $\mathrm{Cu}$ e $\mathrm{Cr}$ que são significativamente maiores no tempo zero do que após 135 dias de vermicompostagem. Em geral, este resultado é positivo, inclusive a diminuição dos teores de $\mathrm{Cu}$ e principalmente de $\mathrm{Cr}$, os quais possivelmente foram bioacumulados pelas minhocas Eisenia fetida. A indisponibilização de $\mathrm{Cr}$ e $\mathrm{Cu}$ pode ser bastante positiva, visto que ambos são elementos tóxicos em concentrações elevadas. 
Tabela 4 - I. O efeito do tempo de vermicompostagem (dias) nos teores de macro e micronutrientes independente dos diferentes tratamentos

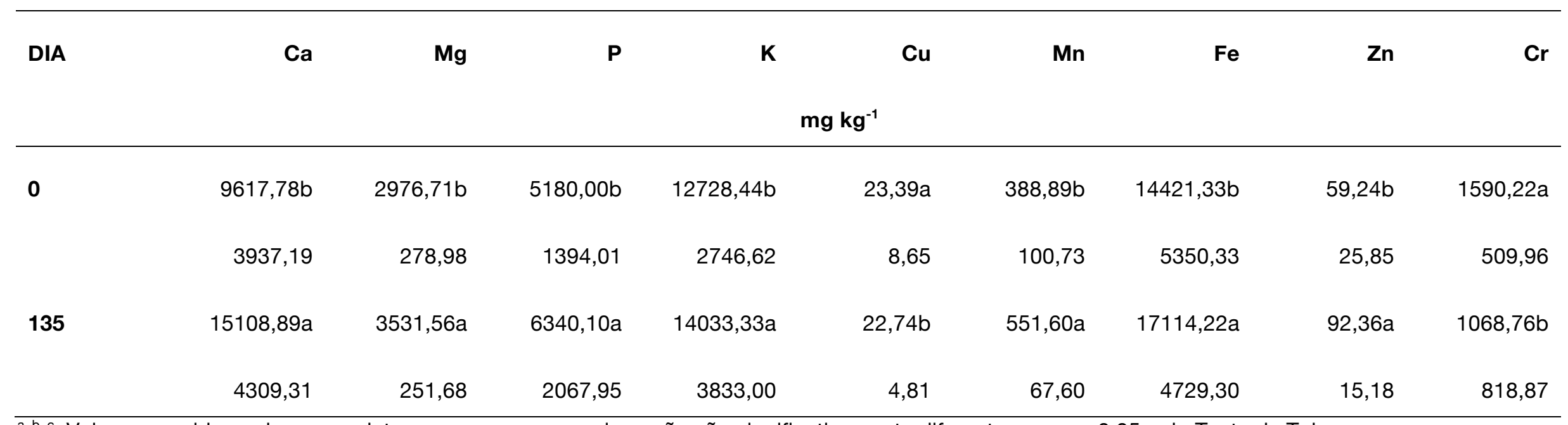

$\overline{a, b, c}$ Valores seguidos pela mesma letra em uma mesma coluna não são significativamente diferentes em $p<0,05$ pelo Teste de Tukey. 
Fialho (2007) observou significativo incremento dos nutrientes, em consequência do aumento relativo da concentração dos elementos inorgânicos durante 210 dias de compostagem. A autora ressalta que os resultados evidenciam o potencial que o composto apresenta para o uso como fertilizante orgânico.

A seguir, a Tabela 5 - I apresenta análise estatística dos dados de macro e micronutrientes, também levando-se em consideração apenas um fator, sendo este os diferentes tratamentos aos 135 dias de vermicompostagem. O intuito foi avaliar qual o melhor tratamento em função do teor de nutrientes dos vermicompostos produzidos.

Analisando-se a Tabela 5 - I, é possível observar que de maneira geral os vermicompostos oriundos das misturas $B L+E B$ e $T F+E B$ são mais ricos em macro e micronutrientes aos 135 dias de vermicompostagem. BL+EB apresenta valores significativamente maiores $(\mathrm{p} \leq 0,05)$ que os demais tratamentos, para $\mathrm{Ca}, \mathrm{Mg} \mathrm{e} \mathrm{K}$, e para o $\mathrm{P}$ apresenta valor estatisticamente igual ao do tratamento $\mathrm{TF}+\mathrm{EB}$, sendo ambos significativamente maiores $(p \leq 0,05)$ que para $E B(C a$ e $M g: B L+E B>T F+E B$ $>\mathrm{EB} ; \mathrm{P}: \mathrm{BL}+\mathrm{EB}=\mathrm{TF}+\mathrm{EB}>\mathrm{EB})$. Para $\mathrm{K}$ os tratamentos são significativamente diferentes entre si $(p \leq 0,05)$, sendo que o maior teor é do $B L+E B$ e o menor teor é do $\mathrm{TF}+\mathrm{EB}(\mathrm{BL}+\mathrm{EB}>\mathrm{EB}>\mathrm{TF}+\mathrm{EB})$.

Com relação aos teores de micronutrientes (Cu, Mn, Fe, $\mathrm{Zn}$ e $\mathrm{Cr}$ ), o tratamento TF+EB apresenta teores significativamente maiores $(p \leq 0,05)$ de $\mathrm{Cu}$ e Fe, seguido do tratamento $\mathrm{BL}+\mathrm{EB}$ (Cu e Fe: TF+EB > BL+EB > EB). BL+EB e TF+EB apresentam os maiores teores de $\mathrm{Mn}$, sendo seus valores estatisticamente iguais e significativamente maiores que para $\mathrm{EB}(\mathrm{Mn}: \mathrm{BL}+\mathrm{EB}=\mathrm{TF}+\mathrm{EB}>\mathrm{EB})$. Para $\mathrm{Zn}$, os tratamentos apresentam teores significativamente diferentes na seguinte ordem: $\mathrm{BL}+\mathrm{EB}>\mathrm{EB}>\mathrm{TF}+\mathrm{EB}$. E para $\mathrm{Cr}, \mathrm{BL}+\mathrm{EB}$ e $\mathrm{EB}$ são estatisticamente iguais e apresentam valores significativamente maiores que TF+EB.

Neste ponto, vale chamar atenção para os teores de $\mathrm{Cr}$ para TF+EB no final da vermicompostagem, os quais são próximos de zero. Lembrando que com 100 dias de vermicompostagem já não havia mais minhocas para os tratamentos $B L+E B$ 
e EB, sugerindo que todo o material já havia sido degradado neste tempo. E que sob as mesmas condições, com 100 dias, para TF+EB as minhocas ainda encontravamse em plena atividade, visto que a torta de filtro é um resíduo bastante fibroso e rico em lignina. Possivelmente o maior tempo de atividade das minhocas em TF+EB possibilitou uma maior bioacumulação do $\mathrm{Cr}$ e por isso os valores no final do processo são próximos de zero para este vermicomposto. 
Tabela 5 - I. Macro e micronutrientes no final do processo de vermicompostagem de acordo com os diferentes tratamentos

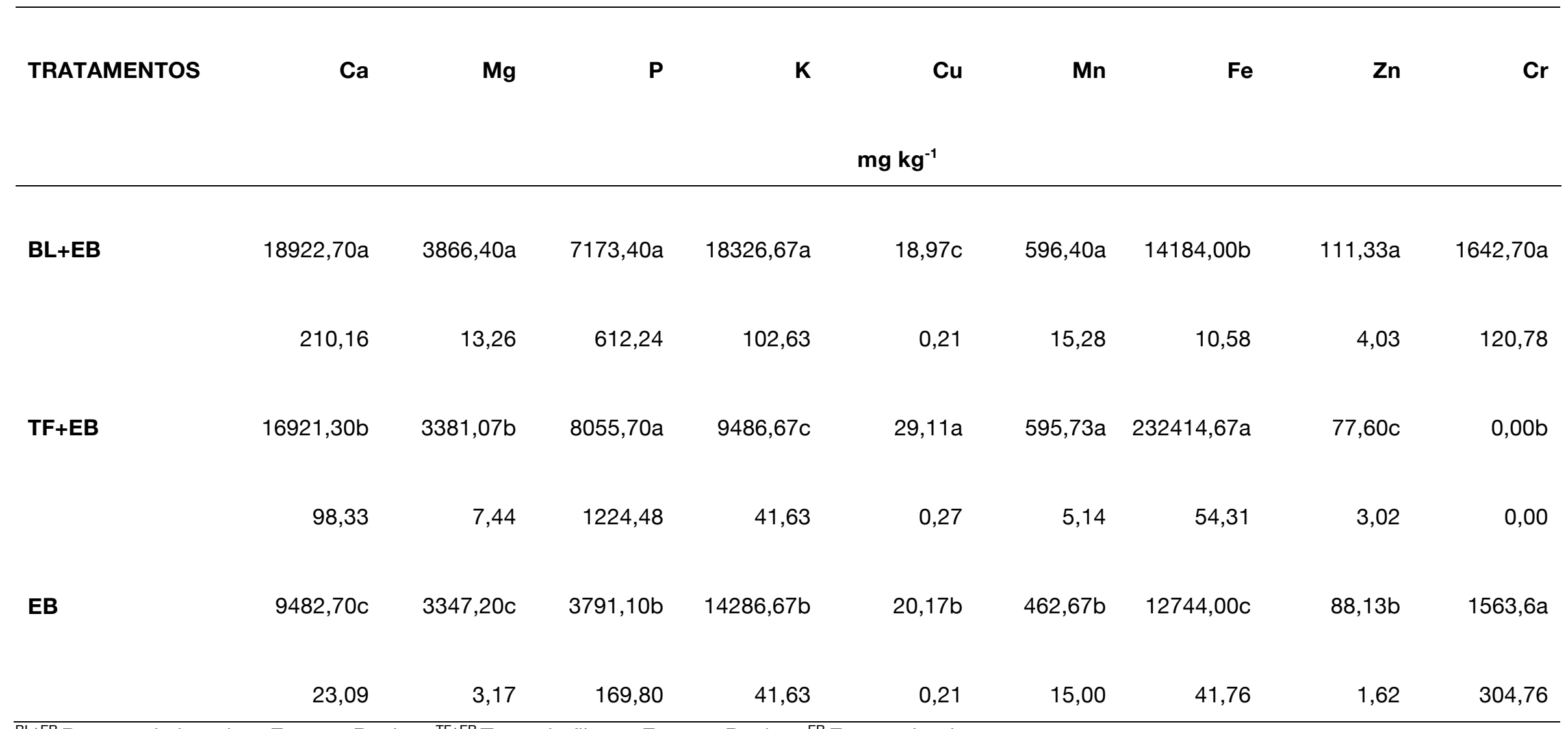

$\overline{\mathrm{BL}+\mathrm{EB}}$ Bagaço de laranja + Esterco Bovino; ${ }^{\mathrm{TF}+\mathrm{EB}}$ Torta de filtro + Esterco Bovino; ${ }^{\mathrm{EB}}$ Esterco bovino.

a, b, c Valores seguidos pela mesma letra em uma mesma coluna não são significativamente diferentes em $\mathrm{p}<0,05$ pelo Teste de Tukey. 
4.2.6 Análise elementar, $\mathrm{C} / \mathrm{N}$, pH e CTC: análise comparativa

A Tabela 6 - I apresenta os resultados de análise elementar, $\mathrm{C} / \mathrm{N}$, pH e CTC no início e no final do processo de vermicompostagem de acordo com os diferentes tratamentos. Foi seguido o mesmo raciocínio da análise estatística para os dados de macro e micronutrientes. Para análise multivariada, neste caso, levaram-se em consideração dois fatores: os diferentes tratamentos (origem dos resíduos) e os diferentes tempos do processo (início e final). Pode-se observar que $B L+E B 11$ possui maior teor de nitrogênio e TF+EB 11 e EB 11 os menores teores. O teor de $\mathrm{N}$ de $B L+E B 11$ não é significativamente diferente de BL+EB 1, TF+EB 1 e EB 1. Para $B L+E B ~ 11$, o teor de $N$ é significantemente maior $(p \leq 0,05)$ do que para $T F+E B 11$ e EB 11. Apenas para o tratamento BL+EB é possível observar um significante aumento $(p \leq 0,05)$ no teor de $\mathrm{N}$ em função do tempo de vermicompostagem (1,57 para 2,00\%). BL+EB 1 e EB 1 apresentam os maiores teores de C, e EB 11 o menor teor. Pode-se observar uma significativa diminuição $(p \leq 0,05)$ do teor de $C$ em função do tempo de vermicompostagem para todos os tratamentos. A diminuição nos teores de $\mathrm{C} \mathrm{em}$ função do tempo de vermicompostagem é devida ao consumo do mesmo por parte dos microrganismos e minhocas atuantes no processo, que utilizam como fonte de nutriente ou energia. Entretanto corroborando-se os resultados de carbono com os do hidrogênio pode-se afirmar que o carbono que permanece no vermicomposto final está mais humificado, ou seja, mais aromático, mais estável. 
Tabela 6 - I. Teores de N, C, H e S, C/N e pH no início e final do processo de vermicompostagem e CTC no final do processo de acordo com os diferentes tratamentos

\begin{tabular}{|c|c|c|c|c|c|c|c|}
\hline \multirow[t]{2}{*}{ TRATAMENTOS } & $\mathbf{N}$ & C & H & $\mathbf{S}$ & $\mathrm{C} / \mathrm{N}$ & pH & СтC \\
\hline & \multicolumn{3}{|c|}{$\%$} & & \multicolumn{3}{|c|}{$\mathrm{mmol}_{\mathrm{c}} \mathbf{k g}^{-1}$} \\
\hline \multirow[t]{2}{*}{ BL+EB 1} & $1,57 a b$ & $34,75 a$ & $4,90 a$ & $0,85 a$ & $25,96 a$ & $7,09 b$ & - \\
\hline & 0,22 & 4,88 & 0,66 & 0,06 & 3,95 & 0,68 & - \\
\hline \multirow[t]{2}{*}{ BL+EB 11} & $2,00 a$ & $16,34 \mathrm{bc}$ & $2,37 b$ & $1,05 a$ & $9,52 \mathrm{c}$ & $8,07 a b$ & $652,50 a$ \\
\hline & 0,32 & 2,95 & 0,27 & 0,63 & 0,46 & 0,11 & 14,36 \\
\hline \multirow[t]{2}{*}{$\mathrm{TF}+\mathrm{EB} 1$} & $1,71 \mathrm{ab}$ & $27,12 a b$ & $4,22 \mathrm{a}$ & $0,89 a$ & $18,39 b$ & $8,40 a$ & - \\
\hline & 0,29 & 8,47 & 0,78 & 0,03 & 4,90 & 0,08 & - \\
\hline \multirow[t]{2}{*}{ TF+EB 11} & $1,38 b$ & $11,39 c$ & $2,03 b$ & $1,15 a$ & $9,62 \mathrm{c}$ & $7,41 a b$ & $490,44 c$ \\
\hline & 0,07 & 0,68 & 0,21 & 0,95 & 0,66 & 0,11 & 15,76 \\
\hline \multirow[t]{2}{*}{ EB 1} & $1,50 a b$ & $29,63 a$ & $4,23 a$ & $0,79 a$ & $23,08 a b$ & $7,78 a b$ & - \\
\hline & 0,11 & 1,83 & 0,29 & 0,02 & 0,88 & 0,71 & - \\
\hline \multirow[t]{2}{*}{ EB 11} & $1,31 b$ & $12,43 c$ & $1,92 b$ & $0,58 \mathrm{a}$ & $11,03 c$ & $7,86 a b$ & $596,19 b$ \\
\hline & 0,16 & 1,91 & 0,24 & 0,00 & 0,36 & 0,21 & 15,02 \\
\hline
\end{tabular}

${ }^{\mathrm{BL}+\mathrm{EB}}$ Bagaço de laranja + Esterco Bovino; ${ }^{\mathrm{TF}+\mathrm{EB}}$ Torta de filtro + Esterco Bovino; ${ }^{\mathrm{EB}}$ Esterco bovino.

${ }^{1}$ Coleta tempo 0; ${ }^{11}$ Coleta após 135 dias. ${ }^{a, b, c}$ Valores médios seguidos de seus desvios padrões de três réplicas laboratoriais.

Valores seguidos pela mesma letra em uma mesma coluna não são significativamente diferentes em $p<0.05$ pelo Teste de Tukey.

$\leftrightarrow$ Valores não determinados 
A Tabela 6 - I mostra a significativa diminuição $(p \leq 0,05)$ dos teores de $\mathrm{H}$ em função do tempo de vermicompostagem para cada tratamento, o que possivelmente está relacionado a perda de estruturas mais lábeis das substâncias húmicas (carbonos e hidrogênios em cadeias alifáticas) que compõem a matéria orgânica fresca e maior aromaticidade da matéria orgânica ao final do processo. Isso pode ser confirmado por meio das análises espectroscópicas (FTIR, RMN, UV-Vis, P-CG/EM) dos ácidos húmicos extraídos dos vermicompostos nos diferentes tempos do processo de degradação (dados apresentados no Capítulo II).

A relação $\mathrm{C} / \mathrm{N}$ dos vermicompostos de todos os tratamentos é estatisticamente igual no final do processo de vermicompostagem e são significativamente menores do que no início para cada tratamento. De acordo com a literatura, os valores obtidos no final do processo são característicos de materiais humificados. Os valores são bastante abaixo do máximo recomentado pelo Ministério de Agricultura, Pecuária e Abastecimento, para comercialização do fertilizante orgânico composto (MAPA, 2009). Os valores de pH são estatisticamente iguais no final do processo (levemente básicos), sendo que o mínimo exigido para comercialização é 6,0 (MAPA, 2009). Os valores de CTC são significativamente diferentes $(p \leq 0,05)$ entre si, sendo que BL+EB 11 apresenta a maior CTC, seguida de EB 11 e TF+EB apresenta a menor CTC.

A Tabela 7 - I apresenta uma análise estatística dos dados de análise elementar, relação $\mathrm{C} / \mathrm{N}$ e pH, levando-se em consideração apenas um fator, o tempo de vermicompostagem, independente dos tratamentos (origem dos resíduos).

Os teores de $\mathrm{N}$ e S são estatisticamente iguais no início e final do processo de vermicompostagem, enquanto os teores de $\mathrm{C}$ e $\mathrm{H}$ apresentam significativa $(\mathrm{p} \leq 0,05)$ diminuição em função do processo de humificação da matéria orgânica. Também em função da humificação da matéria orgânica pode-se observar a diminuição significativa $(p \leq 0,05)$ da relação $\mathrm{C} / \mathrm{N}$ com o tempo de vermicompostagem. $\mathrm{E}$ considerando apenas o fator tempo, os valores de pH no tempo 0 e após 135 dias de processo são estatisticamente iguais $(p \leq 0,05)$ (Tabela 6$)$. 
A seguir, a Tabela 8 -I apresenta uma análise estatística dos dados de análise elementar, $\mathrm{C} / \mathrm{N}, \mathrm{pH}$ e CTC, também levando em consideração apenas um fator, sendo este os diferentes tratamentos após 135 dias de vermicompostagem. Assim como para os dados de macro e micronutrientes, o intuito foi avaliar qual o melhor tratamento, neste caso em função destes parâmetros (análise elementar, $\mathrm{C} / \mathrm{N}, \mathrm{pH}$ e CTC).

O tratamento $\mathrm{BL}+\mathrm{EB}$ apresenta o maior teor de $\mathrm{N}$, o qual é significantemente maior que o teor de $\mathrm{N}$ de $\mathrm{TF}+\mathrm{EB}$ e EB $(\mathrm{p} \leq 0,05)$. Os teores de $\mathrm{N}$ de $\mathrm{TF}+\mathrm{EB}$ e $\mathrm{EB}$ não são significativamente diferentes $(p \leq 0,05)$. Os teores de $\mathrm{C}, \mathrm{H}$ e $\mathrm{S}$ são estatisticamente iguais para todos os tratamentos estudados. Os vermicompostos oriundos da mistura de esterco bovino com bagaço de laranja ou torta de filtro são estatisticamente iguais quanto a $\mathrm{C} / \mathrm{N}$ e possuem $\mathrm{C} / \mathrm{N}$ significativamente menor que $\mathrm{O}$ vermicomposto de esterco bovino puro (EB). Teoricamente, este resultado indica que $\mathrm{BL}+\mathrm{EB}$ e TF+EB apresentam um maior nível de condensação a nível molecular, ou seja, encontram-se em um estágio de humificação mais avançado que EB. 
Tabela 7 - I. O efeito do tempo de vermicompostagem na Análise Elementar, $\mathrm{C} / \mathrm{N}$ e pH independente dos diferentes tratamentos

\begin{tabular}{|c|c|c|c|c|c|c|}
\hline Dia & $\mathbf{N}$ & C & $\mathbf{H}$ & $\mathbf{S}$ & $\mathrm{C} / \mathrm{N}$ & $\mathrm{pH}$ \\
\hline \multicolumn{7}{|c|}{$\%$} \\
\hline \multirow[t]{2}{*}{0} & $1,59 a$ & $30,50 a$ & $4,45 a$ & $0,84 a$ & $22,48 a$ & $7,75 a$ \\
\hline & 0,21 & 6,01 & 0,63 & 0,05 & 4,59 & 0,75 \\
\hline \multirow[t]{2}{*}{135} & $1,56 a$ & $13,38 b$ & $2.10 \mathrm{~b}$ & $0,93 a$ & $10,06 b$ & $7,78 \mathrm{a}$ \\
\hline & 0,38 & 2,88 & 0,29 & 0,63 & 0,85 & 0,32 \\
\hline
\end{tabular}

a,b,c Valores seguidos pela mesma letra em uma mesma coluna não são significativamente diferentes em $\mathrm{p}<0.05$ pelo Teste de Tukey.

${ }^{(-)}$Valores não determinados.

Tabela 8 - I. Análise Elementar, C/N, pH e CTC no final do processo de vermicompostagem de acordo com os diferentes tratamentos

\begin{tabular}{|c|c|c|c|c|c|c|c|}
\hline Dia & $\mathbf{N}$ & C & $\mathbf{H}$ & $\mathbf{S}$ & $\mathrm{C} / \mathrm{N}$ & $\mathrm{pH}$ & СTC \\
\hline \multicolumn{5}{|c|}{$\%$} & \multicolumn{3}{|c|}{$\mathrm{mmol}_{\mathrm{c}} \mathbf{k g}^{-1}$} \\
\hline \multirow[t]{2}{*}{$B L+E B$} & $2,00 a$ & $16,34 a$ & $2,37 a$ & $1,05 a$ & $9,52 b$ & $8,07 a$ & $652,50 a$ \\
\hline & 0,32 & 2,95 & 0,27 & 0,63 & 0,46 & 0,11 & 14,36 \\
\hline \multirow[t]{2}{*}{ TF+EB } & $1,38 b$ & $12,43 a$ & $2,03 a$ & $1,15 a$ & $9,62 b$ & $7,41 b$ & $490,44 b$ \\
\hline & 0,07 & 0,68 & 0,21 & 0,95 & 0,66 & 0,11 & 15,76 \\
\hline \multirow[t]{2}{*}{ EB } & $1,31 b$ & $11,39 a$ & $1,92 a$ & $0,58 a$ & $11,03 a$ & $7,86 a$ & $596,19 c$ \\
\hline & 0,16 & 1,91 & 0,24 & 0,00 & 0,36 & 0,21 & 15,02 \\
\hline
\end{tabular}

a, b, c Valores seguidos pela mesma letra em uma mesma coluna não são significativamente diferentes em $\mathrm{p}<0.05$ pelo Teste de Tukey. 
4.2.7 Correlações: macro e micronutrientes, análise elementar, $\mathrm{C} / \mathrm{N}, \mathrm{pH}$ e CTC

A Tabela 9 - I apresenta as correlações entre os parâmetros químicos determinados para o vermicompostos após 135 dias de vermicompostagem. Observa-se que os parâmetros pH e CTC estão fortemente correlacionados ( $r=$ $0,851^{\star *}$ e de forma positiva. Esta correlação acontece devido aos cátions básicos que também apresentam correlação positiva com a CTC (Mg: $r=0,713^{*} ; \mathrm{K}: r=$ $\left.0,977^{\star *}\right)$. Isto acontece, pois, os cátions básicos influenciam no $\mathrm{pH}$, o qual consequentemente afeta a CTC. Existe uma correlação positiva entre CTC e teor de $C\left(r=0,706^{\star}\right)$, e isto acontece pois ao final do processo de vermicompostagem há uma maior disponibilização de nutrientes devido à atividade dos microrganismos. $\mathrm{C}$ e $\mathrm{H}$ apresentam forte correlação positiva $\left(r=0,911^{* *}\right)$, o que está relacionado à evolução do processo de humificação da matéria orgânica, à perda de $\mathrm{C}$ mais lábil e a formação de duplas ligações em moléculas mais condensadas. O aumento linear entre os teores de $\mathrm{C}$ e $\mathrm{N}\left(\mathrm{r}=0,941^{\star *}\right)$ está relacionado ao processo de mineralização, pois ao final do processo de vermicompostagem, com a morte das minhocas e microrganismos, há uma maior disponibilização dos nutrientes, os quais no início do processo estavam imobilizados, pois os mesmos os utilizavam como fonte de energia e nutrientes. Assim como acontece para $\mathrm{Mg}$ e $\mathrm{K}\left(r=0,806^{\star \star}\right)$ e para $\mathrm{P}$ e $\mathrm{Ca}(\mathrm{r}=$ $\left.0,867^{\star \star}\right)$. 
Tabela 9 - I. Correlações entre as propriedades químicas dos vermicompostos produzidos

\begin{tabular}{|c|c|c|c|c|c|c|c|c|c|c|c|c|c|c|c|}
\hline & $\mathrm{Cu}$ & $\mathrm{Mn}$ & $\mathrm{Fe}$ & $\mathrm{Zn}$ & $\mathrm{Cr}$ & $\mathrm{Ca}$ & $\mathrm{Mg}$ & $P$ & $\mathrm{~K}$ & $\mathrm{~N}$ & $\mathrm{C}$ & $\mathrm{H}$ & $\mathrm{S}$ & $\mathrm{C} / \mathrm{N}$ & $\mathrm{pH}$ \\
\hline $\mathrm{Mn}$ & ,395 & & & & & & & & & & & & & & \\
\hline $\mathrm{Fe}$ & $.988^{* *}$ & ,523 & & & & & & & & & & & & & \\
\hline $\mathrm{Zn}$ & $-.798^{*}$ & , 187 & $-.701^{\circ}$ & & & & & & & & & & & & \\
\hline $\mathrm{Cr}$ & $-.981^{* *}$ &,- 430 & $-.976^{* *}$ & $.739^{\circ}$ & & & & & & & & & & & \\
\hline $\mathrm{Ca}$ & 210 & $.965^{* *}$ & ,353 & ,402 &,- 268 & & & & & & & & & & \\
\hline $\mathrm{Mg}$ &,- 542 &, 543 &,- 412 & $.920^{* *}$ & ,474 & $.706^{\circ}$ & & & & & & & & & \\
\hline $\mathrm{P}$ & ,548 & $.931^{* *}$ & ,649 &,- 011 &,- 563 & $.867^{*}$ & ,354 & & & & & & & & \\
\hline $\mathrm{K}$ & $-.933^{* *}$ &,- 043 & $-.871^{* *}$ & $.949^{* *}$ & $.891^{* *}$ & ,152 & $.806^{\circ *}$ &,- 228 & & & & & & & \\
\hline $\mathrm{N}$ &,- 440 & ,562 &,- 331 & $.743^{\circ}$ & ,446 & ,632 & $.859^{* *}$ &, 413 & $.692^{\circ}$ & & & & & & \\
\hline $\mathrm{C}$ &,- 575 & ,320 &,- 494 & $.715^{\circ}$ & ,606 & ,386 & $.742^{\circ}$ & ,133 & $.739^{\circ}$ & $.941^{*}$ & & & & & \\
\hline $\mathrm{H}$ &,- 270 &, 540 &,- 173 &, 574 & ,315 &, 574 & $.678^{\circ}$ & ,355 & ,496 & $.896^{*}$ & $.911^{* *}$ & & & & \\
\hline $\mathrm{S}$ & 241 & ,364 & 289 & ,135 &,- 229 & ,412 & 171 & ,356 &,- 099 & ,128 &, 002 & ,328 & & & \\
\hline $\mathrm{C} / \mathrm{N}$ &,- 302 & $-.840^{* *}$ &,- 410 &,- 225 &, 361 & $\begin{array}{c}- \\
.851^{*}\end{array}$ &,- 522 &. &,- 008 &,- 425 &,- 096 &,- 223 &,- 357 & & \\
\hline $\mathrm{pH}$ & $-.903^{* *}$ &,- 175 & $-.861^{* *}$ & $.833^{* *}$ & $.861^{* *}$ &,- 005 &, 647 &,- 420 & $.904^{* *}$ &, 475 &, 562 &, 343 &,- 067 &, 156 & \\
\hline СТC & $-.953^{* *}$ &,- 163 & $-.910^{* *}$ & $.882^{* *}$ & $.911^{*}$ &, 024 & $.713^{\circ}$ &,- 326 & $.977^{* *}$ & ,623 & $.706^{\circ}$ & ,412 &,- 263 & , 107 & $.851^{* *}$ \\
\hline
\end{tabular}

*^ Correlação é significante ao nível de 0,01 (2 - talled); * Correlação é significante ao nível de 0,05 (2 - talled) 


\section{CONCLUSÕES}

A composição química dos resíduos em vermicompostagem teve efeito sobre a duração do processo de degradação. $\mathrm{O}$ pH e os teores de carbono total apresentam-se acima dos valores mínimos recomendados para fertilizantes orgânicos. A vermicompostagem de esterco bovino com bagaço de laranja ou torta de filtro resultou em baixa relação $\mathrm{C} / \mathrm{N}$. Para todos os tratamentos o teor de $\mathrm{N}$ foi superior ao valor mínimo recomendado pela legislação (MAPA, 2009), bem como a relação $\mathrm{C} / \mathrm{N}$. Os valores de $\mathrm{C} / \mathrm{N}$ foram mais baixos para as misturas de esterco bovino com outros resíduos (BL+EB e $T F+E B)$ do que para o tratamento de esterco bovino isolado (EB). Os teores de $\mathrm{N}$ dos tratamentos foram significativamente diferentes, sendo que o tratamento $\mathrm{BL}+\mathrm{EB}$ apresentou maior teor de $\mathrm{N}$. Os teores de micronutrientes foram reduzidos em alguns tratamentos e aumentados em outros. $\mathrm{O}$ teor de $\mathrm{Ca}, \mathrm{Mg}, \mathrm{Mn}$ e Fe foi nitidamente mais elevado nos vermicompostos finais de todos os tratamentos. O vermicomposto TF+EB apresentou diferença muito significativa no teor de $\mathrm{Cr}$ devido ao aumento da atividade das minhocas, sugerindo a bioacumulação de Cr pelas mesmas.

Constatou-se que os vermicompostos oriundos das misturas de torta de filtro e bagaço de laranja com esterco bovino apresentaram melhor potencial fertilizante do que o vermicomposto de esterco bovino isolado. Assim, recomenda-se o uso desses resíduos orgânicos agrícolas após vermicompostados como fertilizantes orgânicos para a agricultura sustentável. Os vermicompostos obtidos atendem às necessidades da legislação brasileira para fertilizantes orgânicos e a vermicompostagem pode ser introduzida como tecnologia eficiente para converter resíduos de esterco bovino com bagaço de laranja e torta de filtro em adubo orgânico. 


\section{REFERÊNCIAS BIBLIOGRÁFICAS}

ASSOCIAÇÃO BRASILEIRA DOS EXPORTADORES DE CÍTRICOS (ABECitrus). Produção de Laranja: série histórica. 2012. Disponível em: <http://www.abecitrus.com.br>. Acesso em: 06 set. 2012.

ATIYEH, R. M.; SUBLER, S.; EDWARDS, C. A.; BACHMAN, G.; METZGER, G. D., SHUSTER W. Effects of vermicomposts and composts on plant growth in horticultural container media and soil. Pedobiologia, v. 44, p. 579-90, 2000.

BERNAL, M. P.; PAREDES, S. M. C.; CEGARRA, J. Maturity and stability parameters of composts prepared with a wide range of organic wastes. Bioresource Technology, v. 63, p. 91-99, 1998.

BHAT, S. A.; SINGH J, VIG, A. P. Potential utilization of bagasse as feed material for earthworm Eisenia fetida and production of vermicompost. SpringerPlus v. 4, p. 11, 2015.

BIDONE, F. R. A; POVINELLI, J. Conceitos básicos de resíduos sólidos. São Carlos: EESC/ USP, 1999. 120 p.

BRASIL. Ministério da Agricultura, Pecuária e Abastecimento. Instrução Normativa n. 25, de 23 de julho de 2009. Diário Oficial da União, Brasília, 23 de julho de 2009. Seção 1, p. 20.

CASTILHOS, R. M. V.; DICK, D.P. Distribuição e caracterização de substâncias húmicas em vermicompostos de origem animal e vegetal. Revista Brasileira de Ciência do Solo, v. 32, p. 2669-2675, 2008.

CHEFETZ, B.; HATCHER, P. G.; HADAR, Y.; CHEN, Y. Chemical and biological characterization of organic matter during composting of municipal solid waste. Journal of Environmental Quality, v. 25, p. 776-785, 1996.

DORES-SILVA, P. R.; LANDGRAF, M.D.; REZENDE, M. O. O. Chemical differentiation of domestic sewage sludge and cattle manure stabilized by microbioreators: study by pyrolysis coupled to gas chromatography coupled to mass spectroscopy. Journal of Brazilian Chemical Society, v. 26, n. 5, p. 860-868, 
2015.

FIALHO, L. L. Caracterização da matéria orgânica em processo de compostagem por métodos convencionais e espectroscópicos. 2007. 170 f. Tese (Doutorado em Ciências, Química Analítica) - Instituto de Química de São Carlos, Universidade de São Paulo, São Carlos, 2007.

FIALHO, L. L.; SILVA, W. T. L.; MILORI, D. M. B. P.; SIMÕES, M. L.; MARTIN-NETO, L. Characterization of organic matter from composting of different residues by physicochemical and spectroscopic methods. Bioresource Technology, v. 101, p. 1927-1934, 2010.

GOEDERT, W. J.; OLIVEIRA, S. A. Fertilidade do solo e sustentabilidade da atividade agrícola. In: NOVAIS, R. F.; ALVAREZ V., V. H.; BARROS, N. F.; FONTES, R. L. F.; CANTARUTTI, R. B.; NEVES, J. C. Sociedade brasileira de ciência do solo, fertilidade do solo. Viçosa: Novais R. F., 2007. p. 994.

HAIT, S.; TARE, V. Vermistabilization of primary sewage sludge. Bioresource Technology, v. 102, p. 2812-2820, 2011.

HAMMERMEISTER, A. M.; WARMAN, P. R.; JELIAKOVA, E. A.; MARTIN, R. C. Nutrient supply and lettuce growth in response to vermicomposted and composted cattle manure. Journal of Bioresource Technology, v. 82, p. 1760-1772, 2004.

HUANG, G. F., WONG, J. W. C.; WU Q. T.; NAGAR, B. B. Transformation of organic matter during co-composting of pig manure with sawdust. Bioresource Technology, v. 97, p. 1834-1842, 2006.

JUÁREZ, P. D. A.; FUENTE, J. L.; PAULÍN, R. V. Vermicomposting as a process to stabilize organic waste and sewage sludge as an application for soil. Tropical and Subtropical Agroecosystems, v. 14, p. 949-963, 2011.

KIEHL, E. J. Fertilizantes orgânicos. Piracicaba: Agronômica Ceres, 1985. 492 p.

LANDGRAF, M. D.; MESSIAS R. A.; REZENDE, M. O. O. A importância ambiental da vermicompostagem: vantagens e aplicações. São Carlos: Rima, 2005. 105 p. 
das plantas: princípios e aplicações. Piracicaba: Associação Brasileira para Pesquisa da Potassa e do Fosfato, 1989. 201 p.

PETRY, F. T. S. Geléia light elaborada artesanalmente a partir do resíduo da filtração do suco de laranja. 2011. 67 f. Dissertação (Mestrado em Ciência e Tecnologia de Alientos)- Universidade Federal de Santa Maria, Santa Maria, 2011.

PROVENZANO, M. R.; OLIVEIRA, S. C.; SILVA, M. R. S.; SENESI, N. Assessment of maturity degree of composts from domestic solid wastes by fluorescence and fourier transform infrared spectroscopies. Journal of Agricultural and Food Chemistry, v. 49, p. 5874-5879, 2001.

RAIJ, B. van; ANDRADE, J. C.; CANTARELLA, H.; QUAGGIO, J. A. Análise química para avaliação da fertilidade de solos tropicais. Campinas: Instituto Agronômico, 2001. 285 p.

SINGH, J.; KAUR, A.; VIG, A. P.; RUP, P. J. Role of Eisenia fetida in rapid recycling of nutrients from bio sludge of beverage industry. Ecotoxicology and Environmental Safety, v. 73, n. 3, p. 430-435, 2010.

SUTHAR, S. Vermicomposting of vegetable market solid waste using Eisenia foetida: impact of bulking material on earthworm growth and decomposition rate. Ecological Engineering, v. 35, p. 914-20, 2009.

WILLIAMS, S. Official methods of analysis of the associations official analytical chemists. 14. ed. Arlington: AOAC, 1984. 1141 p. 


\section{CAPÍTULO II}

ESTUDO DA DINÂMICA DE RESÍDUOS ORGÂNICOS EM PROCESSO DE VERMICOMPOSTAGEM

CARACTERIZAÇÕES ESPECTROSCÓPICAS DA MATÉRIA ORGÂNICA 



\section{LISTA DE FIGURAS}

Figura 1 - II. Teor de carbono total nas amostras de ácidos húmicos extraídos das amostras coletadas nos tempos 0, 30, 7590 e 135 dias de vermicompostagem. $\mathrm{BL}+\mathrm{EB}$ : bagaço de laranja + esterco bovino; $\mathrm{TF}+\mathrm{EB}$ : torta de filtro + esterco bovino e EB: $100 \%$ esterco bovino 100

Figura 2 - II. Espectros de FTIR dos ácidos húmicos extraídos do vermicomposto $\mathrm{BL}+\mathrm{EB}(\mathrm{a})$; do vermicomposto $\mathrm{TF}+\mathrm{EB}$ (b); e do vermicomposto $\mathrm{EB}$ (c), nos tempos 0 , 30, 60, 90 e 135 dias de vermicompostagem 101

Figura 3 - II. Espectros de absorção UV-Vis dos AH extraídos dos tratamentos BL+EB (a), TF+EB (b), EB (c) em função do tempo de vermicompostagem. 105

Figura 4 - Il. Espectros de RMN de ${ }^{13} \mathrm{C}$ dos ácidos húmicos extraídos das amostras de vermicomposto com bagaço de laranja $(\mathrm{BL})(\mathrm{a})$, vermicomposto com torta de filtro (TF) (b) e vermicomposto de esterco bovino (c), coletadas nos tempos 0, 30, $7590 \mathrm{e}$ 135 dias de vermicompostagem 108

Figura 5 - Il. Cromatograma dos produtos da pirólise de ácidos húmicos extraídos das amostras de vermicomposto de bagaço de laranja + esterco bovino $(B L+E B)$ coletadas no início da vermicompostagem (tempo 0) 112

Figura 6 - II. Cromatograma dos produtos da pirólise de ácidos húmicos extraídos das amostras de vermicomposto de bagaço de laranja + esterco bovino $(B L+E B)$ coletadas após 135 dias de vermicompostagem 113

Figura 7 - II. Cromatograma dos produtos da pirólise de ácidos húmicos extraídos das amostras de vermicomposto de torta de filtro + esterco bovino (TF+EB) coletadas no início da vermicompostagem (tempo 0)

Figura 8 - Il. Cromatograma dos produtos da pirólise de ácidos húmicos extraídos das amostras de vermicomposto de torta de filtro + esterco bovino (TF+EB) coletadas após 135 dias de vermicompostagem .114 
Figura 9 - Il. Cromatograma dos produtos da pirólise de ácidos húmicos extraídos das amostras de vermicomposto de esterco bovino (EB) coletadas no início da vermicompostagem (tempo 0)

Figura 10 - II. Cromatograma dos produtos da pirólise de ácidos húmicos extraídos das amostras de vermicomposto de esterco bovino (EB) coletadas após 135 dias de vermicompostagem . 115 


\section{LISTA DE TABELAS}

Tabela 1 - II. Distribuição de ${ }^{13} \mathrm{C}$ nos $\mathrm{AH}$ extraídos das amostras nos diferentes tempos de vermicompostagem $(B L+E B$ : bagaço de laranja+esterco bovino; $T F+E B$ : torta de filtro+esterco bovino; EB: esterco bovino) 110

Tabela 2 - II. Grau de aromaticidade e alifaticidade dos AH extraídos das amostras dos diferentes tempos de vermicompostagem (BL+EB: bagaço de laranja+esterco bovino; TF+EB: torta de filtro+esterco bovino; EB: esterco bovino) 



\section{INTRODUÇÃO}

\subsection{Matéria Orgânica e Substâncias Húmicas}

O aporte de matéria orgânica no solo por meio da utilização agrícola de vermicomposto tem influência em quase todas as propriedades do solo, pois melhora suas propriedades físicas, químicas e biológicas. Sua presença caracteriza os solos de boa fertilidade, aos quais proporciona uma estruturação favorável à vida das plantas. O vermicomposto ajuda na reciclagem dos nutrientes para o solo e também evita sua degradação. A escassez da matéria orgânica faz com que os solos tendam a ficar compactados, impedindo a permeação da água, por exemplo. Também devese considerar o benefício econômico da utilização agrícola de vermicomposto, que resulta na diminuição da carga de fertilizantes inorgânicos aplicada, sendo que esta atividade propicia a manutenção da sustentabilidade do ecossistema (SINGH et al, 2010; LANDGRAF; MESSIAS; REZENDE, 2005).

O fracionamento químico da matéria orgânica permite a separação das substâncias húmicas, por diferença de solubilidade em solução aquosa, e após purificadas essas substâncias podem ser caracterizadas quanto à composição química e identidade molecular.

A avaliação das substâncias húmicas (SH), quanto à quantidade de ácidos húmicos $(\mathrm{AH})$ e fúlvicos $(\mathrm{AF})$ e sua qualidade permite inferir sobre o grau de estabilidade e maturidade da matéria orgânica presente nos produtos finais (SENESI et al., 1996). Os métodos espectroscópicos e analíticos fornecem informações valiosas no estudo da dinâmica da matéria orgânica e seus constituintes húmicos. Entre outras técnicas, as espectroscopias de Infravermelho com Transformada de Fourier (FTIR), Ressonância Magnética Nuclear (RMN), Ressonância Paramagnética Eletrônica (EPR), Fluorescência, Absorção na região do UV-Vis, Pirólise acoplada à Cromatografia Gasosa e Espectroscopia de Massas (P-CG/MS), permitem identificar os grupos reacionais e componentes estruturais nas substâncias húmicas, e desta 
forma pode-se inferir sobre o grau de maturação, de estabilidade do material húmico.

\subsection{Caracterização dos Ácidos Húmicos}

Os AH são caracterizados química e fisicamente com o objetivo de se conhecer melhor o objeto de estudo e assim comparar SH de diferentes origens. Para tanto, vários parâmetros são avaliados (LANDGRAF; MESSIAS; REZENDE, 2005). Na literatura encontram-se vários testes químicos e biológicos para caracterizar a qualidade dos compostos orgânicos, no entanto o conceito de estabilidade e maturidade dos compostos ainda não é claramente distinto (WANG et al., 2004). Análises espectroscópicas de ressonância magnética nuclear de ${ }^{13} \mathrm{C}$, ressonância paramagnética eletrônica, fluorescência, absorção de luz na região do UV-Vis e infravermelho com transformada de Fourier vêm sendo amplamente estudadas, com o objetivo de monitorar o processo de compostagem (PROVENZANO et al., 2001; OUTMANE et al., 2002). A razão C/N, por sua vez, indica o grau de incorporação do nitrogênio na estrutura húmica e, por consequência, o nível de fertilidade desse material, pois via diversos mecanismos de mineralização da MO do solo, o nitrogênio é liberado para as raízes das plantas sob a forma de nitrato (CANELLAS et al., 1999).

Estudos realizados sobre a compostagem de resíduos agroindustriais (ANTUNES et al., 2005), resíduos sólidos urbanos (CHEN e INBAR, 1993; CHEFETZ et al., 1996) e sobre a decomposição de lodos orgânicos oriundos de fabricação de papel (DICK et al., 1997) mostraram que esses processos tendem a reduzir os teores totais de C (COT) e a proporção da fração ácidos fúlvicos, com aumento da fração de ácidos húmicos, refletindo-se no aumento do seu grau de maturidade. Em $\mathrm{AH}$ de resíduos agroindustriais compostados por 150 dias, Antunes (2005) constatou aumento no teor de $\mathrm{N}$, decréscimos no de $\mathrm{O}$ e na relação $\mathrm{C} / \mathrm{N}$ e constância nos teores de C e H. No caso específico de vermicompostos, Leal et al. (2006) observaram diferenças entre cinco compostos de resíduos agroindustriais após 89 dias de vermicompostagem: os teores de COT e de $\mathrm{SH}$ e o grau de humificação foram maiores em compostos de origem vegetal comparados com os de origem animal. 
Durante o processo de compostagem de resíduos sólidos urbanos (RSU), ocorre a mineralização e humificação da matéria orgânica (SENESI; MIANO; BRUNETTI, 1996). A intensidade destas alterações depende dos métodos que são usados para acumular os resíduos e das condições do processo de compostagem (INBAR; CHEN; HADAR, 1990). As condições do processo de compostagem afetam as propriedades químicas e físico-químicas dos ácidos húmicos e fúlvicos isolados dos compostos de RSU (CHEN et al., 1997). Estas propriedades correspondentes a diferentes níveis de maturidade do composto foram estudadas usando métodos espectroscópicos: EPR, UV-Vis, FTIR. Essas medições mostraram alterações na estrutura das substâncias húmicas dependendo do tempo e das condições de compostagem.

São necessários estudos prolongados sobre as transformações químicas da matéria orgânica em decomposição para desenvolver meios e métodos de identificação e normatização da "boa qualidade" do produto. Identificação de compostos húmicos e caracterização de mudanças na sua composição durante o processo de compostagem são de grande importância para se inferir sobre a qualidade e as propriedades do produto final (SENESI e BRUNETTI, 1996).

Os processos de compostagem ou vermicompostagem são métodos usuais de produção de um material estabilizado que pode ser usado como fonte de nutrientes e condicionador de solos. No entanto, o problema de se estabelecerem parâmetros de estabilização físicos, químicos e biológicos adequados para dar indicações sobre o verdadeiro grau de evolução da matéria orgânica durante o processo de compostagem ainda existe (SEQUI, 1991). Soluções poderiam ser encontradas estudando-se as transformações que a matéria orgânica sofre durante o processo e compilando os resultados de todas as técnicas que podem ajudar a obter um conhecimento das transformações envolvidas (ADANI et al., 1999).

O grau de maturação de um composto está diretamente relacionado ao seu potencial efeito condicionador dos solos agrícolas e, consequentemente, promotor do desenvolvimento vegetal, bem como da microbiologia, simbiótica ou não, inerente aos agroecossistemas. Por sua vez, influenciará o potencial de autoregulação das espécies interrelacionadas, de modo a contribuir para o equilíbrio do sistema. $O$ 
condicionamento das propriedades do solo pela matéria orgânica proporciona melhores condições de cultivo. Esta influência global das substâncias húmicas sobre a macro e microestrutura dos solos que, por sua vez, promove a atividade biológica, é considerada como efeito indireto da matéria orgânica humificada sobre o crescimento vegetal. Evidências experimentais indicam que as substâncias húmicas participam de reações importantes que ocorrem na interface solução com a parte sólida do solo, influenciando a fertilidade por meio da liberação de nutrientes, da detoxificação de elementos químicos, na formação de estrutura, ou seja, da melhoria das condições químicas, físicas e biológicas do solo (CANELLAS et al., 1999). Canellas et al., (2000) caracterizaram físico-quimicamente ácidos húmicos obtidos de composto de resíduos sólidos urbanos e de lodo de estação de tratamento de esgoto por meio da análise da composição elementar, acidez total, de dados espectroscópicos (UV-Vis; IV, RMN de ${ }^{13} \mathrm{C}-\mathrm{CP} / \mathrm{MAS}$ ) e microscopia eletrônica de varredura (MEV). O conjunto de propriedades avaliadas permitiu indicar que a fração ácidos húmicos dos resíduos é análoga aos ácidos húmicos de origem pedogênica, no entanto é estrutural e morfologicamente menos evoluída quimicamente, ou seja, menos humificada.

Chefetz et al. (1996) também afirmam que um dos principais obstáculos para a utilização bem sucedida da compostagem de resíduos sólidos urbanos na agricultura é a falta de critérios confiáveis para avaliar a qualidade e compreender as transformações da matéria orgânica em todo o processo. Afirmam que a avaliação adequada da maturidade do composto é essencial para o estabelecimento de tais critérios. Para tanto, os autores estudaram as transformações da matéria orgânica durante a compostagem de resíduos sólidos urbanos e correlacionaram espectros químicos de DRIFT, com análises de plantas e ${ }^{13} \mathrm{C}-\mathrm{RMN}$ e bioensaios de desempenho.

É difícil definir a maturidade do composto por apenas um atributo, normalmente são necessários vários. Chen e Inbar (1993) demonstraram que a espectroscopia ${ }^{13} \mathrm{C}$ RMN e DRIFT podem fornecer informações úteis sobre as transformações da matéria orgânica ocorridas durante o processo de compostagem. Bioensaios de crescimento de plantas, teores de ácidos húmicos e a razão 1650/1560 
obtida a partir do espectro de DRIFT apresentaram a mesma tendência durante a compostagem e podem, portanto, ser utilizados como índices de maturação. Todos estes parâmetros exibiram três fases: (i) a rápida decomposição, durante os primeiros 30 dias, (ii) a fase de estabilização até 90 dias, e (iii) a fase de maturação do centésimo dia em diante. Os autores observaram que o composto de resíduos sólidos urbanos estava pronto para uso como um substrato agrícola, depois de cerca de 110 dias de compostagem.

Análises químicas e espectroscópicas de transformações da matéria orgânica durante a compostagem, em relação à maturidade do composto de várias matériasprimas, foram revistas por Chen e Inbar, (1993) e por Fialho et al, (2010), por exemplo. As mesmas análises foram conduzidas nesta tese para vermicompostagem, de acordo com a colocação de Chen e Inbar (1993) de que a compreensão da maturidade do composto tem de ser melhorada análises de parâmetros adicionais como a bioquímica dos componentes húmicos e reações da matéria orgânica que ocorrem na interface entre as fases sólida e aquosa.

1.2.1 Espectroscopia na região do infravermelho médio com transformada de Fourier (FTIR)

Na espectroscopia são empregados níveis de energia situados entre a região do visível e a de microondas, o que permite distinguir as vibrações moleculares de diversos grupos funcionais e estruturas (SILVERSTEIN et al., 1994). A região de maior interesse para a espectroscopia de infravermelho é a de 4000 a $400 \mathrm{~cm}^{-1}$. Essa técnica viabiliza a análise qualitativa de grupos reativos, como por exemplo, $\mathrm{COOH}$, $\mathrm{OH}$-fenólico, $\mathrm{OH}$-alcoólico, $\mathrm{OH}$-enólico, $\mathrm{C}=\mathrm{O},-\mathrm{NH}_{2}$, etc., e de componentes estruturais alifáticos e aromáticos (STEVENSON, 1994).

Em um espectrofotômetro de infravermelho (IV), a porcentagem de radiação transmitida pela amostra em um intervalo de comprimento de onda de 2,5 a $25 \mu \mathrm{m}$ é registrada, resultando num espectro contínuo de bandas de absorção. Usualmente 
no espectro de infravermelho está relacionada a transmitância (ou absorbância) em função do número de onda, expresso em $\mathrm{cm}^{-1}$ (SILVERSTEIN et al., 1994).

O espectro de IV é característico da molécula como um todo, porém certos grupos funcionais dão origem a bandas que ocorrem mais ou menos na mesma frequência independentemente da estrutura da molécula. Devido à presença dessas bandas características de grupos funcionais, é possível obter informações sobre a estrutura das moléculas. Diferentemente das radiações nas regiões do ultravioleta e do visível, que, ao incidirem sobre uma molécula, causam transições eletrônicas, a radiação na região do infravermelho promove alterações nos modos rotacionais e vibracionais das moléculas (SILVERSTEIN et al., 1994).

A espectroscopia IV se baseia no fato de que os diversos tipos de ligações químicas e de estruturas moleculares existentes em uma molécula, absorvem radiação eletromagnética na região do infravermelho, em comprimentos de ondas característicos e, como consequência, os átomos envolvidos entram em diferentes estados de vibração. Dois tipos fundamentais de vibrações moleculares podem ser distinguidos: a) estiramento, em que os átomos vibram no mesmo eixo, variando a distância entre eles; b) deformação, em que a posição dos átomos em vibração muda em relação ao eixo da ligação. Quando luz na região do infravermelho ressonante à frequência de vibração de estiramento ou de deformação incide na amostra, a energia é absorvida e a amplitude de vibração é aumentada. Devido à energia de absorção na frequência de ressonância, o detector do espectrômetro de infravermelho grava um pico de absorção naquele comprimento de onda (STEVENSON, 1994).

Vibrações de estiramento são mais energéticas, e ocorrem, portanto, em frequências superiores às das vibrações de deformação. Estiramentos de ligações envolvendo próton $(\mathrm{O}-\mathrm{H}, \mathrm{C}-\mathrm{H}$ e $\mathrm{N}-\mathrm{H})$ ocorrem em maiores frequências (3700 a 2650 $\left.\mathrm{cm}^{-1}\right)$ do que estiramentos de ligações do tipo C-C, C-O, e $-\mathrm{N}\left(1300\right.$ a $\left.800 \mathrm{~cm}^{-1}\right)$ (STEVENSON, 1994).

As análises de FTIR têm sido tradicionalmente usadas para identificar grupos funcionais como: grupos carboxila, amina, hidroxila, carbonila e outros (SCHNITZER; KHAN, 1972; STEVENSON, 1994). Estas informações são úteis, pois permitem 
identificar possíveis processos de oxidação e alteração de grupos funcionais, associados aos efeitos de manejos, devido, por exemplo, ao aumento ou redução de aeração do solo, mudança no pH, complexação com micronutrientes provenientes de fertilizantes ou naturalmente ocorrendo no solo. Trata-se de um método relativamente acessível e de interpretação simples dos dados. Em muitas situações pode haver sobreposição de bandas, o que requer $\circ$ uso de outros métodos analíticos concomitantemente.

A espectroscopia de infravermelho tem sido extensivamente usada para a pesquisa de substâncias húmicas e tem fornecido considerável entendimento sobre a natureza, reatividade e arranjo estrutural dos grupos funcionais contendo oxigênio. Espectros no infravermelho de substâncias húmicas resultam da absorção da radiação do infravermelho por uma mistura complexa de moléculas que são multifuncionais. $\mathrm{O}$ resultado do espectro infravermelho contém uma variedade de bandas que podem indicar diferentes grupos funcionais presentes nesta mistura complexa (STEVENSON, 1994).

A interpretação exata dos espectros nem sempre é possível devido a sua alta complexidade. Segundo Tan (1996), a restrição quanto à aplicação mais abrangente da espectroscopia IV em substâncias húmicas não se deve à inadequação deste método para o material a ser analisado, porém está relacionada com a complexidade do espectro e, também, com o baixo grau de pureza das amostras analisadas. Ceretta et al. (2008) concordam com esta afirmação e alertam que esses obstáculos são facilmente contornados por estudo mais aprofundado dos espectros e respectivas interpretações, bem como por um procedimento mais apurado na purificação das amostras. 
Segundo Niemeyer (1992), as principais bandas de absorção dos grupos funcionais no espectro no infravermelho médio (região $4000-400 \mathrm{~cm}^{-1}$ ) nas substâncias húmicas são:

\section{Região $\left(\mathrm{cm}^{-1}\right)$}

3380

3030

2930

2840

2600

1720

1610

$1520-1525$

1450

1350

1270

1225

1170

1050 e 1040

830

\section{Origem}

Estiramento $\mathrm{OH}$ do grupo fenólico (contribuição de $\mathrm{OH}$ alifático), $\mathrm{H}_{2} \mathrm{O}$ e possivelmente $\mathrm{NH}$

Estiramento $\mathrm{CH}$ aromático

Estiramento $\mathrm{CH}$ assimétrico

Estiramento $\mathrm{CH}$ simétrico

Estiramento $\mathrm{OH}$ de $\mathrm{H}$ ligado a $-\mathrm{COOH}$

Estiramento $-\mathrm{C}=\mathrm{O}$ de $-\mathrm{COOH}$

Estiramento $\mathrm{C}=\mathrm{C}$ aromático e/ou estiramento $-\mathrm{COO}^{-}$assimétrico

Estiramento $\mathrm{C}=\mathrm{C}$ aromático, deformação $\mathrm{N}-\mathrm{H}$ e estiramento $\mathrm{C}=\mathrm{N}$ de amidas

Deformação - $\mathrm{CH}$ de $\mathrm{CH}_{3}$ e dobramento $\mathrm{CH}$ e $-\mathrm{CH}_{2}$

Estiramento -COO simétrico e/ ou dobramento $-\mathrm{CH}$ de alifáticos

Estirmamento -C-O de fenólico

Estiramento -C-O de deformação $\mathrm{OH}$ de $-\mathrm{COOH}$

Estiramento -C-OH de alifáticos $\mathrm{OH}$

Estiramento -C-O de polissacarídeos ou derivados de polissacarídeos e $\mathrm{Si}-\mathrm{O}$ de impurezas silicatadas

Vibração $\mathrm{CH}$ fora do plano. Impurezas argilosas.

Vibração $\mathrm{CH}$ fora do plano 
O aporte de resíduos orgânicos animais e vegetais, compostados ou não, ao solo é prática comum que visa a aumentar a quantidade tanto de matéria orgânica do solo (MOS) quanto de nutrientes disponíveis às plantas. Plaza et al. (2003), estudaram o efeito consecutivo da adição anual de esterco de suínos nos teores de ácido fúlvico na matéria orgânica do solo. Entre outras técnicas espectroscópicas, FTIR foi usado para caracterização da MOS. Mudanças nas bandas de absorção em 2900, 1520, 1230 e $1040 \mathrm{~cm}^{-1}$ mostraram que o esterco de suíno apresentou grande alifaticidade, grande quantidade de grupos funcionais que continham $\mathrm{N}$ e $\mathrm{S}$ e, consequentemente, maior degradabilidade, quando comparados com resíduos de bovinos. Foi observado o aumento de material muito lábil no solo, mostrando que este tipo de resíduo deve necessariamente passar por estabilização prévia, por meio de compostagem antes da incorporação ao solo, a fim de aumentar seu estado de humificação e, consequentemente, ser melhor incorporado ao solo.

1.2.2 Espectroscopia de ressonância magnética nuclear de ${ }^{13} \mathrm{C}\left({ }^{13} \mathrm{C} R M N\right)$ - técnica de polarização cruzada com amplitude variável ( ${ }^{13} \mathrm{C}$ RMN VACP-MAS)

Em RMN de ${ }^{13} \mathrm{C}$ os valores de energia medidos referem-se às transições entre estados magnéticos nucleares, os quais têm sua degenerescência quebrada pela aplicação de um intenso campo magnético sobre a amostra $\left(\mathrm{B}_{0}\right)$. São observáveis por RMN os isótopos que contêm spin nuclear $I \neq 0$, como por exemplo, aqueles que possuem número de massa ímpar $\left({ }^{1} \mathrm{H},{ }^{13} \mathrm{C},{ }^{15} \mathrm{~N},{ }^{17} \mathrm{O}\right)$. Como os valores de $\Delta \mathrm{E}$ para estas transições são muito pequenos, a frequência de ressonância $\left(v=\Delta \mathrm{E} h^{-1}\right)$ apresenta valores típicos de radiofrequência (4 a $900 \mathrm{MHz}$ ). Quando a condição de ressonância é satisfeita ocorre a transição entre os estados de energia (Fialho, 2007).

Experimentos com $\mathrm{SH}$ usando espectroscopia de RMN em estudos com amostras sólidas utilizam, geralmente, a técnica de rotação no ângulo mágico e polarização cruzada (CP-MAS, da abreviatura em inglês, Cross Polarization and Magic Angle Spinning) monitorando os núcleos do isótopo ${ }^{13} \mathrm{C}$. As informações para 
as $\mathrm{SH}$ com as análises de RMN são: o grau de aromaticidade e alifaticidade das amostras e a caracterização estrutural com identificação de compostos, como ligninas, taninos, carboidratos, grupos alquil, metoxílicos, fenólicos e carboxílicos, dentre outros (STEVENSON, 1994; PRESTON, 1996).

As amostras no estado sólido apresentam interações anisotrópicas decorrentes do deslocamento químico, interação dipolar e quadrupolar.

- Anisotropia do deslocamento químico: está relacionada ao caráter não esférico das núvens eletrônicas na vizinhança dos núcleos;

- Interação dipolar: está relacionada ao campo local produzido pelo momento magnético dos núcleos vizinhos (hidrogênios $-{ }^{1} \mathrm{H}$ - no caso do ${ }^{13} \mathrm{C}$ );

- Interação quadrupolar: ocorre com isótopos com I>1/2, que está relacionada com a distribuição assimétrica de cargas nos núcleos e das nuvens eletrônicas.

Tais parâmetros originados da imobilidade das moléculas causam o alargamento das linhas espectrais, tornando-as de baixa resolução (ABREU-JUNIOR et al., 2009). Outra limitação está relacionada à baixa abundância isotópica do ${ }^{13} \mathrm{C}$ : $\mathrm{O}$ C contém dois isótopos estáveis, ${ }^{12} \mathrm{C}$ e ${ }^{13} \mathrm{C}$, cujas abundâncias naturais são $98,9 \mathrm{e}$ $1,1 \%$, respectivamente, e sendo somente ${ }^{13} \mathrm{C}$ o que apresenta momento magnético ( $\mu$ ) (Silverstein et al., 2010).

Para obter espectros de RMN de ${ }^{13} \mathrm{C}$ de boa resolução em estado sólido, é necessário eliminar tanto a interação dipolar quanto a anisotropia do deslocamento químico. A interação dipolar pode ser eliminada com a utilização da técnica de desacoplamento em que se aplica um pulso de alta potência na frequência de ressonância dos $\mathrm{H}$. A anisotropia do deslocamento químico pode ser eliminada girando-se a amostra em alta rotação em torno de um ângulo de $54,74^{\circ}$ conhecido como ângulo mágico (MAS - Magic Angle Spinning). A interação dipolar e as outras interações anisotrópicas, que provocam alargamento dos sinais de RMN de sólidos, têm dependências geométricas do tipo $\left(3 \cos ^{2} \theta-1\right)$, sendo $\theta \circ$ ângulo entre o vetor internuclear e o campo magnético $B_{0}$. Girando-se a amostra em torno de um eixo inclinado a $\theta=54,74^{\circ}$ em relação ao campo magnético externo, orientam-se, todos 
os vetores internucleares ao longo do eixo de rotação e a interação dipolar é anulada (Silverstein et al., 2010).

O tempo de relaxação T1 (relaxação spin-rede ou relaxação longitudinal) é bastante longo para análise de amostras sólidas, exigindo experimentos de longa duração. Para reduzir o tempo de análise, usa-se a técnica de polarização cruzada (CP - Cross Polarizatin), em vez de apenas um pulso. Esta técnica transfere a magnetização do H (mais abundante naturalmente - 99,98\%) para o C. O tempo de espera entre as sequências de pulsos é dependente do $T_{1}$ dos átomos de $H$, que normalmente é bem mais curto que o de $\mathrm{C}$. Na técnica de polarização cruzada os núcleos ${ }^{1} \mathrm{H}$ e ${ }^{13} \mathrm{C}$ submetidos a um mesmo campo magnético pressecionam em diferentes frequências (frequência de Larmor). Utilizando diferentes potências de radiofrequência (diferentes $\mathrm{B} 1$ ) para cada núcleo, é possível atingir uma situação em que ambos precessionem à mesma frequência (condição de Hartmann-Hahn - os núcleos estarão em contato térmico podendo ocorrer transferência de energia entre eles) (NOVOTNY, 2002). Visando ao aumento da sensibilidade e da resolução dos espectros são utilizados campos magnéticos cada vez mais intensos, o que leva à necessidade de girar a amostra a velocidades maiores. Os efeitos de rotação são seletivos para os grupos com menor interação dipolar, tais como os de maior mobilidade e/ ou não protonados. Dessa forma, para minimizar este efeito, tem sido utilizada a técnica de amplitude variada (VA - Variable Amplitude) em que ocorre a variação da amplitude do pulso de radiofrequência durante o tempo de contato na polarização cruzada). Desta forma, o campo de $1 \mathrm{H}$ apresenta gradiente capaz de abranger as diferentes condições de Hartmann-Hahn (NOVOTNY, 2002).

$\mathrm{O}{ }^{13} \mathrm{C}$ tem sido o núcleo mais utilizado no estudo da matéria orgânica do solo e de resíduos orgânicos em diferentes estágios de decomposição. Segundo AbreuJunior et al. (2009), considerando a natureza complexa e heterogênea das SH, o núcleo de ${ }^{13} \mathrm{C}$ pode estar em ampla variedade de ambientes químicos, que são evidenciados nos distintos deslocamentos químicos encontrados nos espectros de ${ }^{13} \mathrm{C}$ RMN. Esse fato permite a avaliação quantitativa relativa dos mesmos mediante a integração das áreas relativas aos tipos de C em consideração ao espectro total, determinando, desse modo, a abundância percentual relativa dos mesmos. 
Os sinais de C observados são atribuídos aos seguintes grupos (Stevenson, 1994):

- 0-45 ppm - alifáticos não substituídos

- 45-60 ppm - metoxil e N-alifáticos

- 60-110 ppm - O-alifáticos

- 110-140 ppm - aromáticos

- 140-160 ppm - fenólicos

- 160-185 ppm - carboxílicos

- 185-230 ppm - carbonílicos

As expressões (1) e (2) foram utilizadas para quantificação do percentual de carbonos aromáticos e alifáticos (STEVENSON, 1994):

(1) AROMATICIDADE (\%) = (área 110-160 ppm/ área 0-160 ppm) x 100

(2) ALIFATICIDADE (\%) = (área 0-110 ppm/ área 0-160) x 100

Canellas, et al. (2000) analisaram por RMN de ${ }^{13} \mathrm{C}$ (CP/MAS), ácidos húmicos obtidos de composto de resíduos sólidos urbanos e de lodo de estação de tratamento de esgoto. A análise das características estruturais mostrou diferenças entre os AHs estudados. Foi possível verificar diferenças quantitativas nos diferentes tipos de C. Os ácidos húmicos obtidos do lodo da estação de tratamento de esgoto apresentaram maior quantidade de grupos aromáticos e $\mathrm{COOH}$. Entre outros grupamentos, a análise ainda mostrou a presença de polissacarídeos, $\mathrm{N}$ em aminoácidos e grupamentos $\mathrm{OCH}_{3}$.

Castaldi, et al. (2005) monitoraram o processo de compostagem de resíduos sólidos urbanos e vegetais durante 100 dias e avaliaram os efeitos da humificação na estrutura molecular do ácido húmico por RMN de ${ }^{13} \mathrm{C}$ (CP/MAS). Os espectros mostraram a degradação do material pseudo-húmico, uma redução de $\mathrm{C}$ alifáticos e um aumento de aromáticos, carboxílicos e carbonílicos, o que sugere a formação parcial de um material humificado. 
Fialho et al. (2010) utilizaram diferentes métodos químicos e espectroscópicos para caracterização das tranformações da matéria orgânica durante o processo de compostagem, dentre eles o RMN de ${ }^{13} \mathrm{C}$ (VACP-MAS). Os resultados de RMN de ${ }^{13} \mathrm{C}$ mostraram intensa diminuição das bandas correspondentes à degradação de carboidratos. Para todas as leiras com esterco bovino, bagaço de laranja e torta de filtro foi constatado aumento no teor de aromaticidade dos AHs. Degradação de estruturas alifáticas e carboidratos e aumento de grupos carboxílicos e aromáticos foram as transformações importantes observadas para todos os resíduos.

1.2.3 Pirolisador acoplado à cromatógrafo à gás com detector de massas (PCG/EM)

A pirólise é caracterizada pela degradação térmica de materiais em atmosfera inerte, diferente da combustão, em que a matéria é queimada na presença de $\mathrm{O}_{2}$ atmosférico. Na pirólise, quando uma macromolécula absorve energia térmica via transferência rápida de calor, ocorre a distribuição da energia ao longo da molécula, promovendo a vibração no eixo das ligações. A relaxação da vibração acontece com a quebra homolítica ou heterolítica das ligações mais fracas. Os fragmentos são removidos rapidamente, separados por cromatografia gasosa e identificados via espectroscopia de massas (CANELLAS et al., 2008).

O uso da pirólise acoplada à cromatografia gasosa - espectrometria de massas é uma técnica poderosa na identificação das unidades estruturais das substâncias húmicas. Os resultados obtidos com a P-CG/EM aliados aos fornecidos pela RMN têm contribuído com a determinação estrutural das substâncias húmicas numa esfera muito além da imaginada antes do advento das espectroscopias (CANELLAS \& SANTOS, 2005).

O instrumento para o desenvolvimento da pirólise é denominado pirolisador, sendo comercialmente classificado como de modo contínuo e pulsado. O primeiro inclui os de fornos ou microfornos, e são pré-aquecidos na temperatura da pirólise final, antes da introdução da amostra (HOSAKA, WATANABE E TSUDE, 2007). Já os 
de modo pulsado incluem sistema usando filamento resistivamente aquecido, ou metal ferromagnético indutivamente aquecido com radiofreqüência. O último é chamado de pirolisador de Ponto de Curie (PC). Há ainda outro tipo de pirolisador, não rotineiramente usado para pirólise de polímeros, que é o de sistema de pirólise a laser (SMITH, 1997). O pirolisador de microforno) caracteriza-se por ser aquecido previamente, sem a presença da amostra, na temperatura desejada. Em seguida, o cadinho contendo a amostra a ser pirolisada é lançado no reator. A quantidade de amostra deve ser extremamente pequena, geralmente menor que $0,5 \mathrm{mg}$, para facilitar o seu aquecimento.

Os principais produtos obtidos com a pirólise de ácidos húmicos e fúlvicos foram compilados por Marbot (1999) como: fenóis; derivados de carboidratos (furanos); ácidos graxos e seus ésteres; hidrocarbonetos aromáticos (alquilbenzeno, naftaleno, antraceno); hidrocarbonetos saturados e insaturados, lineares ou ramificados, cíclicos e acíclicos, bem como os compostos nitrogenados e sulfurados.

Canellas et al. (2000) estudaram a composição das unidades estruturais de ácidos húmicos isolados de matéria orgânica de origem urbana (composto de lixo domicliar urbano e lodo da estação de tratamento de esgoto por meio da P-CG/EM. Os cromatogramas dos produtos da pirólise foram bastante diferentes, dependentes da fonte de matéria orgânica de onde os ácidos húmicos foram isolados. Na região de $C$ alquílicos foram identificados compostos com longas cadeias alquílicas ( $\mathrm{m} / \mathrm{z}$ 270 e 185), principalmente de 2-metil hexadecano ( $\mathrm{m} / \mathrm{z}$ 192). Os compostos com fragmentos de razão massa:carga maior foram predominantes nos ácidos húmicos isolados do lodo de esgoto ( $\mathrm{m} / \mathrm{z} 541,549,555,556,559,563,578$ e 590) e correspondem ao padrão de fragmentação de mono e diaril ésteres com cadeia alquílica longa.

Nos ácidos húmicos isolados do composto de lixo urbano, foi mais intensa a presença dos ácidos octadecanóico ( $\mathrm{m} / \mathrm{z} 284)$, heptadecanóico $(\mathrm{m} / \mathrm{z} 282)$ e palmítico ( $\mathrm{m} / \mathrm{z} 256$ ), enquanto, nos ácidos húmicos isolados do lodo de esgoto predominaram os ácidos hexanóico ( $\mathrm{m} / \mathrm{z} 120)$ e limoneno ( $\mathrm{m} / \mathrm{z}$ 136), ou seja, ácidos graxos de cadeia mais curta. Canellas \& Santos, (2005), ressaltam que segundo Keeling et al., (1994), a presença de ácidos graxos voláteis pode ser indicativo de algum grau de 
anaerobiose nos estágios iniciais da compostagem dos resíduos. E que de acordo com Khan \& Schnitzer (1972) a tendência, com a maturação dos AH, é o desaparecimento dos ácidos graxos e a permanência de alcanos na região de $C$ alquílicos.

Dores-Silva et al. (2015) avaliaram as alterações químicas em substratos de vermicompostos de resíduos domésticos e de esterco bovino via análise elementar, e espectroscopia de infravermelho e de absorção na região do UV-vis. As caracterizações químicas dos vermicompostos indicaram que eles podem ser utilizados como fertilizantes orgânicos, principalmente no que diz respeito ao teor de matéria orgânica, $\mathrm{pH}$, relação $\mathrm{C} / \mathrm{N}$, e os níveis de nitrogênio e fósforo. Os principais componentes das substâncias húmicas extraídas de vermicompostos foram obtidos por pirólise acoplada à cromatografia gasosa com detector de espectrometria de massas (CG/EM), mostrando que estes compostos são bastante semelhantes, apesar de terem diferentes origens.

\subsubsection{Espectroscopia de absorção na região do UV-Visível}

A espectroscopia na região do ultravioleta-visível (UV/Vis) utiliza luz na faixa do visível, do ultravioleta próximo e do infravermelho próximo. Nessas faixas de energia as moléculas sofrem transições eletrônicas moleculares. A absorção de radiação é resultado das transições eletrônicas de cromóforos que apresentam elétrons livres (como os oxigenados ou nitrogenados, por exemplo). Quando recebem esse tipo de radiação, as moléculas sofrem transições eletrônicas, indo do menor estado energético (estado fundamental) para um estado de maior energia (estado excitado). Quando um feixe de luz monocromática atravessa uma solução com moléculas absorventes, parte da luz é absorvida pela solução e o restante é transmitido. A absorção de luz depende basicamente da concentração das moléculas absorventes e da espessura da solução - caminho óptico (SILVERSTEIN et al. 2006). 
Essa técnica já foi largamente utilizada em estudos com substâncias húmicas de solo para avaliar o grau de humificação, principalmente de ácidos fúlvicos ou húmicos, porém, hoje, a espectroscopia de UV-Vis não é a única responsável pela elucidação de modelos estruturais ou de reatividade química, mas foi a primeira técnica utilizada para criar o conceito de grau de humificação de substâncias húmicas. Os primeiros trabalhos relacionando coloração escura com evolução das substâncias húmicas são da década de 1950. Atualmente, novos conceitos foram incorporados com o desenvolvimento de outras técnicas espectroscópicas, porém há uma persistência do uso da relação $E_{4} / E_{6}$ e consolidação do uso da fluorescência como uma técnica sensível para avaliar tanto o grau de humificação como a capacidade das substâncias húmicas em formar complexos com íons (CANELLAS et al. 2005).

Segundo Canellas et al. (2005), no caso das substâncias húmicas, que contém muitos grupos aromáticos, as moléculas absorvem luz no UV e deixam o espectro com pouca resolução, consequentemente, com poucas informações sobre as características estruturais das substâncias húmicas. Porém, Fuentes et al. (2006) afirmam que os valores obtidos por espectroscopia de absorção de radiação UV-Vis, assim como a espectroscopia de fluorescência, têm fornecido dados úteis para o acompanhamento da evolução do grau de humificação de SH extraídas de materiais orgânicos de diversas origens. Geralmente as SH apresentam forte absorbância na faixa do UV-Vis (entre 200 e $800 \mathrm{~nm}$ ), particularmente na região do UV, devido à presença de cromóforos aromáticos e outros compostos orgânicos (CHEN et al., 2003).

Dentre os diversos índices existentes, a razão E4/E6 tem se mostrado de uso mais frequente (HELAL et al. 2011). De acordo com Helal et al. (2011), a razão de absorbância em SH é considerada um parâmetro tradicional para a avaliação do grau de humificação e tamanho molecular. Os valores de razão E4/E6 geralmente decrescem com o aumento da massa molecular e conteúdo de anéis aromáticos condensados. Segundo Polak et al. (2009), valores baixos de razão E4/E6 podem ser atribuídos à absorção por grupos funcionais $\mathrm{C}=\mathrm{C}$ conjugados. 


\section{OBJETIVOS}

O objetivo geral deste capítulo foi avaliar as transformações químicas dos resíduos orgânicos agroindustriais durante o processo de vermicompostagem utilizando técnicas espectroscópicas.

Objetivos específicos:

a) Extração, isolamento e purificação das substâncias húmicas dos vermicompostos coletados ao longo do processo e

b) Caracterização espectroscópica dos ácidos húmicos extraídos: FTIR, Absorção no UV-Vis, $C^{13}$ RMN e P-CG/EM. 


\subsection{Extração, Isolamento e Purificação das Substâncias Húmicas}

No fracionamento químico para obtenção das substâncias húmicas, as amostras coletadas nos diferentes tempos de vermicompostagem foram submetidas a um processo de extração por diferença de solubilidade e purificação, segundo a metodologia recomendada para solos pela Sociedade Internacional de Substâncias Húmicas (SWIFT, 1989).

Partindo de 100,0 g de vermicomposto, inicialmente foi realizada uma extração com $\mathrm{HCl} \mathrm{0,1} \mathrm{mol} \mathrm{L}^{-1}$, em proporção de $1,0 \mathrm{~g}$ de vermicomposto para $10,0 \mathrm{~mL}$ de solução. Durante uma hora a solução permaneceu sob agitação manual. Em seguida foi deixada em repouso por duas horas, para separar o sobrenadante do precipitado por decantação, sendo este sobrenadante o primeiro extrato de ácido fúlvico. Em

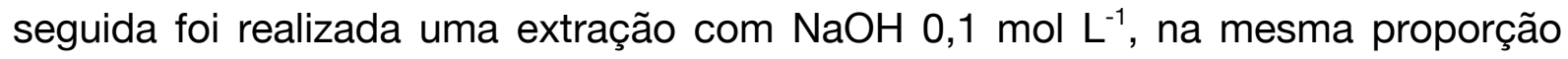
anteriormente citada. A solução permaneceu sob agitação manual durante quatro horas. A solução foi mantida em repouso durante dezesseis horas, para separar o sobrenadante do resíduo por decantação. $O$ precipitado era referente à fração mineral (humina), a qual foi descartada. O sobrenadante foi centrifugado, por vinte minutos a 10000 rpm, para a separação da argila. Em seguida, com um conta-gotas, o sobrenadante foi acidificado com $\mathrm{HCl} 6 \mathrm{~mol} \mathrm{~L}^{-1}$ até pH 1-2, sob agitação constante e foi deixado em repouso por mais doze horas, para decantação. O precipitado é referente à fração de ácido húmico e o sobrenadante é o extrato 2 do ácido fúlvico, que foi separado por sifonação. A partir dessa etapa teve início a purificação dos ácidos húmicos, o precipitado foi redissolvido em solução de $\mathrm{KOH} 0,1 \mathrm{~mol} \mathrm{~L}^{-1}$ e foi adicionado $\mathrm{KCl}$ para completar uma concentração de íons $\mathrm{K}^{+}$equivalente a $0,3 \mathrm{~mol}$ $\mathrm{L}^{-1}$. A solução foi centrifugada para a eliminação dos sólidos suspensos (impurezas). Após a centrifugação sob alta velocidade (15000 rpm - $20 \mathrm{~min}$ ) para que os sólidos suspensos fossem removidos, o $\mathrm{AH}$ foi então reprecipitado, adicionando-se $\mathrm{HCl}$ 6,0 mol L ${ }^{-1}$ com agitação simultânea até que fosse atingido pH 1-2 e, após, a suspensão 
foi mantida em repouso por 16 horas. Centrifugou-se a solução (10000 rpm - 10 min) e o sobrenadante foi então descartado. O precipitado $(A H)$ foi suspenso em solução $\mathrm{HCl}$ 0,1 $\mathrm{mol} \mathrm{L}^{-1}+\mathrm{HF}$ 0,3 $\mathrm{mol} \mathrm{L}^{-1}$ em um recipiente plástico e agitado durante 16 horas a temperatura ambiente. Em seguida a solução foi centrifugada (12000 rpm - 20 min) e o precipitado foi transferido para uma membrana de diálise (Spectra/Por 6000 8000 Da), preparada segundo a metodologia de Mc Phie (1971), utilizando água destilada, padrão MiliQ. Procedeu-se à diálise até que a água de diálise apresentasse teste negativo de $\mathrm{Cl}^{-}$com nitrato de prata. Para isso, tal procedimento foi mantido durante aproximadamente sete dias, fazendo-se a troca da água diariamente. Após a diálise, as amostras foram congeladas com nitrogênio líquido e liofilizadas. Após a liofilização os $\mathrm{AH}$ foram macerados e armazenados para as caracterizações.

Os ácidos húmicos extraídos das amostras coletadas nos diferentes tempos de vermicompostagem foram caracterizados por Espectroscopia na Região do Infravermelho Médio com Transformada de Fourier (FTIR), Absorção na região do UVVis (UV-Vis), Ressonância Magnética Nuclear de ${ }^{13} \mathrm{C}\left(\mathrm{RMN}\right.$ de $\left.{ }^{13} \mathrm{C}\right)$, Pirólise acoplada à Cromatografia Gasosa e Espectrometria de Massas (P-CG/EM) e Teor de Carbono Total.

\subsection{Teor de Carbono Total}

As análises, em triplicata, foram feitas com 30,0 mg de ácido húmido. Os ácidos húmicos analisados são referentes aos tempos 0, 30, 75, 90 e 135 dias do processo de vermicompostagem. As amostras secas foram oxidadas à $900{ }^{\circ} \mathrm{C}$, utilizando um fluxo de oxigênio de $0,3 \mathrm{~L} \mathrm{~min}^{-1}$. O aparelho utilizado foi o TOC-VCPH Shimadzu, acoplado a um módulo para amostras sólidas SSM-5000A Shimadzu, com detector de combustão, pertencente ao Laboratório de Química Ambiental. 


\subsection{Espectroscopia na Região do Infravermelho com Transformada de Fourier (FTIR)}

As determinações por FTIR foram feitas com base na metodologia sugerida por Stevenson (1994). As pastilhas foram preparadas na proporção de 1,0 mg de amostra de ácido húmico para $100,0 \mathrm{mg}$ de $\mathrm{KBr}$ (seco em estufa a $105^{\circ} \mathrm{C}$ ). As pastilhas foram prensadas por 2 minutos com uma carga equivalente a aproximadamente 10 toneladas. Os espectros foram obtidos a partir de 32 varreduras no intervalo de 4000 a $400 \mathrm{~cm}^{-1}$ com resolução espectral de $4 \mathrm{~cm}^{-1}$. O equipamento utilizado foi 0 espectrômetro de FTIR da Bombem MB-102, pertencente à CAQUI - IQSC - USP.

\subsection{Espectroscopia de Absorção na Região do UV-Visível (UV-Vis)}

Foram obtidos espectros de absorção na região de 800 a $400 \mathrm{~nm}$ e na região de 400 a 200 a partir da solução de $200 \mathrm{mg} \mathrm{L}^{-1}$ de $\mathrm{AH}$ em $\mathrm{NaHCO}_{3} 0,05 \mathrm{~mol} \mathrm{~L}^{-1}$. A varredura do espectro foi feita com passo de $0,1 \mathrm{~nm}$. Utilizou-se um Espectrômetro de Absorção UV - Vis Jasco V-630, pertencente à CAQUI - IQSC - USP.

\subsection{Ressonância Magnética Nuclear de ${ }^{13} \mathrm{C}\left({ }^{13} \mathrm{C}\right.$ RMN)}

Os espectros de RMN de ${ }^{13} \mathrm{C}$ no estado sólido foram obtidos com polarização cruzada e amplitude variável - "Variable Amplitude Cross-Polarization" (VACP) - e rotação segundo o ângulo mágico - "Magic Angle Spinning" (MAS) - em um espectrômetro da Oxford 400, campo de 9,4 T, operando a 100,6 $\mathrm{MHz}$ para o ${ }^{13} \mathrm{C} \mathrm{e}$ $400 \mathrm{MHz}$ para $\mathrm{O}^{1} \mathrm{H}$, pertencente à Embrapa Instrumentação. Utilizou-se probe para amostras sólidas da marca DOTY, do tipo supersônico, com dois canais e rotores cilíndricos $(\varnothing 5 \mathrm{~mm}$ ) de zircônia com tampas de Kel-Fda marca Doty. A velocidade de rotação segundo o ângulo mágico foi de $6,5 \mathrm{kHz}$. Os espectros foram adquiridos em 
uma largura espectral de $50 \mathrm{kHz}$ e os dados foram coletados em um tempo de aquisição de 12,8 ms. Utilizou-se a sequência de pulsos ${ }^{13} \mathrm{C}$ VACP/MAS que inclui um pulso de preparação ${ }^{1} \mathrm{H}$ de $4 \mu \mathrm{s}, 1 \mathrm{~ms}$ de tempo de contato e $500 \mathrm{~ms}$ de tempo de espera para relaxação (Novotny et al., 2006). Os deslocamentos químicos foram expressos em ppm em relação ao hexametilbenzeno (HMB) que apresenta uma banda de maior intensidade em 17,2 ppm. Um total de, aproximadamente, 15000 aquisições foram feitas para obtenção de cada espectro. Utilizou-se um Espectrômetro de RMN Varian, pertencente à Embrapa Instrumentação.

\subsection{Pirólise acoplada à Cromatografia Gasosa com Detector de Espectrometria de Massas (P-CG/EM)}

Para pirólise dos AHs e identificação dos compostos foi utilizado pirolisador acoplado à cromatografia à gás com detector de espectrometria de massas. Foi utilizado um pirolisador de microforno à temperatura interna de $610^{\circ} \mathrm{C}$ e uma temperatura de interface de $400^{\circ} \mathrm{C}$.

As condições cromatográficas utilizadas foram: pressão de 100,00 kPa, split de 60:1, rampa de aquecimento iniciando em $40^{\circ} \mathrm{C}$ por 1 min e aumentando 6 graus por minuto até a temperatura de $250^{\circ} \mathrm{C}$ (resultando em um tempo de análise de 36 min), temperatura do detector de $200^{\circ} \mathrm{C}$, detecção iniciando em $0,10 \mathrm{~min}$ e terminando em 36 min e monitoramento de 45 a $300 \mathrm{~m} / \mathrm{z}$.

Amostras de $0,50 \mathrm{~g}$ de $\mathrm{AH}$, foram pesadas em cadinho de platina e introduzidas no pirolisador a temperatura de $610^{\circ} \mathrm{C}$ e, então, iniciou-se a corrida cromatográfica.

Assim como Canellas et al. (2001), devido à presença de um número bastante elevado de fragmentos obtidos nos cromatogramas após a pirólise dos ácidos húmicos, somente os principais picos foram assinalados. Foram caracterizados sete grupos de produtos nominados de derivados da lignina, derivados de carboidratos, compostos nitrogenados, compostos aromáticos, compostos alifáticos e derivados 
do ftalato. A atribuição dos principais compostos obtidos nos cromatogramas foi realizada pela comparação direta com a base de dados Nist library, com grau de similaridade na fragmentação acima de $90 \%$. 


\section{RESULTADOS E DISCUSSÃO}

\subsection{Teor de Carbono Total}

A Figura 1 - II apresenta os resultados de carbono total para os ácidos húmicos dos diferentes tratamentos extraídos nos tempos 0, 30, 75, 90 e 135 dias de vermicompostagem. Para os ácidos húmicos extraídos dos vermicompostos de bagaço de laranja + esterco bovino $(B L+E B)$ pode-se observar uma tendência de aumento do teor de $\mathrm{C}$ total com um máximo em 90 dias e uma leve diminuição de 90 a 135 dias. Para os ácidos húmicos extraídos dos vermicompostos de esterco bovino (EB) não há variação do teor de $\mathrm{C}$ total de 0 a 75 dias, no entanto de 75 para 90 dias há um aumento significativo e de 90 para 135 dias uma leve diminuição. E para os ácidos húmicos extraídos dos vermicompostos de torta de filtro + esterco bovino ( $T F+E B)$ há, na média, uma tendência de diminuição de 0 a 75 dias e, assim como nos demais tratamentos, ocorre um aumento de 75 para 90 dias e uma leve diminuição de 90 para 135 dias.

Vale ressaltar que o processo de vermicompostagem foi dividido em duas etapas:

i. Etapa 1: compostagem até estabilização da temperatura das pilhas.

ii. Etapa 2: após 60 dias de compostagem foi feita a adição das minhocas para vermicompostagem.

Possivelmente este máximo de $\mathrm{C}(\%)$ em 90 dias está relacionado à atividade de degradação das minhocas e a diminuição de 90 a 135 dias está relacionada ao consumo do $\mathrm{C}$ como fonte de energia para as mesmas, visto que após 105 dias já não se encontravam minhocas nos vermicompostores. As condições de umidade e aeração dos vermicompostores foram mantidas até que as minhocas morressem (considerado ponto final da vermicompostagem, devido à falta de alimento fresco). 
Figura 1 - II. Teor de carbono total nas amostras de ácidos húmicos extraídos das amostras coletadas nos tempos 0, 30, 7590 e 135 dias de vermicompostagem. BL+EB: bagaço de laranja + esterco bovino; TF+EB: torta de filtro + esterco bovino e EB: $100 \%$ esterco bovino

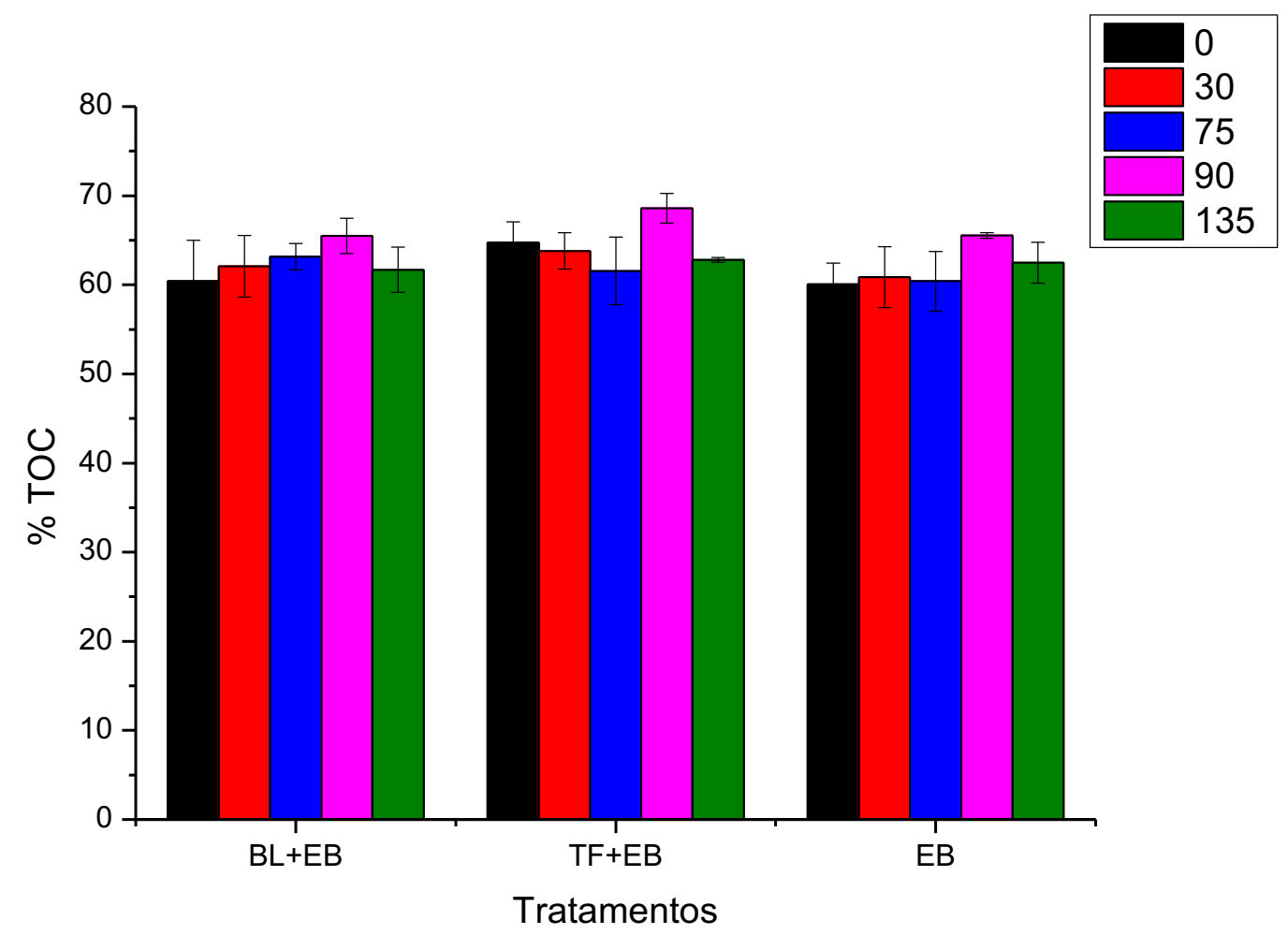

\subsection{Espectroscopia na Região do Infravermelho com Transformada de Fourier (FTIR)}

Os espectros de FTIR apresentaram bandas típicas de ácidos húmicos (Figura 2 - II a, b e c). As bandas foram atribuídas de acordo com publicações de Stevenson (1994), Silverstein et al. (2010), Amalfitano et al. (2002), Fialho et al. (2010), Castaldi et al. (2005), Canellas et al. (2000) e Mangrich et al. (2000).

Os espectros de FTIR dos ácidos húmicos extraídos de todos os tratamentos nos diferentes tempos de vermicompostagem mostram uma banda em torno de 3400-3300 $\mathrm{cm}^{-1}$ que corresponde à banda de estiramento $\mathrm{O}-\mathrm{H}$ de grupos fenólicos ou N-H de amidas. Em geral pode-se observar que para todos os ácidos húmicos estudados ocorre uma redução dessa banda, possivelmente devido ao desaparecimento dos grupos em função do tempo de vermicompostagem. Para os 
ácidos húmicos do vermicomposto $\mathrm{BL}+\mathrm{EB}$ pode-se observar um aumento de intensidade do $T_{0}$ ao $T_{30}$, e do $T_{30}$ em diante observa-se uma redução da intensidade dessa banda. Para os ácidos húmicos do vermicomposto TF+EB ocorre a diminuição da banda com o aumento do tempo de vermicompostagem. E para os ácidos húmicos do vermicomposto EB ocorre um aumento de $\mathrm{T}_{0} a \mathrm{~T}_{60}$ e uma diminuição de intensidade de $T_{60}$ para $T_{135}$. Castaldi et al. (2005) observaram uma redução acentuada na banda entre $3400-3300 \mathrm{~cm}^{-1}$ para ácidos húmicos referentes a 70 e 100 dias de compostagem e afirmam que é devido ao desaparecimento dos grupos $\mathrm{O}-\mathrm{H}$.

Figura 2 - II. Espectros de FTIR dos ácidos húmicos extraídos do vermicomposto BL+EB (a); do vermicomposto TF+EB (b); e do vermicomposto EB (c), nos tempos 0, 30, 60, 90 e 135 dias de vermicompostagem

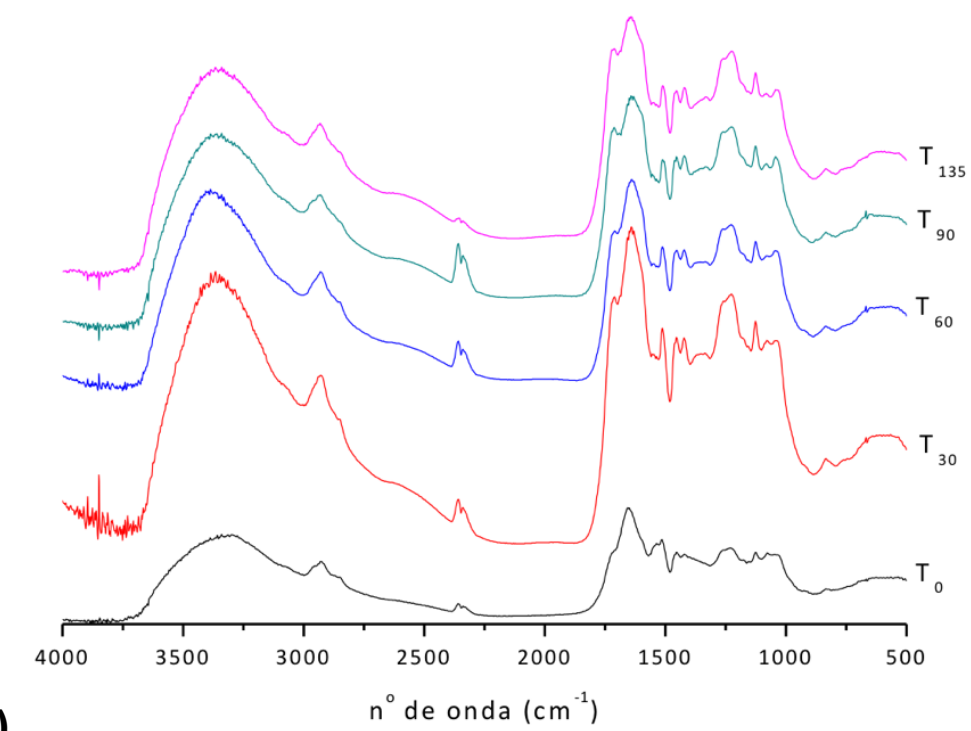

(a) 
(b)
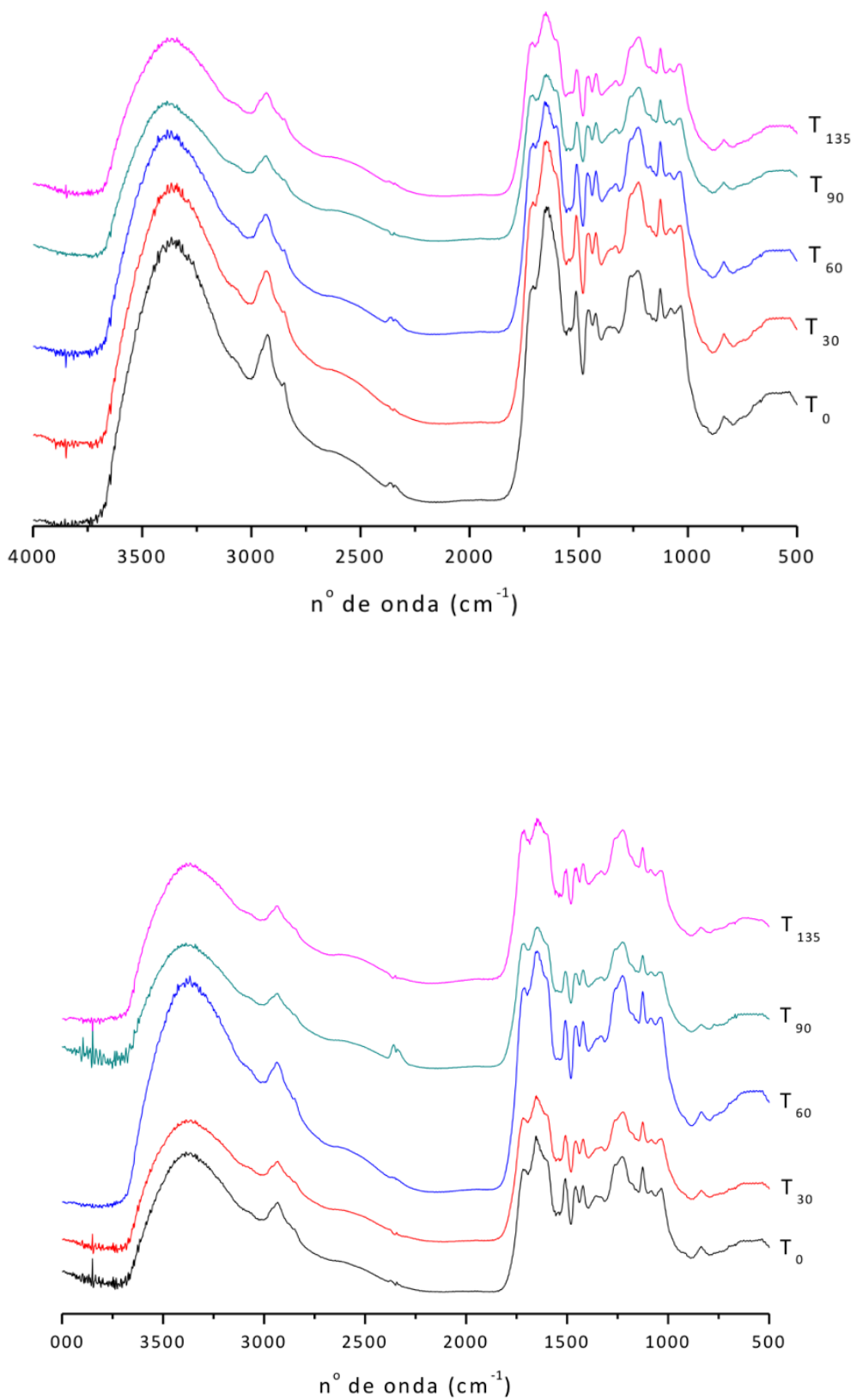

(c)

Duas bandas distintas estão presentes em 2930 e $2850 \mathrm{~cm}^{-1}$, as quais são referentes a estiramento $\mathrm{C}-\mathrm{H}$ de estruturas alifáticas nos espectros dos ácidos húmicos de todas os tratamentos. Para $B L+E B$ são mais evidentes em $T_{30}$ (primeira etapa: compostagem). A partir de $\mathrm{T}_{60}$ observa-se uma redução das mesmas. Este comportamento é devido à perda de estruturas alifáticas que são mais facilmente decompostas. Para o tratamento EB as duas bandas são mais evidentes em $\mathrm{T}_{0}$. 
Para todos os tempos pode-se observar um pequeno ombro em $1711 \mathrm{~cm}^{-1}$ referente a grupamentos carbonílicos $(\mathrm{C}=\mathrm{O})$ não conjugados e em torno de 1640$1655 \mathrm{~cm}^{-1}$ uma banda mais ampla referente a $\mathrm{C}=\mathrm{O}$ conjugados, $\mathrm{C}=\mathrm{C}$ em estruturas aromáticas, deformação $\mathrm{N}-\mathrm{H}$ de amidas primárias ou ainda estiramento assimétrico $\mathrm{C}-\mathrm{O}$ de íons carboxilato $\mathrm{COO}$. Para $\mathrm{BL}+\mathrm{EB}$, a partir de $\mathrm{T}_{60}$, segunda fase da vermicompostagem esta banda apresenta-se menos evidente. Para o tratamento $\mathrm{TF}+\mathrm{EB}$ e EB as duas bandas também são observadas, mas não há uma tendência tão clara de diminuição da intensidade com o tempo como para o tratamento BL+EB. Para TF+EB em $1650 \mathrm{~cm}^{-1}$ é bastante pronunciada em $\mathrm{T}_{0}$.

Bandas de absorção em 1652, 1600 e 1511 cm ${ }^{-1}$ estão presentes nos espectros de todos os tratamentos em todos os tempos de vermicompostagem. As bandas são originadas de estiramentos de anéis aromáticos de monômeros de lignina (AMALFITANO et al., 1992; FIALHO et al., 2010). Para BL+EB a intensidade dessas bandas decresceu em função do tempo de vermicompostagem, particularmente após a adição das minhocas às misturas $\left(T_{45}\right)$, na segunda fase do processo. Para os demais tratamentos, as bandas apresentaram diminuição da intensidade após 90 dias de vermicompostagem.

Nas bandas entre 950-1200 $\mathrm{cm}^{-1}$ há um decréscimo significativo de intensidade em função do tempo para todos os tratamentos, o que corresponde à degradação de carboidratos. Assim como constatado por Fialho et al. (2010), a análise dos espectros de FTIR indica a biodegradação de cadeias alifáticas como celulose e hemicelulose $\left(2930 \mathrm{~cm}^{-1}\right)$ e pectina $\left(950-1200 \mathrm{~cm}^{-1}\right)$ que podem ser facilmente assimiladas pelos microorganismos.

\subsection{Espectroscopia de Absorção na Região do UV-Visível (UV-Vis)}

Os espectros na região do UV-Visível dos ácidos húmicos estudados apresentaram decréscimo na absorção com o aumento do comprimento de onda (Figura 3 - III a, b e c). Apenas os ácidos húmicos extraídos do tratamento EB apresentaram valores para a razão $E_{4} / E_{6}$ dentro da faixa esperada para ácidos 
húmicos extraídos de solos (entre 4,5 e 4,8 durante todo o processo de vermicompostagem), que normalmente são menores que 5,0, indicando massa molecular relativamente mais elevada, estruturas mais condensadas e, por consequência, graus de humificação mais elevados (KONONOVA, 1982). Para os tratamentos $\mathrm{BL}+\mathrm{EB}$ e $\mathrm{TF}+\mathrm{EB}$ foram encontrados valores superiores, sendo para $\mathrm{BL}+\mathrm{EB}$ em torno de 7,0 durante todo o tempo e para $\mathrm{TF}+\mathrm{EB}$, após 90 dias, valores em torno de 15,5. Em estudos com esterco compostado e lodos orgânicos, Inbar et al. (1990) e Dick et al. (1997) obtiveram valores acima do valor referência para ácidos húmicos extraídos de solos. Esses valores altos indicam a presença de $\mathrm{AH}$ pouco evoluídos em fontes não-pedogênicas de matéria orgânica. Segundo Landgraf \& Rezende (1997), valores mais elevados estão correlacionados com estruturas mais abertas e de menor complexidade. 
Figura 3 - II. Espectros de absorção UV-Vis dos AH extraídos dos tratamentos BL+EB (a), TF+EB (b), EB (c) em função do tempo de vermicompostagem

(a)

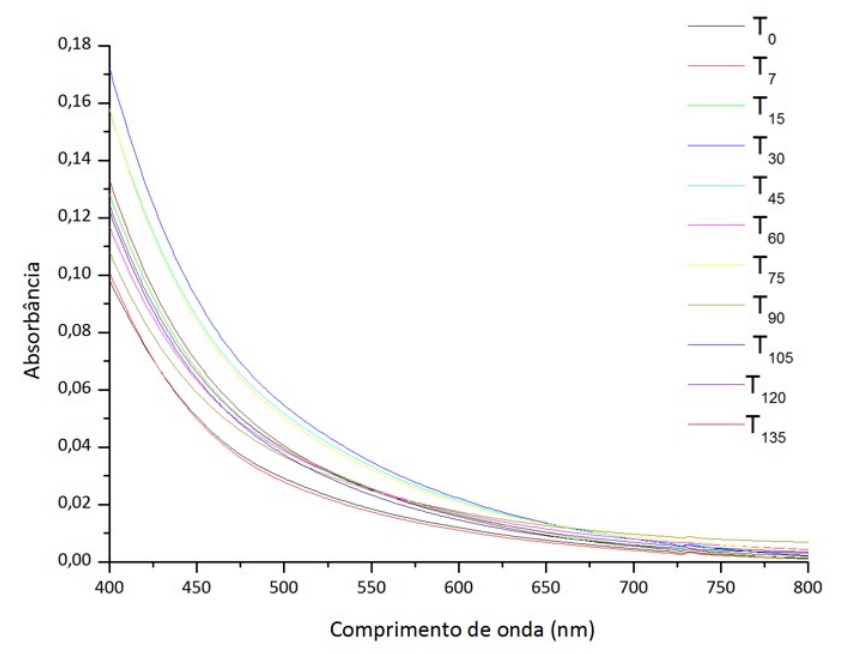

(b)

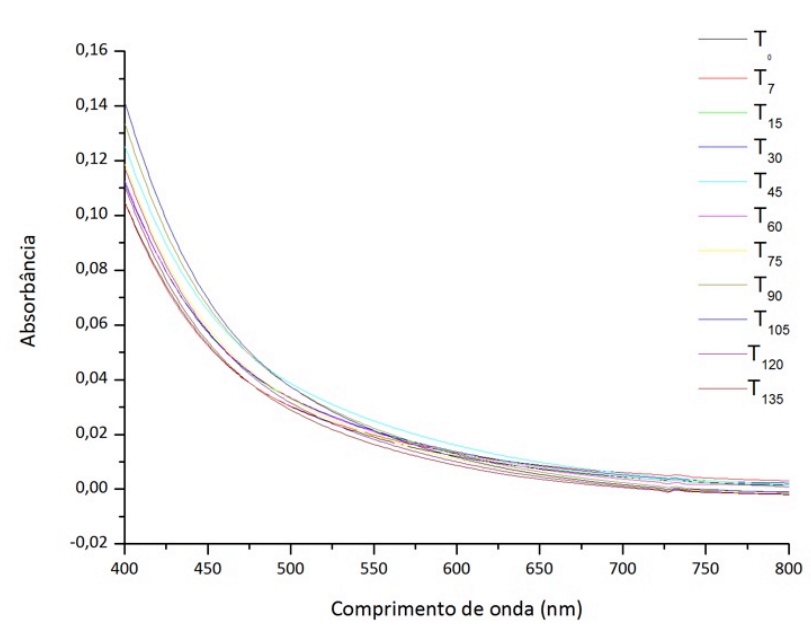

(c)

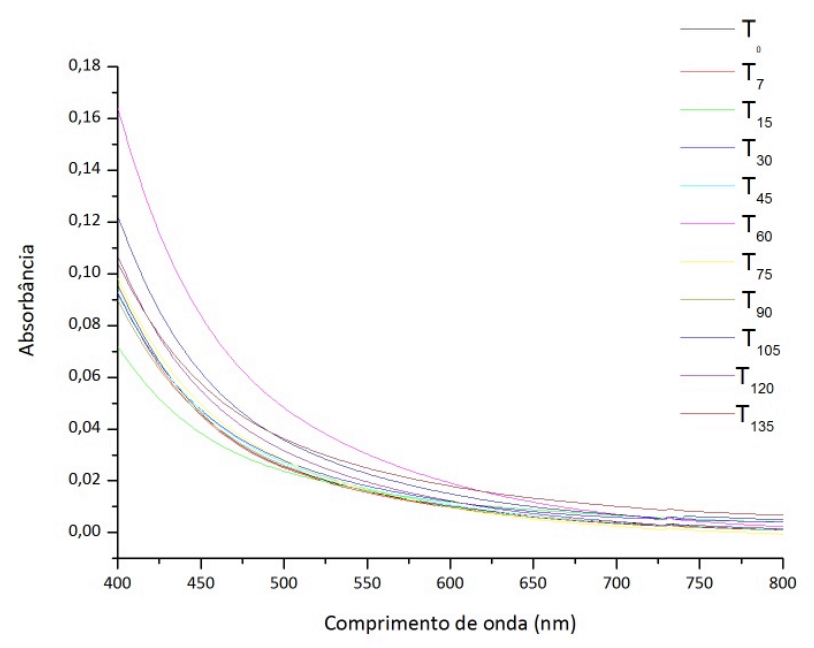

Outra razão utilizada é a $E_{2} / E_{4}$, a qual tem sido usada para distinguir diferentes origens da matéria orgânica. Para os ácidos húmicos referentes ao tratamento TF+EB foram encontrados valores de 3,0 a 5,1, sendo crescentes em função do tempo, o que, segundo Budziak et al. (2004), indica o consumo de estruturas porfirínicas nesta fase do processo, e/ou a formação de estrutura aromática não condensada ligada a funções oxigenadas. 
Para $\mathrm{BL}+\mathrm{EB}$ foram encontrados valores entre 3,7 e 4,7, e para EB valores praticamente constantes com máximo de 4,8. Segundo Novotny et al. (1999), uma baixa razão $E_{2} / E_{4}$ está relacionada a maior participação de estruturas porfirínicas (absorção em $407 \mathrm{~nm}$ ) com relação a estruturas de ligninas. A razão $E_{2} / E_{4}$ mais alta sugere maior participação de plantas terrestres com altos níveis de estruturas de ligninas (absorção em 270 nm).

\subsection{Ressonância Magnética Nuclear de ${ }^{13} \mathrm{C}\left({ }^{13} \mathrm{C}\right.$ RMN $)$}

A técnica de VACP-MAS ${ }^{13} \mathrm{C}$ RMN forneceu informações importantes acerca das transformações da $\mathrm{MO}$ durante o processo de vermicompostagem. Os espectros de RMN de ${ }^{13} \mathrm{C}$ dos ácidos húmicos (Figuras $10 \mathrm{a}, \mathrm{b}$ e c), extraídos nos diferentes tempos do processo de vermicompostagem (0, 30, 75, 90 e 135 dias), mostraram uma banda em 174,5 ppm (carboxílico) dominante na região entre 160 e 185 ppm (carboxílicos). Para os AH extraídos de BL+EB, as alterações nesta banda são claras, sendo esta mais intensa no tempo 0 , diminuindo até 90 dias e tornando a aumentar após 135 dias. Os AH de TF+EB e de EB apresentam comportamento similar, mas menos evidente. Após 75, dias as minhocas já haviam sido adicionadas.

Na região de fenólicos (140-160 ppm), uma banda com a sobreposição de dois picos é observada em todos os espectros (sendo um em 148 ppm: C fenólico; e outro em 153 ppm: O-substituído de C aromático). Para todos os $\mathrm{AH}$ estudados, o pico em $153 \mathrm{ppm}$ torna-se mais intenso no decorrer do processo de vermicompostagem, sendo que, para os $\mathrm{AH}$ de $\mathrm{BL}+\mathrm{EB}$ e TF+EB, no tempo 0, 148 ppm era mais intenso. Para EB o pico em 153 ppm já era o mais evidente da banda, mas com o decorrer do processo o pico em 148 ppm tornou-se apenas um ombro em 153 ppm. Castaldi et al. (2005), também observaram os dois picos para AH extraídos de resíduo sólido urbano em tempos diferentes de compostagem, sendo ambos mais intensos no início do processo.

Entre 110 e 140 ppm, região de aromáticos, pode-se observar dois picos para todos os AH caracterizados: 130, 116. 
$\mathrm{Na}$ região de 60-110 ppm (O-alifáticos) e de 45-60 ppm ( $\mathrm{N}$-alifáticos), as bandas mais intensas encontram-se em 56 ppm (radical metoxil $-\mathrm{OCH}_{3}$ ); em 72-75 ppm (carboidratos ou álcoois alifáticos), com um ombro em 82 ppm inexistente em $t_{0}$ para todos os $\mathrm{AH}$ caracterizados. As duas bandas são mais intensas nos $\mathrm{AH}$ extraídos das amostras do início do processo. Uma banda em 104 ppm apresenta o mesmo comportamento. Segundo Skjemstad et al. (1998), materiais pouco decompostos, como por exemplo resíduos de plantas, apresentam picos mais acentuados na região de $55-110$ ppm devido à presença da celulose. Fialho et al. (2010) observaram esses picos mais acentuados nessa região para todas as pilhas de compostagem. Assim como os autores citados anteriormente, pode-se observar nas Figuras 4 - II a, b e c, que estes mesmo picos foram constatados para os $\mathrm{AH}$ de todos os tratamentos, sendo que o pico mais evidente se encontra na região de 55 ppm, em todos os tempos de vermicompostagem. Segundo Chen (2003), este pico é usualmente atribuído ao carbono metoxil de lignina.

Entre 0-45 ppm (alquil), região referente aos alifáticos não substituídos, apresenta-se uma banda com alguns picos sobrepostos, os quais diminuem de intensidade com o decorrer do processo de vermicompostagem para os $\mathrm{AH}$ de $\mathrm{BL}+\mathrm{EB}$ e TF+EB. Para os AH de EB observa-se um pico bastante evidente em 24 ppm, o qual se torna mais intenso do tempo 0 para 30 dias em seguida diminui significativamente com a adição das minhocas (tempos 75 e 90 dias) e volta a aumentar após 135 dias. 
Figura 4 - II. Espectros de RMN de ${ }^{13} \mathrm{C}$ dos ácidos húmicos extraídos das amostras de vermicomposto com bagaço de laranja (BL) (a), vermicomposto com torta de filtro (TF) (b) e vermicomposto de esterco bovino (c), coletadas nos tempos 0, 30, 7590 e 135 dias de vermicompostagem

(a)

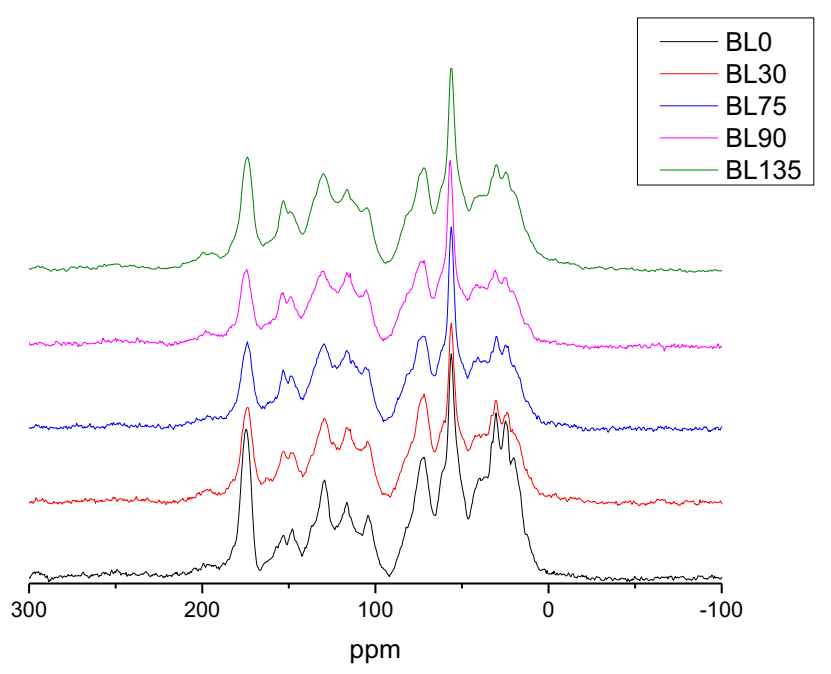

(b)

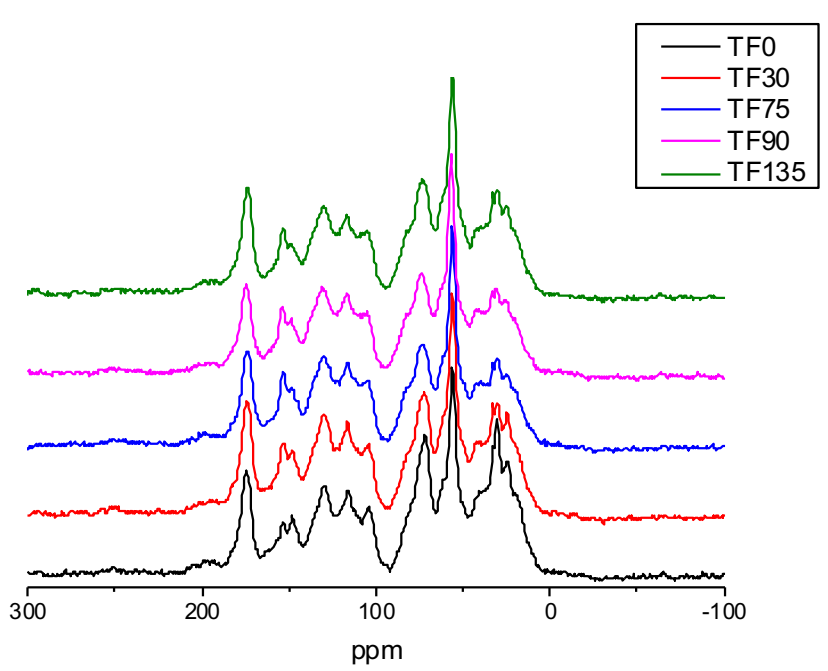

(c)

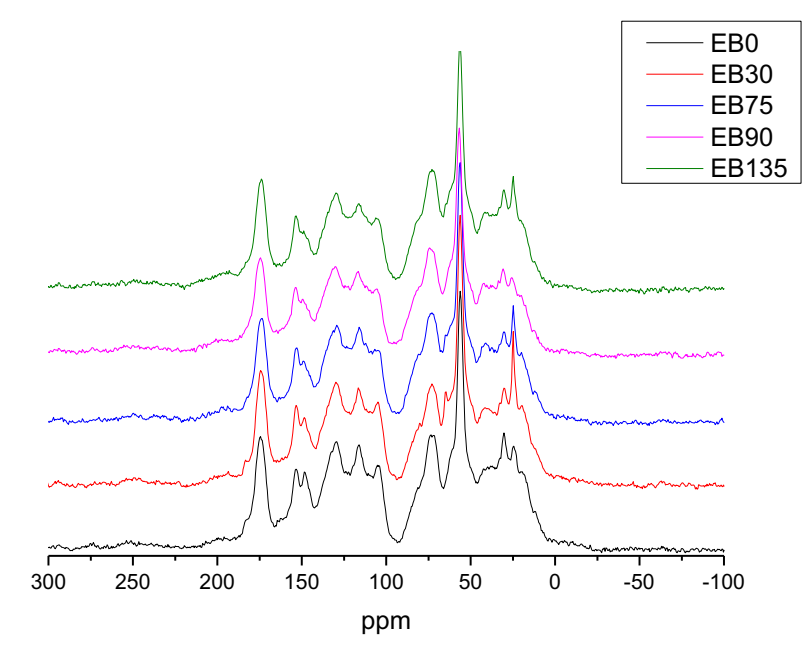

$\mathrm{Na}$ Tabela 1 - II estão apresentadas as porcentagens de distribuição de ${ }^{13} \mathrm{C}$ dentro das regiões em ppm indicadas e na Tabela 2 - II os respectivos graus de aromaticidade e alifaticidade.

Os sinais de C observados são atribuídos aos seguintes grupos (STEVENSON, 1994): 
- 0-45 ppm - alifáticos não substituídos

- 45-60 ppm - metoxil e N-alifáticos

- 60-110 ppm - O-alifáticos

- 110-140 ppm - aromáticos

- 140-160 ppm - fenólicos

- 160-185 ppm - carboxílicos

- 185-230 ppm - carbonílicos

Como base nos espectros de $\mathrm{RMN}$ de ${ }^{13} \mathrm{C}$ pode-se inferir sobre o grau de alifaticidade e aromaticidade do ácido húmico. As expressões (1) e (2) são utilizadas para quantificação do percentual de carbonos aromáticos e alifáticos (Stevenson, 1994):

AROMATICIDADE (\%) = (área 110-160 ppm/ área 0-160 ppm) x 100

ALIFATICIDADE (\%) = (área 0-110 ppm/ área 0-160) x 100

Para os $\mathrm{AH}$ extraídos de $\mathrm{BL}+\mathrm{EB}$ e EB observa-se um aumento no grau de aromaticidade, enquanto que para os de TF+EB ocorre uma diminuição após 135 de vermicompostagem. Como apresentado na Tabela 2 - II, foram encontrados para vermicompostos de $\mathrm{BL}+\mathrm{EB}, \mathrm{TF}+\mathrm{EB}$ e EB, graus de aromaticidade de 31, 30 e 30, respectivamente, após 135 de vermico 
Tabela 1 - II. Distribuição de ${ }^{13} \mathrm{C}$ nos $\mathrm{AH}$ extraídos das amostras nos diferentes tempos de vermicompostagem (BL+EB: bagaço de laranja+esterco bovino; $T F+E B$ : torta de filtro+esterco bovino; EB: esterco bovino)

\begin{tabular}{|c|c|c|c|c|c|c|c|}
\hline \multirow[t]{2}{*}{ Vermicomposto } & \multirow[t]{2}{*}{$\begin{array}{c}\text { Tempo } \\
\text { (dias) }\end{array}$} & \multicolumn{6}{|c|}{$\begin{array}{c}\text { Porcentagem de distribuição de }{ }^{13} \mathrm{C} \text { dentro das regiões em } \\
\text { ppm indicadas (\%) }\end{array}$} \\
\hline & & $0-45$ & $45-60$ & $60-110$ & $110-140$ & $140-160$ & $160-185$ \\
\hline \multirow[t]{5}{*}{$B L+E B$} & 0 & 31,0 & 14,5 & 22,9 & 15,3 & 6,1 & 11,1 \\
\hline & 30 & 25,3 & 25,2 & 18,5 & 13,4 & 10,7 & 8,1 \\
\hline & 75 & 25,0 & 23,8 & 19,7 & 14,1 & 10,2 & 8,5 \\
\hline & 90 & 25,7 & 22,3 & 20,0 & 14,1 & 10,2 & 9,0 \\
\hline & 135 & 24,8 & 23,5 & 18,9 & 13,4 & 11,6 & 9,0 \\
\hline \multirow[t]{5}{*}{$\mathrm{TF}+\mathrm{EB}$} & 0 & 26,9 & 26,2 & 17,5 & 13,3 & 9,9 & 7,4 \\
\hline & 30 & 25,7 & 22,8 & 18,9 & 13,4 & 11,1 & 9,1 \\
\hline & 75 & 26,1 & 20,8 & 20,1 & 14,2 & 10,7 & 9,4 \\
\hline & 90 & 26,5 & 21,2 & 20,0 & 14,2 & 10,4 & 9,1 \\
\hline & 135 & 26,9 & 22,1 & 18,6 & 14,3 & 10,8 & 8,4 \\
\hline \multirow[t]{5}{*}{ EB } & 0 & 24,2 & 23,4 & 19,9 & 14,0 & 10,4 & 9,4 \\
\hline & 30 & 23,9 & 23,7 & 19,9 & 14,7 & 10,3 & 8,9 \\
\hline & 75 & 27,8 & 23,9 & 21,3 & 16,0 & 11,0 & 9,3 \\
\hline & 90 & 26,4 & 20,8 & 19,8 & 14,3 & 10,7 & 8,9 \\
\hline & 135 & 26,7 & 21,9 & 19,2 & 14,5 & 10,5 & 8,4 \\
\hline
\end{tabular}

Fialho et al. (2010) encontraram valores mais baixos de graus de aromaticidade para compostos de bagaço de laranja, torta de filtro e esterco bovino (24, 30 e 25, respectivamente) após 210 dias de compostagem convencional. Os autores mostraram que, para os ácidos húmicos referentes ao composto de torta de filtro, do tempo 0 para 30 dias de compostagem, houve aumento no grau de aromaticidade de 23 para $28 \%$. Porém, de 30 a 210 dias ocorreu constante diminuição do grau de aromaticidade até atingir $25 \%$. 
Tabela 2 - II. Grau de aromaticidade e alifaticidade dos AH extraídos das amostras dos diferentes tempos de vermicompostagem (BL+EB: bagaço de laranja+esterco bovino; $\mathrm{TF}+\mathrm{EB}$ : torta de filtro+esterco bovino; EB: esterco bovino)

\begin{tabular}{|c|c|c|c|}
\hline \multirow{2}{*}{ Vermicomposto } & \multirow{2}{*}{$\begin{array}{c}\text { Tempo } \\
\text { (dias) }\end{array}$} & \multicolumn{2}{|c|}{ Grau (\%) } \\
\hline & & Alifaticidade & Aromaticidade \\
\hline \multirow[t]{5}{*}{$\mathrm{BL}+\mathrm{EB}$} & 0 & 76 & 24 \\
\hline & 30 & 71 & 29 \\
\hline & 75 & 69 & 31 \\
\hline & 90 & 68 & 32 \\
\hline & 135 & 69 & 31 \\
\hline \multirow[t]{5}{*}{$\mathrm{TF}+\mathrm{EB}$} & 0 & 68 & 32 \\
\hline & 30 & 68 & 32 \\
\hline & 75 & 69 & 31 \\
\hline & 90 & 68 & 32 \\
\hline & 135 & 70 & 30 \\
\hline \multirow[t]{5}{*}{ EB } & 0 & 73 & 27 \\
\hline & 30 & 69 & 31 \\
\hline & 75 & 67 & 33 \\
\hline & 90 & 68 & 32 \\
\hline & 135 & 70 & 30 \\
\hline
\end{tabular}

De fato, a torta de filtro, resíduo das usinas de açúcar e álcool, é um material bastante fibroso e de mais difícil degradação. Observações experimentais do comportamento das minhocas Eisenia fetida durante o processo de vermicompostagem corroboram com este contexto, pois se encontravam em plena atividade e reprodução com 90 dias, enquanto que para os demais resíduos, neste mesmo período, já se encontravam poucas minhocas, sob as mesmas condições de umidade e aeração.

\subsection{Pirólise Acoplada à Cromatografia Gasosa e Espectroscopia de Massas (P- CG/EM)}

Nas Figura 5 - II a 10 - II são apresentados os cromatogramas de produtos 
voláteis separados após a pirólise dos ácidos húmicos estudados no início e no final do processo. Em geral, os cromatogramas apresentaram o mesmo perfil. A identificação e a possível composição estrutural dos produtos foram realizadas por meio da análise do padrão de fragmentação por espectrometria de massas e comparação com banco de dados.

Avaliando-se os resultados de comparação com a biblioteca NIRST, algumas diferenças interessantes entre os ácidos húmicos extraídos do início e do final do processo de vermicompostagem puderam ser observadas para os diferentes tratamentos.

Figura 5 - II. Cromatograma dos produtos da pirólise de ácidos húmicos extraídos das amostras de vermicomposto de bagaço de laranja + esterco bovino (BL+EB) coletadas no início da vermicompostagem (tempo 0)

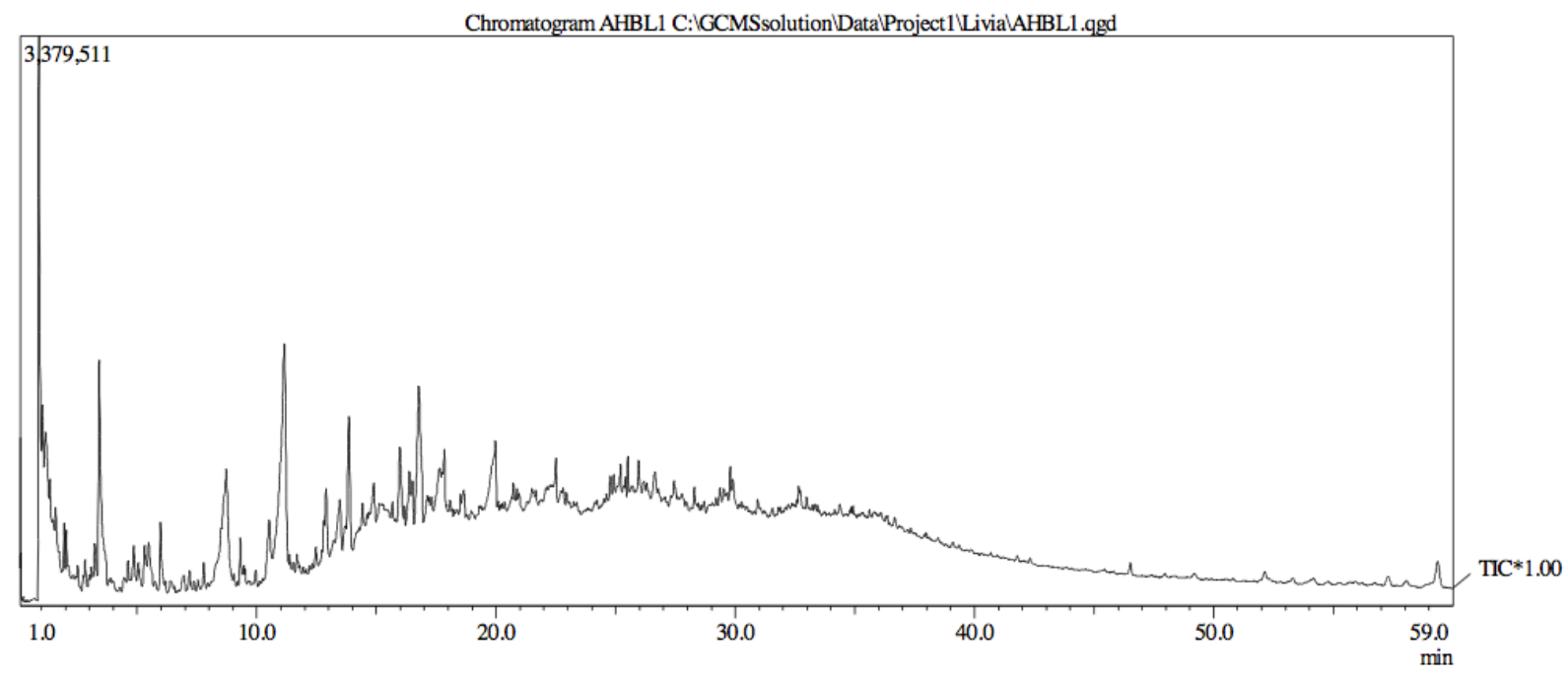


Figura 6 - Il. Cromatograma dos produtos da pirólise de ácidos húmicos extraídos das amostras de vermicomposto de bagaço de laranja + esterco bovino (BL+EB) coletadas após 135 dias de vermicompostagem

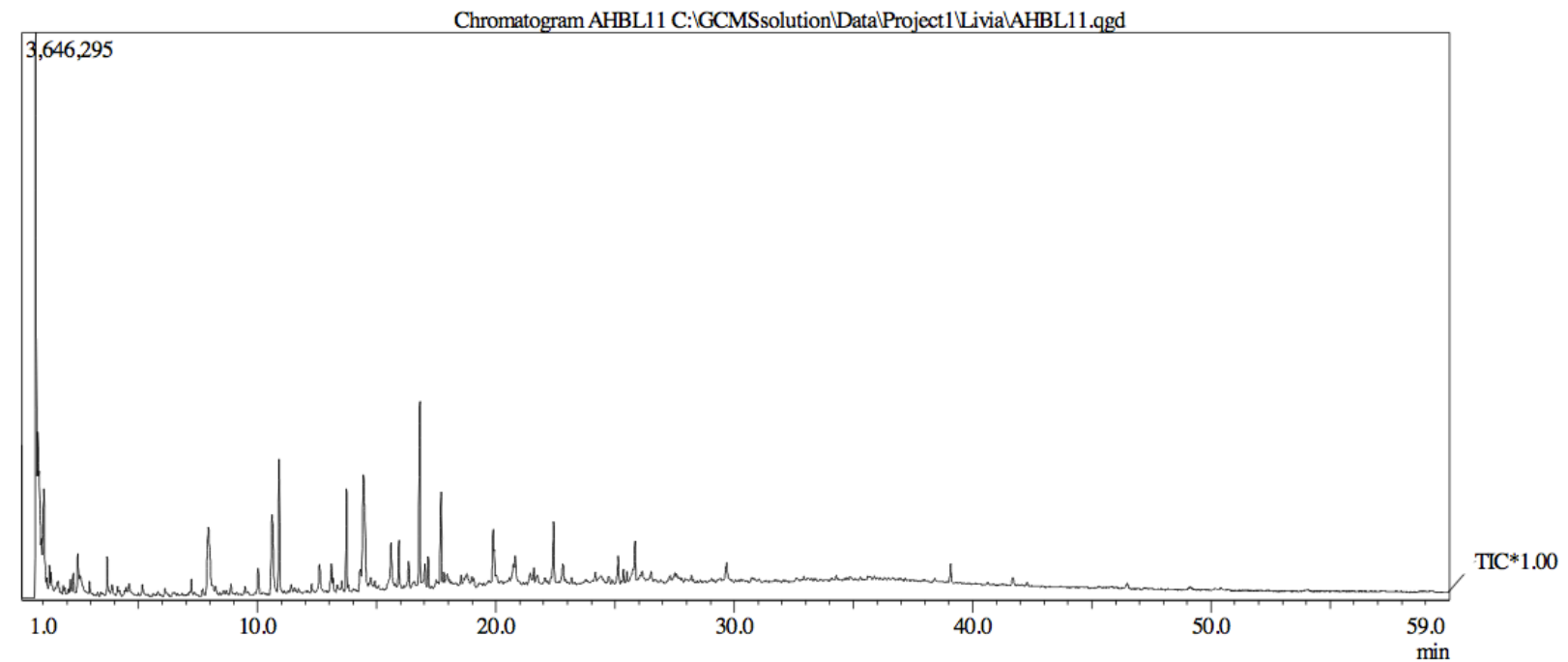

Figura 7 - II. Cromatograma dos produtos da pirólise de ácidos húmicos extraídos das amostras de vermicomposto de torta de filtro + esterco bovino $(T F+E B)$ coletadas no início da vermicompostagem (tempo 0)

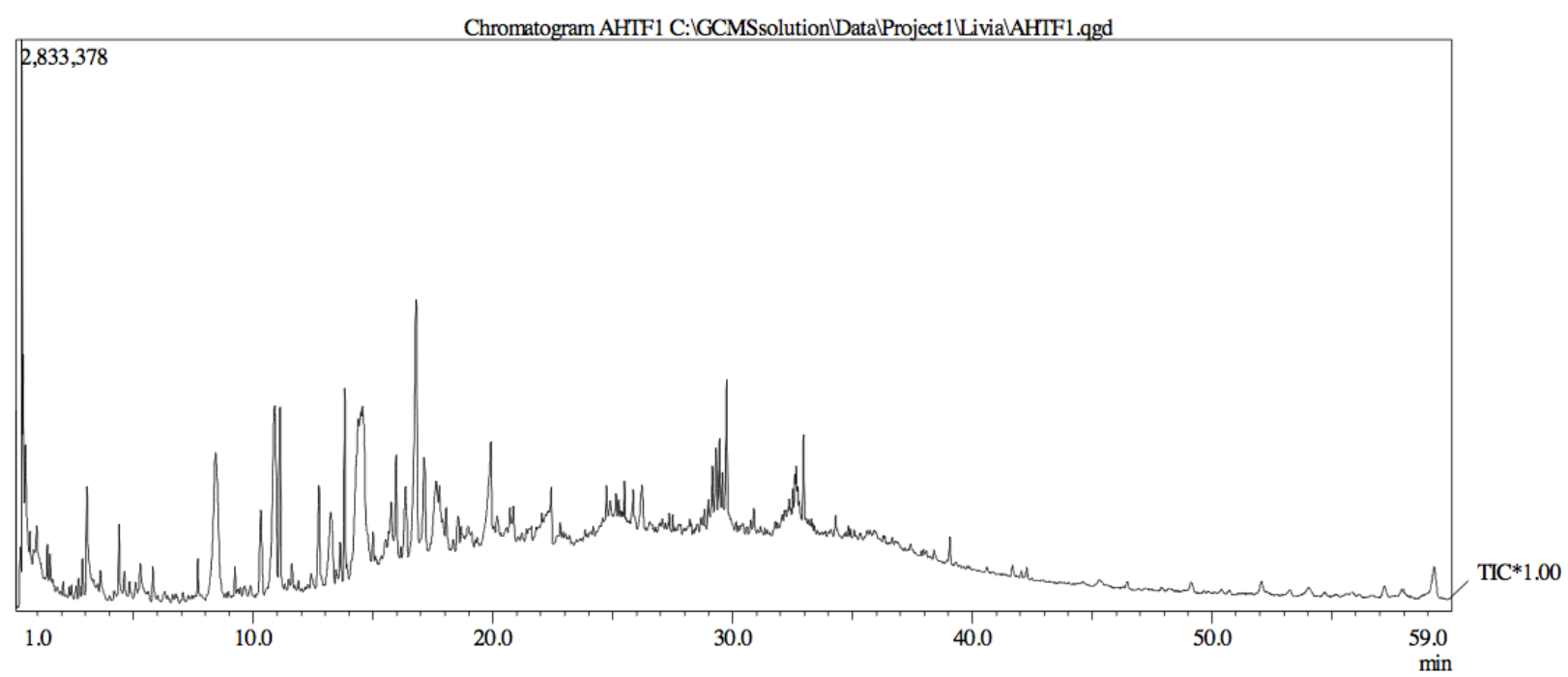


Figura 8 - II. Cromatograma dos produtos da pirólise de ácidos húmicos extraídos das amostras de vermicomposto de torta de filtro + esterco bovino $(T F+E B)$ coletadas após 135 dias de vermicompostagem

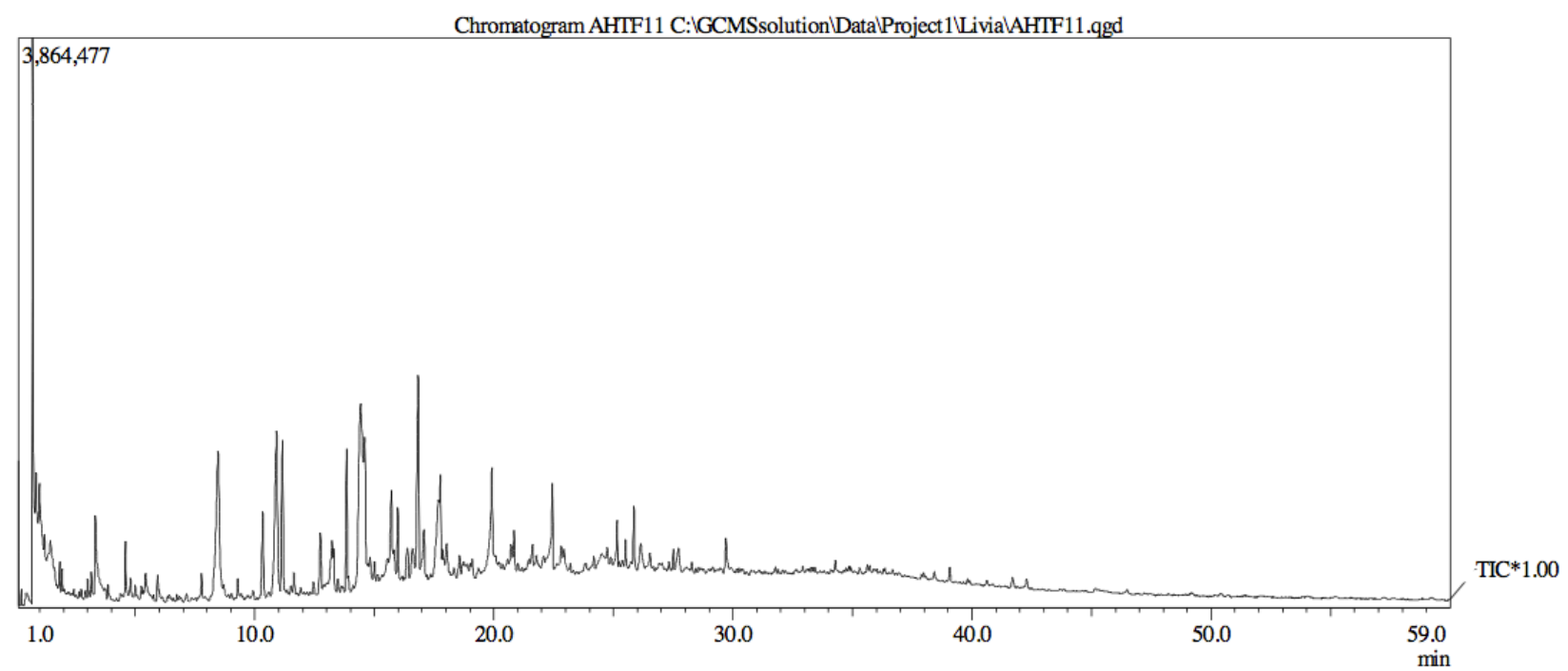

Figura 9 - II. Cromatograma dos produtos da pirólise de ácidos húmicos extraídos das amostras de vermicomposto de esterco bovino (EB) coletadas no início da vermicompostagem (tempo 0 )

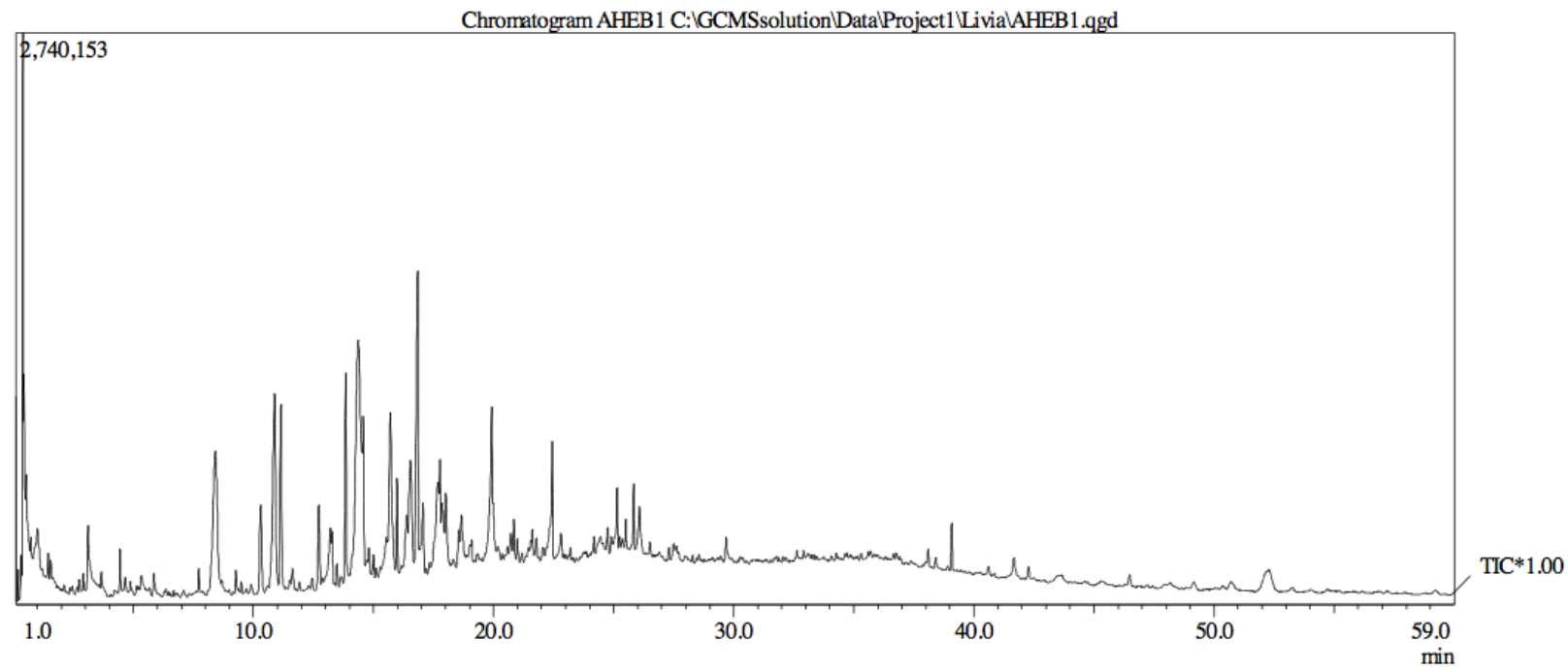


Figura 10 - II. Cromatograma dos produtos da pirólise de ácidos húmicos extraídos das amostras de vermicomposto de esterco bovino (EB) coletadas após 135 dias de vermicompostagem

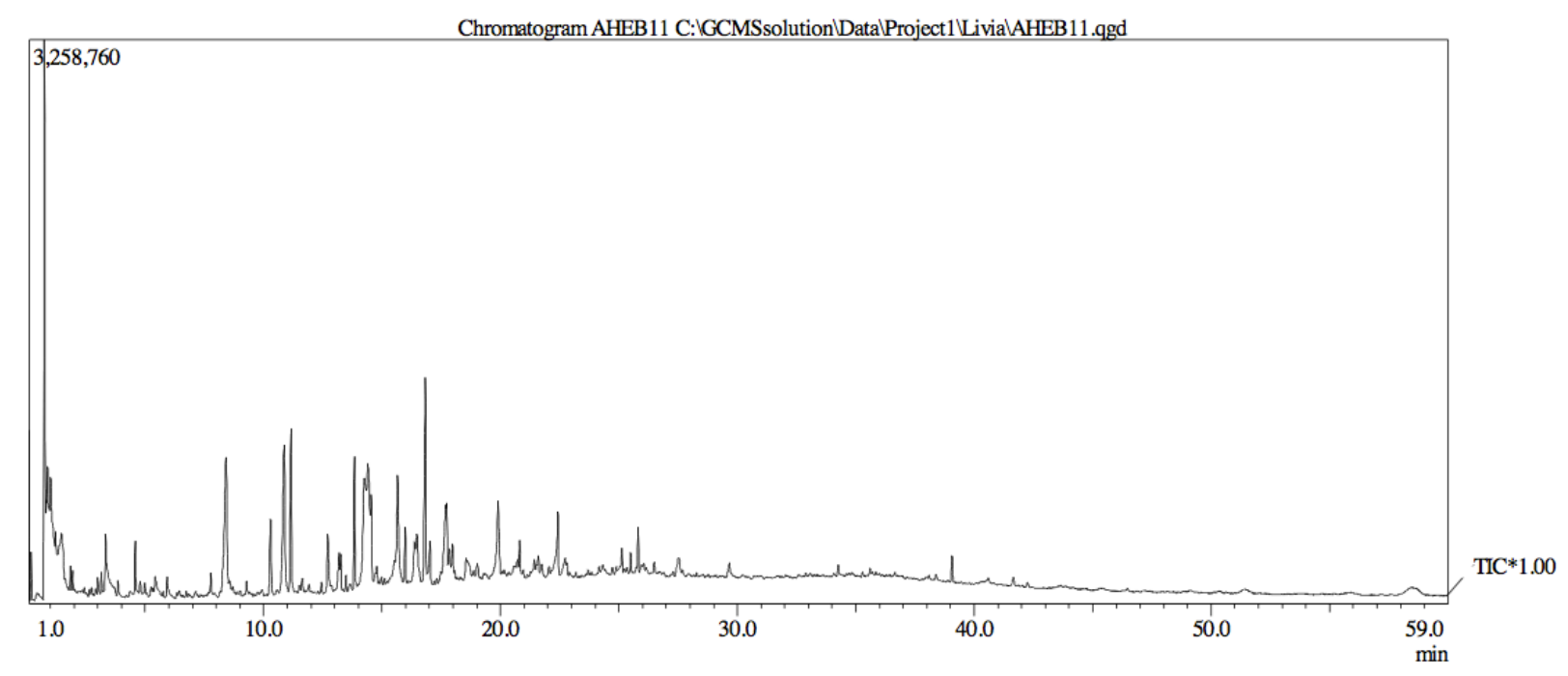

Assim como Canellas et al. (2000), na região de C alquílicos foram identificados compostos com longas cadeias alquílicas sendo que a intensidade dos picos cromatográficos é maior nos AHs extraídos do início do processo de vermicompostagem, o que está de acordo com a maior área integrada na região entre $\delta C 0$ e $\delta C 45$ observada por RMN 13C-CP/MAS e pela espectroscopia de infravermelho. Os compostos com fragmentos de razão massa:carga maior são predominantes nos ácidos húmicos extraídos aos 135 dias de vermicompostagem para todos os tratamentos, e correspondem ao padrão de fragmentação de mono e diaril ésteres com cadeia alquílica longa. Picos intensos atribuídos a ácidos graxos foram encontrados nos ácidos húmicos estudados. A presença de ácidos graxos voláteis, segundo Keeling et al. (1994), é indicativo de algum grau de anaerobiose nos estádios iniciais da compostagem dos resíduos. Segundo Canellas et al., (2000) outro importante indicativo de que os $\mathrm{AH}$ estudados estão numa fase relativamente inicial de evolução é a presença, em grande proporção, de ácidos graxos esterificados. A tendência, com a maturação dos $\mathrm{AH}$, é o desaparecimento dos ácidos graxos e a permanência de alcanos na região de C alquílicos (KHAN \& SCHNITZER, 1972).

Na região de carbonos aromáticos, foram identificados em maior quantidade 
nos $\mathrm{AH}$ extraídos após 135 dias de vermicompostagem, compostos derivados do benzeno. Os compostos derivados do benzeno presentes nos produtos da pirólise dos ácidos húmicos de $\mathrm{BL}+\mathrm{EB}$ e de $\mathrm{EB}$ do final do processo apresentaram fragmentos de menor massa, tais como tolueno, o qual não foi encontrado nos $\mathrm{AH}$ de TF+EB. Estes compostos foram identificados também por Schnitzer \& Schulten, (1992) como parte dos compostos aromáticos de ácidos húmicos extraídos de solos de clima temperado e por Canellas et al. (2000), como parte de compostos aromáticos de ácidos húmicos extraídos de vermicompostos de lodo de estação de tratamento de esgoto e de resíduos sólidos urbanos.

Em todos os pirogramas dos ácidos húmicos estudados foram identificados representantes dos compostos oxiaromáticos, foram encontrados picos característicos de fenóis substituídos. Assim como Canellas et al. (2000), nas cadeias carbônicas oxigenados, foram observados furanos substituídos, característicos da degradação de carboidratos. A presença de compostos derivados das ligninas, de fenóis e de furanos na estrutura dos ácidos húmicos mostra que as vias de formação das substâncias húmicas em solos, descritas em Stevenson (1994), são válidas também para a evolução da matéria orgânica de resíduos de origem urbana. A alteração de compostos lignificados, as reações de condensação de polifenóis e a neossíntese microbiana de compostos são as principais vias de formação dessas substâncias húmicas (CANELLAS et al., 2000).

Assim como observado por Canellas et al. (2000), os picos obtidos da pirólise de grupos nitrogenados revelaram a predominância de compostos nitrogenados heterocíclicos nas unidades estruturais dos ácidos húmicos, principalmente os derivados pirrol, pirróis substituídos e piridinas. Segundo os autores, estes compostos representam uma reserva importante de nitrogênio, quando adicionados ao solo, pois sua transformação em $\mathrm{N}$-mineral disponível às plantas é possível com a transformação química dos $\mathrm{AH}$.

Foram encontrados também na estrutura dos AH extraídos aos 135 dias de vermicompostagem, ácidos benzocarboxílicos os quais apresentaram função cetona. Estes fragmentos também foram identificados para os ácidos húmicos de EB no tempo zero. A presença desses grupamentos pode ser uma evidência que permite 
justificar a acidez correspondente à área integrada na região de $\delta C$ 160-185 ppm na espectroscopia de RMN 13C-CP/MAS. 


\section{$5 \quad$ CONCLUSÕES}

A análise das características estruturais revelou diferenças entre os ácidos húmicos estudados. Os espectros de FTIR dos ácidos húmicos de todos os tratamentos apresentaram bandas típicas de substâncias húmicas, indicando transformações moleculares como a perda de estruturas mais lábeis devido ao processo de biodegradação. A presença de estruturas alifáticas nos ácidos húmicos e maior complexidade nos sinais de absorção devido a polissacarídeos. Também foram observados grupos $\mathrm{OH}, \mathrm{COOH}, \mathrm{COO}, \mathrm{CO}_{2} \mathrm{NH}_{2}$, que confirmam a presença de sistemas aromáticos. A similaridade dos espectros de FTIR sugere que a lignina foi extraída junto com os ácidos húmicos.

A constante presença de bandas características da lignina nos espectros de FTIR de todos os ácidos húmicos estudados está de acordo com os resultados obtidos por espectroscopia de UV-Vis. A presença de sistemas aromáticos foi observada por meio desta técnica, principalmente por meio das baixas razões $E_{2} / E_{4}$, que é indicativo de presença de estruturas porfirínicas relacionadas à lignina.

Assim como os resultados apresentados por FTIR os espectros de RMN de

${ }^{13} \mathrm{C}$ apresentam picos correspondentes à degradação de carboidratos. Houve aumento do teor de aromaticidade e diminuição do teor de alifaticidade dos $\mathrm{AH}$, exceto para os referentes ao tratamento com torta de filtro que apresentou comportamento contrário. Em geral as observações feitas por meio dos espectros de RMN são coerentes com os cromatogramas obtidos por P-CG/EM, os quais mostram alterações importantes na estrutura dos $\mathrm{AH}$ estudados. Nos $\mathrm{AHs}$ extraídos no tempo 0 há predominância de longas cadeias alquílicas enquanto que nos $\mathrm{AHs}$ extraídos após 135 dias de vermicompostagem a maior presença de compostos aromáticos é evidenciada. 
ABREU-JUNIOR, C. H., MARTIN-NETO, L; MILORI, D. M. B. P.; SIMÕES, M. L.; SILVA, W. T. L. Métodos Analíticos usados em química do solo. In: SENESI, N.; XING, B.; HUANG, P.M. (Org.). Química e mineralogia do solo: aplicações. Viçosa: SBCS, 2009. v. 2, p. 624.

ADANI, F.; GENEVINI, P. L.; GASPERI, F.; TAMBONE, F. Compo- sting and humification. Compost Science Utilization v. 7, p. 24-33, 1999.

AMALFITANO, C.; PIGNALOSA, V.; AURIEMMA, L.; RAMUNNI, A. The contribution of lignin to the composition of humic acids from a wheat-straw amended soil during 3 years of incubation in pots. The Journal of Soil Science, v. 43, p. 495-504, 1992.

ANTUNES, Rui Martins. Substâncias húmicas originadas de resíduos sólidos agroindustriais compostados. (2005). 65 f. Dissertação (Mestrado em Ciências) Universidade Federal de Pelotas, Pelotas, 2005.

BUDZIAK C. R.; MAIA C. M. B. F.; MANGRICH A. S. Transformações químicas da matéria orgânica durante a compostagem de resíduos da indústria madeireira.

Quimica Nova, v. 27, n. 3, p. 399-403, 2004.

CASTALDI, P.; ALBERTI, G.; MERELLA, R.; MELIS, P. Study of the organic matter during municipal solid waste composting aimed at identifying suitable parameters for the evaluation of compost maturity. Waste Management, v. 25, p. 209-213, 2005.

CANELLAS, L.P.; SANTOS, G.A.; AMARAL-SOBRINHO, N.M.B. Reações da matéria orgânica. In: SANTOS, G.A.; CAMARGO, F.A.O. (Ed). Fundamentos da matéria orgânica do solo: ecossistemas tropicais e subtropicais. Porto Alegre: Gênesis, 1999. p. 69-90.

CANELLAS L. P.; SANTOS G. A.; MORAES A. A.; RUMJANEK V. M.; OLIVARES F. L. Avaliação de características de ácidos húmicos de resíduos de origem urbana: métodos espectroscópicos (UV-Vis, IV,RMN ${ }^{13} \mathrm{C}-\mathrm{CP} / \mathrm{MAS}$ ) e microscopia eletrônica de varredura. Revista Brasileira de Ciência do Solo, v. 24, p. 741-750, 2000. 
CANELLAS, L. P.; SANTOS, G. A. Humosfera: tratado preliminar sobre a química das substâncias húmicas. Campos dos Goytacazes: UENF, 2005. p. 309.

CANELLAS L. P.; OLIVARES F. L.; RUNJANEK V. M.; SANTOS G. A. Métodos Complemetares. In: SANTOS, G. A.; SILVA, L.; CANELLAS, L. P.; CAMARGO F. A. $O$ (Ed.). Fundamentos da matéria orgânica do solo: ecossistemas tropicais e subtropicais. 2 ed. Porto Alegre: Metropole, 2008. p. 277.

CERETTA, C. A.; BAYER, C.; DICK, D. P.; MARTIN-NETO, L.; COLNAGO, L. A. Métodos espectroscópicos. In: SANTOS, G. A.; SILVA, L.; CANELLAS, L. P.; CAMARGO F. A. O (Ed.). Fundamentos da matéria orgânica do solo: ecossistemas tropicais e subtropicais. Porto Alegre: Metropole, 2008. p. 201-205.

CHEN, Y.; INBAR, Y. Chemical and spectroscopic analyses of organic matter transformations during composting in relation to compost maturity. In: HOITINK, H. A. J.; KEENER, H. M. (Ed.). International composting research symposium: science and engineering of composting - design, environmental, microbiological and utilization aspects. Wooster: Worthington, Remaissance Publications, 1993. p. 551600 .

CHEN, Y.; INBAR, Y.; CHEFETZ, B.; HADAR, Y. Composting and recycling of organic waste. In: ROSEN, D.; TEL-OR, E.; HADAR, Y.; CHEN, Y. (Ed.). Modern agriculture and the environment. Dordrecht: Kluwer Academic Publishers, 1997. p. 341- 362.

CHEN, Y. Nuclear magnetic resonance, infra-red and pyrolysis: aplication of spectroscopic methodologies to maturity determination of composts. Compost Science \& Utilization, v. 11, n. 2, p. 152-168, 2003.

CHEFETZ, B.; HATCHER, P.; HADAR, Y.; CHEN, Y. Chemical and biological characterization of organic matter during composting of municipal solid waste. Journal Environmental Quality, v. 25, p. 776-785, 1996.

DICK, D.P.; DICK, Y.P.; DA SILVA, L.F.; ESSIG, C.; ZORTEC, R.B. Caracterização de produtos de decomposição de lodos orgânicos em diferentes tempos de meio de digestão. Revista Brasileira de Ciência do Solo, v. 21, p. 1-8, 1997. 
FIALHO, L. L.; SILVA, W. T. L.; MILORI, D. M. B. P.; SIMÕES, M. L.; MARTIN-NETO, L. Characterization of organic matter from composting of different residues by physicochemical and spectroscopic methods. Bioresource Technology, v. 101, p. 1927- 1934, 2010.

HELAL, A. A.; MURAD, G. A.; HELAL, A. A. Characterization of different humic materials by various analytical techniques. Arabian Journal of Chemistry, v. 4, p. 51-54, 2011.

HOSAKA, A.; WATANABE, C.; TSUGE, S. Development of a new "flow-through" sample cup for the vertical micro-furnace pyrolyzer to reduce undesirable secondary reactions and band broadening of resulting pyrolyzates. Journal of Anaytical and Applied Pyrolysis, v. 78, p. 452, 2007.

INBAR, Y.; CHEN, Y.; HADAR, Y. Humic substances formed during composting of organic matter. Soil Science American Journal, v. 54, p. 1316-1323, 1990.

KEELING, A.A., MULLET, J.A.J; PATON, I.K. CG-mass spectrometry of refusederived composts. Soil Biology and Biochemistry, v. 26, p. 773-776, 1994.

KHAN, S.U.; SCHNITZER, M. The retention of hidrophobic organic compounds by humic acid. Geochimica et Cosmochimica Acta, v. 36, p. 745-754, 1972.

KONONOVA, M. M. Matéria orgânica del suelo: su natureza, propriedades e métodos de investigacion. Barcelona: Oikos-Tau, 1982. 365 p.

LANDGRAF, M.D. \& REZENDE, M.O.O. Physicochemical characterization of humic acids extracted from vermicomposting obtained by animal manure. Ciência e Culura, v. 49, p. 117-120, 1997.

LANDGRAF, M. D.; MESSIAS R. A.; REZENDE, M. O. O. A importância ambiental da vermicompostagem: vantagens e aplicações. São Carlos: Rima. 2005. 106 p.

LEAL, M. A. A. Produção e eficiência agronômica de compostos obtidos com palhada de gramínea e leguminosa para o cultivo de hortaliças orgânicas. 2006. 133 f. Tese (Doutorado em Ciência em Agronomia) - Universidade Federal Rural do Rio de Janeiro, Rio de janeiro, 2006. 
MANGRICH, A. S.; LOBO, M. A.; TANCK, C.B.; WYPYCH, F.; TOLEDO, E. B. S.; GUIMARÃES, E. Criterious preparations and characterization of earthworm composts. Journal of Brazilian Chemical Society, v. 11, n. 2, p. 164-169, 2000.

MARBOT, R. Pirólisis analítica de sustáncias húmicas. 1999. 150 f. Tese (Doutorado em Química) - Centro Nacional de Investigación científica, Dirección de Química, Centro de Produtos Naturales, La Habana, 1999.

NIEMEYER, J.; CHEN, Y.; BOLLAG, J.M. Characterization of humic acids, composts and peat by diffuse reflectance Fourier-transform infrared spectroscopy. Soil Science Society of America Journal, v. 56, p. 130-135, 1992.

NOVOTNY, E. H.; BLUM, W. E. H.; GERZABEK, M. H.; MANGRICH, A. S. Soil management system effects on size fractionated humic substances. Geoderma, v. 92, p. 87, 1999.

NOVOTNY, E. H. Estudos espectroscópicos e cromatográficos de substâncias húmicas de solos sob diferentes sistemas de preparo. 2002. $216 \mathrm{f}$. Tese (Doutorado em Físico-Química) - Instituto de Química de São Carlos, Universidade de São Paulo, São Carlos, 2002.

NOVOTNY, E. H.; KNICKER, H.; COLNAGO, L. A.; MARTIN-NETO, L. Effect of residual vanadyl on the spectroscopic analysis of humic acids. Organic Geochemistry, v. 37, p. 1562-1572, 2006.

SENESI, N.; MIANO, T.M. \& BRUNETI, G. Humic-like substances in organic amendments and effects on native soil humic substances. In: PICCOLO, A. Humic substances in terrestrial ecosystems. Amsterdam: Elsevier, 1996. p. 531-595.

SINGH, J.; KAUR, A.; VIG, A. P.; RUP, P. J. Role of Eisenia fetida in rapid recycling of nutrients from bio sludge of beverage industry. Ecotoxicology and Environmental Safety, v. 73, n. 3, p. 430-435, 2010.

OUATMANE, A.; D'ORAZIO, V.; HAFIDI, M.; SENESI, N. Chemical and physicochemical characterization of humic acid-like materials from composts.

Compost Science Land Utilization, v. 10, n. 1, p. 39-46, 2002.

PLAZA, C.; SENESI, N.; POLO, A.; BRUNETTI, G.; GARCIA-GIL, G.; D'ORAZIO, V. Soil fulvic acid properties as a means to assess the use of pig slurry amendment.

Soil and Tillage Research, v. 74, p. 179-190, 2003. 
PRESTON, C. M. Applications of NMR to soil organic matter analysis: history and prospects. Soil Science, v. 161, n. 3, p. 144-166, 1996.

PROVENZANO, M. R.; OLIVEIRA, S. C.; SILVA, M. R. S.; SENESI, N. Assessment of maturity degree of composts from domestic solid wastes by fluorescence and fourier transform infrared spectroscopies. Journal of Agricultural and Food Chemistry, v. 49, p. 5874-5879, 2001.

SCHULTEN, H-R.; SCHNITZER, M. Structural studies on soil humic acids by curiepoint pyrolysis-gas chromatography/ mass spectrometry. Soil Science, v. 153, p. 205-224, 1992.

SEQUI, P. Criteri di qualita` del compost: la maturazione della sostanza organica. Riciclo di biomasse di rifiuto e di scarto e fertilizzazione organica del suolo. Patron Editore. 1991. 187 p.

SILVERSTEIN, R. M.; BASSLER, G.; MORRIL, T. C. Identificação espectroscópica de compostos orgânicos. Rio de Janeiro: Guanabara-Koogan, 1994. 387 p.

SILVERSTEIN, R. N.; BASSLER, G. C.; MORRIL, T. C. Identificação espectrométrica de compostos orgânicos. São Paulo: Guanabara, 2010. p. 198.

SKJEMSTAD, J. O.; JANIK, L. J.; TAYLOR, J. A. Non-living soil organic matter: what do we know about it? Australian Journal of Experimental Agriculture, v. 38, p. 667-680, 1998.

SMITH, C. Pyrolysis measurements. In: FRANK, S. (Ed.). Handbook of instrumental techniques for analytical chemistry. Upper Saddle River: Prentice Hall PTR, 1997, p. 893-931.

STEVENSON, F. J. Humus chemistry: genesis, composition, reactions. 2. ed. New York: J. Wiley, 1994. 496 p.

SWIFT, R. S. Molecular weight, size, shape, and charge characteristics of humic substances: Some basic considerations. In: HAYES, M. H. B.; MacCARTHY, P.; MALCOLM, R. L.; SWIFT, R. S. (Ed.). Humic substances II: in search of structure. New York: John Wiley, 1989. p. 449-466. 
WANG, P.; CHANGA, C. M.; WATSON, M. E.; DICK, W. A.; CHEN, Y.; HOITINK, H. A. J. Maturity indices for composted dairy and pig manures. Soil Biology \& Biochemistry, v. 25, p. 767-776, 2004. 


\section{CAPÍTULO III}

\section{INFLUÊNCIA DE VERMICOMPOSTOS DE ORIGEM AGROINDUSTRIAL NA PRODUÇÃO DE MANJERICÃO (Ocimum basilicum L.)}





\section{LISTA DE FIGURAS}

Figura 1 - III. Casa de vegetação em que foram conduzidos os experimentos em vasos (USP, São Carlos) 136

Figura 2 - III. Produção de mudas de Manjericão (Ocimum basilicum L.). À esquerda, mudas de manjericão após 30 dias da semeadura e à direira, mudas de manjericão após 60 dias da semeadura

Figura 3 - III. Transplante das mudas aos vasos (as mudas foram transplantadas dos potes aos vasos) 138

Figura 4 - III. Coleta da parte aérea do manjericão (Ocimum balicum L.) (a); Amostra de tecido vegetal seca a $40^{\circ} \mathrm{C}$ e triturada em cadinho de porcelana (b) 138

Figura 5 - III. Sistema de destilação por arraste de vapor montado para extração do óleo essencial das folhas de Manjericão 140

Figura 6 - III. Medições de altura das plantas (Manjericão - Ocimum basilicum L.), duas semanas após o transplante das mudas aos vasos (a) Tratamento BL+EB $30 \mathrm{t}$ ha $^{-1}$ em latossolo (a), Testemunha (sem adubação orgânica ou mineral) em latossolo (b) Testemunha em Vertissolo (c) 142

Figura 7 - III. Ocimum basilicum L. (Manjericão) 30 dias após o transplante das mudas aos vasos 143

Figura 8 - III. Ocimum basilicum L. (Manjericão) 60 dias após o transplante das mudas aos vasos

Figura 9 - III. Cromatograma do óleo essencial de Manjericão (Ocimum basilicum L.) 



\section{LISTA DE TABELAS}

Tabela 1 - III. Altura (cm) do Manjericão (Ocimum basilicum L.) para os diferentes tratamentos em latossolo vermelho em função do tempo de cultivo 145

Tabela 2 - III. Altura (cm) do Manjericão (Ocimum basilicum L.) para os diferentes tratamentos em vertissolo em função do tempo de cultivo 146

Tabela 3 - III. Massa seca de folhas (g) de Manjericão (Ocimum basilicum L.) para os diferentes tratamentos em latossolo e em vertissolo após 60 dias de experimento 149

Tabela 4 - III. Massa seca de folhas de Manjericão utilizada na extração do óleo essencial, volume de óleo essencial extraído e classificação de cor do óleo 151

Tabela 5 - III. Composição do óleo essencial (compostos identificados e seus respectivos teores em porcentagem) extraído das folhas do manjericão (Ocimum basilicum L.) de acordo com os diferentes tratamentos de adubação em latossolo e vertissolo 



\section{INTRODUÇÃO}

\subsection{Manjericão (Ocimum basilicum L.)}

As plantas aromáticas, além de fornecedoras de óleos voláteis ou essenciais, são também medicinais e estão presentes no cotidiano das pessoas. Essas plantas, ou as substâncias voláteis delas extraídas, têm sido usadas como flavorizantes, aromatizantes e terapêuticos nas indústrias alimentícias, farmacêutica e cosmética. Pesquisas indicam aumento regular no mercado de produtos naturais, apresentando a média anual de crescimento estimada em $22 \%$, nos setores industriais de perfumaria, aromatizantes para produtos alimentícios, assim como em setores de processamento de óleos essenciais. Dados relativos à década de 90 demonstram que a produção mundial chegou a 45.000 t anuais, o que representa 700 milhões de dólares, sendo que desse total, $35 \%$ são provenientes de espécies cultivadas. Estima-se que a produção brasileira de óleos essenciais corresponda a 13,15\% da produção mundial, sendo responsável por uma receita de 45 milhões de dólares anuais (MORAIS, 2006).

O manjericão (Ocimum basilicum L.) é empregado na indústria culinária, fitoterápica e na medicina tradicional, devido ao teor e composição de seu óleo essencial. É um subarbusto aromático, anual, ereto, muito ramificado, de $30-50 \mathrm{~cm}$ de altura, nativo da Ásia tropical e introduzido no Brasil pela colônia italiana. Possui folhas simples, membranáceas, com margens onduladas e nervuras salientes, de 4$7 \mathrm{~cm}$ de comprimento. Apresenta flores brancas, reunidas em racemos terminais curtos. Multiplica-se por sementes e estacas. É muito cultivado em quase todo o Brasil em hortas domésticas para uso condimentar e medicinal, sendo inclusive comercializado na forma fresca em feiras e supermercados. Existem cultivares de folhagem arroxeada utilizados, principalmente, para uso ornamental. É uma erva aromática, restaurativa, que alivia espasmos, baixa a febre e melhora a digestão, além de ser efetiva contra infecções bacterianas e parasitas intestinais. Sua análise química revelou a presença de taninos, flavonóides, saponinas, cânfora e no óleo 
essencial: timol, metil-chavicol, linalol, eugenol, cineol e pireno (LORENZI \& MATOS, 2002). As espécies mais conhecidas apresentam como constituintes majoritários em seu óleo essencial o metilchavicol, eugenol, linalol, 1,8-cineol (BARITAUX et al., 1992), cinamato de metila (PEREZ et al., 1995), geraniol (CHARLES \& SIMON, 1990) e timol (NTEZURUBANZA et al., 1984).

Para o cultivo de plantas medicinais é recomendado o uso da adubação orgânica, uma vez que esta melhora as propriedades físicas e biológicas do solo, além de corrigir possíveis deficiências de macro e micronutrientes no solo. A cama de frango, por exemplo, é uma excelente fonte de nutrientes, especialmente de nitrogênio, e quando os nutrientes são manejados adequadamente, podem suprir, parcial ou totalmente, o fertilizante químico. Além do benefício como fonte de nutrientes, o adubo orgânico adiciona matéria orgânica que melhora os atributos físicos do solo, aumenta a capacidade de retenção de água, reduz a erosão, melhora a aeração e cria um ambiente mais adequado para o desenvolvimento da flora microbiana do solo. Dessa forma, os resíduos orgânicos são considerados insumos de baixo custo e de alto retorno econômico para a agropecuária, além do retorno direto da atividade (MORAIS, 2006).

A adubação orgânica tem grande importância no cultivo de hortaliças, plantas medicinais, aromáticas e condimentares, principalmente em solos de clima tropical, onde a necessidade de reposição de matéria orgânica é mais intensa (SWIFT e WOOMER, 1993).

O manjericão é uma planta que responde muito à adubação nitrogenada, desenvolvendo-se muito bem quanto à produção de massa verde; um ponto a questionar e verificar é o quanto essas adubações nitrogenadas interferem na produção quantitativa e qualitativa de óleo essencial. Talvez, essa relação possa ser marcante ao se atentar que determinadas plantas produzem muito mais princípios ativos (também óleo essencial) quando submetidas ao 'stress', como exemplo, sabese que a babosa (Aloe vera) tem aumento significativo no teor de princípios ativos se submetida a um 'stress' hídrico cerca de um mês antes de sua colheita. É uma característica significante daquela xerófita, e certamente corresponde a uma estratégia de sobrevivência à hostilidade do ambiente (BARRACA, 1999). Apesar da 
importância do manjericão no mercado, ainda são poucos os trabalhos sobre a sua exigência nutricional. 


\section{OBJETIVOS}

O objetivo deste capítulo foi avaliar a influência de vermicompostos obtidos a partir de resíduos agroindustriais (bagaço de laranja, torta de filtro e esterco bovino), na produção de manjericão (Ocimum basilicum L.) em um Latossolo Vermelho tipicamente arenoso da região de São Carlos, SP, e em Vertissolo tipicamente argiloso da região Pantaneira.

Objetivos específicos:

a) Produção das mudas de manjericão em substrato comercial;

b) Coleta e preparo (peneiramento e correção do pH) do Latossolo Vermelho e do Vertissolo a serem utilizados para o cultivo;

c) Montagem do experimento em vasos em ambiente protegido - casa de vegetação (adubação orgânica e transplante das mudas aos vasos);

d) Avaliação nutricional pelo método visual e avaliação biométrica das plantas durante o período de cultivo;

e) Coleta da parte aérea das plantas, preparo das amostras de tecido vegetal (secagem e maceramento) para análises químicas e extração do óleo essencial das folhas;

f) Avaliação da produção de matéria seca das folhas;

g) Determinação do teor de macro e micronutrientes no tecido vegetal e

h) Extração e avaliação da qualidade do óleo essencial produzido. 


\section{PARTE EXPERIMENTAL}

\subsection{Cultivo de Manjericão (Ocimum basilicum L.), Análise Biométrica e Determinação da Matéria Seca de Folhas (MSF)}

O experimento foi conduzido em vasos, em casa de vegetação (Figura 1 - III). Foi inteiramente randomizado em um planejamento fatorial de $3 \times 3 \times 3$ (três tratamentos, três doses e três réplicas). Os tratamentos foram: vermicomposto de esterco bovino (EB); vermicomposto de bagaço de laranja + esterco bovino 2:1 m/m $(B L+E B)$ e vermicomposto de torta de filtro + esterco bovino 3:1 m/m (TF+EB). Essas proporções foram definidas em função do material de origem e para manter uma relação $\mathrm{C} / \mathrm{N}$ adequada para início do processo de vermicompostagem, conforme descrito no Capítulo I.

As doses de vermicomposto aplicadas no solo foram correspondentes a 15, 30 e $40 \mathrm{t} \mathrm{ha}^{-1}$. Foram montados três vasos sem aplicação de vermicomposto (Testemunha) e outros três vasos com aplicação de fertilizante mineral comercial (NPK 4:14:8). 
Figura 1 - III. Casa de vegetação em que foram conduzidos os experimentos em vasos (USP, São Carlos)

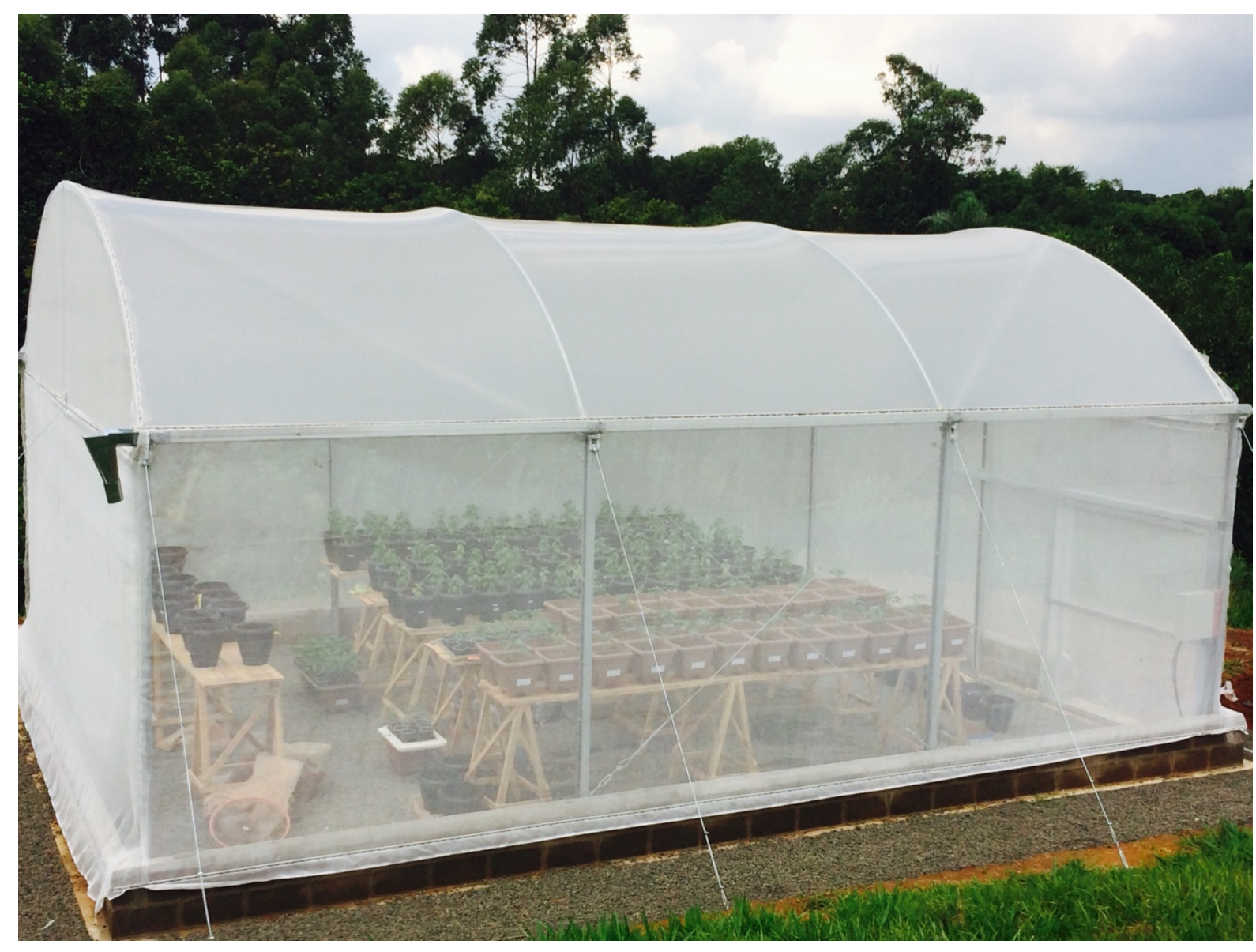

Foi utilizado um genótipo de manjericão (Ocimum basilicum L.), que apresenta como característica formato da copa irregular, pétala branca e sépala verde (BLANK et al., 2004). Foi conduzido um teste de germinação (Germitest) para verificar a qualidade do lote de sementes, em octuplicada, de acordo com a metodologia sugerida pelo Regras Para Análise de Sementes do MAPA (BRASIL, 2009). Diferentes tratamentos foram avaliados para retirar a dormência das sementes (fervura em água, banho em solução de hipoclorito e nenhum tratamento). De acordo com os resultados do teste de germinação, optou-se por retirar a dormência das sementes utilizando banho de hipoclorito $1 \%$.

A semeadura em bandejas de poliestireno foi feita no dia 22 de janeiro de 2014 utilizando-se substrato comercial para produção de mudas e depois de 30 dias, em 
21 de fevereiro de 2014, foram repicadas para recipientes maiores quando atingiram cerca de $10,0 \mathrm{~cm}$ de altura (Figura 2 - III).

Figura 2 - III. Produção de mudas de Manjericão (Ocimum basilicum L.). À esquerda, mudas de manjericão após 30 dias da semeadura e à direira, mudas de manjericão após 60 dias da semeadura
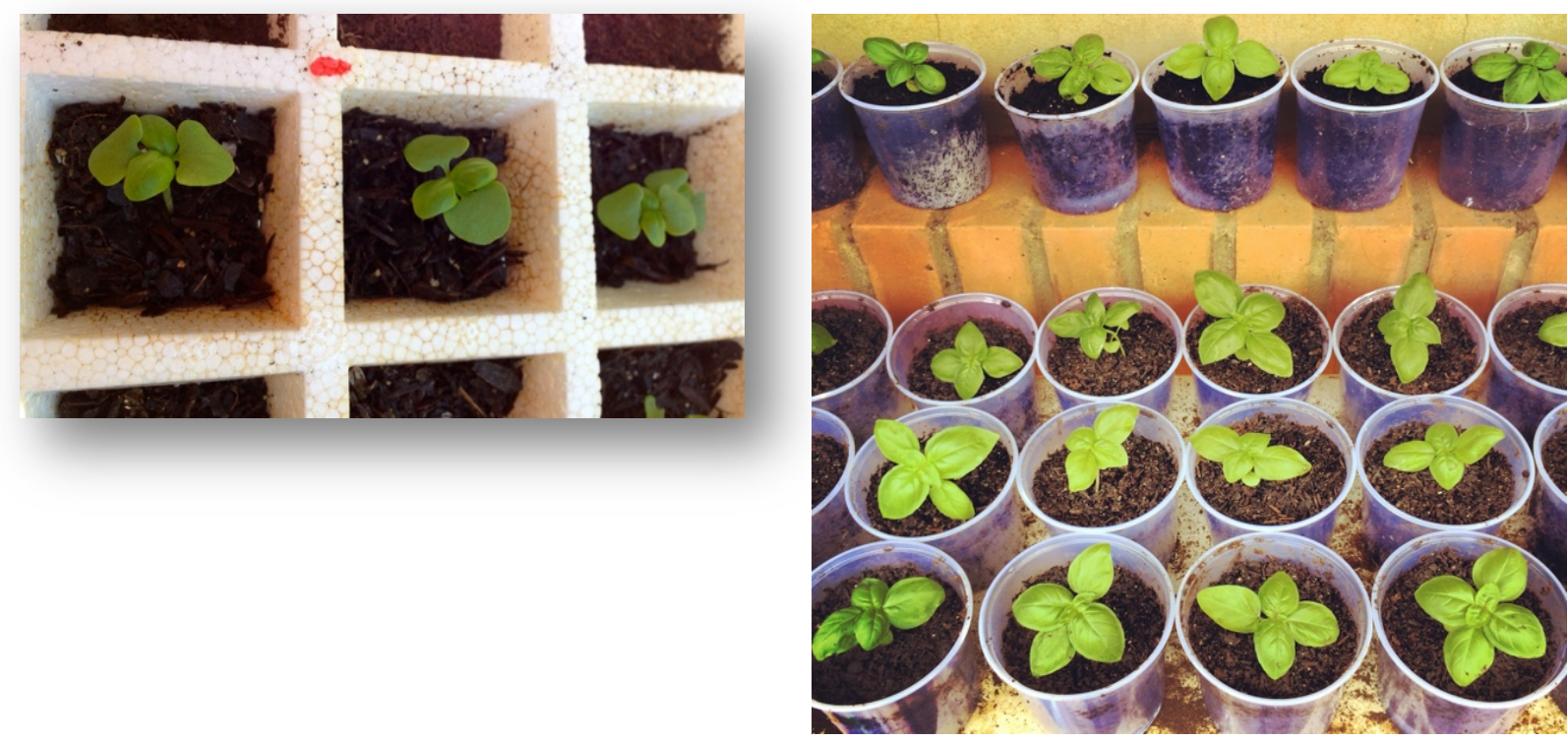

O transplante para os vasos de 10,0 L foi feito quando as plantas atingiram $15,0 \mathrm{~cm}$ de altura, 60 dias após a semeadura. O espaçamento utilizado foi $60 \mathrm{~cm}$ entre linhas e $30 \mathrm{~cm}$ entre plantas (vasos). Os vasos foram acomodados em bancadas de madeira, e cada vaso recebeu a mesma luminosidade (Figura 3 - III). As plantas foram irrigadas manualmente uma vez ao dia. Quando necessário, foi realizada a capina para eliminação de plantas indesejáveis. Foi necessário o uso de óleo da casca de laranja para controle de pragas.

As determinações biométricas foram feitas medindo-se a altura das plantas a cada 15 dias. A medida foi feita da base do caule até o último par de folhas. Após 60 dias de cultivo, foi feita a coleta da parte aérea das plantas (Figura 4 a - III). 
Figura 3 - III. Transplante das mudas aos vasos (as mudas foram transplantadas dos potes aos vasos)

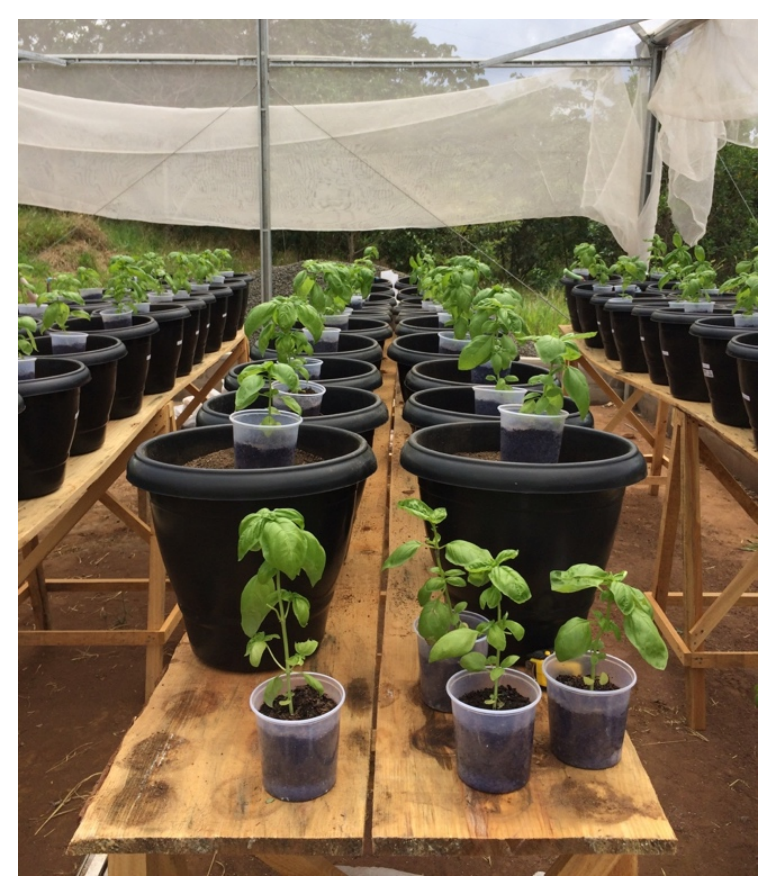

Figura 4 - III. Coleta da parte aérea do manjericão (Ocimum balicum L.) (a); Amostra de tecido vegetal seca a $40^{\circ} \mathrm{C}$ e triturada em cadinho de porcelana (b)

(a)

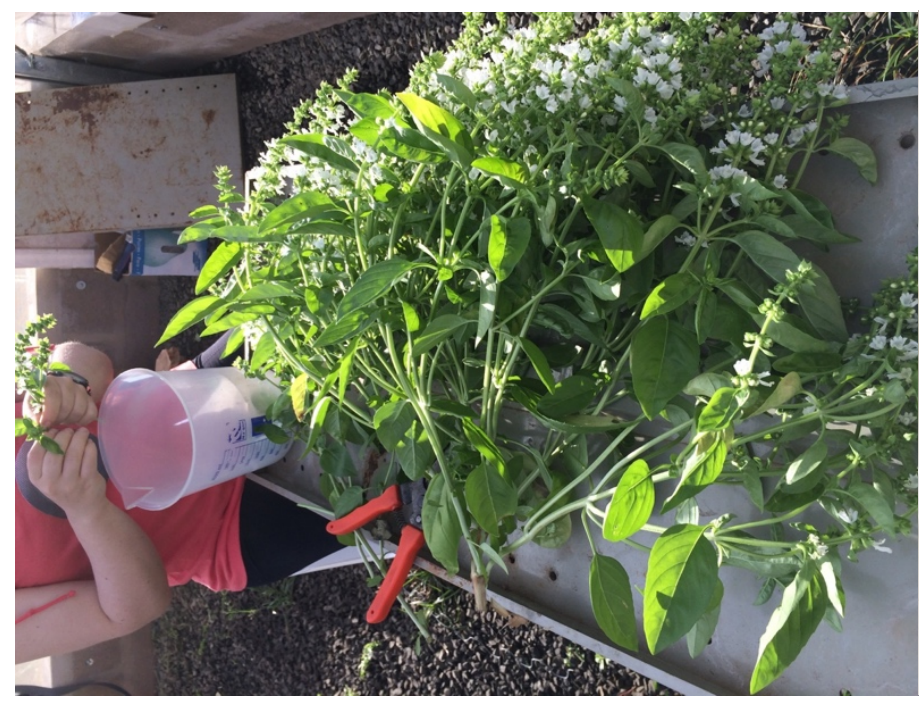

(b)

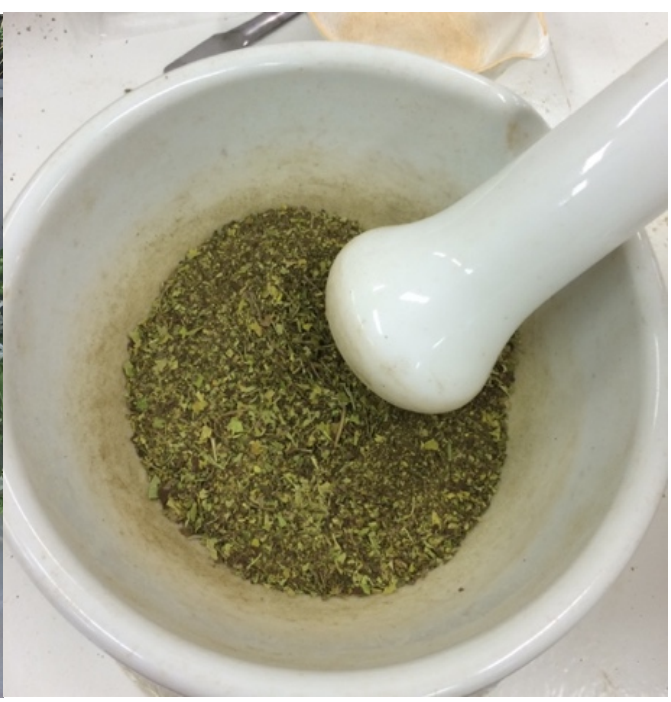

As colheitas foram realizadas no início da manhã nos dias 20 e 21 de maio de 2014, quando as plantas estavam em pleno florescimento (SIMON, 1995). As folhas 
foram secas a $40^{\circ} \mathrm{C}$ até massa constante, em estufa com circulação de ar, maceradas e pesadas para obtenção da biomassa (Figura 4 b) (CARVALHO FILHO et al., 2006).

\subsection{Determinação da Composição e Avaliação da Qualidade do Óleo Essencial Extraído das Folhas de Manjericão}

\subsubsection{Hidrodestilação}

A extração de óleo essencial das folhas de Manjericão foi realizada por hidrodestilação, fazendo uso do aparelho Tipo Clevenger Modificado (Figura 5 -III). Foram utilizadas amostras de massa fresca de folhas secas e trituradas. O material foi colocado em balões de 2 litros, onde foram adicionados $800,0 \mathrm{~mL}$ de água destilada, dando-se início ao processo de extração através do arraste do óleo essencial pelo vapor d'água. Considerou-se como início do processo quando as primeiras gotas de óleo essencial desceram pelo condensador. A extração permaneceu por 3 horas. A Figura 16 apresenta o sistema de destilação por arraste de vapor. Ao final das 3 horas, esperou-se o sistema esfriar por completo e o óleo essencial foi colhido e armazenado em frascos de vidro previamente pesados para posterior análise de sua composição química (GUENTHER, 1972). 
Figura 5 - III. Sistema de destilação por arraste de vapor montado para extração do óleo essencial das folhas de Manjericão

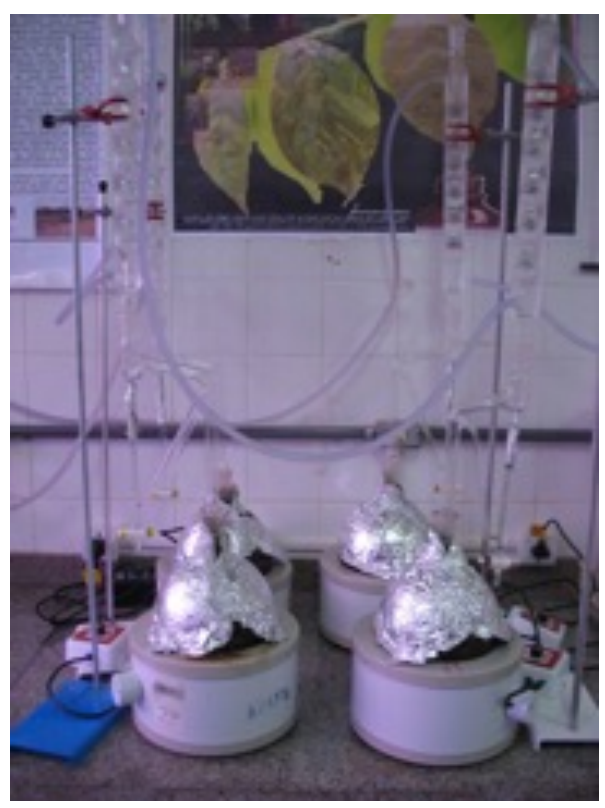

3.2.2 Determinação da composição e avaliação da qualidade do óleo essencial extraído das folhas de manjericão

Para identificação dos compostos presentes no óleo essencial foi utilizado um cromatógrafo a gás acoplado a detector de massas (Varian CP3800/Saturn 2000), equipado com uma coluna CPSil $8 C B(30 \mathrm{~m} \times 0,25 \mathrm{~mm})$. As condições analíticas foram: temperatura inicial de $60^{\circ} \mathrm{C}$ com elevação de temperatura na razão de $3 \% \mathrm{~min}$ até a temperatura final de $250^{\circ} \mathrm{C}$. Temperatura do injetor a $250^{\circ} \mathrm{C}$, split 1:200 e faixa de varredura de 30 a $500 \mathrm{~m} / \mathrm{z}$. Calculou-se o índice aritmético de cada composto e comparou-se com literatura específica (ADAMS, 2007).

Para a quantificação foi utilizado um cromatógrafo a gás Varian 450 GC FID, equipado com uma coluna CPSil $8 C B(30 \mathrm{~m} \times 0,25 \mathrm{~mm})$. As condições analíticas foram: temperatura inicial de $60{ }^{\circ} \mathrm{C}$ com elevação de temperatura na razão de $3 \% \mathrm{~min}$ até a temperatura final de $250{ }^{\circ} \mathrm{C}$. Temperatura do injetor a $250^{\circ} \mathrm{C}$, split 1:100 e temperatura do detector a $300^{\circ} \mathrm{C}$. Quantificação por normalização de área. 


\section{RESULTADOS E DISCUSSÃO}

\subsection{Observações Experimentais}

Após 2 semanas do transplante das mudas de Manjericão aos vasos, as plantas referentes ao tratamento testemunha (sem adubação orgânica ou mineral) apresentaram menor crescimento com relação às demais, bem como apresentaram amarelecimento das folhas (Figura 6 - III). Esse amarelecimento das folhas ocorreu devido à deficiência nutricional do Latossolo sem adubação. Neste mesmo tempo as plantas cultivadas em Vertissolo, independente do tratamento, apresentaram crescimento similar e coloração verde intenso das folhas (Figura 6 - III). A Figura 7 III apresenta as plantas após 1 mês (30 dias) de transplante aos vasos e a Figura 8 III após 2 meses de transplante aos vasos (60 dias). Com 60 dias de experimentos, as plantas referentes aos tratamentos com menor dose de vermicomposto aplicada (15 $\mathrm{t} \mathrm{ha}^{-1}$ ou 1,5\%), independente da origem do vermicomposto, e para ambos os solos estudados, apresentaram amarelecimento das folhas, tanto das mais velhas quanto das mais novas. 
Figura 6 - III. Medições de altura das plantas (Manjericão - Ocimum basilicum L.), duas semanas após o transplante das mudas aos vasos (a) Tratamento $\mathrm{BL}+\mathrm{EB} 30 \mathrm{t} \mathrm{ha}^{-1}$ em latossolo (a), Testemunha (sem adubação orgânica ou mineral) em latossolo (b) Testemunha em Vertissolo (c)

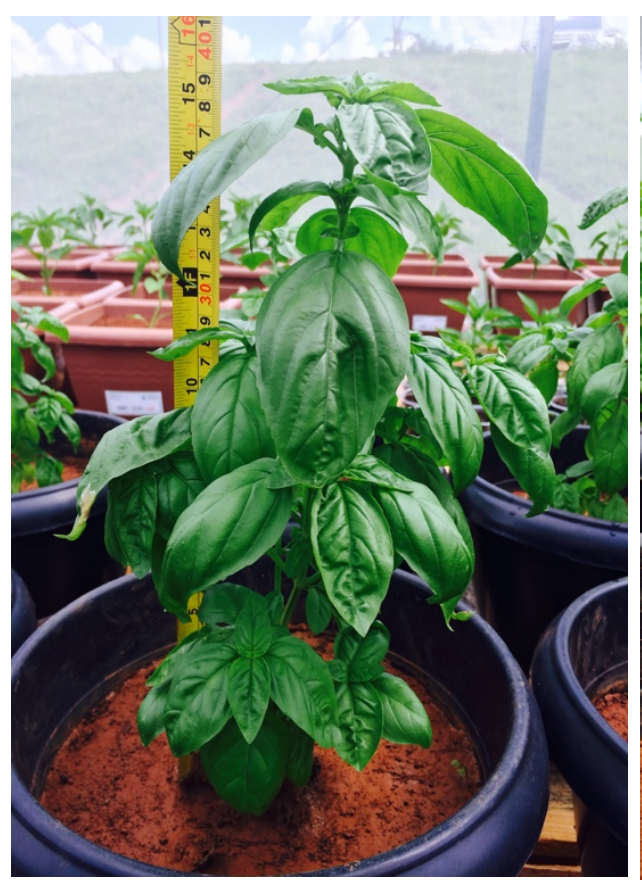

(a)

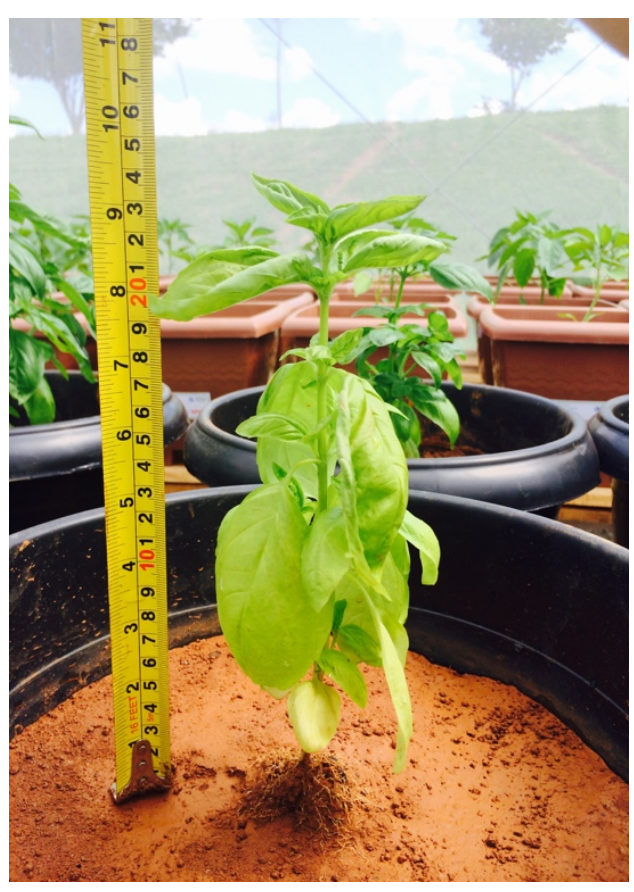

(b)

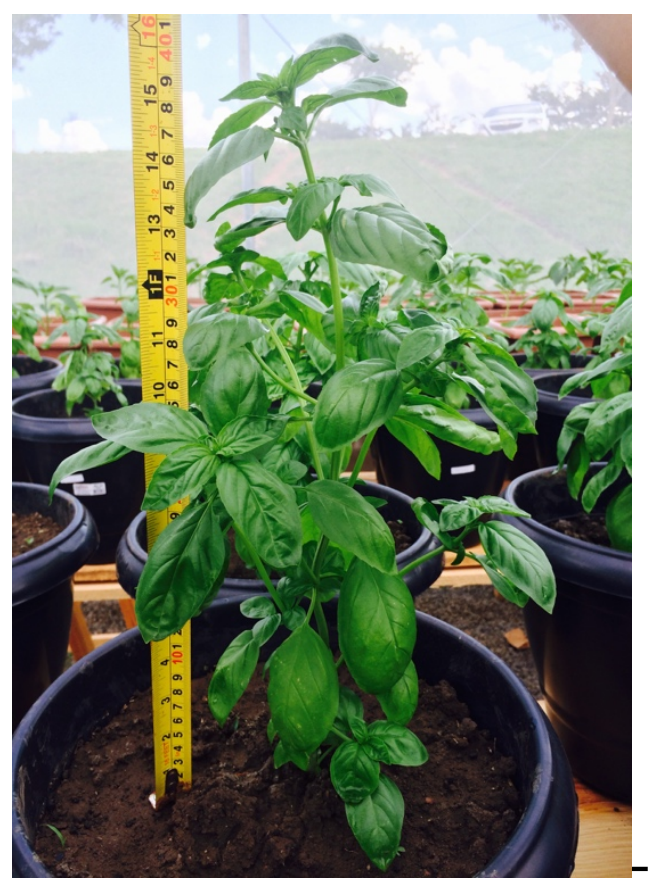

(c) 
Figura 7 - III. Ocimum basilicum L. (Manjericão) 30 dias após o transplante das mudas aos vasos
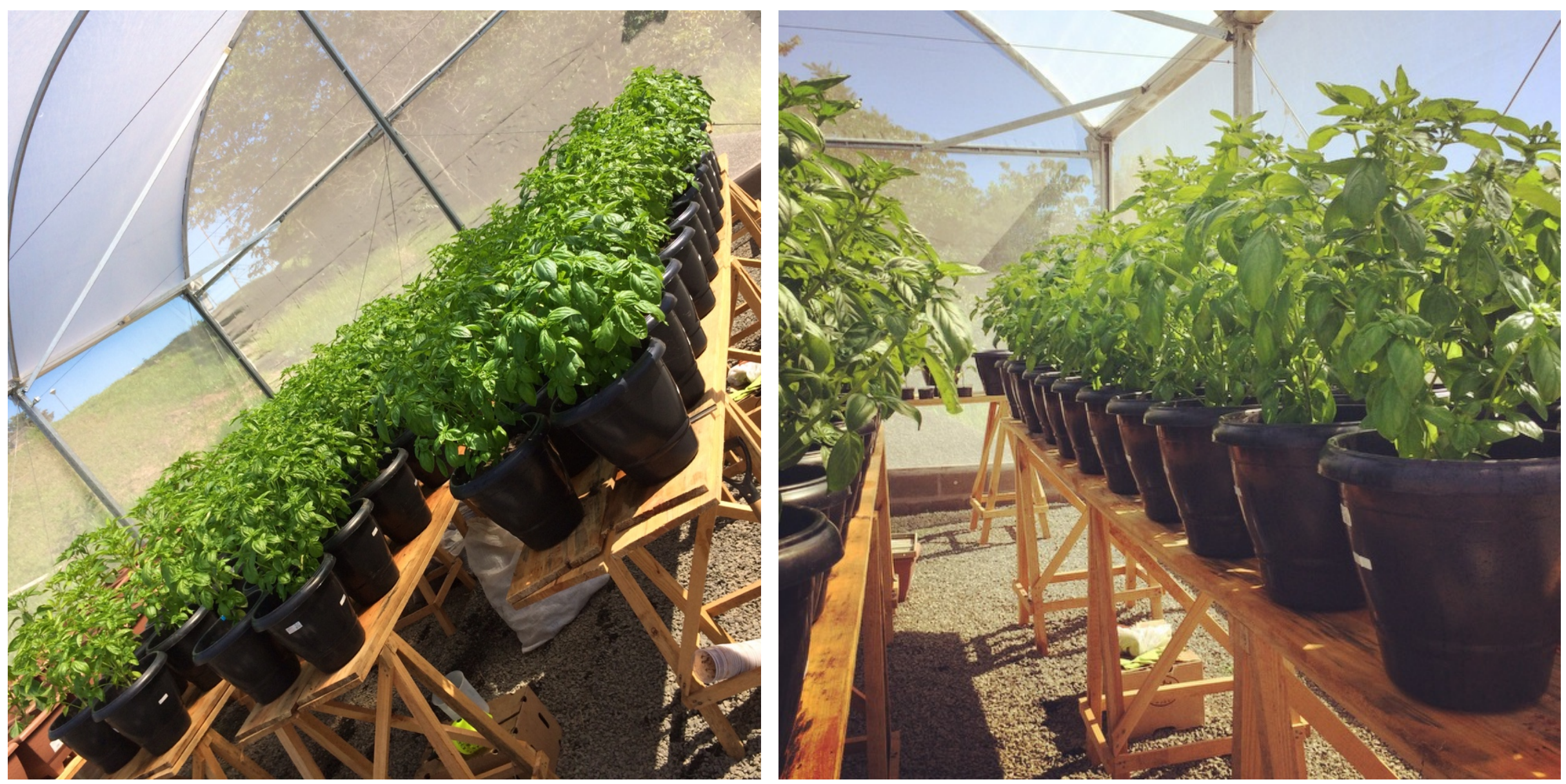
Figura 8 - III. Ocimum basilicum L. (Manjericão) 60 dias após o transplante das mudas aos vasos

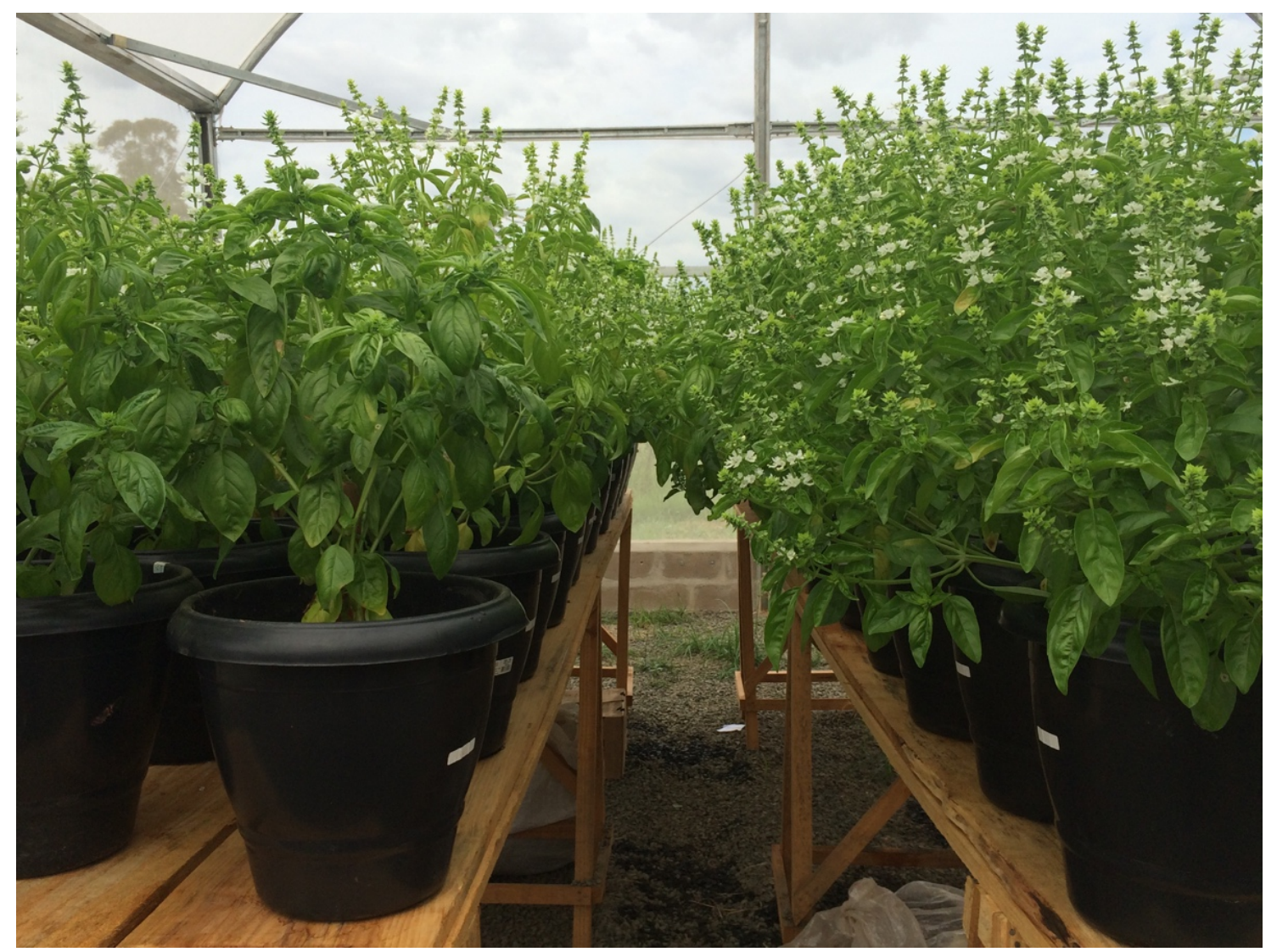

\subsection{Análise Biométrica do Manjericão}

As Tabelas 1 - III e 2 - III apresentam os dados de crescimento do Manjericão (Ocimum basilicum L.) durante 60 dias de experimento em vasos para os diferentes tratamentos e tipos de solo estudados (latossolo e vertissolo). Para o latossolo, a influência dos diferentes vermicompostos e dosagens aplicadas é mais evidente que para o vertissolo, e isso se deve às características físicas e químicas dos dois solos estudados. O vertissolo, oriundo da região Pantaneira, é um solo argiloso, que apesar de suas restrições físicas quanto a permeabilidade de água, devido à presença de argila expansiva em sua composição, é um solo muito rico em matéria orgânica, com alto teor de C. Em contrapartida, o latossolo característico da região de São Carlos, $\mathrm{SP}$, é um solo arenoso, com baixo teor de $\mathrm{C}$ e baixo potencial agrícola, sendo assim o efeito da adubação orgânica foi mais notório para este tipo de solo. 
Tabela 1 - III. Altura (cm) do Manjericão (Ocimum basilicum L.) para os diferentes tratamentos em latossolo vermelho em função do tempo de cultivo

\begin{tabular}{|c|c|c|c|c|c|}
\hline TRATAMENTOS & TO & T15 & T30 & T45 & T60 \\
\hline \multirow[t]{2}{*}{$\mathrm{BL}+\mathrm{EB} 15 \mathrm{t} \mathrm{ha}^{-1}$} & $15,0 \mathrm{a}$ & $30,0 \mathrm{ac}$ & $38,0 \mathrm{bc}$ & $46,0 a$ & $47,7 \mathrm{~b}$ \\
\hline & 0,0 & 2,4 & 2,0 & 3,6 & 4,0 \\
\hline \multirow[t]{2}{*}{$\mathrm{BL}+\mathrm{EB} 30 \mathrm{tha^{-1 }}$} & $15,0 \mathrm{a}$ & $29,0 a b c$ & $44,7 a b$ & $54,0 a$ & $57,0 a b$ \\
\hline & 0,0 & 3,5 & 5,8 & 6,1 & 6,1 \\
\hline \multirow[t]{2}{*}{$\mathrm{BL}+\mathrm{EB} 40 \mathrm{tha}^{-1}$} & $15,0 a$ & $24,7 \mathrm{bdc}$ & $33,5 \mathrm{~cd}$ & $47,0 a$ & $55,3 a b$ \\
\hline & 0,0 & 1,5 & 3,5 & 4,0 & 2,5 \\
\hline \multirow[t]{2}{*}{ TF+EB $15 \mathrm{tha}^{-1}$} & $15,0 a$ & $31,8 a b$ & $49,0 a$ & $57,3 a$ & $61,3 a$ \\
\hline & 0,0 & 3,0 & 2,0 & 3,5 & 4,9 \\
\hline \multirow[t]{2}{*}{$\mathrm{TF}+\mathrm{EB} 30 \mathrm{t} \mathrm{ha}^{-1}$} & $15,0 \mathrm{a}$ & $31,0 a b$ & $49,3 a$ & $57,0 a$ & $61,0 a$ \\
\hline & 0,0 & 1,0 & 1,5 & 3,6 & 1,7 \\
\hline \multirow[t]{2}{*}{$\mathrm{TF}+\mathrm{EB} 40 \mathrm{tha}^{-1}$} & $15,0 a$ & $24,7 \mathrm{bdc}$ & $38,3 b c$ & $49,7 a$ & $59,3 a$ \\
\hline & 0,0 & 3,8 & 7,8 & 9,9 & 3,1 \\
\hline \multirow[t]{2}{*}{ EB $15 \mathrm{tha}^{-1}$} & $15,0 a$ & $34,7 a$ & $48,3 a$ & $52,0 a$ & $54,3 a b$ \\
\hline & 0,0 & 8,4 & 7,2 & 7,0 & 3,8 \\
\hline \multirow[t]{2}{*}{ EB $30 \mathrm{t} \mathrm{ha}^{-1}$} & $15,0 a$ & $27,7 a b c$ & $42,0 a b c$ & $53,3 a$ & $58,0 a b$ \\
\hline & 0,0 & 2,5 & 5,3 & 7,8 & 11,5 \\
\hline \multirow[t]{2}{*}{ EB $40 \mathrm{tha}^{-1}$} & $15,0 \mathrm{a}$ & $27,2 \mathrm{bc}$ & $39,7 \mathrm{abc}$ & $52,7 a$ & $57,7 a b$ \\
\hline & 0,0 & 4,9 & 9,0 & 10,0 & 10,8 \\
\hline \multirow[t]{2}{*}{ TESTEMUNHA } & $15,0 \mathrm{a}$ & $23,3 d c$ & $26,0 d$ & $29,3 b$ & $34,0 \mathrm{c}$ \\
\hline & 0,0 & 2,5 & 3,0 & 5,5 & 5,6 \\
\hline \multirow[t]{2}{*}{ NPK 4:14:8 } & $15,0 \mathrm{a}$ & $19,5 d$ & $32,3 \mathrm{~cd}$ & $47,0 a$ & $57,3 a b$ \\
\hline & 0,0 & 3,3 & 0,6 & 2,0 & 2,3 \\
\hline
\end{tabular}


Tabela 2 - III. Altura (cm) do Manjericão (Ocimum basilicum L.) para os diferentes tratamentos em vertissolo em função do tempo de cultivo

\begin{tabular}{|c|c|c|c|c|c|}
\hline TRATAMENTOS & TO & T15 & T30 & T45 & T60 \\
\hline \multirow[t]{2}{*}{$\mathrm{BL}+\mathrm{EB} 15 \mathrm{t} \mathrm{ha}^{-1}$} & $15,0 a$ & $36,5 a b$ & $48,3 a b$ & $56,0 a b c$ & $63,3 a b$ \\
\hline & 0,0 & 3,9 & 4,2 & 2,0 & 1,5 \\
\hline \multirow[t]{2}{*}{$\mathrm{BL}+\mathrm{EB} 30 \mathrm{t} \mathrm{ha}^{-1}$} & $15,0 a$ & $34,0 a b$ & $45,3 a b$ & $54,0 \mathrm{abc}$ & $64,3 a b$ \\
\hline & 0,0 & 6,2 & 4,0 & 5,7 & 5,1 \\
\hline \multirow[t]{2}{*}{$\mathrm{BL}+\mathrm{EB} 4,0 \mathrm{tha}^{-1}$} & $15,0 a$ & $30,0 a b$ & $50,0 a b$ & $60,3 a b c$ & $75,3 a$ \\
\hline & 0,0 & 3,6 & 6,6 & 3,5 & 11,6 \\
\hline \multirow[t]{2}{*}{$\mathrm{TF}+\mathrm{EB} 15 \mathrm{tha}^{-1}$} & $15,0 a$ & $37,0 a b$ & $50,3 a b$ & $63,0 a b$ & $66,0 a b$ \\
\hline & 0,0 & 3,6 & 5,1 & 8,9 & 8,0 \\
\hline \multirow[t]{2}{*}{$\mathrm{TF}+\mathrm{EB} 30 \mathrm{tha}^{-1}$} & $15,0 a$ & $30,3 a b$ & $45,7 a b$ & $54,0 \mathrm{bc}$ & $66,7 a b$ \\
\hline & 0,0 & 6,0 & 5,0 & 5,6 & 16,9 \\
\hline \multirow[t]{2}{*}{$\mathrm{TF}+\mathrm{EB} 40 \mathrm{tha}^{-1}$} & $15,0 a$ & $29,0 b$ & $43,0 b$ & $56,0 a b c$ & $62,3 a b$ \\
\hline & 0,0 & 4,4 & 10,8 & 5,3 & 2,5 \\
\hline \multirow[t]{2}{*}{ EB $15 \mathrm{t} \mathrm{ha}^{-1}$} & $15,0 a$ & $36,0 a b$ & $54,0 a$ & $62,0 a b$ & $67,0 a b$ \\
\hline & 0,0 & 2,0 & 1,0 & 4,0 & 4,0 \\
\hline \multirow[t]{2}{*}{ EB $30 \mathrm{t} \mathrm{ha}^{-1}$} & $15,0 \mathrm{a}$ & $37,7 a$ & $50,0 a b$ & $62,7 a b$ & $65,7 a b$ \\
\hline & 0,0 & 4,5 & 4,4 & 1,2 & 2,3 \\
\hline \multirow[t]{2}{*}{ EB $40 \mathrm{t} \mathrm{ha}^{-1}$} & $15,0 a$ & $29,3 a b$ & $42,7 b$ & $52,0 c$ & $57,7 b$ \\
\hline & 0,0 & 1,2 & 1,2 & 6,1 & 6,4 \\
\hline \multirow[t]{2}{*}{ TESTEMUNHA } & $15,0 a$ & $35,0 a b$ & $55,7 a$ & $65,0 a$ & $69,3 a b$ \\
\hline & 0,0 & 2,6 & 1,2 & 1,7 & 3,5 \\
\hline \multirow[t]{2}{*}{ NPK 4:14:8 } & $15,0 \mathrm{a}$ & $30,0 a b$ & $49,0 a b$ & $55,7 \mathrm{abc}$ & $62,0 a b$ \\
\hline & 0,0 & 6,1 & 7,2 & 6,7 & 7,2 \\
\hline
\end{tabular}


LATOSSOLO: após 60 dias de cultivo (T60), foi observado maior crescimento das plantas referentes à adubação com vermicomposto de TF+EB, independente da dose aplicada (15, 30 e $\left.40 \mathrm{t} \mathrm{ha}^{-1}\right)$. Os valores altura no final do experimento são significativamente maiores $(p \leq 0,05)$ do que para os tratamentos $B L+E B 15 t^{-1} \mathrm{ha}^{-1} \mathrm{e}$ testemunha (sem adubação). Entretanto não apresenta diferença significativa dos demais tratamentos, BL+EB 30 e $40 \mathrm{t} \mathrm{ha}^{-1}$, EB 15, 30 e $40 \mathrm{t} \mathrm{ha}{ }^{-1}$ e NPK 4:14:8, os quais são estatisticamente iguais $(p \leq 0,05)$. Todas as adubações estudadas (orgânica e mineral) apresentam valores de altura significativamente maiores $(p \leq 0,05)$ que o tratamento testemunha, em todas as dosagens estudadas, entretanto nenhum dos tratamentos de adubação orgânica são estatisticamente diferentes do tratamento com adubação mineral (NPK 4:14:8) para o atributo altura das plantas. Apenas o tratamento $\mathrm{BL}+\mathrm{EB}$ apresenta aumento na altura das plantas com o incremento da dose de adubação, atingindo um valor máximo entre 55,3 e $57 \mathrm{~cm}$ com a aplicação de 30 e 40 t ha $^{-1}$ respectivamente, valores estatisticamente iguais e significativamente diferentes $(p \leq 0,05)$ da altura atingida pela menor dose aplicada $\left(15 t \mathrm{tha}^{-1}\right)$, que foi 47,7 cm (Tabela 1 - III). Estudos anteriores com Ocimum basilicum (BLANK et al., 2005) e Chamomilla recutita (CORRÊA JÚNIOR, 1998) não detectaram efeito das adubações orgânica e química sobre a altura das plantas medicinais. Entretanto, Costa et al. (2008) observaram aumento na altura das plantas com o incremento das doses de adubação, atingindo um valor máximo de $67,3 \mathrm{~cm}$ com a aplicação de 8,0 $\mathrm{kg} \mathrm{m}^{-2}$ de esterco bovino e $78,0 \mathrm{~cm}$ com a dose de $4,7 \mathrm{~kg} \mathrm{~m}^{-2}$ de esterco avícola, utilizando solo com 3,0 \% de matéria orgânica.

VERTISSOLO: após 60 dias de cultivo (T60), foi observado maior crescimento das plantas referentes à adubação com vermicomposto de $B L+E B$ na maior dose aplicada $\left(40 \mathrm{t} \mathrm{ha}^{-1}\right)$. Os valores altura no final do experimento são significativamente maiores $(p \leq 0,05)$ do que para os tratamentos EB $40 \mathrm{t} \mathrm{ha}^{-1}$ (esterco bovino em sua maior dosagem). Entretanto, com relação aos demais tratamentos, não se observou diferença significativa $(p \leq 0,05)$. As plantas referentes ao tratamento testemunha não apresentaram crescimento inferior que as plantas referentes aos tratamentos com 
adubação orgânica e mineral. Isso aconteceu, pois o vertissolo utilizado é bastante rico em matéria orgânica, o que possivelmente mascarou o efeito do aporte de vermicomposto ao solo, independente da origem do material e da dosagem (Tabela $2-$ III).

\subsection{Produção de Matéria Seca de Folhas (MSF)}

A Tabela 3 - III apresenta os valores de matéria seca de folhas (MSF), ou biomassa seca das plantas, para os diferentes tratamentos em latossolo e vertissolo após 60 dias de experimento.

LATOSSOLO: após 60 dias de cultivo, foi constatada maior produção de biomassa seca para as plantas referentes aos seguintes tratamentos: $B L+E B 30$ tha' 1, TF+EB 30 e $40 \mathrm{t} \mathrm{ha}^{-1}$, EB $30 \mathrm{t} \mathrm{ha}^{-1}$. Estes tratamentos apresentaram valores de biomassa estatisticamente iguais entre si e significativamente maiores que os tratamentos $B L+E B ~ 40 t^{\text {ha }}{ }^{-1}$ e testemunha. Não ficou evidente uma tendência de aumento ou diminuição da produção de biomassa seca com o aumento da dose de vermicomposto aplicadas e nem uma diferença entre os diferentes vermicompostos aplicados. O que fica claro, é que todos os tratamentos referentes à adubação orgânica apresentam uma significativa maior produção de biomassa seca $(p \leq 0,05)$ comparados ao tratamento testemunha (plantas em solo sem adubação orgânica ou mineral) (Tabela 3 - III).

VERTISSOLO: após 60 dias de cultivo não foi observada diferença significativa $(p \leq 0,05)$ entre todos tratamentos estudados, inclusive o tratamento testemunha. Como citado para os resultados de crescimento das plantas, o vertissolo é um solo naturalmente rico em matéria orgânica, o que mascarou o efeito do aporte de vermicomposto ao solo (Tabela 3 - III). 
Tabela 3 - III. Matéria seca de folhas (g) de Manjericão (Ocimum basilicum L.) para os diferentes tratamentos em latossolo e em vertissolo após 60 dias de experimento

\section{TRATAMENTOS}

$\mathrm{BL}+\mathrm{EB} 15 \mathrm{t} \mathrm{ha}^{-1}$

$\mathrm{BL}+\mathrm{EB} 30 \mathrm{t} \mathrm{ha}^{-1}$

$B L+E B$ 4,0 tha-1

$\mathrm{TF}+\mathrm{EB} 15 \mathrm{t} \mathrm{ha}^{-1}$

$\mathrm{TF}+\mathrm{EB} 30 \mathrm{tha}^{-1}$

$\mathrm{TF}+\mathrm{EB} 40 \mathrm{tha}^{-1}$

EB $15 \mathrm{t} \mathrm{ha}^{-1}$

EB $30 \mathrm{t} \mathrm{ha}^{-1}$

EB $40 \mathrm{t} \mathrm{ha}^{-1}$

TESTEMUNHA

NPK 4:14:8

\section{LATOSSOLO}

VERTISSOLO

17,84ab

$17,35 \mathrm{a}$

2,35

$24,02 a$

$17,76 a$

6,50

$11,27 b$

$17,29 a$

4,92

10,35

$15,12 \mathrm{ab}$

$17,00 a$

1,55

5,71

$19,76 a$

$17,99 a$

6,20

$20,92 a$

$15,11 a$

4,79

1,97

16,13ab

$18,09 a$

1,52

1,62

$23,24 a$

$15,76 a$

6,66

2,98

17,73ab

$17,69 a$

3,08

3,01

$0,80 \mathrm{c}$

$15,09 a$

0,38

3,08

$15,40 a b$

$18,73 a$

6,35

$\frac{6,35}{1,02}$

${ }^{c}$ Valores médios seguidos de seus desvios padrões de três réplicas experimentais. Valores seguidos pela mesma letra em uma mesma coluna não são significativamente diferentes em $p<0.05$ pelo Teste de Tukey.

O efeito das doses de matéria orgânica no aumento de produção de biomassa já foi registrado para Hyptis suaveolens (MAIA, 2006) atribuindo-se à crescente disponibilidade e à absorção de nutrientes. Entretanto, este comportamento não é 
constante, pois em Justicia pectoralis as doses de adubações orgânicas e minerais não influenciaram a produção de biomassa da planta (BEZERRA et al., 2006).

\subsection{Determinação da Composição do Óleo Essencial Extraído das Folhas de Manjericão}

Pôde-se observar uma grande variação na coloração dos óleos essenciais extraídos das folhas de manjericão em função dos diferentes tratamentos de adubação. As cores variaram desde o amarelo claro até laranja escuro. A Tabela 4 III apresenta os resultados volume de óleo essencial extraído e classificação de cor do óleo.

Devido à baixa produção de matéria seca de folhas, para alguns tratamentos, não foi possível fazer a qualificação e quantificação das substâncias presentes no óleo essencial extraído. Geralmente a extração de óleo essencial é feita a partir de $200,0 \mathrm{~g}$ de amostra, entre matéria seca e fresca de folhas e inflorescências. Como o experimento foi conduzido em vasos, e a produção de biomassa foi referente a apenas uma poda, a quantidade de MSF foi no máximo de 75,2 g. Também existe o fato de o Manjericão não poder ser conservado por longo período após a colheita, pois sua qualidade pode ser prejudicada (SILVA et al., 2005). Este fato possivelmente corroborou para ineficiência da extração, visto que as folhas secas foram armazenadas por um período maior do que o recomendado na literatura devido a demanda de laboratórios externos para realização da extração. 
Tabela 4 - III. Matéria seca de folhas de Manjericão utilizada na extração do óleo essencial, volume de óleo essencial extraído e classificação de cor do óleo

\begin{tabular}{lccc}
\hline TRATAMENTOS & $\begin{array}{c}\text { MSF } \\
\mathbf{( g )}\end{array}$ & $\begin{array}{c}\text { Volume de óleo } \\
\text { essencial extraído } \\
(\mathbf{m L})\end{array}$ & $\begin{array}{c}\text { Coloração do óleo } \\
\text { essencial extraído }\end{array}$ \\
\hline BL 1,5 - L & 30,2 & 0,15 & Amarelo fosco \\
BL 3,0 - L & 75,2 & 0,11 & Amarelo \\
BL 4,0 - L & 22,3 & - & - \\
TF 1,5 - L & 46,1 & 0,07 & Amarelo claro \\
TF 3,0 - L & 70,6 & 0,22 & Amarelo escuro \\
TF 4,0 - L & 65,2 & 0,22 & Laranja \\
EB 1,5 - L & 41,9 & 0,04 & Laranja \\
EB 3,0 - L & 63,0 & 0,11 & Amarelo fosco \\
EB 4,0 - L & 57,5 & 0,07 & Amarelo claro \\
Test - L & 2,0 & - & - \\
NPK - L & 47,7 & 0,07 & Amarelo escuro \\
BL 1,5 - V & 52,7 & 0,11 & Laranja fosco \\
BL 3,0 - V & 53,7 & 0,22 & Laranja claro \\
BL 4,0 - V & 68,3 & 0,07 & Laranja \\
TF 1,5 - V & 54,0 & 0,11 & Laranja claro \\
TF 3,0 - V & 58,7 & 0,11 & Laranja claro \\
TF 4,0 - V & 34,6 & 0,22 & Laranja claro \\
EB 1,5 - V & 59,7 & 0,07 & Laranja claro \\
EB 3,0 - V & 51,5 & 0,11 & Laranja claro \\
EB 4,0 - V & 58,1 & 0,11 & Laranja fosco \\
Test - V & 53,1 & 0,11 & Amarelo fosco \\
NPK - V & 66,0 & 0,07 & Amarelo escuro \\
\hline
\end{tabular}

${ }_{\mathrm{BL}+\mathrm{EB}}$ Bagaço de laranja + Esterco Bovino; ${ }^{\mathrm{TF}+\mathrm{EB}}$ Torta de filtros + Esterco Bovino; ${ }^{\mathrm{EB}}$ Esterco bovino. Doses: 1,5, 3,0 e 4,0 \% do volume do vaso. *As letras $L$ e $V$ apresentadas em frente ao nome dos tratamentos, são referentes ao solo em que o manjericão foi cultivado, sendo L: latossolo e V: vertissolo. $\mathrm{MSF}=$ Matéria seca de folhas, Test $=$ testemunha.

Para as amostras de óleos essenciais nas quais foi possível realizar a análise cromatográfica, foi constatado que dentre as substâncias que se apresentam como majoritárias estão: o linalol, o epi-alfa-cadinol, o alfa acoradieno e o gama-cadineno (Figura 9 - III e Tabela 5 - III).

Carvalho Filho et al. (2006) também verificaram que o linalol (68\%) é o principal compostos presente nas folhas e inflorescências de Ocimum basilicum L. Fernandes et al. (2004) verificaram o linalol, o alfa-trans-bergamoteno, o germacreno D e o gamacadineno como substâncias majoritárias no óleo essencial do manjericão. A localização geográfica, época da coleta, forma de cultivo, condições climáticas, idade 
do material vegetal, período e condições de armazenamento podem influenciar o teor em extrato e o perfil químico de óleos essenciais/extratos de plantas (BLANCO et al., 2000; FARIAS, 1999).

Figura 9 - III. Cromatograma do óleo essencial de Manjericão (Ocimum basilicum L.)

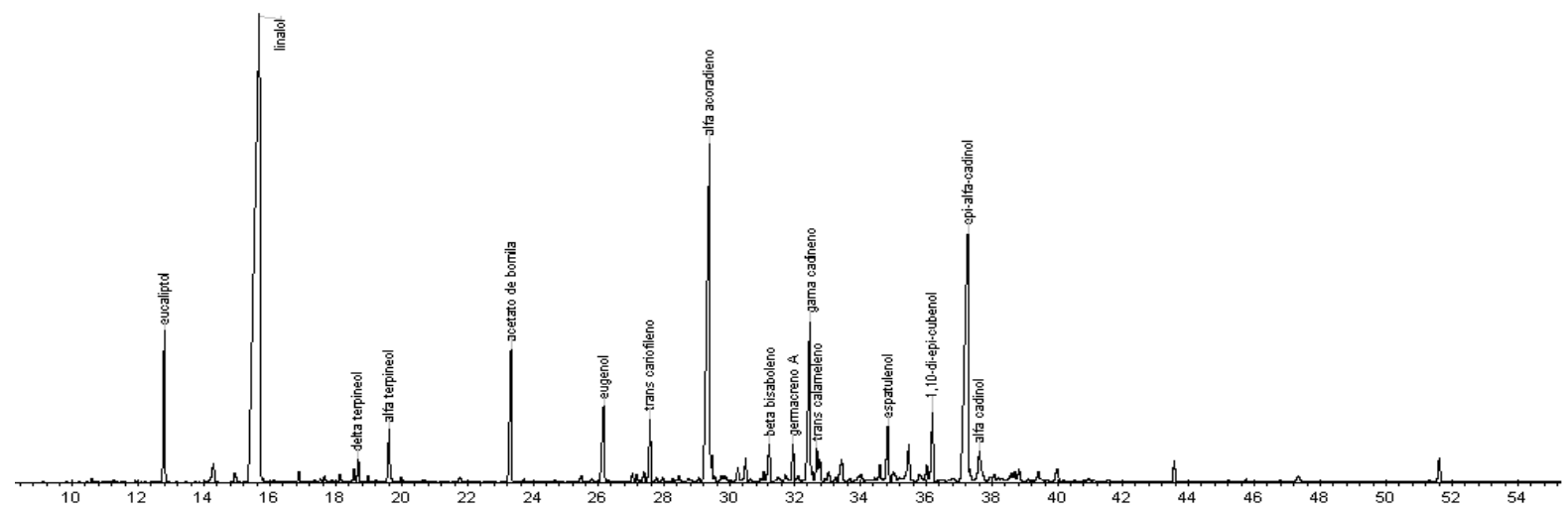

Pode-se observar uma tendência de aumento no teor de linalol de acordo com o aumento da dosagem de vermicomposto aplicada, tanto para as plantas cultivadas em latossolo quanto em vertissolo (Tabela 5 - III). Para o latossolo, constatou-se um aumento de $20,28 \%$ para $31,58 \%$ com o aumento da dosagem de vermicomposto de torta de filtro + esterco bovino de 30 para $40 \mathrm{t} \mathrm{ha}^{-1}$. Para o tratamento $\mathrm{BL}+\mathrm{EB} 15 \mathrm{t}$ ha $^{-1}$ em latossolo, o teor de linalol foi de $17,99 \%$. Para as plantas cultivadas em vertissolo, fica evidente a mesma tendência de aumento do teor de linalol devido ao aumento da dosagem de vermicomposto aplicado independente de sua origem. Constatou-se um aumento de $18,48 \%$ para $28,28 \%$ com o aumento da dosagem de vermicomposto de bagaço de laranja + esterco bovino de 30 para $40 \mathrm{t} \mathrm{ha}^{-1} \mathrm{e}$ um aumento de 6,85\% para 34,9\% com o aumento da dosagem de vermicomposto de torta de filtro + esterco bovino de 15 para $30 \mathrm{t} \mathrm{ha}^{-1}$. Para o vermicomposto de esterco bovino puro a mesma tendência não foi observada. Houve uma diminuição de $28,64 \%$ para $26,05 \%$ com o aumento da dosagem de 30 para 40 t ha ${ }^{-1}$. É importante salientar que todos os tratamentos referentes à adubação orgânica analisados apresentaram aumento considerável no teor de linalol quando comparados ao 
tratamento testemunha. Em contrapartida, o tratamento referente à adubação mineral em vertissolo resultou na redução de $6,37 \%$ para $1,97 \%$ o teor de linalol. 
Tabela 5 - III. Composição do óleo essencial (compostos identificados e seus respectivos teores em porcentagem) extraído das folhas do manjericão (Ocimum basilicum L.) de acordo com os diferentes tratamentos de adubação em latossolo e vertissolo

\begin{tabular}{|c|c|c|c|c|c|c|c|c|}
\hline $\begin{array}{l}\text { COMPOSTOS } \\
\text { IDENTIFICADOS }\end{array}$ & BL+EB 1,5 - L & TF+EB 3,0 - L & $\mathrm{TF}+\mathrm{EB} 4,0$ - L & EB 4,0 - L & $B L+E B ~ 3,0-V$ & $B L+E B \quad 4,0-V$ & TF+EB 1,5 - V & TF+EB 3,0 - V \\
\hline Eucaliptol & 2,07 & 0,72 & 3,07 & 0,18 & 2,80 & 5,07 & 1,10 & 9,29 \\
\hline Linalol & 17,99 & 20,28 & 31,58 & 1,11 & 18,43 & 28,28 & 6,85 & 34,90 \\
\hline Delta terpineol & Não detectada & 0,27 & 0,47 & 0,07 & 0,02 & 0,19 & 0,16 & 0,29 \\
\hline Alfa terpineol & 1,20 & 1,36 & 1,3 & 0,34 & 0,86 & 0,94 & 0,81 & 1,51 \\
\hline Acetato de bornila & 2,04 & 2,18 & 3,38 & 0,4 & 2,87 & 1,81 & 1,23 & 3,38 \\
\hline Eugenol & 1,10 & 2,00 & 2,32 & 1,22 & 1,62 & 0,92 & 2,41 & 2,06 \\
\hline Trans cariofileno & 2,24 & 1,28 & 1,48 & 1,39 & 1,88 & 1,93 & 1,8 & 1,21 \\
\hline Alfa acoradieno & 8,24 & 14,54 & 13,6 & 12,45 & 12,19 & 11,08 & 9,75 & 9,64 \\
\hline Beta bisaboleno & 0,65 & 1,39 & 1,08 & 1,38 & 0,89 & 0,75 & 0,76 & 0,61 \\
\hline Germacreno A & 1,71 & 1,11 & 0,94 & 1,23 & 0,68 & 0,7 & 0,73 & 0,49 \\
\hline Gama cadineno & 6,69 & 6,81 & 5,01 & 8,49 & 5,60 & 4,97 & 7,00 & 3,46 \\
\hline Trans calameleno & 0,77 & 1,19 & 0,8 & 1,34 & 1,16 & 0,89 & 1,27 & 0,67 \\
\hline espatulenol & 2,1 & 2,11 & 1,54 & 2,51 & 2,14 & 1,33 & 2,88 & 1,33 \\
\hline 1,10-di-epi-cubenol & 2,72 & 2,54 & 1,85 & 3,22 & 2,55 & 2,13 & 3,19 & 1,55 \\
\hline epi-alfa cadinol & 16,06 & 15,33 & 11,04 & 20,14 & 15,13 & 11,83 & 18,88 & 9,3 \\
\hline alfa cadinol & 1,34 & 1,75 & 1,26 & 2,34 & 2,10 & 1,17 & 1,51 & 0,96 \\
\hline SOMAÓRIA & 66,92 & 74,86 & 80,72 & 57,81 & 70,92 & 73,99 & 60,33 & 80,65 \\
\hline DESCONHECIDO & 33,08 & 25,14 & 19,28 & 42,19 & 29,08 & 26,01 & 39,67 & 19,35 \\
\hline
\end{tabular}




\begin{tabular}{|c|c|c|c|c|c|}
\hline $\begin{array}{l}\text { COMPOSTOS } \\
\text { IDENTIFICADOS }\end{array}$ & $T F+E B$ 4,0 - V & EB 3,0 - V & EB 4,0 - V & Test - V & NPK - V \\
\hline Eucaliptol & 5,41 & 6,35 & 5,62 & 0,57 & 0,30 \\
\hline Linalol & 28,5 & 28,65 & 26,05 & 6,37 & 1,97 \\
\hline Delta terpineol & 0,26 & 0,3 & 0,3 & 0,11 & 0,11 \\
\hline Alfa terpineol & 1,47 & 1,45 & 1,53 & 0,84 & 0,57 \\
\hline Acetato de bornila & 1,99 & 4,15 & 4,37 & 1,76 & 0,5 \\
\hline Eugenol & 1,95 & 1,95 & 2,51 & 1,75 & 2,81 \\
\hline Trans cariofileno & 2,3 & 1,42 & 1,96 & 1,52 & 1,16 \\
\hline Alfa acoradieno & 9,64 & 9,19 & 9,09 & 14,00 & 6,21 \\
\hline Beta bisaboleno & 0,62 & 0,6 & 0,59 & 0,99 & 0,56 \\
\hline Germacreno A & 0,53 & 0,54 & 0,57 & 0,82 & 0,77 \\
\hline Gama cadineno & 4,59 & 4,27 & 4,74 & 6,96 & 7,12 \\
\hline Trans calameleno & 1,06 & 0,89 & 0,89 & 1,61 & 1,29 \\
\hline & 1,84 & 1,69 & 2,1 & 2,46 & 3,51 \\
\hline 1,10-di-epi-cubenol & 2,36 & 2,1 & 2,29 & 2,96 & 4,02 \\
\hline epi-alfa cadinol & 14,31 & 12,88 & 13,6 & 17,22 & 22,59 \\
\hline alfa cadinol & 1,15 & 1,33 & 0,94 & 2 & 2,56 \\
\hline SOMA & 77,98 & 77,76 & 77,15 & 61,94 & 56,05 \\
\hline DESCONHI & 22,02 & 22,24 & 22,85 & 38,06 & 43,95 \\
\hline
\end{tabular}

$\widehat{{ }^{B L+E B}}$ Bagaço de laranja + Esterco Bovino; ${ }^{\mathrm{TF}+\mathrm{EB}}$ Torta de filtros + Esterco Bovino; ${ }^{\mathrm{EB}}$ Esterco bovino. Doses: 15,30 e $40 \mathrm{t}$ ha ${ }^{-1}$ do volume do vaso. ${ }^{\mathrm{A}} \mathrm{As}$ letras $\mathrm{L}$ e $\mathrm{V}$ apresentadas em frente ao nome dos tratamentos, são referentes ao solo em que o manjericão foi cultivado, sendo L: latossolo e V: vertissolo. 
Analisando os dados do rendimento de óleo essencial de manjericão sob doses de cama de frango, Morais (2006) verificou que não houve diferença estatística para ambos os genótipos de Ocimum basilicum L., com a adição de doses crescentes de adubo orgânico. Segundo Chaves (2002), não há na literatura um consenso em relação à resposta do rendimento de óleo essencial frente ao uso de tipos de adubos e muito menos de doses. Mas existem relatos de que adubação orgânica com composto influenciou positivamente e aumentou o rendimento de óleo essencial de Achillea millefolium (SCHEFFER, 1998). Chaves (2002) verificou que o teor de óleo essencial de Ocimum basilicum aumentou com quatro NPK, ou com NPK adicionado ao esterco de aves em O. basilicum (SILVA et al., 2001) 


\section{CONCLUSÕES}

Após 60 dias do transplante das mudas de manjericão aos vasos, observouse influência positiva no crescimento e na produção de matéria seca de folhas devido ao aporte de matéria orgânica transformada ao solo.

Com os resultados dos diferentes arranjos de dados para análise estatísticas, foi possível identificar qual o melhor vermicomposto produzido em função de cada atributo químico analisado. Os vermicompostos oriundos das misturas de esterco bovino com resíduos industriais (bagaço de laranja ou torta de filtro) apresentam-se, em geral, como melhores propostas, pois foi impossível observar um incremento nos teores nutricionais dos vermicompostos finais comparados ao vermicompoto de esterco bovino puro.

Foi possível conduzir o cultivo de Manjericão para dois solos com características físicas e químicas bastante diferentes, o que refletiu nos resultados das análises biométricas. Para o latossolo foi possível observar significativa influência do aporte de matéria orgânica nos atributos avaliados neste período. As plantas referentes aos tratamentos com vermicomposto oriundo da mistura de esterco bovino e torta de filtro, apresentaram maior crescimento com relação às plantas do tratamento testemunha, e o crescimento das plantas referentes aos demais tratamentos de adubação orgânica, em geral, apresentaram resultados estatisticamente iguais ao TF+EB. Para o atributo altura e produção de biomassa, não foi possível observar uma tendência de aumento ou diminuição de acordo com o aumento de dose de vermicomposto aplicado. Em geral o desenvolvimento das plantas que receberam adubação orgânica foi similar ao desenvolvimento das plantas que receberam adubação mineral comercialmente recomendada e significativamente superior ao das plantas referente ao tratamento testemunha. Para $\circ$ vertissolo $\circ$ efeito dos vermicompostos sobre os atributos altura e biomassa das plantas foi mascarado, possivelmente pelo alto teor de matéria orgânica naturalmente existente naquele solo.

A análise cromatográfica do óleo essencial extraído do Manjericão mostrou 
que a adubação orgânica influenciou positivamente a produção do principal componente do óleo essencial, o linalol, havendo aumento de seu teor com o aumento da dosagem de vermicomposto aplicado, nos dois solos estudados. Dos tratamentos analisados, o referente à adubação com vermicomposto de torta de filtro + esterco bovino $30 \mathrm{t} \mathrm{ha}^{-1}$, em vertissolo, proporcionou ao manjericão produzir o maior teor de linalol $(34,90 \%)$. 
ADAMS, R. P. Identification of Essential Oil Components by Gas Chromatography/Mass Spectrometry. Gruver, TX: Carol Stream, 2007. 803 p.

BEZERRA, A.M.E.; NASCIMENTO-JÚNIOR, F. T.; LEAL, F. R.; CARNEIRO, J. G.M. Rendimento de biomassa, óleo essencial, teores de fósforo e potássio de chambá em resposta à adubação orgânica e mineral. Revista Ciência Agronômica, v. 37, n. 2, p.124-129, 2006.

BLANCO, M.C.S.G, MING, L.C., MARQUES, M.O.M., BOVI, O.A. Influência da temperatura de secagem no teor e na composição química do óleo essencial de menta. Horticultura Brasileira, Brasília, v. 8, p. 901-903, 2000.

BLANK, A.F.; FONTES, S.M.; OLIVEIRA, A.S.; MENDONÇA, SILVA-MANN, R.; ARRIGONI-BLANK, M.F. Produção de mudas, altura e intervalo de corte em melissa. Horticultura Brasileira, Brasília, v. 23, n. 3, p. 780-784, 2005.

CARVALHO FILHO, J.L.S.; BLANK, A.F.; ALVES, P.B.; EHLERT, P.A.D.; MELO, A.S.; CA V ALCANTI, S.C.H.; ARRIGONI-BLANK, M.F.; SILV A-MANN, R. Influence of the harvesting time, temperature and drying period on basil (Ocimum basilicum L.) essential oil. Revista Brasileira de Farmacognosia, João Pessoa, v. 16, n. 4, p. 2430, 2006.

CHAVES, F.C.M. Produção de biomassa, rendimento e composição de óleo essencial de alfavaca-cravo (Ocimum gratissimum L.) em função da adubação orgânica e épocas de colheita. 2002.144 f. Tese (Doutorado) - Faculdade de Ciências Agronômicas, Universidade Estadual Paulista, Faculdade de Ciências Agronômicas. Botucatu-SP, 2002.

CORRÊA JÚNIOR, C. Influência das adubações orgânica e química na produção de camomila (Chamomilla recutita L. Rauschert) e do seu óleo essencial. In: MING, L.C. Plantas medicinais, aromáticas e condimentares: avanços na pesquisa agronômica. Botucatu: UNESP, 1998. v.1, p.130-164. 
FARIAS, M. R. Farmacognosia da planta ao medicamento. In: SIMÕES, C. M. O.; SCHENKEL, E. P.; GOSMANN, G.; MELLO, J. C. P.; MENTZ, L. A.; PETROVICK, P. R. (Ed.). Avaliação da qualidade de matéria primas vegetais. 5.ed. Porto Alegre: UFSC, UFRGS, 1999, p. 197-220.

GUENTHER, E. The essential oils. Malabar: Krieger, 1972. 427 p.

MAIA, S.S.S. Propagação, adubação orgânica e níveis de radiação nas características anatômicas e composição de óleo essencial em Hyptis suaveolens (L.) Poit. (Lamiaceae). 2006. 105 f. Tese (Doutorado em Agronomia/ Fitotecnia) - Curso de Pós-graduação em Agronomia, Universidade Federal de Lavras, Lavras, 2006.

McLAFFERTY, F. W.; STAUFFER, D.B. The Willey / NBS registry of mass spectral data. New York: John Willey, 1989. v. 1-6.

MINISTÉRIO DA AGRICULTURA, PECUÁRIA E ABASTECIMENTO. Regras para análise de sementes. Brasília, DF: Mapa/ACS, 2009. 395 p.

MORAIS, T. P. S. Produção e composição do óleo essencial de manjericão (Ocimum basilicum I.) sob doses de cama de frango. 2006. 38 f. Dissertação (Mestrado em Fitotecnia) - Universidade Federal de Uberlândia, Uberlândia, 2006.

SCHEFFER, M.C. Influência da adubação orgânica sobre a biomassa, rendimento e a composição do óleo essencial de Achillea millefolium L. - mil folhas. In: MING, L.C. (Org.) Plantas Medicinais, aromáticas e condimentares: avanços na pesquisa agronômica. Botucatu: Universidade Estadual Paulista, 1998. v. 2, p. 1-22.

SIMON, J. E. Basil. West Lafayette: Purdue University, 1995. 6 p.

SILVA, P.A.; BLANK, A.F.; ARRIGONI-BLANK, M.F.; ALVES, P.B.; SANTOS NETO, A L.; CARVALHO FILHO, J.L.S.; AMANCIO, V.F. Efeito da adubação mineral e orgânica e do horário de colheita em manjericão-doce. Horticultura Brasileira, v.19, suplemento, 2001. (Editado em CD-ROM).

SILVA, F.; SANTOS, R.H.S.; ANDRADE, N.J.; BARBOSA, L.C.A.; CASALI, V.W.D.; LIMA, R.R.; PASSARINHO, R.V.M. Basil conservation affected by cropping season, harvest time and storage period. Pesquisa Agropecuária Brasileira, Brasília, v. 40, n. 4, p. 323-328, 2005. 


\section{CAPÍTULO IV}

CARACTERIZAÇÃO QUÍMICA E ESPECTROSCÓPICA DO SOLO PÓS-CULTIVO DE MANJERICÃO (Ocimum basilicum L.)

AVALIAÇÃO DA INFLUÊNCIA DA ADUBAÇÃO ORGÂNCIA COM VERMICOMPOSTO NA MATÉRIA ORGÂNICA DO SOLO 



\section{LISTA DE FIGURAS}

Figura 1 - IV. Distribuição ambiental da matéria orgânica do solo (LANDGRAF et al., 2005) 171

Figura 2 - IV. Modelo macromolecular de ácido húmico mostrando os diversos grupos funcionais, estruturas aromáticas e alifáticas, adaptado por Schulten \& Schnitzer (1993) 173

Figura 3 - IV. Modelo conceitual proposto pela teoria macromolecular: ácido húmico proposto por Schulten e Schnitzer (1997), carbono = azul; oxigênio = vermelho; nitrogênio $=$ preto e hidrogênio $=$ branco. As letras $A, B$ e C indicam os espaços "vazios" presentes na molécula das substâncias húmicas capazes de interagir com outros compostos 174

Figura 4 - IV. Esquema das substâncias húmicas proposto por Simpson et al. (2002b). As unidades vermelhas representam os cátions metálicos, as unidades pretas os polissacarídeos, as unidades azuis os polipeptídios, as unidades verdes as cadeias alifáticas e as unidades marrons os fragmentos aromáticos provenientes da lignina

Figura 5 - IV. Fracionamento químico e purificação dos ácidos húmicos. 179

Figura 6 - IV Espectro de NIRS de solos afetados por diferentes ocorrências de fogo. Traduzida de: Vergnoux et al., 2009 182

Figura 7 - IV. Gráfico de Scree (Scree Plot) (a), Importância das Variáveis (b), Scores (c) e Loadings (d), para os 22 tratamentos em Latossolo e Vertissolo

Figura 8 - IV. Gráfico de Importância das Variáveis de cada PC, para os 22 tratamentos em Latossolo e Vertissolo 194

Figura 9 - IV. Gráfico Scores e Loadings da PC1 x PC3 (a, b), PC1 x PC4 (c, d), PC2 x PC3 (e, f), PC2 x PC4 (g, h) e PC3 x PC4 (i, j), para os 22 tratamentos em latossolo 
e vertissolo

Figura 10 - iV. Gráfico de Scree (Scree Plot) (a) e Importância das Variáveis (b), para os 11 tratamentos em vertissolo

Figura 11 - IV. Gráfico de Importância das Variáveis de cada PC, para os 11 tratamentos em vertissolo .198

Figura 12 - IV. Gráfico de Scores (a) e Loadings (b) de PC1 x PC2, para os 11 tratamentos em vertissolo

Figura 13 - IV. Gráfico de Scores (a) e Loadings (b) de PC1 x PC3, para os 11 tratamentos em vertissolo 200

Figura 14 - IV. Gráfico de Scree (Scree Plot) (a) e Importância das Variáveis (b), para os 11 tratamentos em latossolo 201

Figura 15 - IV. Gráfico de Importância das Variáveis de cada PC, para os 11 tratamentos em latossolo 202

Figura 16 - IV. Gráfico de Scores (a) e Loadings (b) de PC1 x PC2, para os 11 tratamentos em latossolo 203

Figura 17 - IV. Espectros de absorbância em infravermelho próximo das amostras de Latossolo (dados brutos) (a) Espectros de absorbância em infravermelho próximo das amostras de Vertissolo (dados brutos) 206

Figura 18 - IV. Espectros de NIRS dos latossolos (a) e vertissolos (b) com aplicação da Correção Multiplicativa de Sinal. Seleção das regiões de maior peso estatístico para realização da PCA nos espectros de NIRS dos Latossolos (c) Vertissolos (d)...207

Figura 19 - IV. Gráfico de Autovalores (Scree Plot) para os dados brutos dos latossolos (a) e vertissolos (b) .208

Figura 20 - IV. Gráficos de Loadings da PC1 e PC2 (a e b) e Gráfico de Scores PC1 x PC2 (c) para os 11 tratamentos em latossolos 
Figura 21 - IV. Gráficos de Loadings da PC1 e PC3 (a e b) e Gráfico de Scores PC1 x PC3 (c) para os 11 tratamentos em latossolos

Figura 22 - IV. Gráficos de Loadings da PC2 e PC3 (a e b) e Gráfico de Scores PC1 x PC3 (c) para os 11 tratamentos em latossolos 212

Figura 23 - IV. Gráfico de Scores PC1 x PC2 x PC3 para os 11 tratamentos em latossolo.

Figura 24 - IV. Gráficos de Loadings da PC1 e PC2 (a e b) e Gráfico de Scores PC1 x PC2 (c) para os 11 tratamentos em vertissolo .214 



\section{LISTA DE TABELAS}

Tabela 1 - IV. Bandas de absorção das vibrações de estiramento dos principais grupos funcionais no espectro no infravermelho próximo $\left(\mathrm{cm}^{-1}\right)$. Adaptada de: Workman, (1998) 183

Tabela 2 - IV. Composição granulométrica, pH, CTC e \% C do latossolo utilizado no cultivo de Manjericão 189

Tabela 3 - IV. Composição granulométrica, pH, CTC e \% C do vertissolo 190

Tabela 4 - VI. Teor de C (\%) dos solos pós-cultivo de Manjericão (Ocimum basilicum L.) para os diferentes tratamentos de adubação orgânica 192

Tabela 5 - IV. Teor de C e N, razão C/N, Hidrofobicidade $\left(\mathrm{I}_{2927} / \mathrm{l}_{1059}\right)$, Aromaticidade $\left(\mathrm{I}_{1660} / \mathrm{I}_{2929}\right)$ e $\mathrm{E}_{4} / \mathrm{E}_{6}$ dos ácidos húmicos extraídos dos solos pós-cultivo de manjericão (Ocimum basilicum L.) 216 



\section{INTRODUÇÃO}

\subsection{Matéria Orgânica do Solo}

Por atuar em várias propriedades físicas, químicas e biológicas do solo, a matéria orgânica do solo (MOS) é importante constituinte do ecossistema e fundamental para seu adequado funcionamento (DICK et al., 2009).

Existem várias definições diferentes para a matéria orgânica do solo. Segundo a Encyclopedia of Soil Science (2006), a definição para MOS consiste em: todos os derivados de materiais vegetais e animais incorporados ao solo ou dispostos sobre sua superfície, na forma viva ou nos vários estágios de decomposição, mas exclui-se a parte aérea das plantas. Segundo Dick et al. (2009), o conceito de matéria orgânica do solo é tema de discussão na comunidade científica e, por ainda não estar consensualmente definido, autores ou grupos de pesquisadores demonstraram entendimentos distintos dos que seja MOS.

A matéria orgânica de solos, bem como de águas naturais, sedimentos, turfas e produtos de compostagem, incluindo o vermicomposto, é constituída basicamente de substâncias húmicas (SH) e substâncias não húmicas (LANDGRAF et al., 2005).

As substâncias não húmicas como proteínas e aminoácidos, carboidratos simples e complexos, resinas, ligninas, e outros, são produtos da decomposição dos resíduos orgânicos e do metabolismo microbiano. Essas macromoléculas constituem, aproximadamente, 10 a $15 \%$ do total do carbono orgânico nos solos minerais. As substâncias húmicas propriamente ditas, constituem 85 a $90 \%$ da reserva total do carbono orgânico (KONONOVA, 1982; ANDREUX, 1996). São macromoléculas ou estruturas supramoleculares, com massa molecular e estrutura variáveis. São produtos de degradação química e microbiológica de resíduos de animais e plantas (LANDGRAF et al., 2005). 


\subsection{Conceito e Classificação da Matéria Orgânica do Solo}

Quimicamente, o húmus consiste de materiais originários de plantas e animais que passaram por um processo de decomposição, via hidrólise, oxidação, redução e síntese por microrganismos. O húmus tem um importante papel na formação de agregados do solo, no controle da acidez, no ciclo dos elementos nutrientes, assim como na descontaminação de compostos indesejáveis. O húmus compreende as biomoléculas, tais como aquelas exemplificadas como substâncias não húmicas, e as substâncias húmicas (SH), grosso modo, são compostos de coloração escura, persistentes, poliméricos e amorfos (LANDGRAF et al., 2005). De modo geral, é aceita a distribuição das frações humificadas em três categorias: as huminas $(H)$ que representam a matéria orgânica intimamente ligada à fração mineral do solo, e por isso insolúvel; os ácidos fúlvicos (AF), que apresentam grande quantidade de grupamentos funcio- nais oxigenados e são solúveis tanto em meio ácido como básico, e os ácidos húmicos $(\mathrm{AH})$, insolúveis em meio fortemente ácido, pois, com a protonação dos grupamentos funcionais ocorre o colapso da estrutura e precipitação das macromoléculas. Os $\mathrm{AH}$ representam a fração reativa mais estável da matéria orgânica humificada (CANELLAS et al., 2001).

As substâncias húmicas são o principal componente da matéria orgânica dos solos, das águas e dos sedimentos sendo assim cruciais para o ciclo global de carbono (NARDI et al., 2002, IKEYA et al., 2011). Ainda segundo Nardi et al., (2002) além de influenciar as propriedades químicas, físicas e biológicas das plantas, determinando a produção biológica dos ecossistemas, elas exercem efeito direto sobre o crescimento e metabolismo das plantas, especialmente sobre o desenvolvimento radicular.

Em síntese, pode-se conceituar SH como aquela parte da $\mathrm{MO}$ ou, particularmente, do húmus que, após várias transformações, permanece no ambiente, consistindo de uma mistura heterogênea, polifuncional, sem características químicas e físicas definidas e em diferentes graus de polidispersão 
(LANDGRAF et al., 2005). A Figura 1 - IV apresenta esquematicamente a distribuição da matéria orgânica no ambiente.

Figura 1 - IV. Distribuição ambiental da matéria orgânica do solo (LANDGRAF et al., 2005)

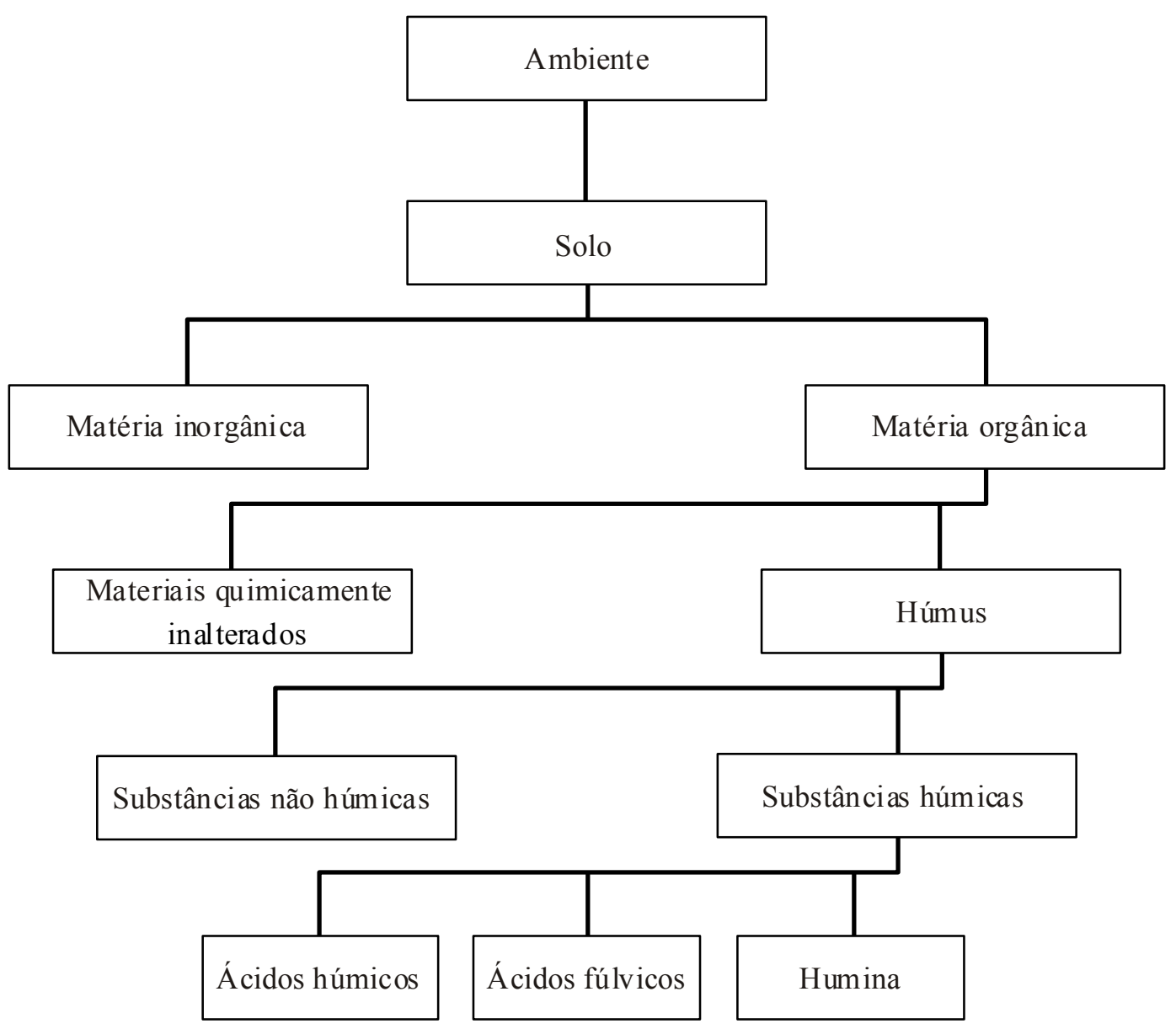

No processo de humificação ocorre a transformação de reservas macromorfologicamente identificáveis em compostos húmicos amorfos. As principais transformações que ocorrem durante a humificação são a perda de polissacarídeos e compostos fenólicos, modificação das estruturas de lignina, e enriquecimento em estruturas aromáticas não lignínicas recalcitrantes. A humificação bem como a decomposição de resíduo, é mediada primeiramente por processo microbiológico, controlado principalmente por variáveis locais específicas, tais como, 
temperatura, regime de água no solo, $\mathrm{pH}$ e disponibilidade de nutrientes. Durante o processo de humificação ocorre um aumento nos grupos C-carboxílicos, Caromáticos e C-alquil, principalmente fenólicos, e a diminuição de grupos O-alquil (ZECH et al., 1997). Segundo Kononova (1984), os produtos formados da degradação de química e biológica de resíduos (animais e vegetais) e da atividade sintética da biota do solo, associam-se em estruturas químicas complexas, atingindo maior estabilidade do que os materiais que o originaram. Parte do material húmico poderá sofrer degradação ou mineralização, dando origem a moléculas simples, que podem ser utilizadas pela biota do solo (KONONOVA, 1984).

Os caminhos pelos quais as substâncias húmicas são formadas são inúmeros, devido à grande quantidade de possíveis estruturas precursoras e ao enorme número de possibilidades de interação entre elas. Essa variedade de materiais de origem e o consequente número de caminhos reacionais possíveis para a formação do húmus são a razão para as dificuldades em se estabelecer uma estrutura precisa para os ácidos húmicos, ácidos fúlvicos e humina (Stevenson, 1994). O modelo estrutural das substâncias húmicas é tema de discussão científica. Ainda não existe um modelo estrutural para as substâncias húmicas que explique totalmente a composição química, a estrutura, a forma e o tamanho, sendo que os modelos existentes geram controvérsias e discussões (CLAPP; HAYES, 1999; BURDON, 2001; HAYES E CLAPP, 2001; MACCARTHY, 2001; PICCOLO, 2001). Entretanto, as similaridades entre diversas substâncias húmicas são mais pronunciadas que suas diferenças. São essas semelhanças que permitem a classificação das substâncias húmicas em categorias com base em sua solubilidade em meio aquoso: ácido húmico, ácido fúlvico e humina (LANDGRAF et al., 2005).

Há alguns anos, estruturas basicamente aromáticas eram as mais aceitas (KONONOVA, 1966; SCHNITZER; 1878; STEVENSON, 1994). Contudo, devido principalmente ao uso da técnica de espectroscopia de ressonância magnética nuclear, verificou-se que o grau de aromaticidade era muito menor do que o esperado, e Schulten \& Schnitzer (1993) propuseram uma estrutura de ácido húmico, incorporando grandes porções alifáticas (Figura 2 - IV). 
Figura 2 - IV. Modelo macromolecular de ácido húmico mostrando os diversos grupos funcionais, estruturas aromáticas e alifáticas, adaptado por Schulten \& Schnitzer (1993)

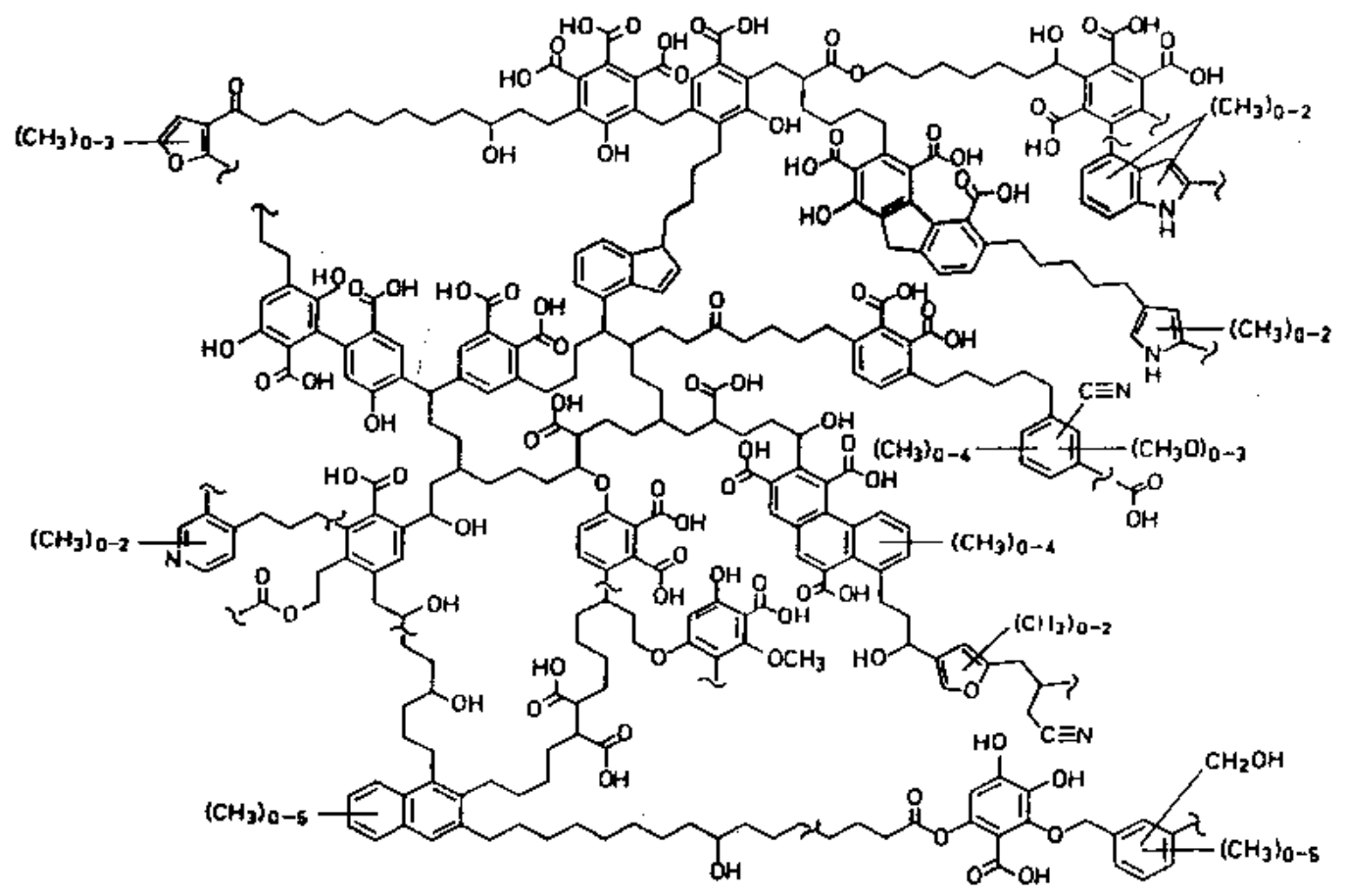

O modelo para ácidos húmicos proposto por Schulten \& Schnitzer (1993) apresenta longas cadeias alifáticas, grupos $\mathrm{OH}$ fenólicos livres e ligados, estruturas de quinona, oxigênio presente como grupos carboxílicos, fenólicos, hidroxílicos, ésteres e éteres, nitrogênio presente como estruturas heterocíclicas e como nitrilas. A composição elementar da estrutura do ácido húmico é $\mathrm{C}_{308} \mathrm{H}_{328} \mathrm{O}_{90} \mathrm{~N}_{5}$. Pressupunhase que as substâncias húmicas seriam macromoléculas orgânicas, com características similares às macromoléculas biológicas como, proteínas, polissacarídeos, ácidos nucléicos e lignina (SWIFT, 1989).

Nos modelos recentemente propostos (SCHULTEN \& SCHNITZER, 1997), têm-se observado que a estrutura de ácidos húmicos contém espaços vazios de diferentes tamanhos, onde poderiam alojar-se outros compostos orgânicos, hidrofílicos ou hidrofóbico, como carboidratos e materiais proteináceos, lipídios, agrotóxicos e outros poluntes (Figura 3 - IV). Elementos inorgânicos também poderiam estar presentes, como por exemplo, argilas e óxidos e hidróxidos 
(SCHULTEN \& SCHNITZER, 1997), o que foi corroborado pelo trabalho de Wandruska (1998), que definiu a estrutura das substâncias húmicas como uma estrutura pseudomicelar de natureza polimérica. A Figura 3 - IV apresenta uma proposta de estrutura tridimensional, tomando-se por base a macromolécula da Figura 2 - IV, obtida a partir de modelagem molecular.

Figura 3 - IV. Modelo conceitual proposto pela teoria macromolecular: ácido húmico proposto por Schulten e Schnitzer (1997), carbono = azul; oxigênio = vermelho; nitrogênio = preto e hidrogênio = branco. As letras A, B e C indicam os espaços "vazios" presentes na molécula das substâncias húmicas capazes de interagir com outros compostos

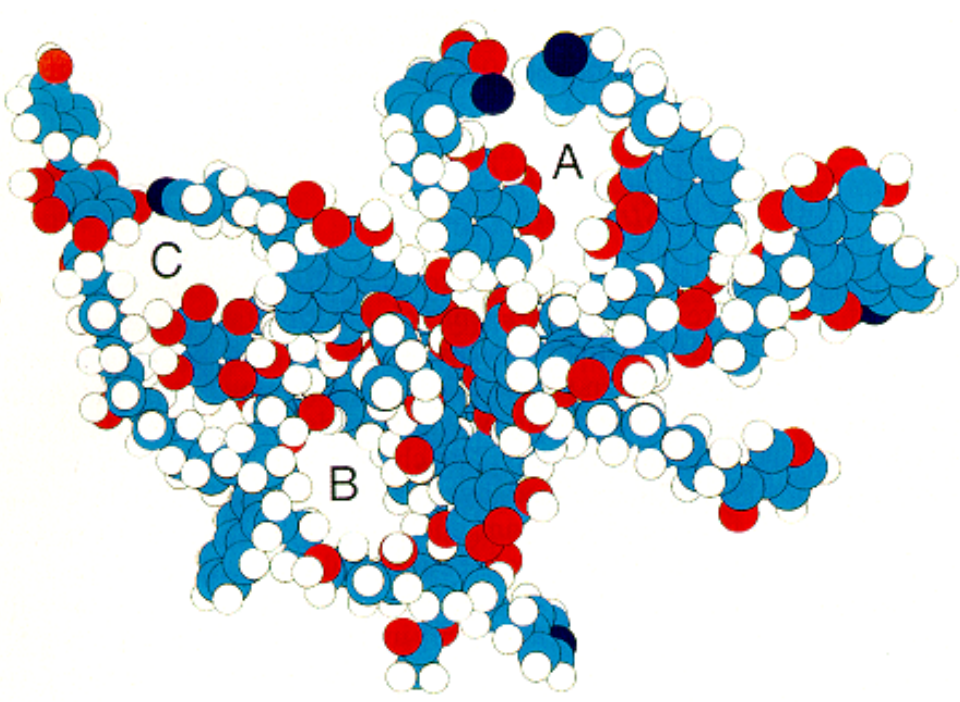

Diallo et al. (2003), por meio de métodos computacionais e também utilizando dados experimentais, excluíram os modelos que sugerem que as substâncias húmicas sejam macromoléculas com alta massa molar ou a mistura de compostos orgânicos complexos e heterogêneos e observaram que as estruturas existentes possuem as características necessárias para formar supramoléculas. O modelo supramolecular apresentado na Figura 4 - IV permitiu grande avanço no entendimento estrutural das substâncias húmicas, porém ainda apresenta várias limitações (CLAPP; HAYES, 1999; BURDON, 2001; HAYES; CLAPP, 2001; MACCARTHY, 2001; PICCOLO, 2001). 
Figura 4 - IV. Esquema das substâncias húmicas proposto por Simpson et al. (2002b). As unidades vermelhas representam os cátions metálicos, as unidades pretas os polissacarídeos, as unidades azuis os polipeptídios, as unidades verdes as cadeias alifáticas e as unidades marrons os fragmentos aromáticos provenientes da lignina

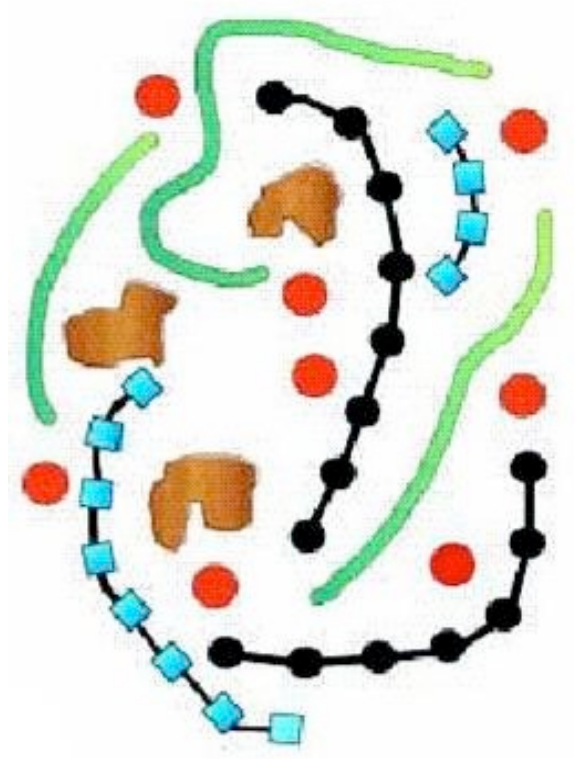

A heterogeneidade química das substâncias húmicas dificulta a definição de um modelo para as mesmas que englobe composição, estrutura, tamanho e reatividade, sendo que há uma variabilidade desta heterogeneidade de acordo com a origem (ecossistemas aquáticos ou terrestres) ou da localização geográfica (SIMÕES, 2005). Segundo os autores Sutton \& Sposito (2005), entende-se que o modelo que melhor descreve essas propriedades é aquele que propõe que as substâncias húmicas são agrupamentos de diversos componentes de relativamente baixa massa molecular formando associações dinâmicas estabilizadas por interações hidrofóbicas e ligações de hidrogênio.

O nível de agregação das $\mathrm{SH}$ depende da estrutura molecular em si e das condições dos meios (força iônica, pH e presença ou não de íons metálicos). Sendo assim, o comportamento das SH com relação a diferentes valores de pH é de suma importância (BAALOUSHA et al., 2006). Segundo Helal et al., (2011) os ácidos húmicos, fúlvicos e humina devem ser individualmente considerados um conjunto de moléculas de diferentes tamanhos que, dentre as quais, poucas apresentam a mesma configuração estrutural ou arranjo de grupos funcionais reativos. 
A reatividade química das $\mathrm{SH}$ é devida, principalmente, a quatro características estruturais (polifuncionalidade, carga macromolecular, hidrofilicidade, labilidade estrutural). Tais propriedades a respeito das $\mathrm{SH}$ são semelhantes a propriedades de outros biopolímeros, como proteínas e polissacarídeos. Contudo, no caso das $\mathrm{SH}$ refletem o comportamento de uma mistura heterogênea de moléculas interagindo entre si, ao invés do comportamento de um único tipo de macromolécula, estruturalmente bem definida (LANDGRAF et al., 2005):

i. Polifuncionalidade: presença de vários grupos funcionais, com reatividade diferente, representativos de uma mistura heterogênea de polímeros que interagem entre si.

ii. Carga macromolecular: caráter aniônico do arranjo molecular, cujos efeitos refletem na reatividade dos grupos funcionais e na conformação molecular.

iii. Hidrofilicidade: reflete-se na tendência que têm as $\mathrm{SH}$ de formarem ligações de hidrogênio com as moléculas da água do meio, solvatando, dessa maneira, grupos funcionais como $\mathrm{COOH}$ e OH.

iv. Labilidade estrutural: devido à capacidade de associações intermoleculares e de mudanças conformacionais em resposta a mudanças de $\mathrm{pH}$, condições redox, concentração iônica e ligações químicas.

\subsection{Origem das Substâncias Húmicas}

O estudo da gênese das SH permite obter informações que levam à compreensão de seus componentes naturais e ao comportamento destas no ambiente. A partir de 1940, duas teorias prevaleceram entre os pesquisadores sobre a origem das $\mathrm{SH}$. A primeira propôs que as $\mathrm{SH}$ originam-se da lignina das plantas e a segunda admitiu como sendo a celulose, ou os açúcares, os precursores das $\mathrm{SH}$ (LANDGRAF et al, 2005).

Segundo Kononova (1966), o processo de humificação segue a seguinte sequência: 
i. Decomposição hidrolítica de resíduos vegetais, dando origem às substâncias de natureza aromática;

ii. Essas substâncias aromáticas, após sofrerem oxidação por enzimas e microrganismos, dariam origem aos fenóis, aos ácidos poliidroxibenzóicos, às quinonas e às hidroxiquinonas;

iii. Os compostos oxidados sofreriam, então, condensação, formando produtos de cor escura, conhecidos como húmus.

Ainda existem outras hipóteses que consideram que a lignina e as proteínas, são precursoras na formação do húmus no solo, visto que:

i. As $\mathrm{SH}$ têm propriedades similares às das ligninas modificadas, tais como presença de anéis aromáticos e certos grupos funcionais $(-\mathrm{OH}$ e $-\mathrm{COOH})$;

ii. $\quad O$ tratamento alcalino das ligninas conduz à formação de substâncias que possuem propriedades semelhantes às das SH naturais (cor, solubilidade etc.).

\subsection{Fracionamento Químico das Substâncias Húmicas}

A metodologia comumente utilizada para o fracionameto químico das substâncias húmicas baseia-se na diferença de solubilidade dos componentes mais recalcitrantes da MOS (ácido húmico, ácido fúlvico e humina) e foi sugerida pela Sociedade Internacional de Substâncias Húmicas (IHSS). Na Figura 5 - IV estão apresentados os procedimentos para o fracionamento das substâncias húmicas e para a purificação dos ácidos húmicos. Uma linha tracejada separa ambos os procedimentos. O processo de extração faz uso de solução diluída de $\mathrm{NaOH}$ e $\mathrm{HCl}$ para dissolver e precipitar os ácidos húmicos.

Comparando a capacidade de extração de SH por vários solventes, verificouse que a maior capacidade de extração simultânea do AH e AF é por $\mathrm{NaOH}$ diluído. 
Estes resultados estão de acordo com os obtidos por Schinitzer e Khan. A solução mais diluída promove uma extração mais branda, com menores possibilidades de alterações da estrutura original (LANDGRAF et al., 2005).

Ácidos húmicos extraídos de solos contém íons inorgânicos considerado impurezas, que dependendo da técnica utilizada, podem interferir em sua caracterização. Considera-se, geralmente, o teor de cinzas adequado até, no máximo $3 \%$, principalmente para caracterizações espectroscópicas como RMN, EPR, FTIR, entre outras técnicas. Há ainda pesquisadores que preferem estudar os $\mathrm{AH}$ sem purificá-los, mantendo-os assim, mais próximos de suas condições naturais, contudo isso depende da exigência inerente a cada estudo. 
Figura 5 - IV. Fracionamento químico e purificação dos ácidos húmicos

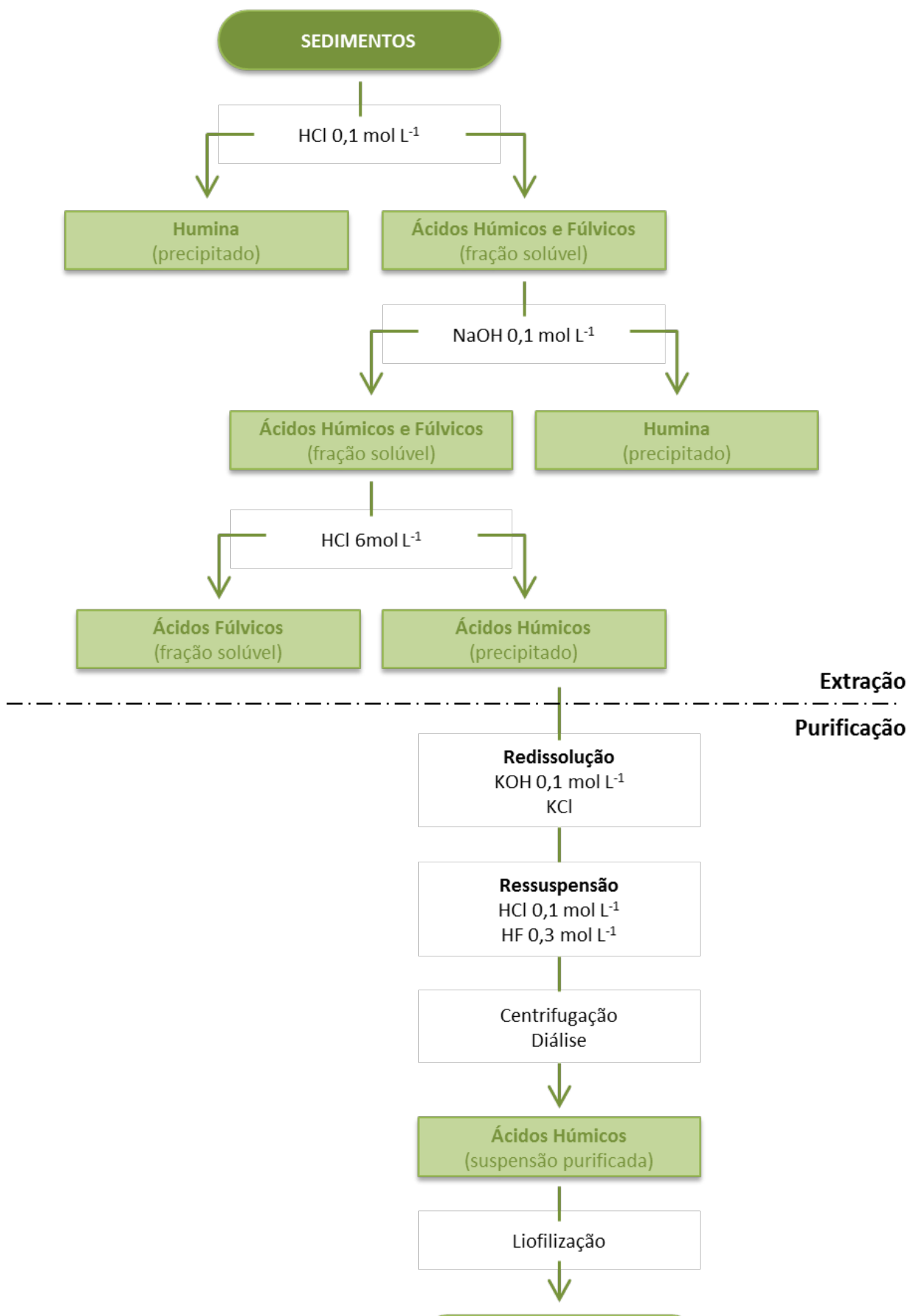

ÁcIDos HÚMıcos 


\subsection{Caracterização de Substâncias Húmicas}

As técnicas analíticas evoluíram significativamente na capacidade de análise quantitativa e qualitativa nas últimas décadas. Dentre elas, destacam-se algumas técnicas espectrométricas e métodos espectroscópicos, que permitem detalhado conhecimento dos processos químicos relacionados com a tranferência e tranformação de elementos e de compostos no sistema solo-água-planta-atmosfesra (ABREU-JUNIOR et al., 2009).

Nos últimos anos, o estudo da matéria orgânica em ambientes terrestres e aquáticos teve um considerável avanço em função da crescente preocupação da humanidade com a qualidade do ambiente. Isso porque a matéria orgânica tem papel decisivo no comportamento de poluentes no solo e na água. Essa situação incentivou o estudo da matéria orgânica do solo, e os principais avanços devem-se à contribuição de métodos espectroscópicos (CERETTA et al., 2008).

Nos solos, a estrutura e a composição das substâncias húmicas parecem ser influenciadas, entre outros parâmetros, pelo material de origem, pela vegetação, pelo sistema de manejo e, sobretudo, pelo $\mathrm{pH}$ do solo. Portanto, o tipo de adubo e o uso da calagem exercem grande influência sobre os teores de carbono total e sobre os teores de carbono contido nas substâncias húmicas, uma vez que alteram o aporte de C ao solo, a síntese e ressíntese de substâncias orgânicas e a taxa de mineralização da matéria orgânica do solo (MARCHI et al., 2008).

A análise elementar, por exemplo, indica o teor de carbono, hidrogênio, oxigênio e enxofre presente nas amostras. A partir desses valores, podem-se calcular as razões atômicas $\mathrm{H} / \mathrm{C}$ (ou $\mathrm{C} / \mathrm{H}), \mathrm{O} / \mathrm{C}$ (ou C/O) e C/N. A razão H/C é muito utilizada como indicador de humificação, uma vez que valores mais baixos de H/C (ou mais elevados de $\mathrm{C} / \mathrm{H}$ ) indicam estruturas mais condensadas. A razão $\mathrm{C} / \mathrm{O}$, juntamente com valores de acidez, é um indicativo de grupos oxigenados presentes na estrutura húmica. A razão $\mathrm{C} / \mathrm{N}$, por sua vez, indica o grau de incorporação do nitrogênio na 
estrutura húmica e, por consequência, o nível de fertilidade desse material, pois pelos diversos mecanismos de mineralização da MO do solo, o nitrogênio é liberado para as raízes das plantas sob a forma de nitrato. As análises de acidez de SH permitem determinar o número de grupamentos ácidos (carboxílicos e fenólicos) presentes na estrutura, que são primordiais na adsorção de íons metálicos e de compostos orgânicos, como pesticidas e outros xenobióticos. O método mais utilizado para a determinação de acidez de AH é o de Schnitzer e Gupta, e é baseado em titulações potenciométricas. Na determinação de acidez total, é utilizada solução de hidróxido de bário $\left(\mathrm{Ba}(\mathrm{OH})_{2}\right)$ livre de $\mathrm{CO}_{2}$, titulando-se o excesso de base com $\mathrm{HCl}$ padronizado. $\mathrm{Na}$ determinação de acidez carboxílica, usa-se acetato de cálcio $\left(\mathrm{Ca}\left(\mathrm{CH}_{3} \mathrm{COO}\right)_{2}\right)$, que consegue desprotonar apenas os grupos carboxílicos, e titula-se o ácido acético formado com $\mathrm{NaOH}$ padronizado. A acidez fenólica é calculada por diferença entre a acidez total e a carboxílica (LANDGRAF et al., 2005).

As análises espectroscópicas nas diferentes regiões do espectro eletromagnético tem ampla aplicação no estudo da MOS, especialmente das substâncias húmicas, tanto para identificação e caracterização dos diferentes compostos húmicos, como para a avaliação das alterações qualitativas desses compostos (ABREU-JUNIOR, 2009).

Técnicas como FTIR, fluorescência de luz uv-visível, fluorescência induzida por laser (FIL), RMN, EPR, entre outras, têm gerado resultados importantes na avaliação da qualidade do solo, sob condições temperadas e tropicais. Essas técnicas fornecem informações sobre grupos funcionais constituintes da matéria orgânica possibilitando a avaliação do grau de humificação. Esses estudos ainda são relativamente reduzidos em sistemas tropicais (MARTIN-NETO et al., 1991, 1994ab, 1998; BAYER et al.,1997; MILORI et al., 2002; GONZÁLEZ-PEREZ et al. 2004). Essas técnicas possuem a vantagem de se trabalhar com pequenas quantidades de amostras (STEVENSON, 1994).

Segundo Mangrich (2001), conhecer as estruturas químicas das substâncias húmicas é essencial para entender a sustentabilidade dos diferentes sistemas agrícolas, o ciclo global do carbono e a lixiviação de espécies químicas, que podem causar poluição das águas e o empobrecimento do solo. 


\subsubsection{Espectroscopia na região do infravermelho próximo (NIRS)}

O uso da espectroscopia de NIRS, para a análise de fibras e proteínas em forragens e grãos tem sido estudado há décadas, entretanto o interesse em aplicálas para estudos quantitativos de características e propriedades dos solos é relativamente recente (MITTELMANN et al., 2005; MADARI et al., 2006b). NIRS utiliza radiação eletromagnética de 1000 a $2500 \mathrm{~nm}\left(10000\right.$ a $\left.4000 \mathrm{~cm}^{-1}\right)$.

Segundo Ben-Dor e Banin (1995), a matéria orgânica também é espectroscopicamente ativa em toda a região do infravermelho próximo. O espectro de NIRS (Figura 6 - IV) é constituído de bandas fracas de acoplamentos e combinações das bandas de vibração de $\mathrm{C}-\mathrm{H}, \mathrm{N}-\mathrm{H}$ e O-H que ocorrem na região do infravermelho médio (GERZABEK et al., 2006), sendo, por esse motivo, não muito seletivo e pouco utilizado para a interpretação e elucidação de estruturas moleculares (WESTAD et al., 2008).

Figura 6 - IV Espectro de NIRS de solos afetados por diferentes ocorrências de fogo. Traduzida de: Vergnoux et al., 2009

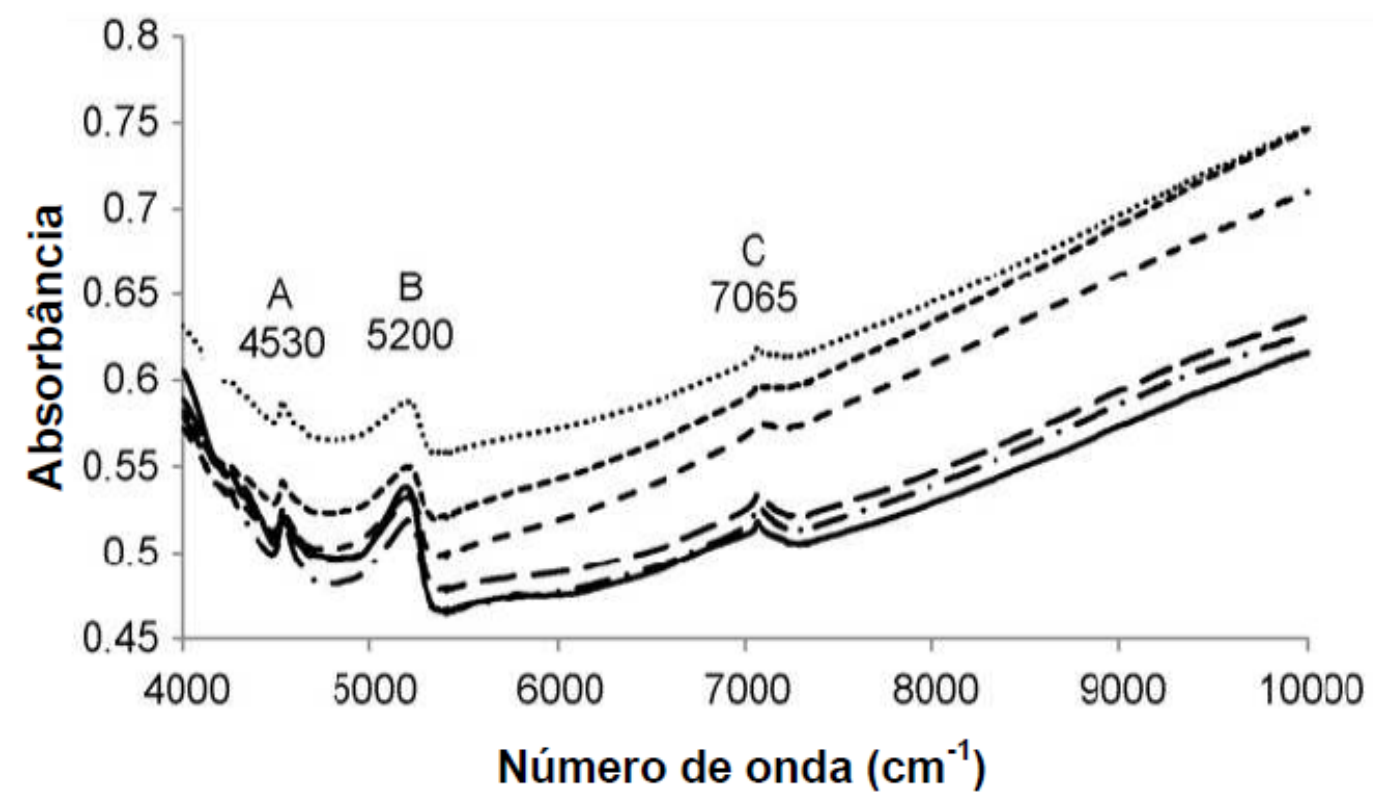

Aparentemente, o espectro no infravermelho médio é mais informativo que aquele obtido por NIRS. Entretanto, deve-se destacar que os componentes 
inorgânicos como a sílica, que são predominantes no solo e dificultam a identificação de bandas características de compostos orgânicos do solo, não absorvem na região do infravermelho próximo, mas sim no infravermelho médio (MADARI et al., 2005). Dentre as vantagens da NIRS está a alta razão sinal-ruído (tipicamente 25000:1) (WORKMAN, 1998). Algumas atribuições de bandas em NIRS são apresentadas na Tabela 1 - IV.

Tabela 1 - IV. Bandas de absorção das vibrações de estiramento dos principais grupos funcionais no espectro no infravermelho próximo $\left(\mathrm{cm}^{-1}\right)$. Adaptada de: Workman, (1998)

\begin{tabular}{|c|c|c|c|c|}
\hline Estrutura & Ligação & $1^{\text {a }}$ harmônica & $2^{2}$ harmônica & $3^{\mathrm{a}}$ harmônica \\
\hline $\mathrm{ArCH}$ (aromáticos) & $\mathrm{C}-\mathrm{H}$ & $8748-8424$ & $8748-8424$ & $11668-11235$ \\
\hline $\mathrm{CH}=\mathrm{CH}$ (metileno) & $\mathrm{C}-\mathrm{H}$ & $8064-8019$ & $8064-8019$ & 10752-10695 \\
\hline $\mathrm{CH}_{3}$ (metil) & $\mathrm{C}-\mathrm{H}$ & $8223-8196$ & $8223-8196$ & 10964-10928 \\
\hline $\mathrm{CH}_{3}$ (metil) & $\begin{array}{c}\text { C-H } \\
\text { combinaçāo }\end{array}$ & $7423-7315$ & $7423-7315$ & $9900-9756$ \\
\hline R-OH (álcoois) & $\mathrm{O}-\mathrm{H}$ & $7092-6872$ & 10638-10309 & * \\
\hline ArOH (fenóis) & $\mathrm{O}-\mathrm{H}$ & $7037-6802$ & 10559-10204 & * \\
\hline $\mathrm{HOH}$ (água) & $\mathrm{O}-\mathrm{H}$ & $6944-6734$ & 10416.-10101 & * \\
\hline Amido & $\mathrm{O}-\mathrm{H}$ & 6891 & 10341 & * \\
\hline Uréia & $\mathrm{N}-\mathrm{H}$ & 6849 & 10277 & * \\
\hline $\mathrm{CONH}_{2}$ (amidas primárias) & $\mathrm{N}-\mathrm{H}$ & $6835-6738$ & 10256-10111 & * \\
\hline CONHR (amidas secundárias) & $\mathrm{N}-\mathrm{H}$ & 6793 & 10193 & * \\
\hline Celulose & $\mathrm{O}-\mathrm{H}$ & 6711 & 10070 & * \\
\hline Uréia & $\mathrm{N}-\mathrm{H}$ & 6711 & 10070 & * \\
\hline $\mathrm{ArNH}_{2}$ (aminas aromáticas) & $\mathrm{N}-\mathrm{H}$ & 6697 & 10050 & * \\
\hline NH (aminas em geral) & $\mathrm{N}-\mathrm{H}$ & 6666 & 10000 & * \\
\hline Proteínas & $\mathrm{N}-\mathrm{H}$ & 6618 & 9930 & * \\
\hline Uréia & $\mathrm{N}-\mathrm{H}$ & 6578 & 9871 & * \\
\hline $\mathrm{RNH}_{2}$ (aminas primárias) & $\begin{array}{c}\text { N-H } \\
\text { combinaçāo }\end{array}$ & * & 9803 & * \\
\hline Amido & $\begin{array}{c}\mathrm{O}-\mathrm{H} \\
\text { combinaçāo }\end{array}$ & * & 9737 & * \\
\hline CONH (amidas primárias) & $\begin{array}{c}\mathrm{N}-\mathrm{H} \\
\text { combinaçāo }\end{array}$ & * & 9551 & * \\
\hline$=\mathrm{CH} 2$ (metileno) & $\begin{array}{c}\text { C-H } \\
\text { combinaçāo }\end{array}$ & * & 9259 & * \\
\hline
\end{tabular}




\section{OBJETIVOS}

O objetivo deste capítulo foi avaliar a influência de vermicompostos produzidos a partir dos resíduos agroindustriais bagaço de laranja, torta de filtro e esterco bovino, na fertilidade e na matéria orgânica de um Latossolo Vermelho tipicamente arenoso da região de São Carlos, SP, e em Vertissolo tipicamente argiloso da região Pantaneira.

Objetivos específicos:

a) Caracterização dos solos pré-culivo de Manjericão: análise granulométrica, $\mathrm{pH}$ e CTC;

b) Coleta do solo pós-cultivo, secagem e peneiramento;

c) Determinação do teor de macro e micronutrientes nos solos referentes a cada tratamento e teor de $\mathrm{C}$ total;

d) Caracterização espectroscópica da matéria orgânica do solo inteiro: Espectroscopia na Região do Infravermelho Próximo (NIRS);

e) Extração e purificação dos ácidos húmicos dos solos pós-cultivo e

f) Caracterização química e espectroscópica dos ácidos húmicos extraídos: Análise Elementar; Absorção na região do UV-Vis, Espectroscopia na Região do Infravermelho Médio com Transformada de Fourier. 


\section{PARTE EXPERIMENTAL}

Após a poda da parte aérea das plantas (60 dias após o transplante das mudas aos vasos), os vasos continuaram montados e devidamente irrigados, mantendo-se as condições para que a planta rebrotasse. Em 1 de julho de 2014, quando completados 100 dias do transplante das mudas aos vasos, iniciou-se a coleta dos solos manejados para secagem, peneiramento e posteriores análises químicas e espectroscópicas.

\subsection{Caracterização Físico-Química dos Solos Pré-Cultivo}

\subsubsection{Análise granulométrica, $\mathrm{C}$ total, $\mathrm{pH}$ e CTC}

Amostras do solo foram secas em estufa à temperatura de aproximadamente $50{ }^{\circ} \mathrm{C}$ até atingirem massa constante, maceradas em almofariz e pistilo e peneiradas em peneira de $2,5 \mathrm{~mm}$ de abertura de malha. Os solos pré-cultivo foram caracterizados quanto à análise granulométrica, $\mathrm{pH}$ em solução de $\mathrm{CaCl}_{2} \quad 0,01 \mathrm{~mol}^{-}$ ${ }^{1}$ (descrição da metodologia no Capítulo I, item 3.4.1), CTC (descrição da metodologia no Capítulo I, item 3.4.4) e C total (descrição da metodologia no Capítulo II, item 3.2).

A análise granulométrica foi realizada de acordo com as NBR 7181 e 6457, a fim de se determinar a porcentagem de argila, silte, areia e pedregulho existentes no solo. Primeiramente, adicionaram-se $100 \mathrm{~mL}$ da solução dispersante $(45,7 \mathrm{~g}$ de hexametafosfato de sódio em 1 litro de água destilada e mantendo-a em agitação até ocorrer a dissolução completa do reagente) em $20 \mathrm{~g}$ da amostra. Em seguida, a amostra com a solução dispersante foi posta em agitação por 16 horas. Após esse procedimento, a suspensão foi passada numa peneira com malha de 0,05 $\mathrm{mm}$. $O$ material retido pela peneira foi lavado e seco em estufa a $100^{\circ} \mathrm{C}$ até atingir uma massa 
constante. $\mathrm{O}$ filtrado foi colocado em uma proveta de $1000 \mathrm{~mL}$, que foi completada com água destilada.

Na sequência, foi feita a análise de argila e silte. Para isso, agitou-se a mistura presente na proveta até a completa suspensão das partículas, inseriu-se um densímetro na proveta e anotou-se o início da sedimentação. Nos tempos de 0,5, 1, $2,4,8,15,30,60,120,240$ e 480 minutos realizaram-se medições referentes à temperatura e à densidade. Com os dados obtidos, foram calculados o diâmetro máximo da partícula e o percentual deste particulado na suspensão de acordo com a NBR 7181.

Juntamente às analises de silte e argila, foi feita a análise de areia $\mathrm{e}$ pedregulho. As frações de pedregulhos e areias fina, média e grossa foram determinadas utilizando-se o método de peneiramento. Neste método, o material retido pela peneira de malha $0,05 \mathrm{~mm}$, já seco, é peneirado novamente através de um jogo de peneiras com malhas: 4,8; 9,5; 19,0; 25,0; 38,0 e 50,0 mm. Para auxiliar no peneiramento, o sistema foi colocado em uma mesa agitadora durante dez minutos. A massa retida em cada peneira foi anotada e os percentuais da composição do solo foram calculados (NBR 6457). A análise granulométrica foi realizada no Laboratório de Geotecnia da Escola de Engenharia de São Carlos, USP.

\subsection{Caracterização Química e Espectroscópica dos Solos Pós-Cultivo}

\subsubsection{Determinação do teor de macro e micronutrientes e $\mathrm{C}$ total}

As metodologias seguidas para determinação dos teores de macro e micronutrientes e de $C$ total encontram-se descritas no Capítulo I, item 3.4.3 e no Capítulo II, item 3.2, respectivamente. 


\subsubsection{Espectroscopia na região do Infravermelho Próximo (NIRS)}

Para a obtenção dos espectros de NIRS dos solos referentes aos diferentes tratamentos, as amostras foram secas ao ar, passadas em peneiras de $0,5 \mathrm{~mm}$ e analisadas em espectrômetros no infravermelho próximo (10000 a $\left.4000 \mathrm{~cm}^{-1}\right)$, com resolução de $16 \mathrm{~cm}^{-1}$ e acumulação de 32 varreduras por espectro. Foram obtidos espectros de refletância transformados automaticamente para absorbância e Kubelka-Munk pelos softwares dos equipamentos. Todos os espectros foram centrados na média e submetidos ao cálculo da $1^{\text {a }}$ derivada com 5 pontos.

O equipamento utilizado foi o espectrômetro no infravermelho próximo com refletância difusa Perkin-Elmer, modelo Spectrum 100N, pertencente à Embrapa Instrumentação, São Carlos-SP.

\subsection{Caracterização Química e Espectroscópica dos Ácidos Húmicos Extraídos dos Solos Pós-Cultivo}

A metodologia utilizada para extração e purificação dos ácidos húmicos foi a sugerida pela Sociedade Internacional de Substâncias Húmicas (SWIFT, 1989), a qual está descrita no Capítulo II, item 3.1 e esquematizada na Figura 5 - V.

\subsubsection{Análise elementar}

Descrição da metodologia no Capítulo I, item 3.4.2. 
3.3.2 Espectroscopia na região do infravermelho médio com transformada de Fourier (FTIR)

Metodologia descrita no Capítulo II, item 3.3.

3.3.4 Espectroscopia de absorção na região do UV-Vis

Metodologia descrita no Capítulo II, item 3.4. 


\section{RESULTADOS E DISCUSSÃO}

\subsection{Caracterização Física e Química dos Solos Pré-Cultivo: Análise Granulométrica, C Total, pH e CTC}

O Latossolo Vermelho, coletado na região de São Carlos, SP, foi caracterizado quanto a sua granulometria como: "areia argilo pouco siltosa" (3,0\% areia grossa, $28 \%$ areia média, $27 \%$ areia fina, 35\% de silte, 31\% argila). O solo é levemente ácido, $5,74 \pm 0,04$ (característico dos latossolos brasileiros), e a porcentagem de C e a CTC são baixas, $(0,25 \% \pm 0,03)$ e $\left(0,005 \mathrm{mmol}_{\mathrm{c}} \mathrm{kg}^{-1} \pm 0,000\right)($ Tabela $2-\mathrm{VI})$.

Tabela 2 - IV. Composição granulométrica, pH, CTC e \% C do latossolo utilizado no cultivo de Manjericão

\begin{tabular}{|c|c|c|c|c|c|}
\hline \multirow[b]{2}{*}{ LATOSSOLO } & \multicolumn{2}{|c|}{$\begin{array}{c}\text { COMPOSIÇÃO } \\
\text { GRANULOMÉTRICA }\end{array}$} & \multirow[t]{2}{*}{ pH } & \multirow{2}{*}{$\begin{array}{c}\text { CTC } \\
\mathrm{mmol}_{\mathrm{c}} \mathrm{kg}^{-1}\end{array}$} & \multirow{2}{*}{$\begin{array}{l}\text { C } \\
\%\end{array}$} \\
\hline & MATERIAL & $\%$ & & & \\
\hline & PEDREG. GROSSO & 0,0 & 5,74 & 0,005 & 0,25 \\
\hline & PEDREG. MÉDIO & 0,0 & $\pm 0,04$ & $\pm 0,000$ & $\pm 0,007$ \\
\hline & PEDREG. FINO & 0,0 & & & \\
\hline & AREIA GROSSA & 3,0 & & & \\
\hline & AREIA MÉDIA & 28,0 & & & \\
\hline & AREIA FINA & 27,0 & & & \\
\hline & SILTE & 11,0 & & & \\
\hline & ARGILA & 31,0 & & & \\
\hline & $\Sigma(\%)$ & 100,0 & & & \\
\hline
\end{tabular}

O Vertissolo, coletado na região de Corumbá, MS, foi caracterizado quanto a sua granulometria como: "argila orgânica siltosa marrom escuro com presença de pedregulho fino" (0,2\% pedregulho fino, 3,4\% areia grossa, 6,4\% areia média, $8 \%$ areia fina, $11 \%$ de silte, $47 \%$ argila). $\mathrm{O}$ solo apresenta $\mathrm{pH}$ de neutro a levemente alcalino, $7,72 \pm 0,02$, e a porcentagem de C e a CTC são altas, $(3,73 \% \pm 0,19)$ e 
$\left(462,33 \mathrm{mmol}_{\mathrm{c}} \mathrm{kg}^{-1} \pm 13,82\right)$ (Tabela $\left.3-\mathrm{VI}\right)$.

Tabela 3 - IV. Composição granulométrica, pH, CTC e \% C do vertissolo

\begin{tabular}{|c|c|c|c|c|c|}
\hline \multirow[b]{2}{*}{ VERTISSOLO } & \multicolumn{2}{|c|}{$\begin{array}{c}\text { COMPOSIÇÃO } \\
\text { GRANULOMÉTRICA }\end{array}$} & \multirow[t]{2}{*}{$\mathrm{pH}$} & \multirow{2}{*}{$\begin{array}{c}\text { стс } \\
\mathrm{mmol} \mathrm{kq}^{-1}\end{array}$} & \multirow[b]{2}{*}{$\%$} \\
\hline & MATERIAL & $\%$ & & & \\
\hline & $\begin{array}{l}\text { PEDREG. } \\
\text { GROSSO }\end{array}$ & 0,0 & 7,72 & 462,333 & 3,73 \\
\hline & PEDREG. MÉDIO & 0,0 & $\pm 0,02$ & $\pm 13,82$ & $\pm 0,19$ \\
\hline & PEDREG. FINO & 0,2 & & & \\
\hline & AREIA GROSSA & 3,4 & & & \\
\hline & AREIA MÉDIA & 6,4 & & & \\
\hline & AREIA FINA & 8,0 & & & \\
\hline & SILTE & 35,0 & & & \\
\hline & ARGILA & 47,0 & & & \\
\hline & $\Sigma(\%)$ & 100,0 & & & \\
\hline
\end{tabular}

\subsection{Caracterização Química dos Solos Pós-Cultivo: C Total e Teor de Macro e Micronutrientes}

\subsubsection{Teor de carbono total}

A Tabela 4 - VI apresenta os teores de C total para os solos submetidos aos diferentes tratamentos de adubação orgânica e mineral.

LATOSSOLO: os latossolos adubados com vermicomposto de bagaço de laranja + esterco bovino $(B L+E B)$ e de torta de filtro + esterco bovino (TF + EB), na maior dosagem (40 tha-1 ou 4,0\%), são estatisticamente iguais $(p<0,05)$ e apresentaram os maiores teores de $C$ total, após 100 dias de experimento $(1,00 \% \pm$ 0,08 e $1,03 \% \pm 0,09$, respectivamente). $O$ solo testemunha e solo com adubação mineral são estatisticamente iguais $(p<0,05)$ apresentaram os menores teores de $C$ 
$(0,27 \% \pm 0,05$ e $0,25 \% \pm 0,04$, respectivamente). Para os solos adubados com vermicomposto de bagaço de laranja + esterco bovino e de torta de filtro + esterco bovino, o aumento da dose de vermicomposto aplicada é diretamente proporcional ao aumento do teor de $\mathrm{C}$ total no solo. Para o vermicomposto de esterco bovino puro, essa mesma tendência pode ser observada, mas ela não comprovada estatisticamente.

VERTISSOLO: os vertissolos adubados com vermicomposto de bagaço de laranja + esterco bovino $(B L+E B)$ e de torta de filtro + esterco bovino (TF+EB), na maior dosagem (40 tha-1 ou 4,0\%), assim como para o Latossolo, bem como o solo referente ao tratamento NPK (adubação mineral) são estatisticamente iguais $(p<0,05)$ e apresentaram os maiores teores de $C$ total, após 100 dias de experimento $(5,87 \pm$ 0,90, 5,67 \pm 0,68 e 5,59 \pm 0,60 respectivamente). Os tratamentos descritos anteriormente são estatisticamente diferentes dos tratamentos $\mathrm{BL}+\mathrm{EB} 15 \mathrm{t} \mathrm{ha}^{-1}$ e de EB $30 \mathrm{t} \mathrm{ha}^{-1}$, os quais são estatisticamente iguais $(p<0,05)$ e apresentaram os menores teores de $C(3,84 \% \pm 0,23$ e 3,87\% $\pm 0,33$, respectivamente). Para os demais tratamentos, as variações nos teores de C são mínimas (Tabela 4 - IV ), o que acontece pois o vertissolo é um solo naturalmente rico em matéria orgânica e consequentemente em $\mathrm{C}$, o que acabou mascarando o efeito dos vermicompostos aplicados sob o teor de $\mathrm{C}$ do solo. 
Tabela 4 - IV. Teor de C (\%) dos solos pós-cultivo de Manjericão (Ocimum basilicum L.) para os diferentes tratamentos de adubação orgânica

TRATAMENTOS

\begin{tabular}{|c|c|c|}
\hline & $\mathbf{C}_{\text {total }}(\%)$ & \\
\hline $\mathrm{BL}+\mathrm{EB} 15 \mathrm{t} \mathrm{ha}^{-1}$ & $0,44 d \pm 0,04$ & $3,84 b \pm 0,23$ \\
\hline $\mathrm{BL}+\mathrm{EB} 30 \mathrm{t} \mathrm{ha}^{-1}$ & $0,79 b \pm 0,13$ & $4,45 a b \pm 0,17$ \\
\hline $\mathrm{BL}+\mathrm{EB} 40 \mathrm{tha}^{-1}$ & $1,00 a \pm 0,08$ & $5,87 a \pm 0,90$ \\
\hline $\mathrm{TF}+\mathrm{EB} 15 \mathrm{tha}^{-1}$ & $0,48 d \pm 0,05$ & $5,09 a b \pm 0,31$ \\
\hline $\mathrm{TF}+\mathrm{EB} 30 \mathrm{tha}^{-1}$ & $0,68 b c \pm 0,14$ & $4,58 a b \pm 0,33$ \\
\hline $\mathrm{TF}+\mathrm{EB} 40 \mathrm{tha}^{-1}$ & $1,03 a \pm 0,09$ & $5,67 a \pm 0,68$ \\
\hline EB $15 \mathrm{t} \mathrm{ha}^{-1}$ & $0,42 \mathrm{de} \pm 0,08$ & $5,02 a b \pm 0,61$ \\
\hline EB $30 \mathrm{t} \mathrm{ha}^{-1}$ & $0,58 c d \pm 0,08$ & $3,87 b \pm 0,33$ \\
\hline EB $40 \mathrm{t} \mathrm{ha}^{-1}$ & $0,67 \mathrm{cb} \pm 0,13$ & $4,89 a b \pm 0,56$ \\
\hline TESTEMUNHA & $0,27 \mathrm{ef} \pm 0,05$ & $4,68 a b \pm 0,91$ \\
\hline NPK 4:14:8 & $0,25 f \pm 0,04$ & $5,59 a \pm 0,60$ \\
\hline
\end{tabular}

4.2.2 Teor de macro e micronutrientes dos solos pós-cultivo: análise das componentes principais

A Figura 7 a - IV apresenta o Gráfico de Scree, o qual mostra a porcentagem de variância que cada PC explica. Optou-se pelo uso de quatro componentes para explicar a variância dos dados, sendo que as 4 componentes principais explicaram 91,4\% da variância dos dados.

O gráfico de Importância das Variáveis (Figura 7 b - IV) avalia os dados como um todo, não há uma variável em destaque, sendo que $\mathrm{P}$ e $\mathrm{K}$ foram as variáveis 
menos importantes para diferenciação dos tratamentos nos dois tipos de solo.

A Figura 7 c - IV apresenta o gráfico de Scores da PC1 x PC2. Pode-se observar que houve uma separação das amostras em dois grandes grupos, e essa separação ocorreu devido à diferença nutricional dos dois tipos de solo utilizados no experimento, Latossolo (O) e Vertissolo (O). As variáveis responsáveis por essa diferenciação dos tipos de solo são: $\mathrm{Zn}, \mathrm{Cd}, \mathrm{Pb}, \mathrm{Mg}, \mathrm{Mn}, \mathrm{Ca}$ e Ni para o Vertissolo, e $\mathrm{K}$ e $\mathrm{P}$ para o Latossolo (Figura $7 \mathrm{~d}-\mathrm{IV}$ ). A PC1 é grande responsável pela diferenciação dos dois tipos de solo. Embora $\mathrm{K}$ e $\mathrm{P}$ sejam as variáveis menos importantes para a separação, elas não deixam de ser consideráveis.

Figura 7 - IV. Gráfico de Scree (Scree Plot) (a), Importância das Variáveis (b), Scores (c) e Loadings (d), para os 22 tratamentos em Latossolo e Vertissolo

(a)

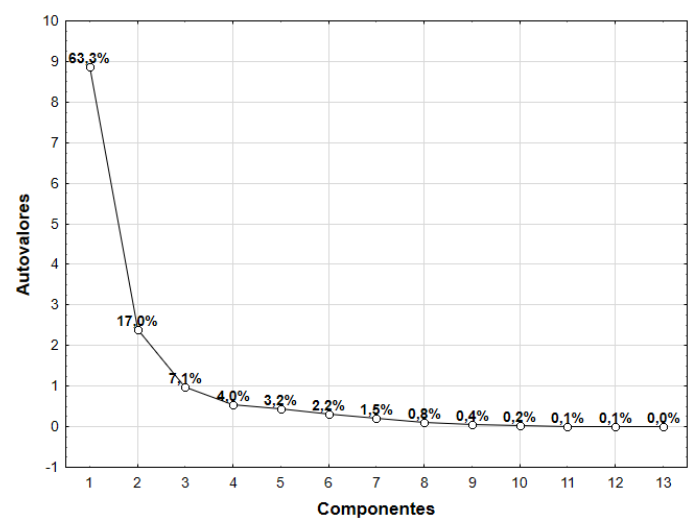

(c)

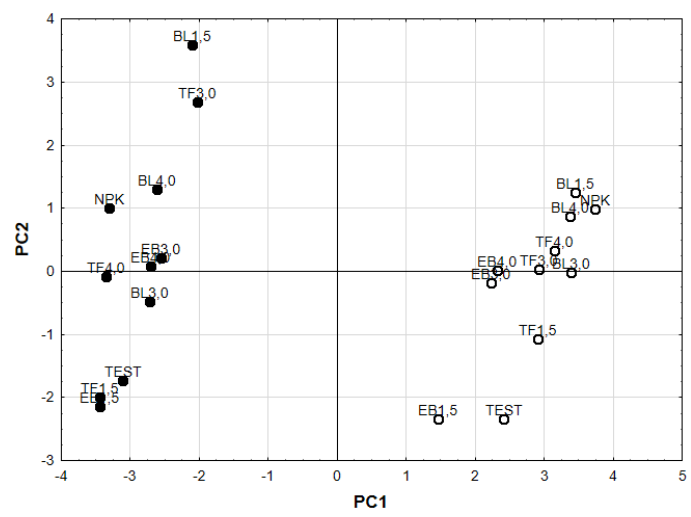

(b)

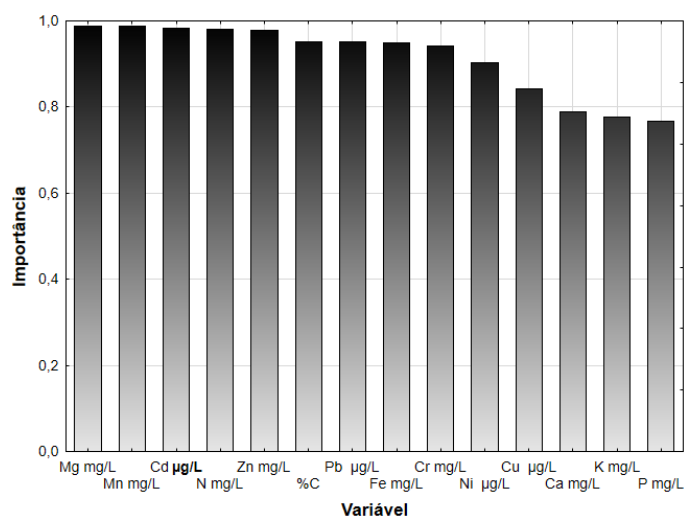

(d)

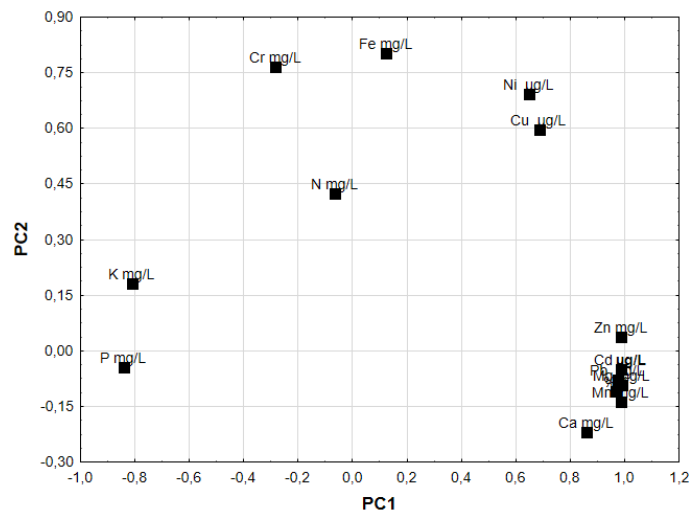


As características intrínsecas de cada tipo de solo possivelmente influenciaram na disponibilidade dos nutrientes após a aplicação dos vermicompostos em suas diferentes dosagens. Dessa forma, o vertissolo apresenta-se como um solo mais rico em micronutrientes enquanto o latossolo apresenta-se como um solo mais rico em macronutrientes.

Em geral, as variáveis mais explicadas pela PC1 (Figura 8 a - IV) são: C, Ca, Mg, Mn, Cu, Zn, Ni, Cd e Pb. Não explicam as variáveis: Cr, P, K, N. A PC 2 explica bem as variáveis $\mathrm{Fe}, \mathrm{Cu}, \mathrm{Ni}, \mathrm{Cr}, \mathrm{K}$ e N (Figura 8 b - IV). A PC 3 explica bem a variável $\mathrm{N}$ (Figura $8 \mathrm{c}$ - IV) e a PC 4 explica bem a variável Fe (Figura $8 \mathrm{~d}-$ IV).

Figura 8 - IV. Gráfico de Importância das Variáveis de cada PC, para os 22 tratamentos em Latossolo e Vertissolo

(a)

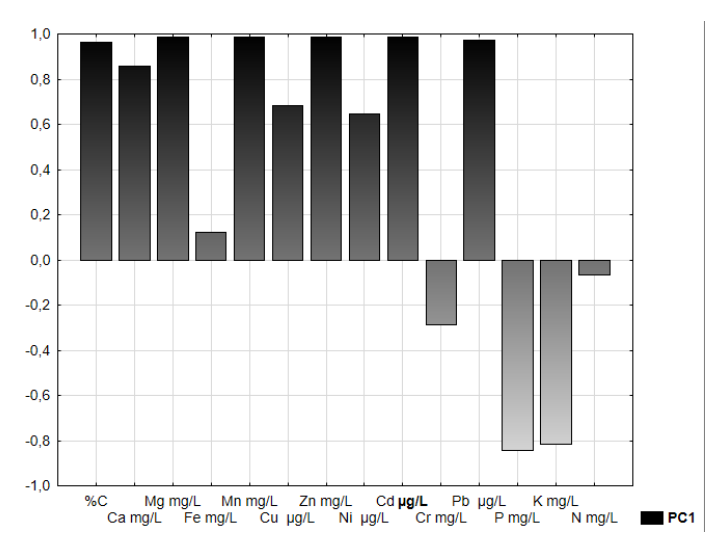

(c)

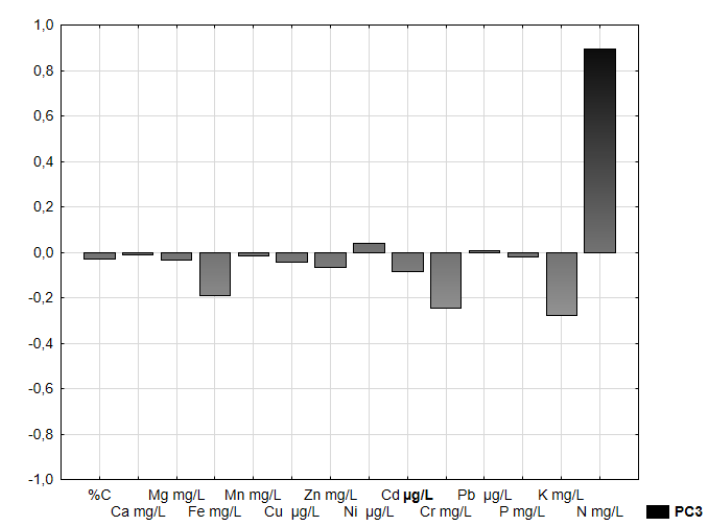

(b)

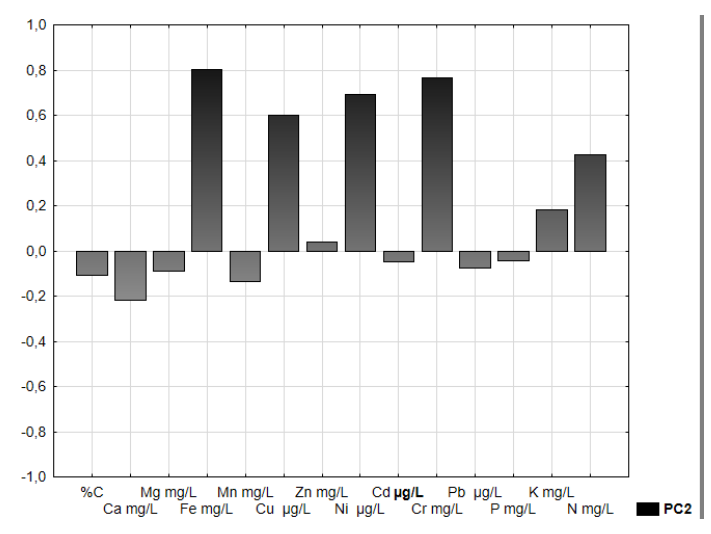

(d)

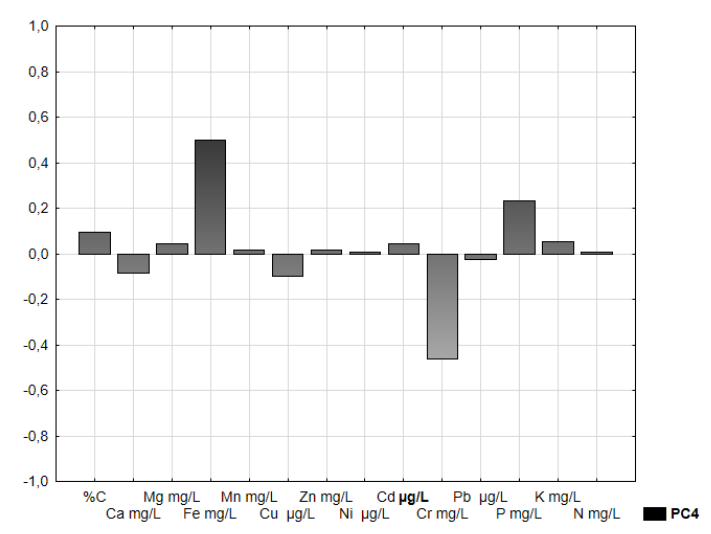


Pode-se observar no gráfico de Scores da PC1 x PC3 (Figura 9 a - IV), que a PC3 separa bastante o tratamento TF+EB $30 \mathrm{t} \mathrm{ha}^{-1}$ em latossolo dos demais tratamentos para os dois tipos de solo, sendo a variável responsável por essa separação o N (Gráfico de Loadings - Figura 9 b - IV). Avaliando-se os gráficos de Scores e Loadings da PC1 x PC4, PC2 x PC3, PC2 x PC4 e de PC3 x PC4, pode-se observar novamente uma separação evidente do tratamento TF+EB $30 \mathrm{t} \mathrm{ha}^{-1} \mathrm{em}$ latossolo, dos demais tratamentos (Figura 9 a, b, c, d, e, f, g, h, i, j - IV). E assim como na PC1 x PC2, a variável responsável por essa separação é o N. Em todos os gráficos de Scores e Loadings fica evidente a separação do tratamento BL+EB $15 \mathrm{t} \mathrm{ha}^{-1} \mathrm{em}$ latossolo devido ao teor de $\mathrm{Cr}$

Figura 9 - IV. Gráfico Scores e Loadings da PC1 x PC3 (a, b), PC1 x PC4 (c, d), PC2 x PC3 (e, f), PC2 x PC4 (g, h) e PC3 x PC4 (i, j), para os 22 tratamentos em latossolo e vertissolo

(a)

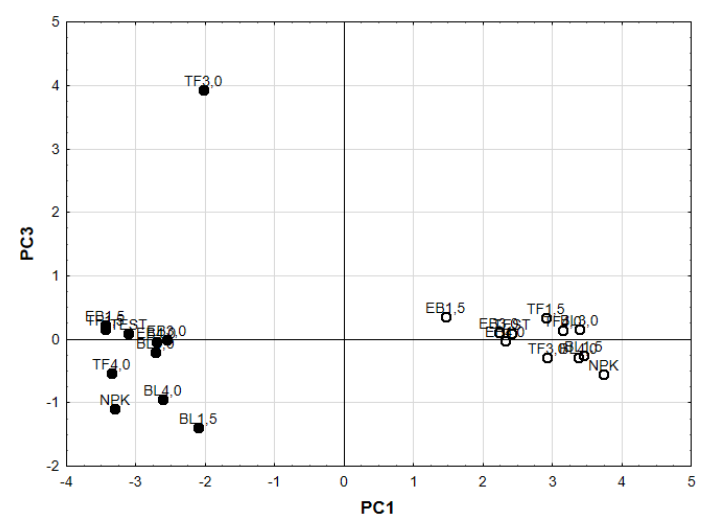

(b)

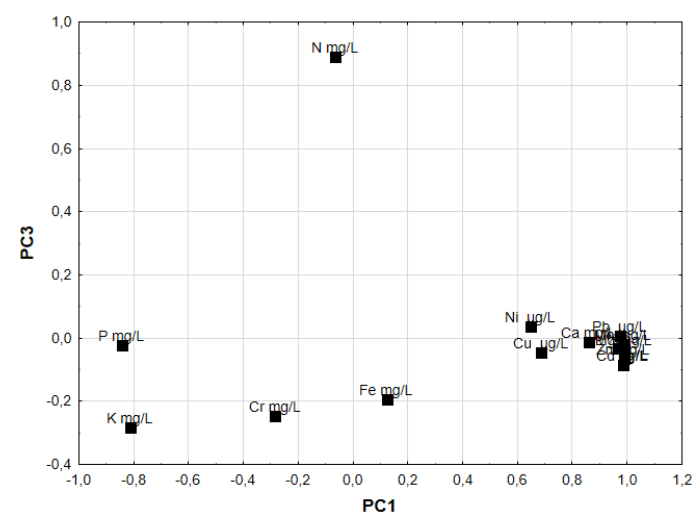


(c)

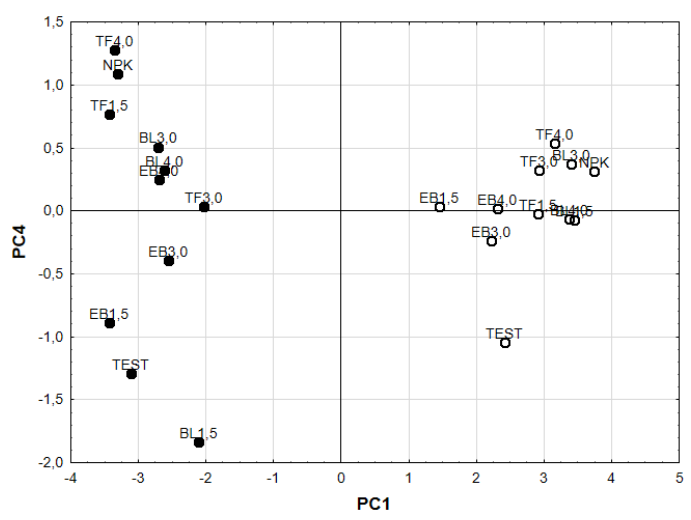

(e)

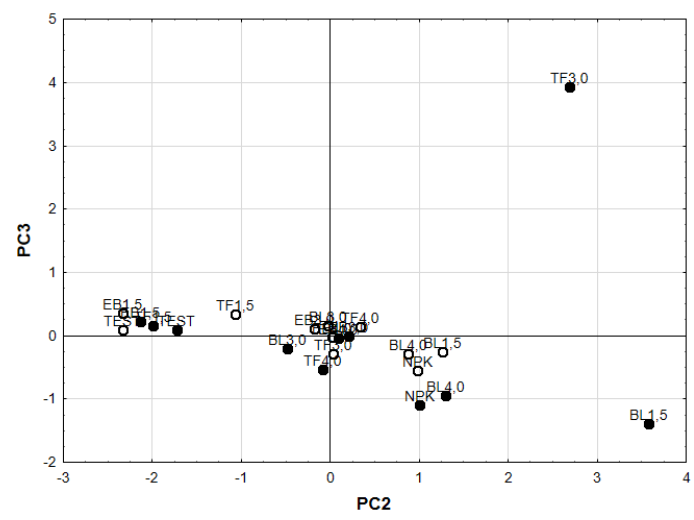

(g)

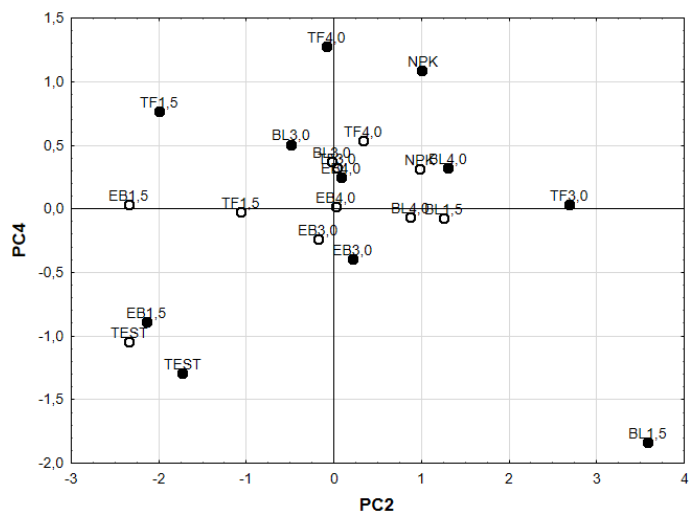

(d)

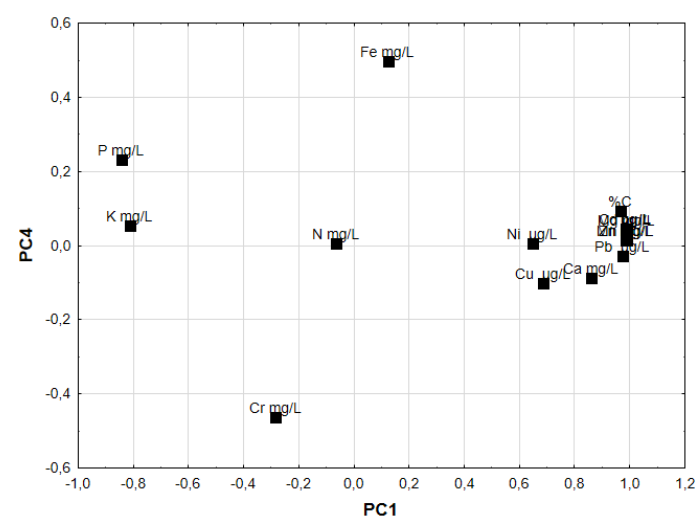

(f)

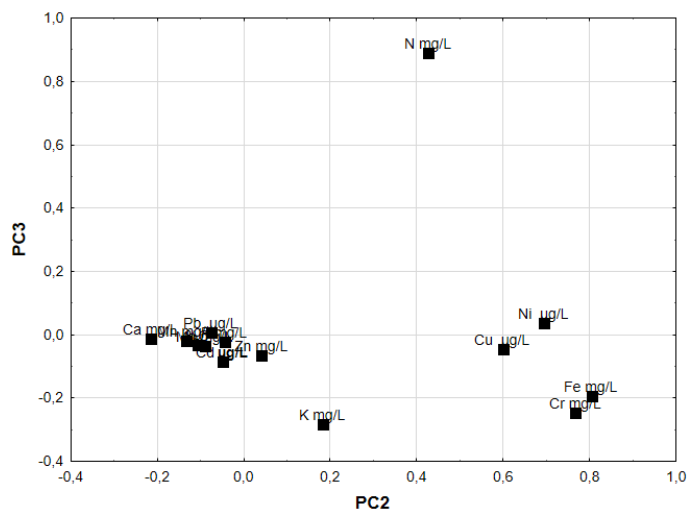

(h)

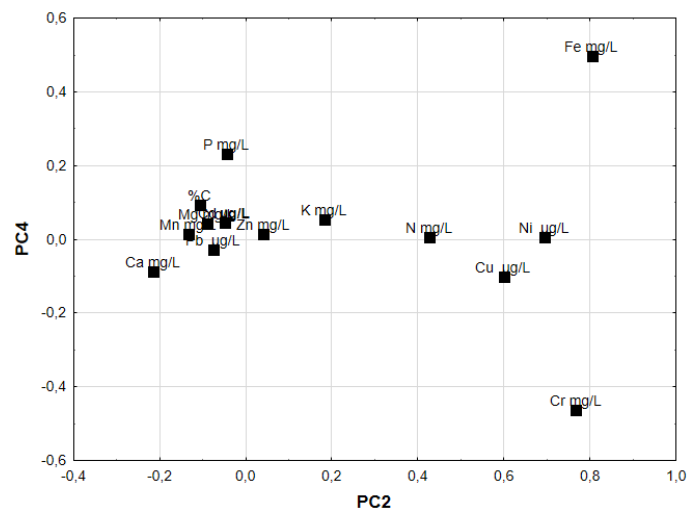


(i)

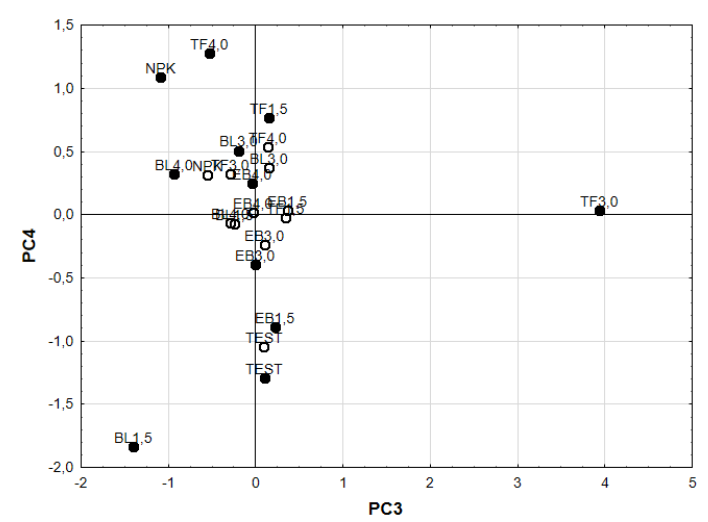

(j)

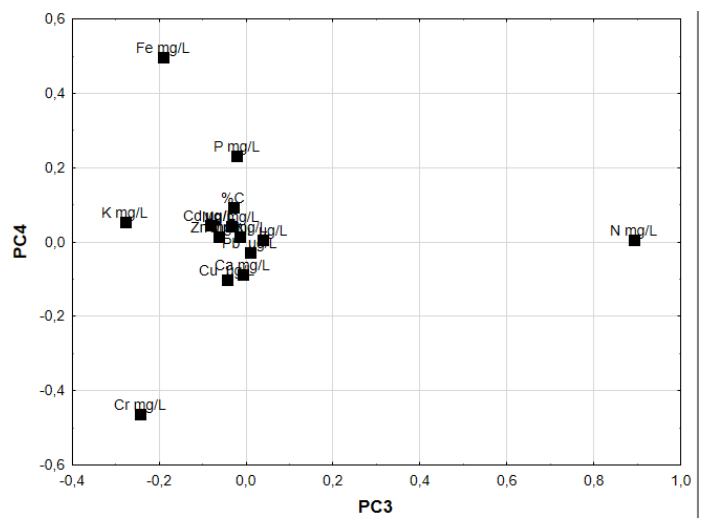

Para melhor compreensão das diferenças existentes entre os tratamentos no mesmo tipo de solo, foi feita a Análise de Componentes Principais com os dados de macro e micronutrientes das amostras de cada tipo de solo individualmente.

VERTISSOLO: A Figura 10 a - IV apresenta o Gráfico de Scree. Optou-se pelo uso de quatro componentes para explicar a variância dos dados, sendo que as 4 componentes principais explicaram 83,8\% da variância dos dados.

O gráfico de Importância das Variáveis (Figura 10 b - IV) mostra que P e K foram as variáveis menos importantes para diferenciação dos tratamentos em vertissolo, embora não exista uma variável de maior peso, pois em geral todas foram relativamente importantes. 
Figura 10 - IV. Gráfico de Scree (Scree Plot) (a) e Importância das Variáveis (b), para os 11 tratamentos em vertissolo

(a)

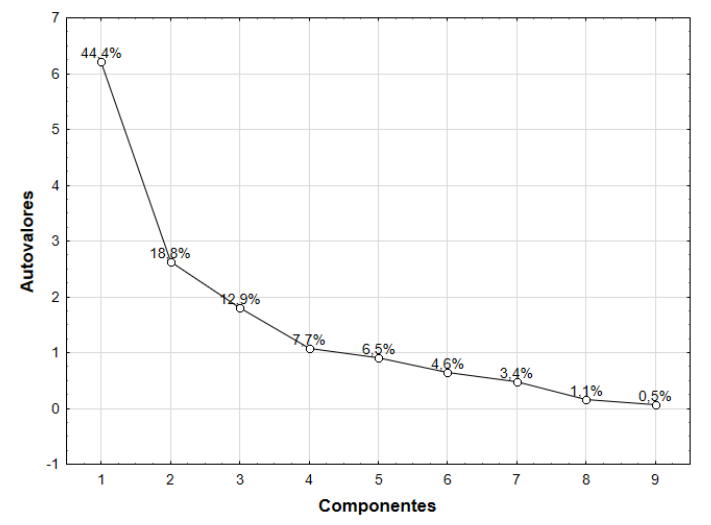

(b)

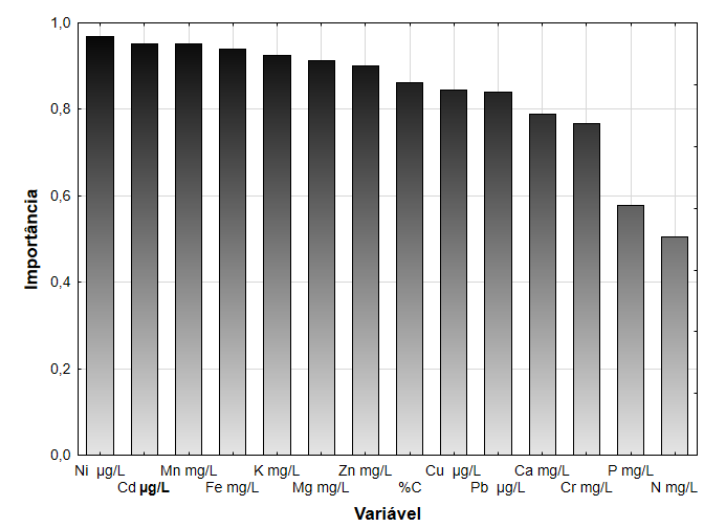

As variáveis mais explicadas pela PC1 são $\mathrm{Mg}, \mathrm{Fe}, \mathrm{Zn}, \mathrm{Ni}, \mathrm{Cd}$, e as menos explicadas são Ca, K, N (Figura 11 a - IV). A PC2 é importante para diferenciar as amostras em função Ca, Mn, Pb e K (Figura 11 b - IV). A PC3 e a PC4 são importantes para explicar a diferença de alguns tratamentos em função do C (Figura 11 c e d IV).

Figura 11 - IV. Gráfico de Importância das Variáveis de cada PC, para os 11 tratamentos em vertissolo

(a)

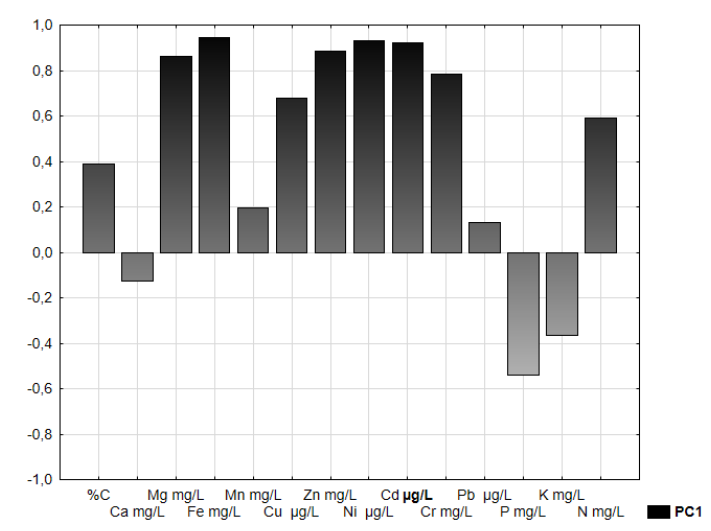

(b)

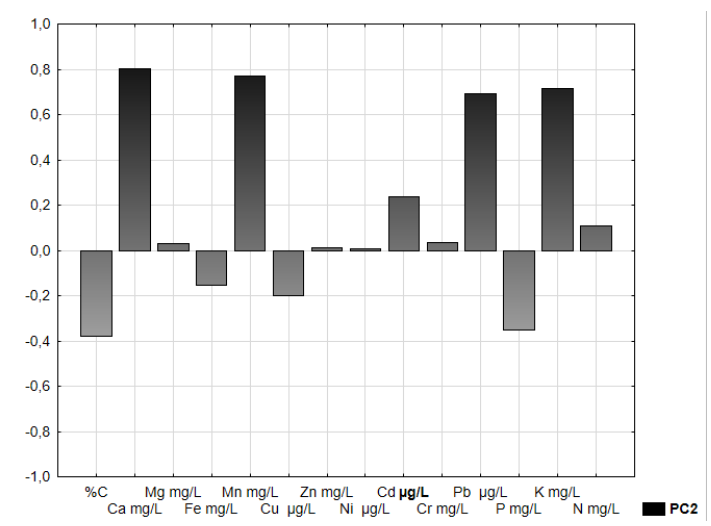


(c)

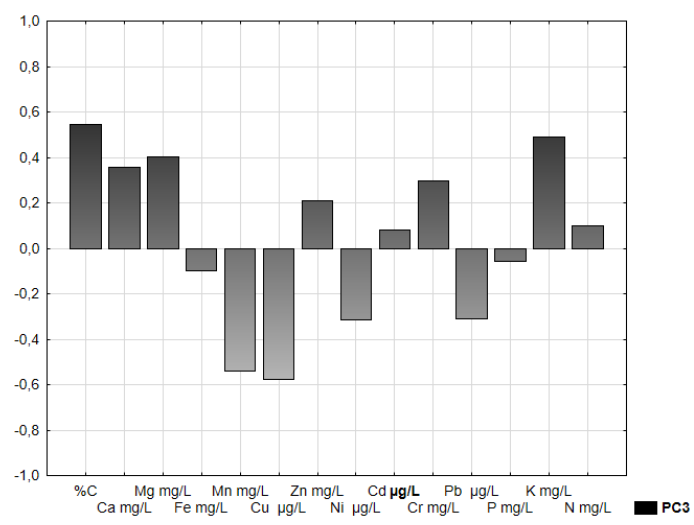

(d)

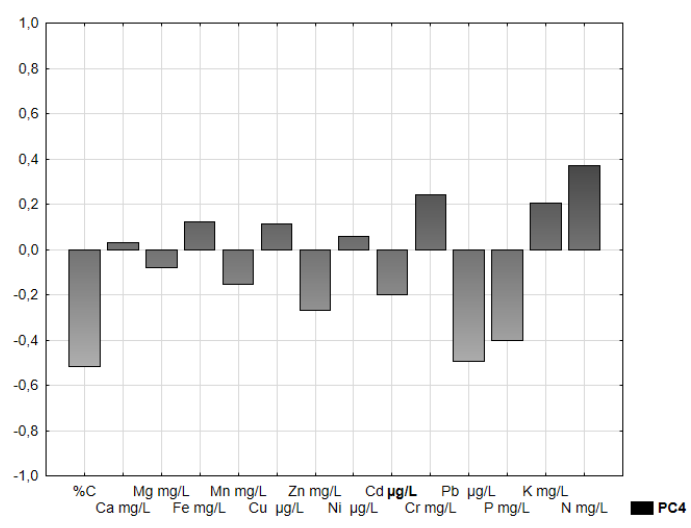

A Figura 12 - IV apresenta o gráfico de Scores da PC1 x PC2. Pode-se observar que houve uma separação das amostras em alguns grupos, e essa separação ocorreu devido às características químicas dos resíduos utilizados na produção dos vermicompostos aplicados no solo.

Figura 12 - IV. Gráfico de Scores (a) e Loadings (b) de PC1 x PC2, para os 11 tratamentos em vertissolo

(a)

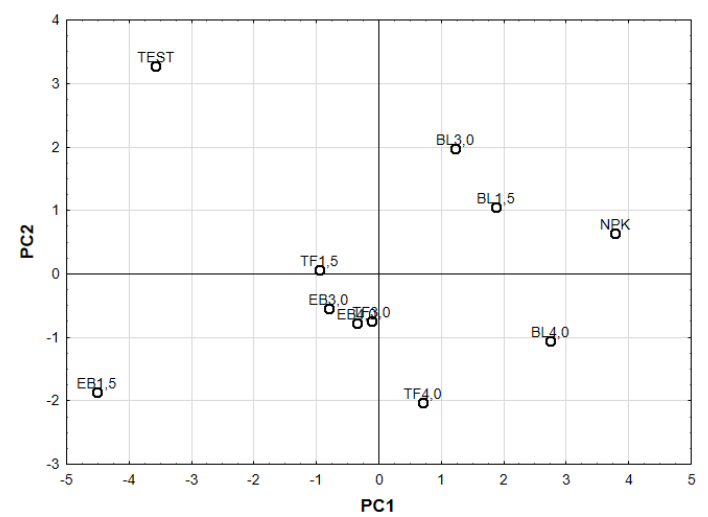

(b)

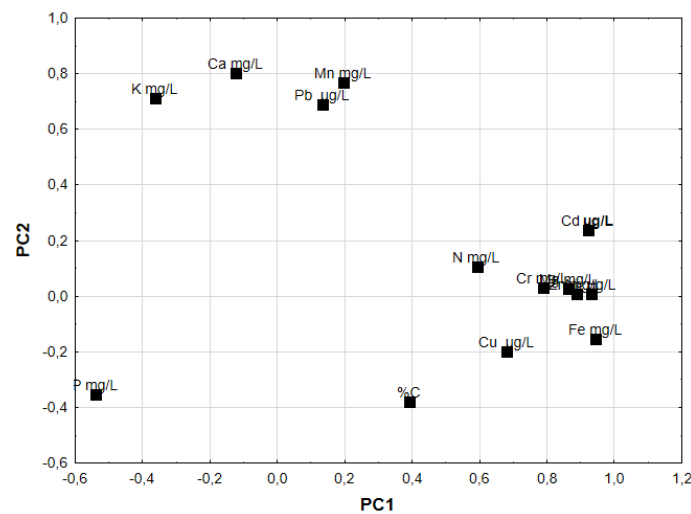

O tratamento TEST (sem adubação orgânica ou mineral) é evidentemente diferente dos demais devido à deficiência de nutrientes, como K e Ca (Figura 12 b IV). O tratamento EB $15 \mathrm{t} \mathrm{ha}^{-1}$ é bastante diferente dos demais, e a variável 
responsável por isso é o $\mathrm{P}$. Os tratamentos $\mathrm{BL}+\mathrm{EB} 15 \mathrm{t} \mathrm{ha}{ }^{-1}, \mathrm{BL}+\mathrm{EB} 30 \mathrm{t} \mathrm{ha}^{-1}$ e NPK são similares devido ao maior teor de N. Esse dado é condizente com a análise nutricional das plantas pelo método visual e também com as análises biométricas. $O$ tratamento TF+EB $40 \mathrm{t} \mathrm{ha}^{-1}$ também é bem diferente dos demais devido à maior quantidade de $\mathrm{C}$ (\%). A torta de filtro e o bagaço de laranja são resíduos ricos em $\mathrm{C}$, o que justifica o fato da aplicação desses vermicompostos em maior dosagem, proporcionar maior aporte de C no solo. Ainda no Gráfico de Scores de PC1 x PC2, pode-se observar uma similaridade entre os tratamentos TF+EB $15 \mathrm{t} \mathrm{ha}^{-1}$, TF+EB 30 $\mathrm{t} \mathrm{ha}^{-1}$, EB $30 \mathrm{t} \mathrm{ha}^{-1}$ e EB $40 \mathrm{t} \mathrm{ha}^{-1}$.

O gráfico de Scores e Loadings da PC1 x PC3 (Figura 13 - IV) mostra uma separação entre o tratamento $\mathrm{BL}+\mathrm{EB} 40 \mathrm{t} \mathrm{ha}^{-1}$ dos tratamentos $\mathrm{BL}+\mathrm{EB} 15 \mathrm{t} \mathrm{ha}^{-1} \mathrm{e}$ $\mathrm{BL}+\mathrm{EB} 30 \mathrm{t} \mathrm{ha}^{-1}$, e a variável responsável por essa diferenciação é o $\mathrm{C}$. BL+EB $30 \mathrm{t}$ ha $^{-1}$, TF+EB 40 t ha $^{-1}$ e NPK são similares entre si, devido ao teor de N.

Figura 13 - IV. Gráfico de Scores (a) e Loadings (b) de PC1 x PC3, para os 11 tratamentos em vertissolo

(a)

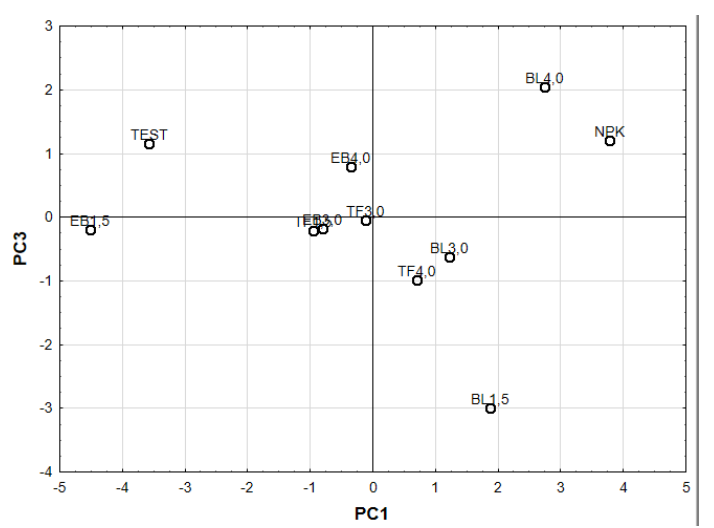

(b)

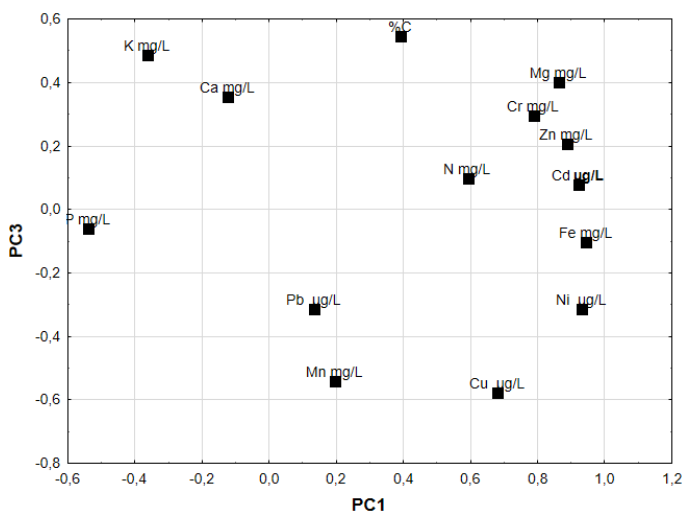

LATOSSOLO: A Figura 14 a - IV apresenta o Gráfico de Scree. Optou-se pelo uso de quatro componentes para explicar a variância dos dados, sendo que as 4 componentes principais explicaram $73,3 \%$ da variância dos dados.

O gráfico de Importância das Variáveis (Figura 14 b - IV) mostra que Ca foi a 
variável menos importante para diferenciação dos tratamentos em latossolo.

Figura 14 - IV. Gráfico de Scree (Scree Plot) (a) e Importância das Variáveis (b), para os 11 tratamentos em latossolo

(a)

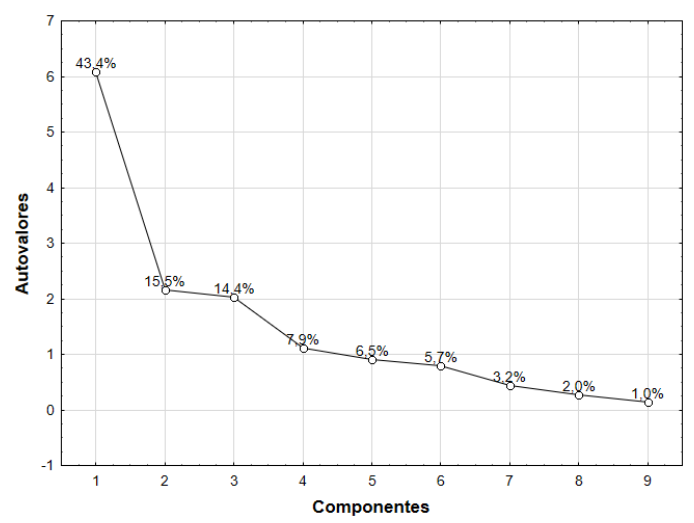

(b)

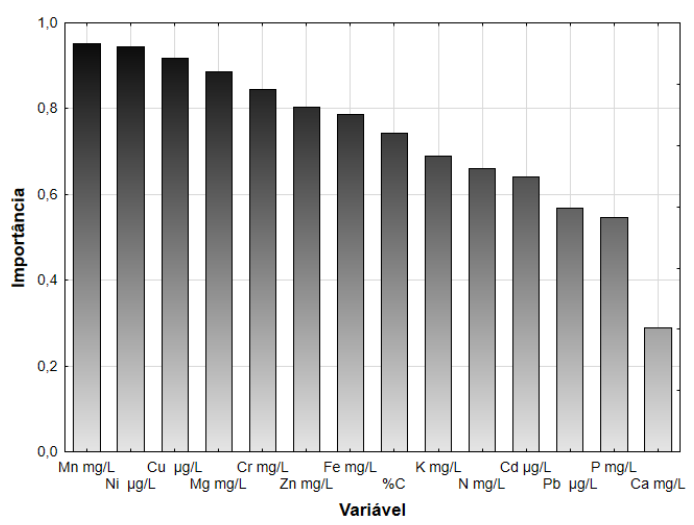

As variáveis mais explicadas pela PC1 são $\mathrm{Mg}, \mathrm{Mn}, \mathrm{Cu}, \mathrm{Fe}, \mathrm{Zn}, \mathrm{Ni}, \mathrm{Cr}$ e Pb (Figura 15a - IV). A PC2 é importante para diferenciar as amostras em função do teor de C (Figura 15 b - IV). A PC3 explica bem as variáveis N, P, K e Cd e a PC4 explica bem $\mathrm{Cd}$ e $\mathrm{Pb}$, embora explique menos que as demais variáveis (Figuras $15 \mathrm{c}$ e d IV). 
Figura 15 - IV. Gráfico de Importância das Variáveis de cada PC, para os 11 tratamentos em latossolo

(s)

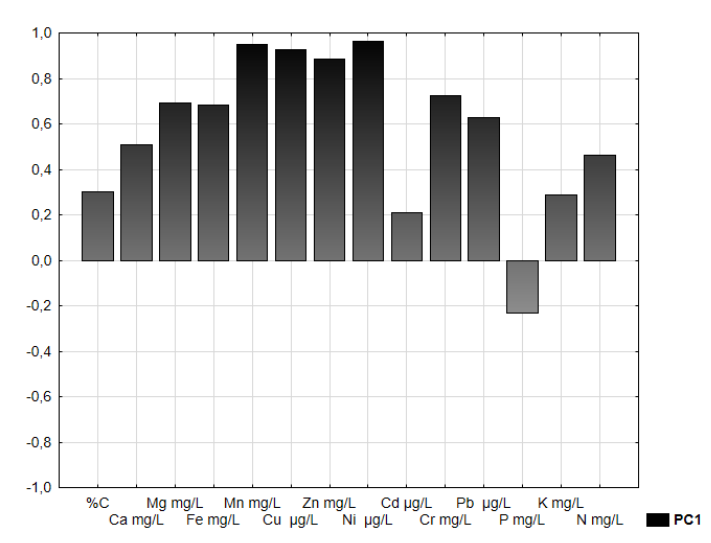

(c)

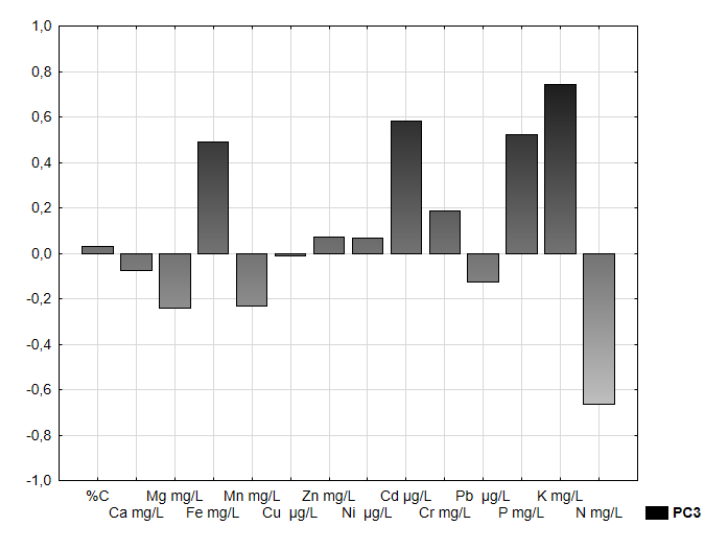

(b)

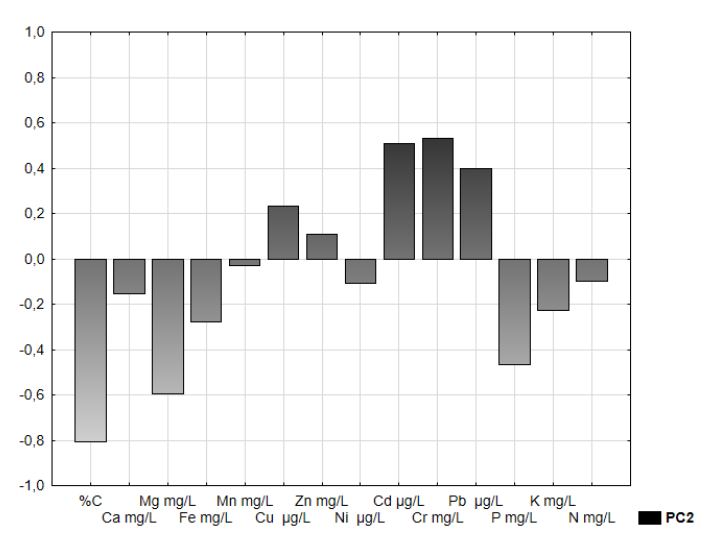

(d)

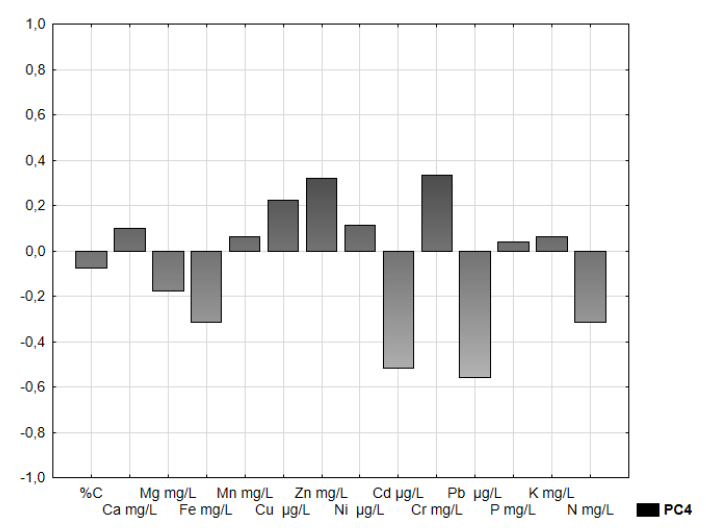

A Figura 16 a - IV apresenta o gráfico de Scores da PC1 x PC2. Pode-se observar que houve separação de algumas amostras, e essa separação ocorreu devido às características químicas dos vermicompostos, das doses de vermicomposto aplicadas e da disponibilidade dos nutrientes no solo. Analisando o gráfico de Scores e Loadings (Figuras 16 a e b - IV), pode-se observar que existe diferença entre os solos com aplicação de vermicomposto de torta de filtro devido às suas diferentes dosagens aplicadas, sendo TF+EB $15 \mathrm{t} \mathrm{ha}^{-1}$ e TF+EB $30 \mathrm{t} \mathrm{ha}^{-1}$ são bem diferentes entre si. As variáveis que os diferenciam são $P$ para o TF+EB 15 t ha' 1, Cu, Zn, Mn e Ni para TF+EB $30 \mathrm{t} \mathrm{ha}^{-1}$ e C para TF+EB $40 \mathrm{t} \mathrm{ha}^{-1}$. A PC1 x PC2 diferencia $\mathrm{BL}+\mathrm{EB} 15 \mathrm{t} \mathrm{ha}^{-1}$ e as principais variáveis responsáveis por isso são $\mathrm{Cr}$, Cu e Zn. 
Os gráficos de Scores e Loadings da PC1 x PC3 (Figuras 16 c e d - IV), mostram o tratamento TF+EB $30 \mathrm{t} \mathrm{ha}^{-1}$ bem diferenciado dos demais em função do seu teor de N. O tratamento NPK bem diferente do TEST em função, principalmente, dos teores de P e K. Os gráficos de PC1 x PC4 (Figuras 16 e e f - IV) mostram os tratamentos EB $40 \mathrm{t} \mathrm{ha}^{-1}$ e TF+EB $40 \mathrm{t} \mathrm{ha}^{-1}$ bem similares, sendo que a variável responsável é o K, o que é coerente com resultados positivos de desenvolvimento dessas plantas, já que o K é um nutriente essencial para o crescimento das mesmas. Os gráficos de PC2 x PC3 (Figuras $16 \mathrm{~g}$ e $\mathrm{h}-\mathrm{IV}$ ), ressaltam em a diferença entre os tratamentos $\mathrm{BL}+\mathrm{EB} 40 \mathrm{t} \mathrm{ha}^{-1}$ e TF+EB $40 \mathrm{tha}^{-1}$ do tratamento TEST, devido ao maior teor de $\mathrm{C}$, o que é coerente com o fato desses vermicompostos terem como matériaprima resíduos ricos em $\mathrm{C}$ (bagaço de laranja e torta de filtro), com elevada relação C/N. O tratamento TF+EB $40 \mathrm{tha}^{-1}$ é diferente de BL + EB $15 \mathrm{tha}{ }^{-1}$, EB $15 \mathrm{tha}^{-1} \mathrm{e}$ TEST devido ao seu elevado teor de $\mathrm{C}$ (Figuras 16 i e j - IV). $\mathrm{O}$ teor de $\mathrm{Pb}$ separa bastante o tratamento $\mathrm{BL}+\mathrm{EB} 30 \mathrm{t}$ ha ${ }^{-1}$ de $\mathrm{BL}+\mathrm{EB} 15 \mathrm{t} \mathrm{ha}{ }^{-1}$. Os gráficos de $\mathrm{PC} 3 \times \mathrm{PC} 4$ (Figuras $16 \mathrm{k}$ el), bem como os de PC1 x PC4 e PC1 x PC3, mostram uma tendência de similaridade entre os tratamentos TEST, EB $15 \mathrm{tha}^{-1}$ e TF+EB $15 \mathrm{t} \mathrm{ha}^{-1}$, porém nunca associados a nutrientes específicos, o que é condizente com outras análises e observações experimentais que mostraram esses três tratamentos com os piores resultados de crescimento das plantas, produção de matéria seca de folhas e qualidade e quantidade de óleo essencial produzido

Figura 16 - IV. Gráfico de Scores (a) e Loadings (b) de PC1 x PC2, para os 11 tratamentos em latossolo

(a)

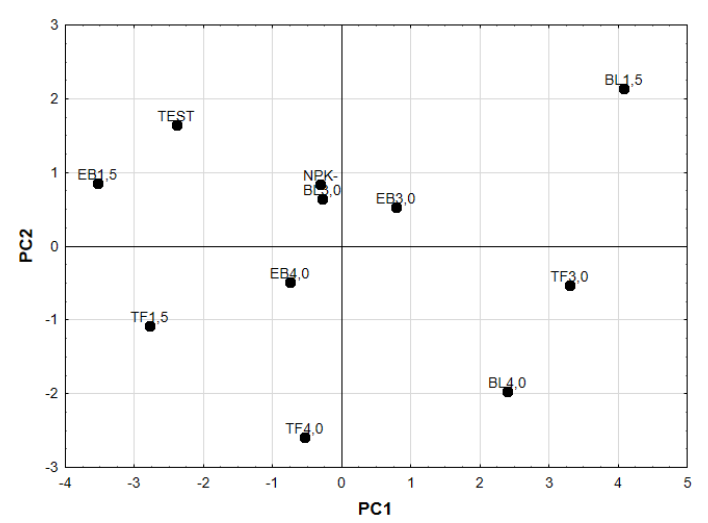

(b)

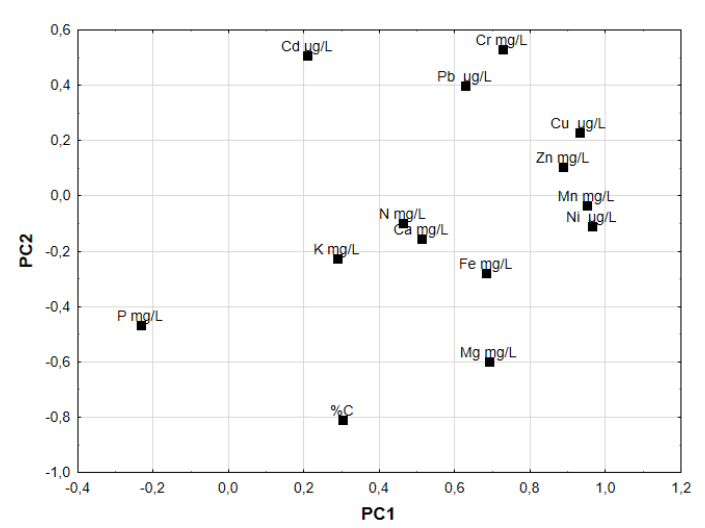


(c)

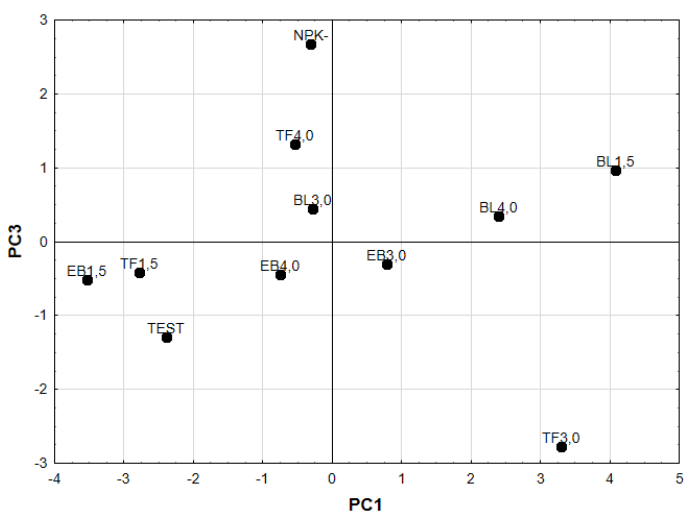

(e)

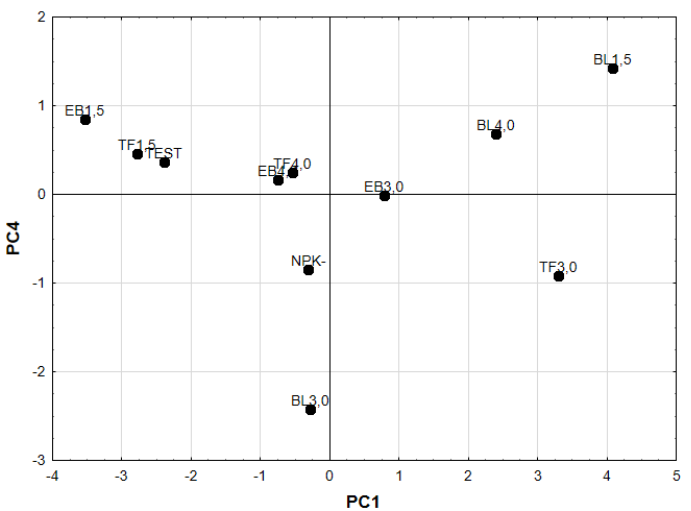

(g)

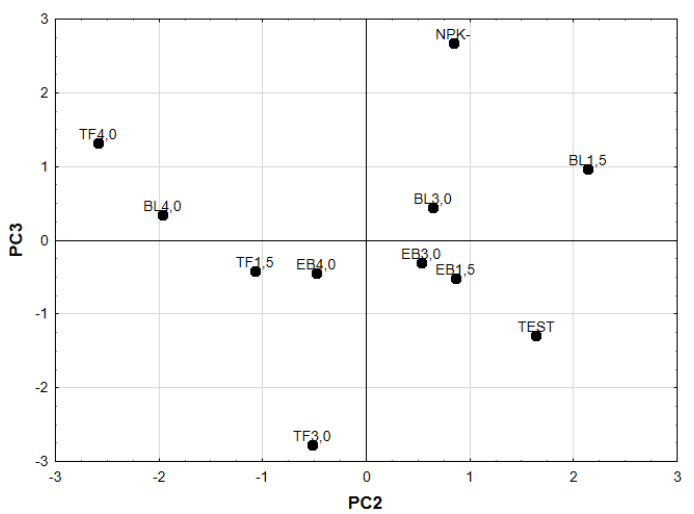

(i) (d)

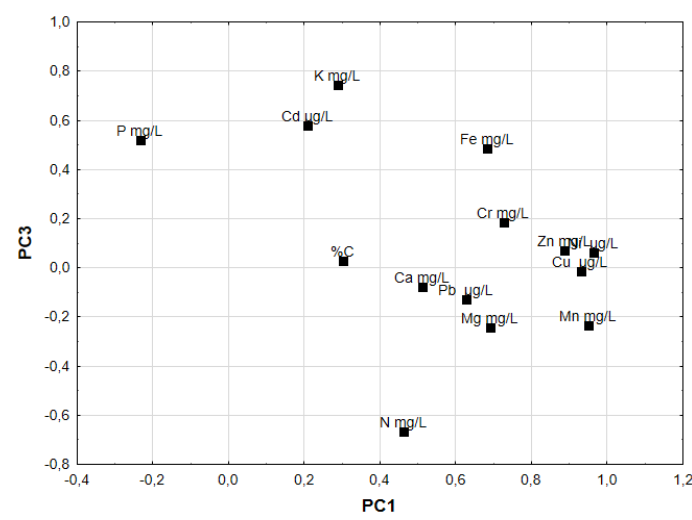

(f)

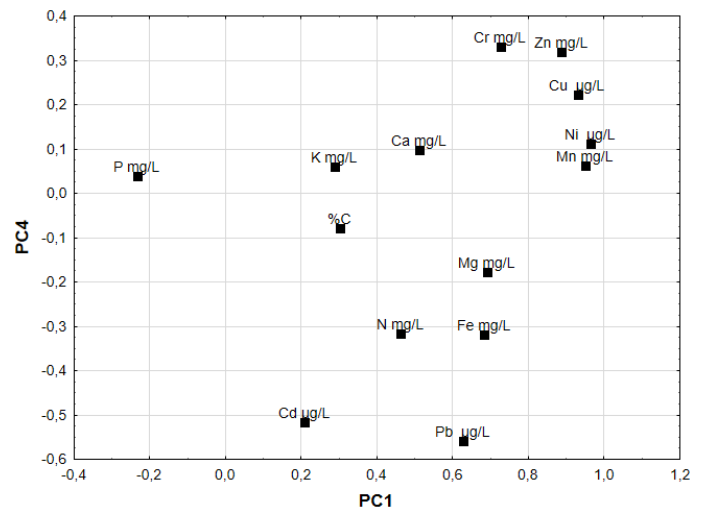

(h)

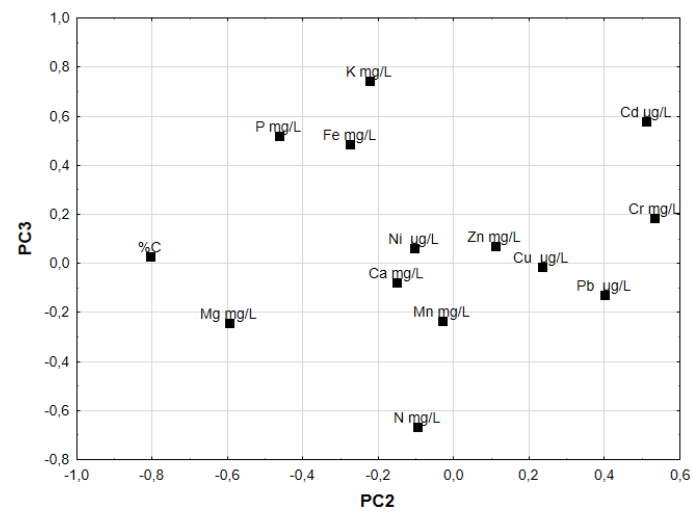

(j) 


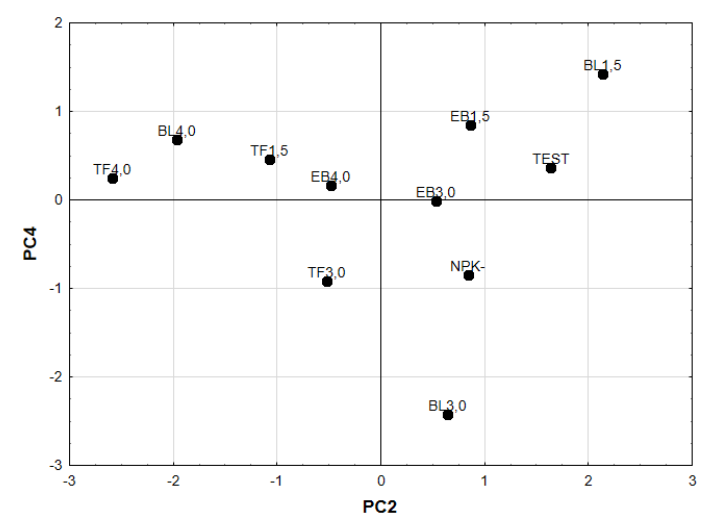

(k)

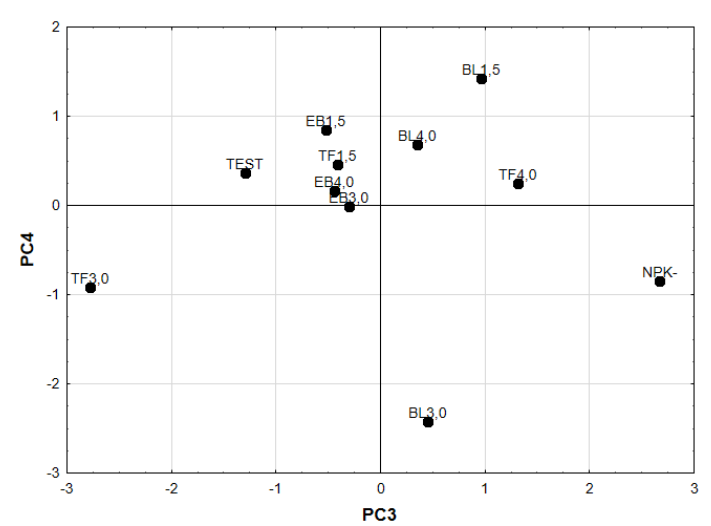

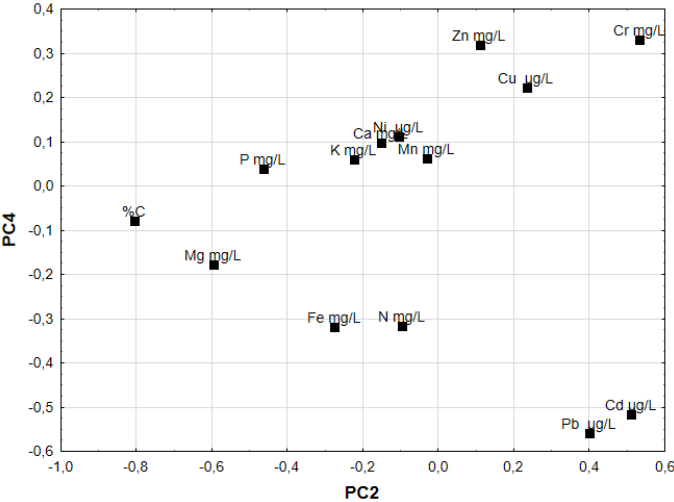

(l)

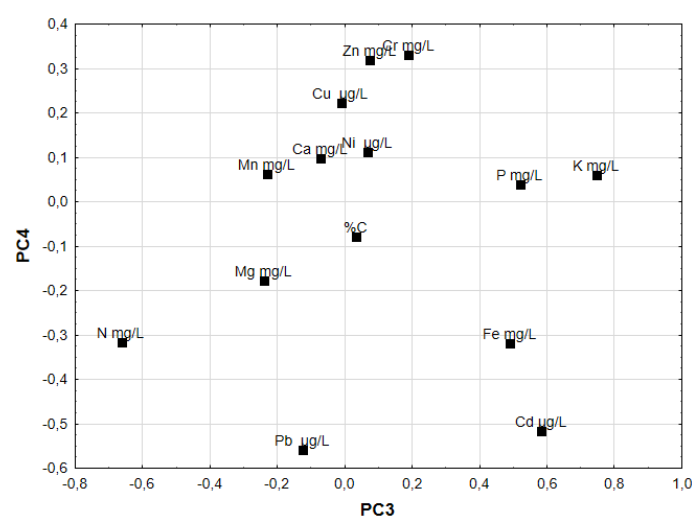

\subsection{Caracterização Espectroscópica da MOS Pós-Cultivo Orgânico de Manjericão}

\subsubsection{Espectroscopia na região do infravermelho próximo (NIRS)}

Os experimentos de NIRS foram realizados para obter informações sobre possíveis diferenças na composição de grupos funcionais da matéria orgânica do solo inteiro para os diferentes tratamentos. A Figura 17 a - IV apresenta os espectros de NIRS das amostras de Latossolo analisadas e a Figura 17 b - IV apesenta os espectros de NIRS referentes às amostras de Vertissolo. Observou-se o mesmo perfil espectral para todos os tratamentos analisados. 
Figura 17 - IV. Espectros de absorbância em infravermelho próximo das amostras de Latossolo (dados brutos) (a) Espectros de absorbância em infravermelho próximo das amostras de Vertissolo (dados brutos) - absorbância $\times \lambda\left(\mathrm{cm}^{-1}\right)$

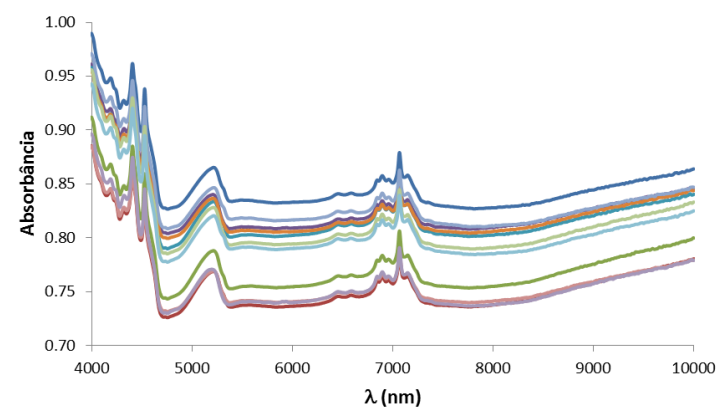

(a)

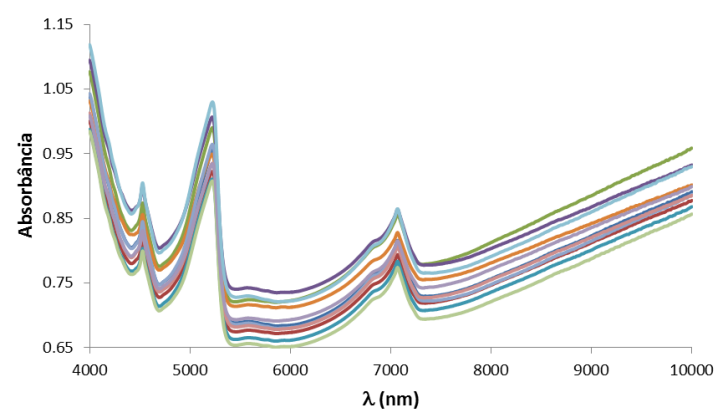

(b)

Os dados brutos foram pré-processados utilizando-se o MSC - Correção Multiplicativa de Sinal (do inglês Multiplicative Scattering Correction), a qual é usada para corrigir efeitos de espalhamento de luz em espectroscopia por refletância, causados por diferenças no tamanho e na forma das partículas (Figuras 18 a e b IV). Assim, pode-se excluir as regiões mais ruidosas do espectro. As Figuras 18 c e d - IV apresentam as regiões de maior peso estatístico dos espectros corrigidos selecionadas para a realização da PCA. 
Figura 18 - IV. Espectros de NIRS dos latossolos (a) e vertissolos (b) com aplicação da Correção Multiplicativa de Sinal. Seleção das regiões de maior peso estatístico para realização da PCA nos espectros de NIRS dos Latossolos (c) Vertissolos (d)

(a)

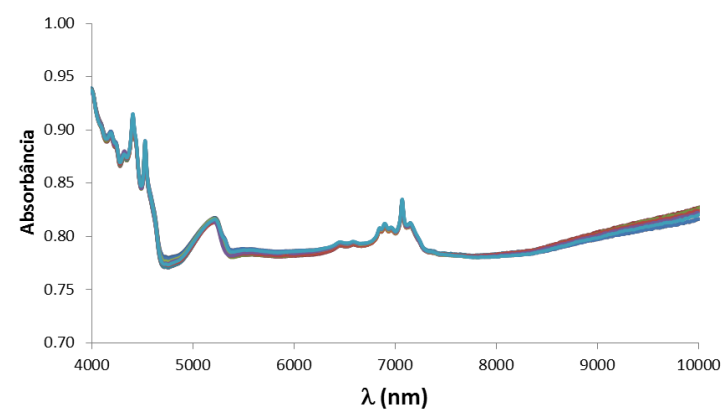

(c)

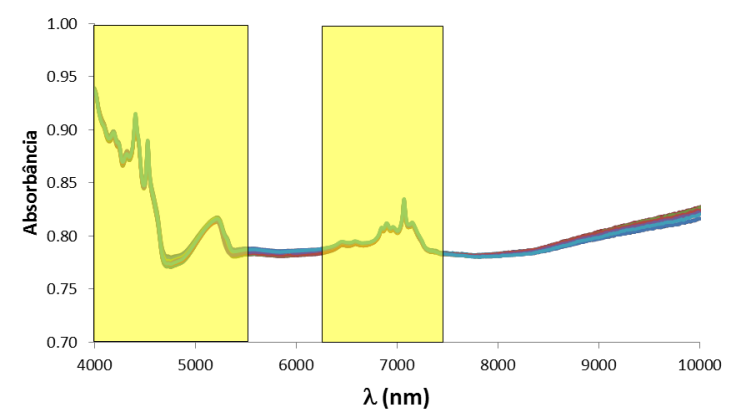

(b)

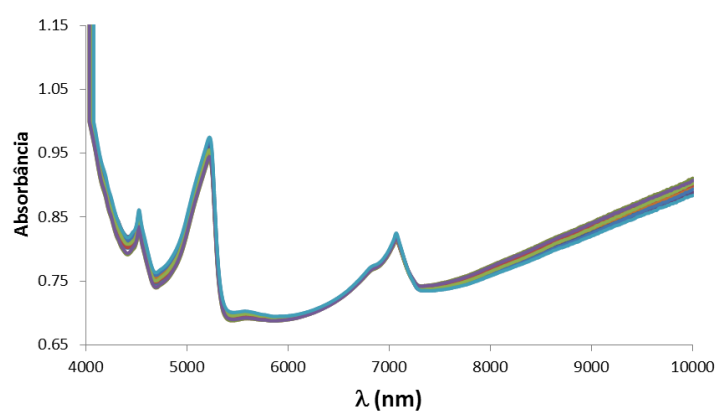

(d)

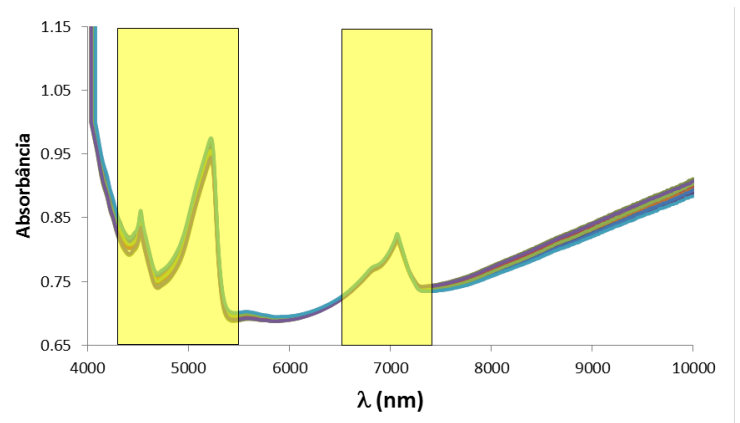

As Figuras 19 - IV (a e b) apresenta o Gráfico de Autovalores ou Scree Plot, o qual mostra a porcentagem de variância que cada PC explica. Este gráfico é utilizado para se descobrir o número de autovalore os importantes. Este procedimento executa uma análise de componentes principais e o objetivo da análise é a obtenção de um pequeno número de combinações lineares das variáveis que representam a maior parte da variabilidade dos dados.

A partir de dados gerados, verificou-se que com a seleção de três componentes principais, é possível explicar $91,5 \%$ da variabilidade dos dados originais do Latossolo com seus diferentes tratamentos. Sendo que a PCA mostrou que a PC1 explica 51,6\% da variância total dos dados, a PC2 explica 28,7\% a PC3 explica 11,2\% (Figura 19 a - IV). 
Para os dados do vertissolo, a PCA mostrou que a PC1 explica $89,6 \%$ da variância total dos dados, a PC2 explica 7,8\% e a PC3 explica 1,2\% (Figura 19 b IV). Dessa forma, com a seleção de três componentes principais, $98,6 \%$ da variância dos dados de latossolo é explicada.

Figura 19 - IV. Gráfico de Autovalores (Scree Plot) para os dados brutos dos latossolos (a) e vertissolos (b)

(a)

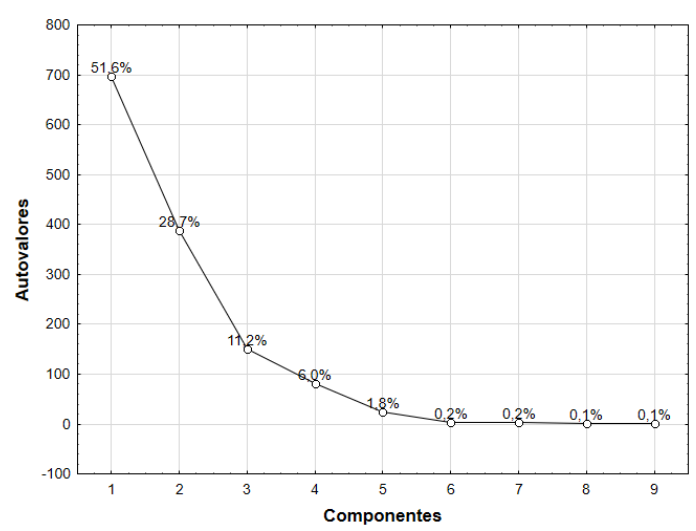

(b)

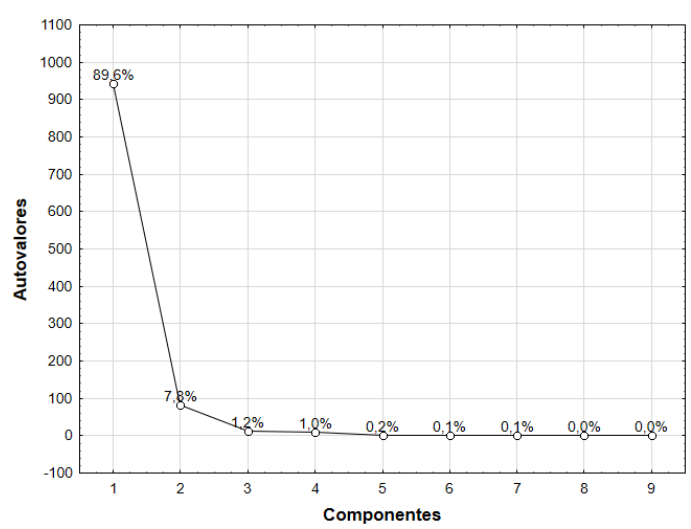

Após o tratamento estatístico dos dados por PCA, com os dados relativos das medidas foram plotados gráficos bidimensionais e tridimensionais (Gráficos de Scores).

LATOSSOLO: A Figura 20 - IV apresenta o Gráfico de Scores da PC1 x PC2 e os Gráficos de Loadings da PC1 e da PC2 para o latossolo. Pode-se observar que houve uma separação das amostras, e essa separação ocorreu devido à diferença de grupos funcionais presentes na matéria orgânica do solo. 
Figura 20 - IV. Gráficos de Loadings da PC1 e PC2 (a e b) e Gráfico de Scores PC1 x PC2 (c) para os 11 tratamentos em latossolos

(a)

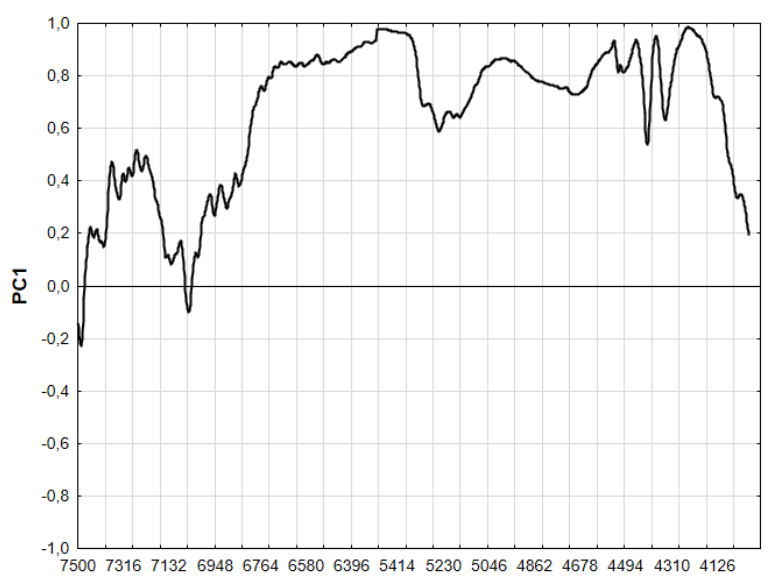

(b)

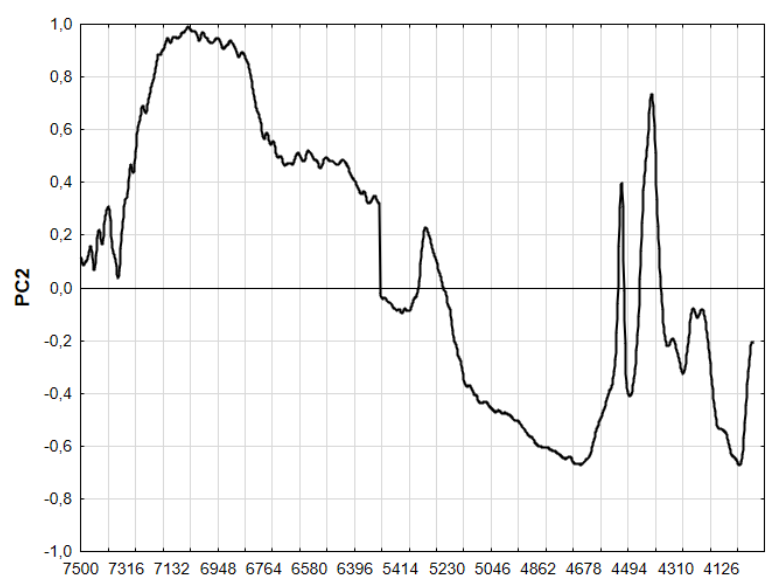

(c)

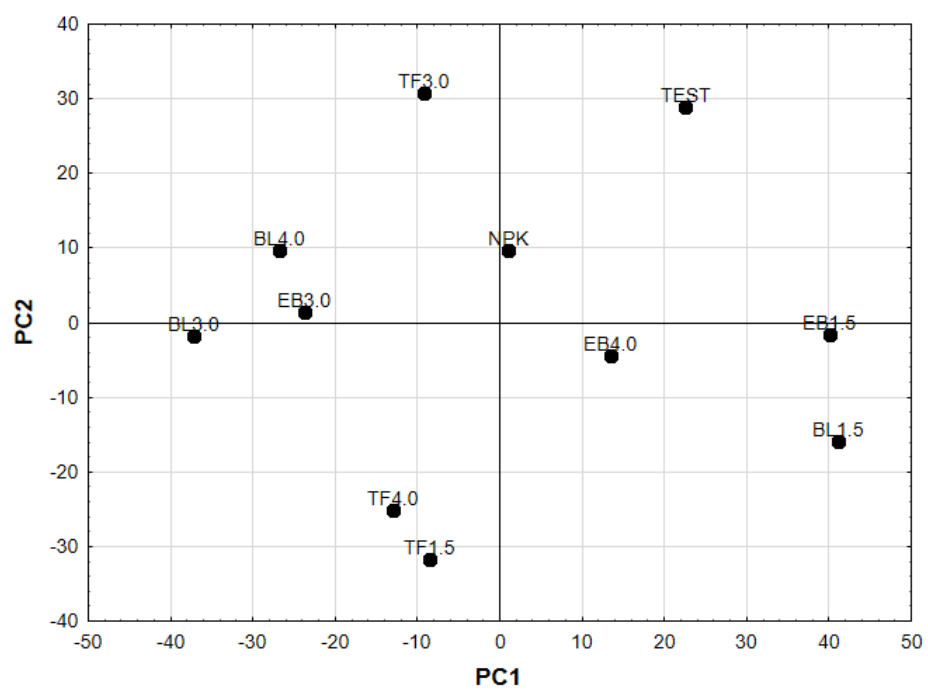

No quadrante superior à esquerda encontra-se um grupo com os tratamentos EB $30 \mathrm{t} \mathrm{ha}^{-1}$, BL+EB $30 \mathrm{t} \mathrm{ha}^{-1}$ e BL+EB $40 \mathrm{ha}^{-1}$ e o TF+EB $30 \mathrm{t} \mathrm{ha}^{-1}$ bem isolado acima. No quadrante superior à direita encontra-se o tratamento TEST bem isolado dos demais. No quadrante inferior à esquerda encontram-se os tratamentos TF+EB $40 \mathrm{t}$ 
$h^{-1}$ e TF+EB $15 \mathrm{t} \mathrm{ha}^{-1}$. E no quadrante inferior à direita $B L+E B 15 \mathrm{t} \mathrm{ha}^{-1}$ e EB $15 \mathrm{t}$ ha ${ }^{1}$ relativamente próximos entre si.

Uma banda em $7144 \mathrm{~cm}^{-1}$ pode ser atribuído a vibrações $\mathrm{OH}$ de $\mathrm{Al}(\mathrm{OH})$ o que indica a presença de caulinita. Já a banda mais bem definido em $7068 \mathrm{~cm}^{-1}$ e outra pouco visível em $6902 \mathrm{~cm}^{-1}$ podem ser resultantes da $1^{\text {a }}$ harmônica da absorção de $\mathrm{OH}$ referentes à álcoois e fenóis. É possível atribuir também a absorção em 7068 cm 1 às vibrações de $\mathrm{OH}$ de moléculas de água e à combinação de estiramentos $\mathrm{CH}$. Essa região é melhor explicada pela PC1 (Figura 20 a - IV).

Duas bandas com absorção máxima marcam a região final dos espectros bem definida. Situadas em $4530 \mathrm{~cm}^{-1}$ e $4408 \mathrm{~cm}^{-1}$, indicam a presença de caulinita e gibbsita além de combinações entre vibrações de estiramentos de $\mathrm{CH}, \mathrm{NH}$ e $\mathrm{OH}$. Nesta região do espectro são observadas outras duas bandas, menos intensas e pouco definidas, em $4320 \mathrm{~cm}^{-1}$ e $4194 \mathrm{~cm}^{-1}$, as quais indicam à presença de água adsorvida à gibbsita. Essas atribuições foram feitas a partir de informações obtidas em Ferraresi, (2010). Essa região é melhor explicada pela PC2 (Figura 20 b - IV).

A Figura 21 - IV apresenta o Gráfico de Scores da PC1 x PC3. No quadrante superior a esquerda encontra-se próximos entre si os tratamentos TF+EB $15 \mathrm{th} \mathrm{ha}^{-1}$, $\mathrm{TF}+\mathrm{EB} 30 \mathrm{t} \mathrm{ha}^{-1}, \mathrm{TF}+\mathrm{EB} 40 \mathrm{t} \mathrm{ha}^{-1}$ e EB $30 \mathrm{t} \mathrm{ha}^{-1}$. No quadrante inferior à esquerda encontram-se BL+EB 30 t ha $^{-1}$ e BL 40 t ha $^{-1}$. O tratamento TEST permanece separado dos demais, isso acontece por ser um solo que não recebeu aporte de matéria orgânica. BL+EB 15 t ha ${ }^{-1}$ e EB 15 t ha $^{-1}$ encontram-se mais próximas entre si.

Em $5186 \mathrm{~cm}^{-1}$ tem-se um sinal mais intenso, sempre presente nas amostras de solo, resultante da $1^{\text {a }}$ harmônica do estiramento $\mathrm{CH}$ de grupos metilas, metilenos e etilenos, da absorção por fosfatos orgânicos e de vários outros grupos funcionais presentes em celulose, lignina, amido, pectina e substâncias húmicas, além de água adsorvida por argilominerais como caulinita e montmorilonita. Essa região é melhor explicada pela PC3 (Figura $21 \mathrm{~b}-$ IV). 
Figura 21 - IV. Gráficos de Loadings da PC1 e PC3 (a e b) e Gráfico de Scores PC1 x PC3 (c) para os 11 tratamentos em latossolos

(a)

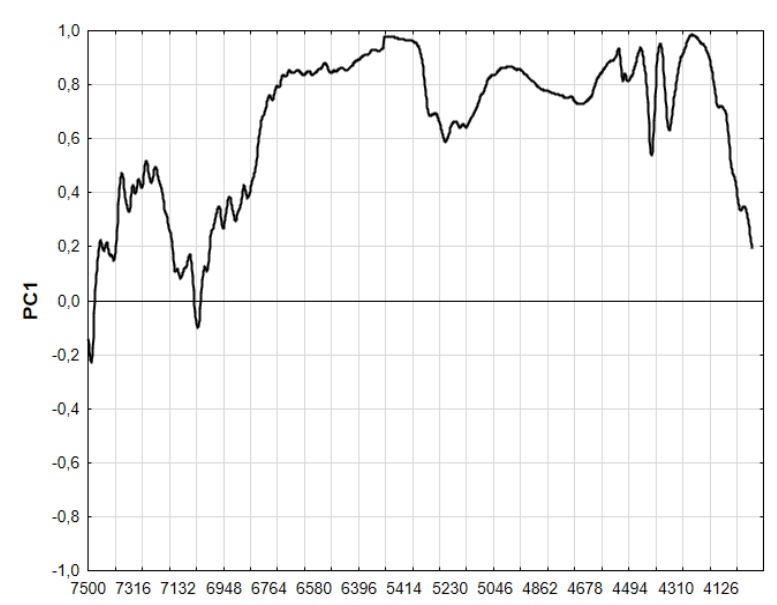

(b)

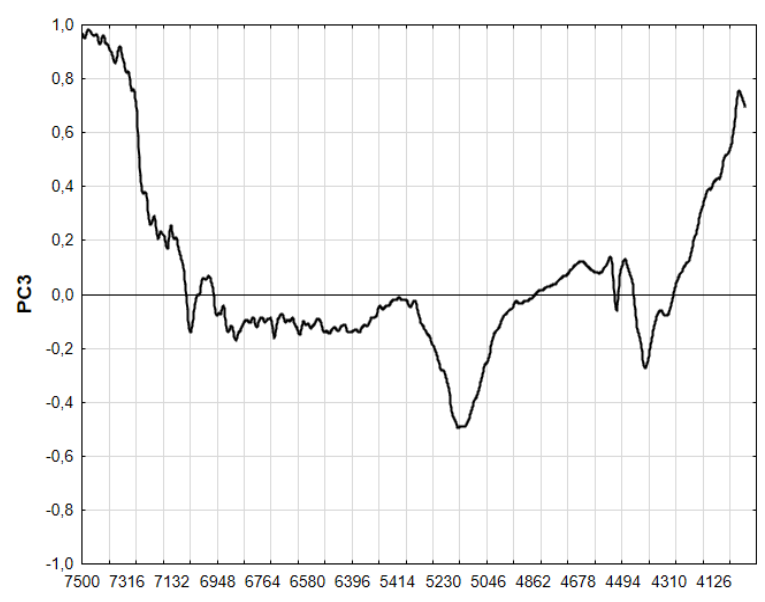

(c)

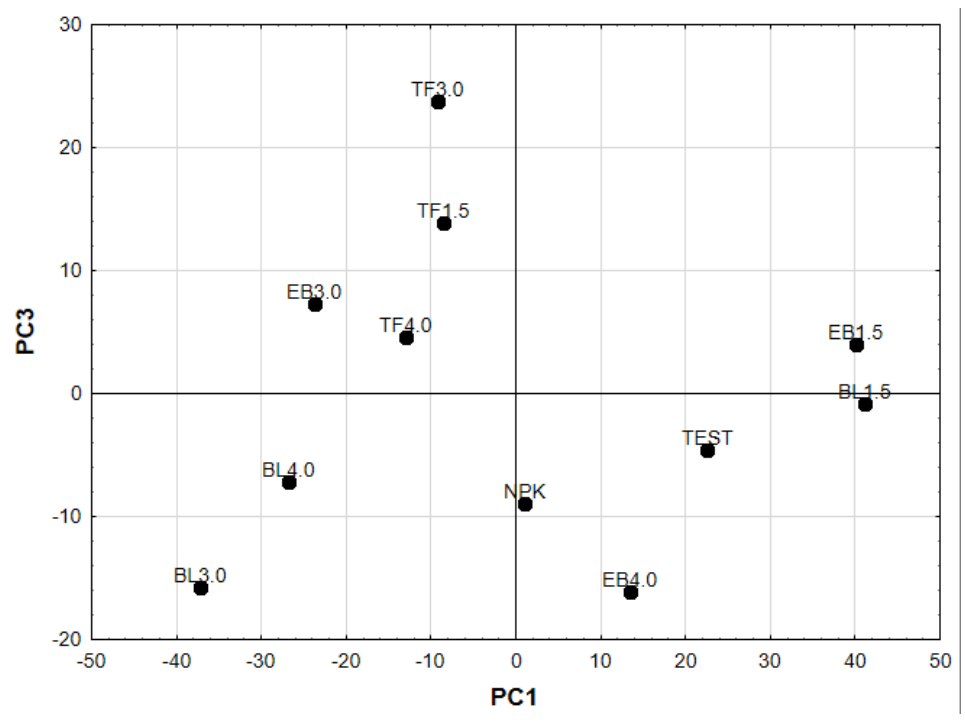

A Figura 22 - IV apresenta o Gráfico de Scores para PC2 x PC3. Os tratamentos TF+EB $30 \mathrm{t} \mathrm{ha}^{-1}$ e o TEST encontram-se bem separados dos demais. É possível observar uma similaridade entre os tratamentos BL+EB $40 \mathrm{t} \mathrm{ha}^{-1}$ e NPK. 
Figura 22 - IV. Gráficos de Loadings da PC2 e PC3 (a e b) e Gráfico de Scores PC1 x PC3 (c) para os 11 tratamentos em latossolos

(a)

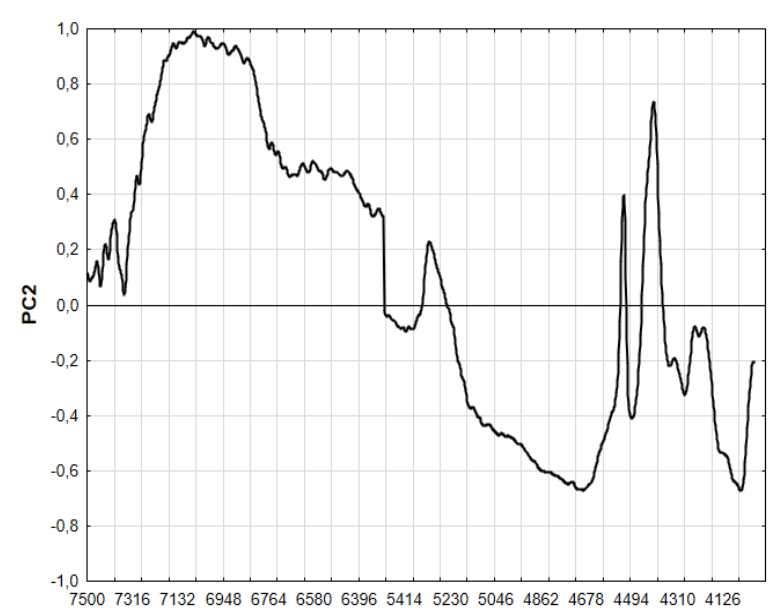

(b)

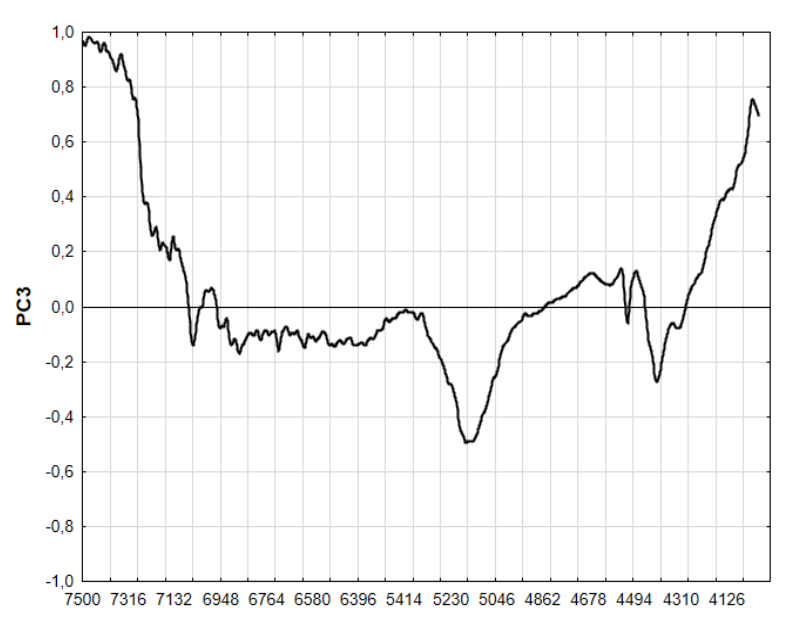

(c)

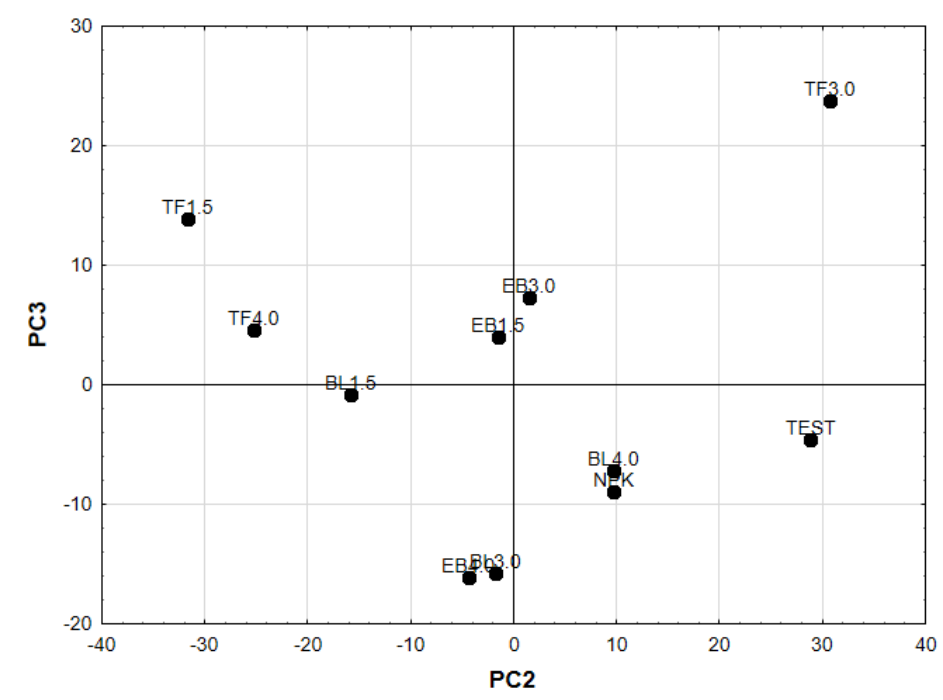

A Figura 23 - IV apresenta o gráfico tridimensional que correlaciona as três componentes principais (PC1, PC2 e PC3). Pode-se observar o tratamento TF+EB 30 t ha ${ }^{-1}$ bem separado dos demais. É possível notar uma tendência de separação dos tratamentos de acordo com as doses de vermicomposto aplicadas no latossolo. 
Figura 23 - IV. Gráfico de Scores PC1 x PC2 x PC3 para os 11 tratamentos em latossolo

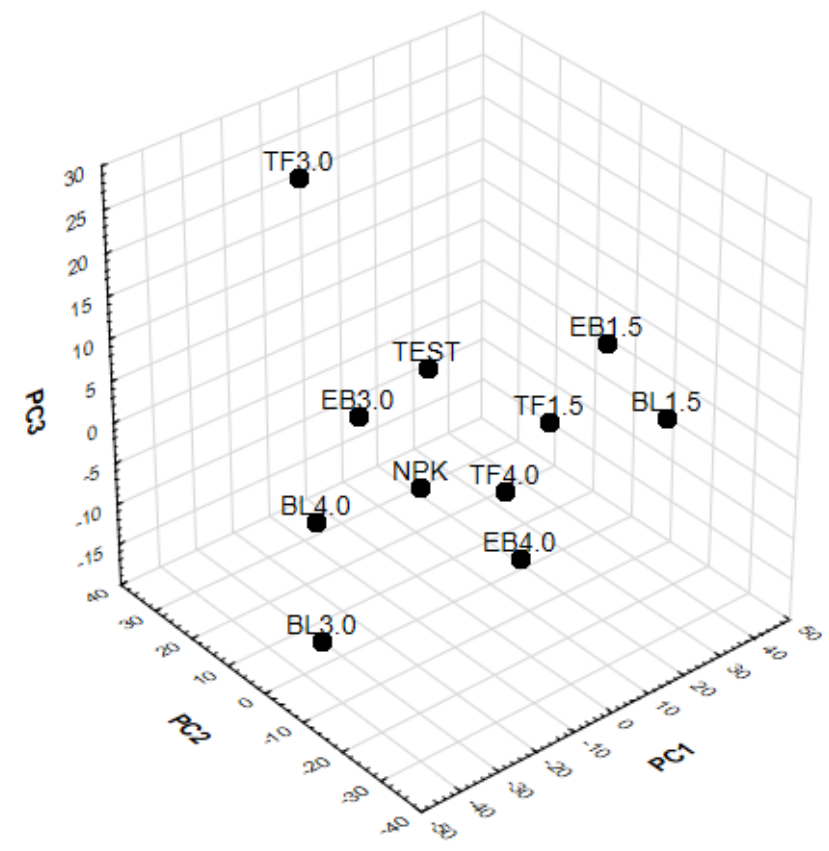

VERTISSOLO: A Figura 24 - IV (c) apresenta o gráfico de Scores da PC1 x PC2 para os dados de vertissolo. Pode-se observar que houve uma separação das amostras em quatro grupos, e essa separação ocorreu devido a diferença de grupos funcionais presentes na matéria orgânica do solo. No quadrante superior à esquerda encontra-se um grupo com os tratamentos NPK, EB $30 \mathrm{t} \mathrm{ha}^{-1} \mathrm{e} B L+E B \quad 40 \mathrm{t} \mathrm{ha}^{-1}$. No quadrante superior à direita encontra-se outro grupo com os tratamentos BL+EB 15 $\mathrm{t} \mathrm{ha}^{-1}$, EB $15 \mathrm{t} \mathrm{ha}^{-1}$ e TEST. No quadrante inferior próximo de zero encontram-se os tratamentos TF+EB $30 \mathrm{t} \mathrm{ha}^{-1}, \mathrm{BL}+\mathrm{EB} 30 \mathrm{t} \mathrm{ha}^{-1}$, EB $40 \mathrm{t} \mathrm{ha}^{-1} \mathrm{e} \mathrm{TF+EB} 40 \mathrm{t} \mathrm{ha}^{-1}$. O tratamento TF+EB $15 \mathrm{t} \mathrm{ha}^{-1}$ encontra-se bem separado dos demais no quadrante inferior à direita. 
Figura 24 - IV. Gráficos de Loadings da PC1 e PC2 (a e b) e Gráfico de Scores PC1 x PC2 (c) para os 11 tratamentos em vertissolo

(a)

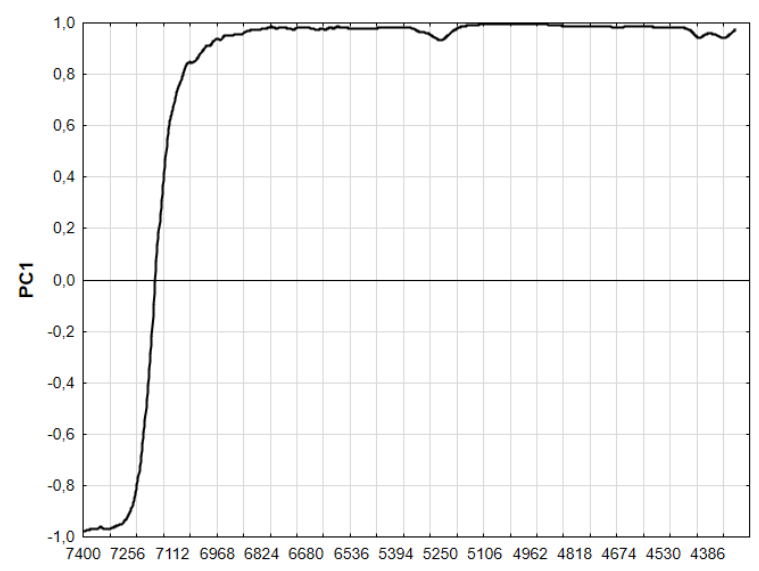

(b)

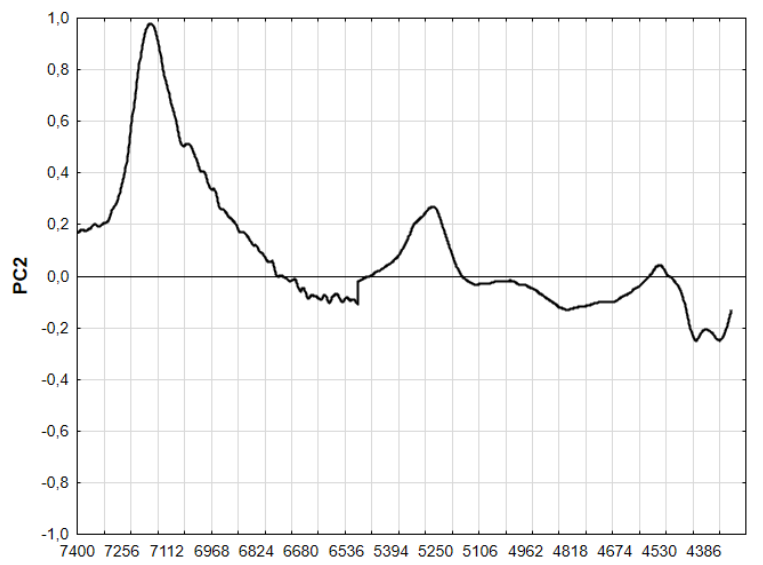

(c)

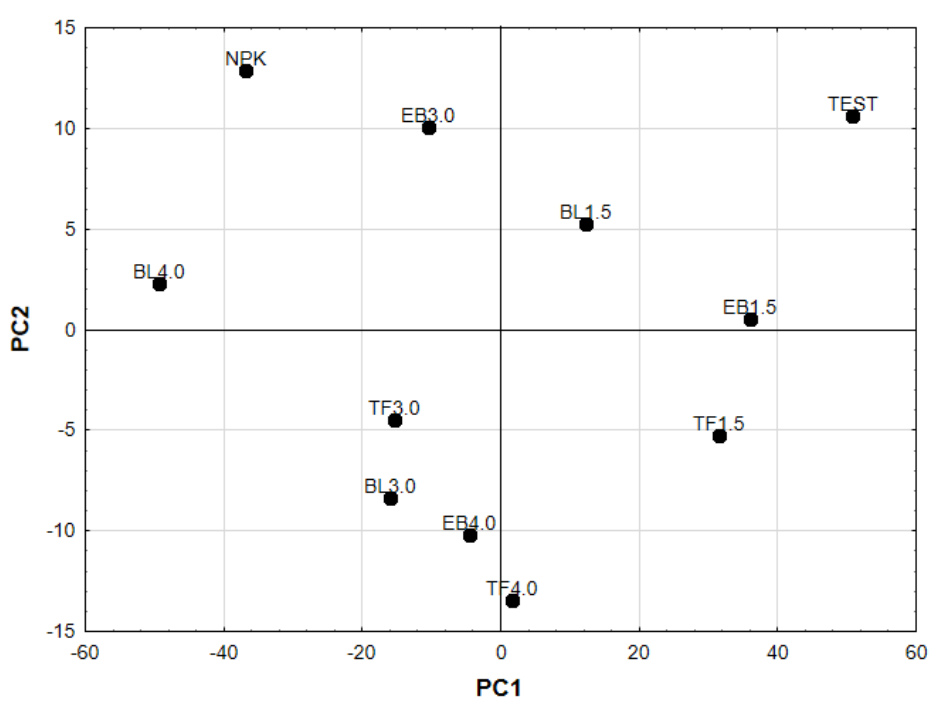

As Figuras 24 - IV a e b apresentam os Gráficos de Loadings das PC1 e PC2 para o Vertissolo. Um sinal em $7144 \mathrm{~cm}^{-1}$ pode ser atribuído a vibrações $\mathrm{OH}$ de $\mathrm{Al}(\mathrm{OH})$ o que indica a presença de caulinita. Já o sinal mais bem definido em $7068 \mathrm{~cm}^{-1} \mathrm{e}$ outro pouco visível em $6902 \mathrm{~cm}^{-1}$ podem ser resultantes da $1^{\text {a }}$ harmônica da absorção de $\mathrm{OH}$ referentes à álcoois e fenóis.

Em $5186 \mathrm{~cm}^{-1}$ tem-se um sinal mais intenso, sempre presente nas amostras de 
solo, resultante da $1^{\text {a }}$ harmônica do estiramento $\mathrm{CH}$ de grupos metilas, metilenos e etilenos, da absorção por fosfatos orgânicos e de vários outros grupos funcionais presentes em celulose, lignina, amido, pectina e substâncias húmicas, além de água adsorvida por argilominerais como caulinita e montmorilonita.

Em $5186 \mathrm{~cm}^{-1}$ tem-se um sinal mais intenso, sempre presente nas amostras de solo, resultante da $1^{\text {a }}$ harmônica do estiramento $\mathrm{CH}$ de grupos metilas, metilenos e etilenos, da absorção por fosfatos orgânicos e de vários outros grupos funcionais presentes em celulose, lignina, amido, pectina e substâncias húmicas, além de água adsorvida por argilominerais como caulinita e montmorilonita. Uma banda com absorção máxima marca a região final dos espectros bem definida. Situadas em 4530 $\mathrm{cm}^{-1}$, indica a presença de caulinita, além de combinações entre vibrações de estiramentos de $\mathrm{CH}, \mathrm{NH}$ e $\mathrm{OH}$. Essas regiões são melhores explicadas pela PC1 (Figura 24 a - IV), porém as bandas estão mais visíveis no Gráfico da PC2 (Figura 24 $\mathrm{b}-\mathrm{VI})$.

\subsection{Caracterização Química e Espectroscópica dos Ácidos Húmicos Extraídos dos Solos Pós-Cultivo: Teores de C e N, Relação C/N, FTIR e Absorção no UV-Vis}

Os teores de C e N (\%) obtidos por Análise Elementar, a razão C/N, os índices de aromaticidade - IA $\left(I_{1660} / I_{2929}\right)$ e de hidrofobicidade - IH $\left(I_{2927} / I_{1059}\right)$ obtidos dos espectros de FTIR e a razãos E4/E6 obtida por UV-vis, estão apresentados na Tabela 5 - IV. 
Tabela 5 - IV. Teor de C e N, razão C/N, Hidrofobicidade $\left(I_{2927} / I_{1059}\right)$, Aromaticidade $\left(I_{1660} / I_{2929}\right)$ e $E_{4} / E_{6}$ dos ácidos húmicos extraídos dos solos pós-cultivo de manjericão (Ocimum basilicum L.)

\begin{tabular}{|c|c|c|c|c|c|c|}
\hline TRATAMENTOS & $\% \mathrm{C}$ & $\% \mathrm{~N}$ & $\mathrm{C} / \mathrm{N}$ & IH $\left(I_{2927} / I_{1059}\right)$ & IA $\left(I_{1660} / I_{2929)}\right.$ & $E_{4} / E_{6}$ \\
\hline $\mathrm{BL}+\mathrm{EB} 15 \mathrm{t} \mathrm{ha}^{-1} \mathrm{~L}$ & $47,76^{\mathrm{ab}} \pm 0,49$ & $3,82^{\mathrm{bcd}} \pm 0,08$ & $14,57 \pm 0,19$ & 1,19 & 1,66 & $8,67^{b c} \pm 0,19$ \\
\hline $\mathrm{BL}+\mathrm{EB} 30 \mathrm{t} \mathrm{ha}^{-1} \mathrm{~L}$ & $56,71^{\mathrm{a}} \pm 17,09$ & $5,26^{a} \pm 1,68$ & $12,62 \pm 0,23$ & 0,22 & 2,40 & $7,64 \pm 0,19$ \\
\hline $\mathrm{BL}+\mathrm{EB} 40 \mathrm{t} \mathrm{ha} \mathrm{a}^{-1} \mathrm{~L}$ & $46,96^{\mathrm{ab}} \pm 1,10$ & $4,20^{\mathrm{abcd}} \pm 0,11$ & $13,04 \pm 0,09$ & 1,25 & 1,08 & $8,00 \pm 0,58$ \\
\hline TF+EB $15 \mathrm{t} \mathrm{ha}^{-1} \mathrm{~L}$ & $44,27^{\mathrm{ab}} \pm 0,24$ & $3,89^{\mathrm{bcd}} \pm 0,04$ & $13,26 \pm 0,24$ & 1,01 & 1,74 & $8,20^{\text {bcd }} \pm 4,14$ \\
\hline $\mathrm{TF}+\mathrm{EB} 30 \mathrm{t} \mathrm{ha}^{-1} \mathrm{~L}$ & $47,57^{\mathrm{ab}} \pm 1,78$ & $4,35^{\mathrm{abc}} \pm 0,22$ & $12,75 \pm 0,18$ & 1,30 & 1,66 & $6,73^{\text {cd }} \pm 0,29$ \\
\hline $\mathrm{TF}+\mathrm{EB} 40 \mathrm{t} \mathrm{ha}^{-1} \mathrm{~L}$ & $45,44^{\mathrm{ab}} \pm 4,38$ & $4,36^{\mathrm{abc}} \pm 0,15$ & $12,15 \pm 0,79$ & 1,20 & 1,59 & $10,83^{a} \pm 0,58$ \\
\hline EB $15 \mathrm{t} \mathrm{ha}^{-1} \mathrm{~L}$ & $44,34^{\mathrm{ab}} \pm 3,42$ & $3,71^{\mathrm{bcd}} \pm 0,08$ & $13,95 \pm 0,08$ & 0,98 & 1,63 & $10,29^{a} \pm 0,61$ \\
\hline EB $30 \mathrm{t} \mathrm{ha}^{-1} \mathrm{~L}$ & $47,25^{\mathrm{ab}} \pm 1,57$ & $4,10^{\mathrm{abcd}} \pm 0,12$ & $13,42 \pm 0,07$ & 1,20 & 1,58 & $7,08^{\text {efg }} \pm 0,29$ \\
\hline EB $40 \mathrm{t} \mathrm{ha}^{-1} \mathrm{~L}$ & $53,99^{\mathrm{ab}} \pm 6,05$ & $4,87^{\mathrm{ab}} \pm 0,96$ & $13,06 \pm 1,14$ & 1,54 & 1,44 & $7,50^{\text {def }} \pm 0,67$ \\
\hline TEST-L & $30,49^{c} \pm 0,03$ & $3,40^{\text {cd }} \pm 0,10$ & $10,47^{\star} \pm 0,30$ & 1,08 & 1,60 & $6,62^{b} \pm 0,58$ \\
\hline NPK-L & $16,5^{d} \pm 0,37$ & $0,42^{\mathrm{e}} \pm 0,02$ & $45,05^{\star} \pm 1,73$ & 1,11 & 1,62 & $8,75^{9} \pm 1,69$ \\
\hline $\mathrm{BL}+\mathrm{EB} 15 \mathrm{t} \mathrm{ha}^{-1} \mathrm{~V}$ & $45,43^{\mathrm{ab}} \pm 0,55$ & $3,54^{\mathrm{bcd}} \pm 0,055$ & $14,99 \pm 0,07$ & 1,42 & 1,55 & $15,00^{a} \pm 0,19$ \\
\hline $\mathrm{BL}+\mathrm{EB} 30 \mathrm{t} \mathrm{ha}^{-1} \mathrm{~V}$ & $45,05^{\mathrm{ab}} \pm 0,38$ & $3,44^{\text {cd }} \pm 0,05$ & $15,27 \pm 0,12$ & 1,52 & 1,72 & $16,67^{\mathrm{a}} \pm 0,19$ \\
\hline $\mathrm{BL}+\mathrm{EB} 40 \mathrm{t} \mathrm{ha}^{-1} \mathrm{~V}$ & $47,19^{\mathrm{ab}} \pm 2,98$ & $3,40^{\text {cd }} \pm 0,18$ & $16,20 \pm 0,17$ & 1,51 & 1,15 & $38,00^{a} \pm 0,58$ \\
\hline $\mathrm{TF}+\mathrm{EB} 15 \mathrm{t} \mathrm{ha}^{-1} \mathrm{~V}$ & $40,46^{\mathrm{bc}} \pm 1,82$ & $2,97^{\mathrm{d}} \pm 0,10$ & $15,52 \pm 0,99$ & 1,27 & 1,42 & $22,50^{\mathrm{a}} \pm 4,14$ \\
\hline $\mathrm{TF}+\mathrm{EB} 30 \mathrm{t} \mathrm{ha}^{-1} \mathrm{~V}$ & $41,16^{\mathrm{bc}} \pm 1,62$ & $3,10^{\text {cd }} \pm 0,15$ & $15,49 \pm 0,29$ & 1,31 & 1,38 & $12,00^{\mathrm{a}} \pm 0,29$ \\
\hline $\mathrm{TF}+\mathrm{EB} 40 \mathrm{t} \mathrm{ha}^{-1} \mathrm{~V}$ & $46,52^{\mathrm{ab}} \pm 0,99$ & $3,58^{b c d} \pm 0,03$ & $15,16 \pm 0,18$ & 1,09 & 1,70 & $33,00^{\mathrm{a}} \pm 0,58$ \\
\hline EB $15 \mathrm{t} \mathrm{ha}^{-1} \mathrm{~V}$ & $46,93^{\mathrm{ab}} \pm 1,12$ & $3,53^{\mathrm{bcd}} \pm 0,11$ & $15,47 \pm 0,12$ & 1,43 & 1,38 & $8,86^{a} \pm 0,61$ \\
\hline EB $30 \mathrm{t} \mathrm{ha}^{-1} \mathrm{~V}$ & $47,76^{\mathrm{ab}} \pm 0,61$ & $3,37^{c d} \pm 0,05$ & $16,54 \pm 0,12$ & 1,50 & 1,61 & $20,50^{\mathrm{a}} \pm 0,29$ \\
\hline EB $40 \mathrm{t} \mathrm{ha}^{-1} \mathrm{~V}$ & $43,56^{\mathrm{abc}} \pm 5,47$ & $3,22^{\text {cd }} \pm 0,46$ & $15,83 \pm 0,33$ & 1,49 & 1,71 & $6,33^{a} \pm 0,67$ \\
\hline TEST-V & $44,41^{\mathrm{ab}} \pm 1,98$ & $3,62^{b c d} \pm 0,12$ & $14,32 \pm 0,17$ & 1,27 & 1,46 & $13,00^{\mathrm{a}} \pm 1,69$ \\
\hline NPK-V & $45,37^{\mathrm{ab}} \pm 2,05$ & $3,55^{\mathrm{bcd}} \pm 0,08$ & $14,93 \pm 0,92$ & 1,29 & 1,48 & $4,00^{\mathrm{a}} \pm 0,57$ \\
\hline
\end{tabular}

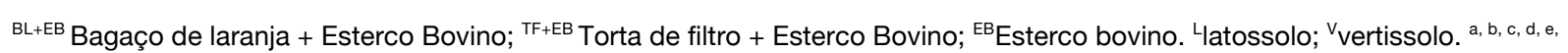
'Valores médios seguidos de seus desvios padrões de três réplicas experimentais. Valores médios seguidos pela mesma letra em uma mesma coluna não são significativamente diferentes em $p<0.05$ pelo Teste de Tukey. 
LATOSSOLO: A adubação com vermicomposto proporcionou as maiores médias para os teores de C-AH. Pode-se observar na Tabela 5 - IV que de acordo com o Teste de Tukey $(p<0,05) \circ \mathrm{AH}$ referente ao tratamento BL+EB $30 \mathrm{t} \mathrm{ha}^{-1}$ apresentou o maior teor de $C(54,71 \% \pm 17,09)$, enquanto que $\circ \mathrm{AH}$ extraído do latossolo testemunha apresentou $30,49 \% \pm 0,03 \mathrm{de} C$. Os teores de $\mathrm{C}$-AH dos demais tratamentos referentes à adubação orgânica em latossolo são estaticamente iguais entre si, sendo que todos proporcionaram importante incremento no teor de $\mathrm{C}$ quando comparados ao AH extraído do solo sem adubação (TEST).

O latossolo que recebeu adubação mineral (NPK) apresentou considerável decréscimo no teor de $\mathrm{C}$ do $\mathrm{AH}(16,5 \% \pm 0,37)$.

O teor elevado de nitrogênio possivelmente proporcionou uma mineralização acelerada dos resíduos vegetais (REINTAM et al., 2000). Sendo um material rico em $\mathrm{N}$, a decomposição do adubo e a degradação das moléculas orgânicas e, talvez, até mesmo do $\mathrm{C}$ original do solo foram mais rápidas resultando em teores menores de $\mathrm{C}$ no solo. Portanto, houve maior mineralização do C (MARCHI et al., 2008). O AH referente ao tratamento $\mathrm{BL}+\mathrm{EB} 30 \mathrm{t} \mathrm{ha}^{-1}$ apresentou o maior teor de $\mathrm{N} 5,26 \% \pm 1,68$ ), enquanto o AH-TEST apresentou $3,4 \% \pm 0,10$.

A partir dos dados da análise elementar é possível calcular a relação $\mathrm{C} / \mathrm{N}, \mathrm{a}$ qual é comumente utilizada para inferir sobre o grau de humificação, sendo que quanto menor a relação $\mathrm{C} / \mathrm{N}$, maior o grau de humificação. A relação $\mathrm{C} / \mathrm{N}$ dos $\mathrm{AH}$ dos diferentes tratamentos não diferem entre si, mas são em geral mais elevados que para o AH-TEST e bem menores que para o AH-NPK. Os AH extraídos dos solos com adubação orgânica apresentam um menor grau de humificação, justamente devido ao aporte de matéria orgânica fresca via vermicompostos.

Para os solos com adição de vermicomposto $B L+E B$, foi possível observar aumento considerável no IA dos ácidos húmicos na dosagem intermediária (30 t ha$\left.{ }^{1}\right)$ e uma diminuição no IA na dosagem maior (40 $\left.\mathrm{t} \mathrm{ha}^{-1}\right)$ quando comparados à dosagem menor (15 t ha-1) e ao tratamento testemunha. $O$ tratamento $B L+E B$ na dosagem intermediária proporcionou maior incorporação de estruturas aromáticas aos ácidos húmicos extraídos do no solo. 
Para os vermicompostos de EB e de TF+EB foi possível observar que o aumento na dosagem aplicada ao solo proporcionou diminuição no IA dos ácidos húmicos extraídos, exceto para o vermicomposto de BL+EB em sua dosagem intermediária (30 t ha-1), o qual propiciou maior incorporação de estruturas aromáticas aos AHs.

A incorporação dos vermicompostos altera a estrutura dos AHs extraídos desses solos. Os índices IA e IH dos AHs do solo testemunha e do solo com adição de NPK foram muito similares, o mesmo não aconteceu com relação aos demais tratamentos.

Os ácidos húmicos representam a fração mais estabilizada da matéria orgânica. A constituição dos AHs depende de diversos fatores tais como: material de origem, tipo de microrganismos presentes durante a humificação, condições climáticas etc. Assim, não foi verificada relação direta entre quantidade de matéria orgânica e quantidade de ácidos húmicos e nem com a estrutura desses ácidos húmicos.

A partir da absorção de radiação no UV-Vis, foram obtidas as razões entre as absorbâncias em $465 \mathrm{~nm}$ e $665 \mathrm{~nm}$, conhecida como razão $\mathrm{E}_{4} / \mathrm{E}_{6}$. Essa razão também está associada ao grau de condensação de grupos aromáticos. $A$ razão $E_{4} / E_{6}$ está relacionada ao sistema $\pi$ da molécula húmica e permite, em alguns casos, uma avaliação relativa da massa molecular das amostras. $O$ decréscimo da razão $E_{4} / E_{6}$ está diretamente relacionado com o aumento da massa molecular, condensação de carbonos aromáticos e aromaticidade, e inversamente relacionado à quantidade de grupos alifáticos. Os valores determinados via $E_{4} / E_{6}$ devem ser utilizados cautelosamente e em conjunto com outros parâmetros espectroscópicos mais precisos (SANTOS, 2006). Os valores determinados pela razão $E_{4} / E_{6}$ variam de 6,62 (AH-TEST) a 10,83 (AH-TF+EB $\left.40 \mathrm{t} \mathrm{ha}^{-1}\right)$.

Para os ácidos húmicos referentes à adubação com vermicomposto de torta de filtro e esterco bovino, pode-se observar uma tendência de diminuição da razão $E_{4} / E_{6}$ com o aumento da dosagem aplicada de vermicomposto. Não foi observada variação significativa para os ácidos húmicos que receberam adição de vermicomposto de bagaço de laranja. 
VERTISSOLO: A adubação com vermicomposto proporcionou diferença significativa entre as médias para os teores de C-AH. Pode-se observar na Tabela 5 - IV que os valores ficam entre 40,46\% $\pm 1,82\left(\mathrm{AH}-\mathrm{TF}+\mathrm{EB} 1,5 \mathrm{t} \mathrm{ha}^{-1}\right)$ e 47,76 $\pm 0,61$ (AH-EB $30 \mathrm{t} \mathrm{ha}^{-1}$ ). Sento que o AH-TEST apresentou teor de $\mathrm{C}$ de $44,41 \% \pm 1,98$. O teor de $\mathrm{C}$ elevado presente naturalmente nos vertissolos pode ter mascarado a influência dos vermicompostos nesse atributo. $\mathrm{O}$ AH referente ao tratamento TF+EB $15 \mathrm{t} \mathrm{ha}^{-1}$ apresentou o menor teor de $N(2,97 \% \pm 0,10)$, enquanto os demais tratamentos não diferiram significativamente entre si. Obviamente os teores de $\mathrm{C} \mathrm{e}$ $\mathrm{N}$ muito similares entre os tratamentos refletiram no cálculo da relação $\mathrm{C} / \mathrm{N}$. Em geral, os tratamentos apresentam valores de $\mathrm{C} / \mathrm{N}$ similares, sendo que para os ácidos húmicos referentes às adubações com vermicomposto de bagaço de laranja podese observar uma tendência de diminuição da $\mathrm{C} / \mathrm{N}$ com o aumento da dose aplicada.

Para os solos com adição de vermicomposto $B L+E B$, foi possível observar um aumento considerável no IA dos ácidos húmicos na dosagem menor e na dosagem intermediária (15 e $30 \mathrm{t} \mathrm{ha}^{-1}$ ) e uma diminuição no IA na dosagem maior (40 t ha-1) quando comparados ao tratamento testemunha e ao NPK. O tratamento BL+EB na dosagem intermediária proporcionou maior incorporação de estruturas aromáticas aos ácidos húmicos extraídos do no solo, assim como foi observado para o latossolo.

Para os tratamentos de TF+EB foi possível observar aumento no IA dos ácidos húmicos extraídos, apenas para a maior dosagem aplicada. As dosagens 15 e $30 \mathrm{t}$ ha $^{-1}$ proporcionaram uma diminuição no IA comparado ao AH-TEST. Os AH de EB 30 e $40 \mathrm{t} \mathrm{ha}^{-1}$ proporcionaram considerável aumento no IA. Assim como observado para o latossolo, a incorporação dos vermicompostos alterou a estrutura dos AHs extraídos desses solos. Os índices IA e IH dos AHs do solo testemunha e do solo com adição de NPK foram muito similares, e o mesmo não aconteceu com relação aos demais tratamentos.

Para os ácidos húmicos referentes à adubação com vermicomposto de bagaço de laranja, pode-se observar que 0 aumento da razão $E_{4} / E_{6}$ foi diretamente proporcional ao aumento da dosagem aplicada. Apenas os ácidos húmicos 
referentes à adubação com EB 15 e $40 \mathrm{t} \mathrm{ha}^{-1}$ apresentaram valores de $\mathrm{E}_{4} / \mathrm{E}_{6}$ inferiores a AH-TEST, sugerindo maior grau de humificação. 


\section{CONCLUSÕES}

Para o latossolo, de maneira geral, houve influência bastante positiva das doses de adubação com os vermicompostos, principalmente para os oriundos das misturas de bagaço de laranja e torta de filtro com esterco bovino (BL+EB e TF+EB). Para o vertissolo as mudanças foram mais discretas, pois o vertissolo é naturalmente um solo bastante rico em nutrientes e em matéria orgânica.

Com auxílio das Análises de Componentes Principais, foi possível diferenciar os tratamentos em função do teor de nutrientes aportado no solo. Os dois solos se mostraram muito diferentes quimicamente. As características intrínsecas de cada tipo de solo influenciaram na disponibilidade dos nutrientes após a aplicação dos vermicompostos em suas diferentes dosagens. Dessa forma, o vertissolo apresentou-se como um solo mais rico em micronutrientes enquanto o latossolo apresentou-se como um solo mais rico em macronutrientes. Os resultados evidenciados por meio das PCA's são condizentes com o diagnóstico nutricional das plantas pelo método visual e com os resultados das análises biométricas do Manjericão.

O estudo da influência dos vermicompostos na matéria orgânica do solo, deixa claro que o aporte de matéria orgânica relativamente humificada é de grande valia para a melhoria das características do solo como um todo.

Principalmente para o solo arenoso (latossolo), a condução do experimento em vasos, em ambiente protejido, propiciou alterações relevantes na dinâmica da matéria orgânica, apesar do curto tempo de duração do experimento (60 dias). Possivelmente pelo fato de solos arenosos serem mais susceptíveis à degradação microbiana da matéria orgânica. Dessa forma, pôde-se inferir sobre dinâmica da matéria orgânica dos solos analisados por técnicas químicas e espectroscópicas utilizadas, visto que essas permitiram a observação de variações na decomposição e humificação, decorrentes da adição do vermicomposto ao solo. Bem como, permitiram determinar a natureza química e as variações de grupamentos funcionais 
da matéria orgânica devido à adição de composto orgânico aos solos analisados.

De modo geral constata-se a viabilidade do uso de vermicompostos de misturas de bagaço de laranja e torta de filtro com esterco bovino como alternativa ao uso de fertilizantes minerais, contudo o manejo e as implicações na nutrição de plantas e a plena produtividade das culturas ainda representa desafio importante para as pesquisas. Dentre as doses dos vermicompostos avaliadas, em geral a aplicação da dosagem intermediária (30 t ha-1 ou 3,0\%) apresenta resultados superiores em termos de qualidade nutricional e da MOS, sendo dessa forma a melhor opção para manejo do solo para cultivo de Manjericão. Em estudos futuros, a dosagem $30 \mathrm{t} \mathrm{ha}^{-1}$ poderia ser adotada como dosagem agronômica recomendada, bem como a mistura de resíduos orgânicos agroindustriais para produção do vermicomposto. 
ABREU-JUNIOR, C. H., MARTIN-NETO, L; MILORI, D. M. B. P.; SIMÕES, M. L.; SILVA, W. T. L. MétodoS Analíticos usados em química do solo. In: SENESI, N.; XING, B.; HUANG, P.M. (Org.). Química e mineralogia do solo: aplicações. Viçosa: SBCS, 2009. v. 2, p. 624.

ANDREUX, F. Húmus in word soils. In: PICCOLO, A. (Ed.) Humic substances in terrestrial ecosystems. Amsterdam: Elsevier, 1996. p. 45-100.

BAALOUSHA, M.; MOTELICA-HEINO, M.; LE COUSTUMER, P. Conformation and size of humic substances: effects on major cation concentration and type, $\mathrm{pH}$, salinity, and residence time. Colloids and Surfaces A: Physicochemical and Engineering Aspects, v. 272, p. 48-55, 2006.

BAYER, C.; MARTIN-NETO, L.; MIELNICZUK, J.; CERETTA, C. A. Fracionamento da matéria orgânica e sua avaliação qualitativa por EPR num solo submetido dez anos a diferentes sistemas de cultura em plantio direto. In: SIMPÓSIO NACIONAL DE INSTRUMENTAÇÃO AGROPECUÁRIA, 1., 1996, São Carlos. Anais... São Carlos: Embrapa Instrumentação Agropecuária, 1997. p. 115-121.

BEN-DOR, E.; BANIN, A. Near-Infrared analysis as a rapid method to simultaneously evaluate several soil properties. Soil Science Society of America Journal, v. 59, p. 364-372, 1995.

BURDON, J. Are the traditional concepts of structures of humic substances realistic? Soil Science, v. 166, n. 11, p. 752-769, 2001.

CANELLAS, L. P.; SANTOS, G. A.; RUMJANEK, V. M.; MORAES, A. A.; GURIDI, F. Distribuição da matéria orgânica e características de ácidos húmicos em solos com adição de resíduos de origem urbana. Pesquisa Agropecuária Brasileira, v. 36, n. 12, p. 1529-1538, 2001.

CERETTA, C. A.; BAYER, C.; DICK, D. P.; MARTIN-NETO, L.; COLNAGO, L. A. Métodos espectroscópicos. In: SANTOS, G.A.; CAMARGO, F.A.O. (Ed). I Fundamentos da Matéria Orgânica do Solo: ecossistemas tropicais e subtropicais. Porto Alegre: Metropole, 2008. p. 201-205. 
CLAPP, C. E.; HAYES, M. H. B. Sizes and shapes of humic substances. Soil Science, v. 164, n. 12, p. 777-789, 1999.

DIALLO, M. S.; SIMPSON, A.; GASSMAN, P.; FAULON, J. L.; JOHNSON, J. H.; GODDARD, W. A.; HATCHER, P. G. 3-D Structural modeling of humic acids through experimental characterization, computer assisted structure elucidation and atomistic simulations. Environmental Science \& Technology, v. 37, p. 1783-1793, 2003.

DICK, D. P.; NOVOTNY, E. H.; DIECKOW, J.; BAYER, C. Química da material orgânica do solo. In: SENESI, N.; XING, B.; HUANG, P.M. (Org.).Química e mineralogia do solo: aplicações. Viçosa: SBCS, 2009. v. 2, p. 2.

ENCYCLOPEDIA of soil science. New York: Rattan Lal, 2006. v. 1.

HAYES, M. H. B.; CLAPP, C. E. Humic substances: considerations of compositions, aspects of structures, and environmental influences. Soil Science, v. 166, p. 723737, 2001.

HELAL, A. A.; MURAD, G. A.; HELAL, A. A. Characterization of different humic materials by various analytical techniques. Arabian Journal of Chemistry, v. 4, p. $51-54,2011$

IKEYA, K.; HIKAGE, T.; ARAI, S.; WATANABE, A. Size distribution of condensed aromatic rings in various soil humic acids. Organic Geochemistry, v. 42, p. 55-61, 2011.

KONONOVA, M. M. Matéria orgânica del suelo: su natureza, propriedades e métodos de investigacion. Barcelona: Oikos-Tau, 1982. 365 p.

KONONOVA, M. M. Soil organic matter. Oxford: Pergamon, 1966. 272 p.

LANDGRAF, M. D.; MESSIAS R. A.; REZENDE, M. O. O. A importância ambiental da vermicompostagem: vantagens e aplicações. São Carlos: Rima, 2005. 105 p.

MACCARTHY, P. The principles of humic substances. Soil Science, v. 166, n. 11, p. 738- 751, 2001. 
MARCHI, Edilene Carvalho Santos et al. Efeito da adubação orgânica sobre as frações de carbono de solos cultivados com alface americana. Ciência Agrotecnologia, Lavras, v. 32, n. 6, p. 1760-1766, Dec. 2008.

NARDI, S.; PIZZEGHELLO, D.; MUSCOLO, A; VIANELLO, A. Physiological effects of humic substances on higher plants. Soil Biology \& Biochemistry, v. 34, p. 15271536, 2002.

PICCOLO, A. The supramolecular structure of humic substances. Soil Science, v. 166, p. 810-832, 2001.

REINTAM, L.; KANN, J.; KAILAS, T.; KÄHRIK, R. Elemental composition of humic and fulvic acids in the Epipedon of some Estonian soils. Proceedings of the Estonian Academy of Scientific Chemistry, v. 49, p. 131-144, 2000.

SANTOS, L. M. Dinâmica da matéria orgânica e destino de metais pesados em dois solos submetidos à aplicação de lodo de esgoto. 2006. 143 f. Dissertação (Mestrado em Ciências - Química Analítica) - Instituto de Química de São Carlos, Universidade de São Paulo, São Carlos, 2006.

SCHULTEN, H. R., SCHNITZER, M. A state of the art structural concept for humic substances. Naturwissenschaften, v. 80, p. 29-30, 1993.

SCHULTEN, H. R.; SCHNITZER, M. Chemical model structures for soil organic matter and soils. Soil Science, v. 162, p. 115-130, 1997.

SIMÕES, M. L. Estudos de interações hidrofóbicas em substâncias húmicas e componentes do solo utilizando análises espectroscópicas. 2005. 147 f. Tese (Doutorado em Ciências e Engenharia de Materiais) - Escola de Engenharia de São Carlos, Universidade de São Paulo, São Carlos, 2005.

STEVENSON, F. J. Humus chemistry: genesis, composition, reactions. 2. ed. New York: John Wiley, 1994. 496 p.

SUTTON, R.; SPOSITO, G. Molecular structure in soil humic substances: the new view. Environmental Science and Technology, v. 39, n. 23, p. 9009-9015, 2005. 
SWIFT, R. S. Molecular weight, size, shape, and charge characteristics of humic substances: Some basic considerations. In: HAYES, M. H. B.; MacCARTHY, P.; MALCOLM, R. L.; SWIFT, R. S. (Ed.) Humic substances II: in search of structure. New York: John Wiley, 1989. p. 449-466.

ZECH, W.; SENESI, N.; GUGGENBERGER, G.; KAISER, K.; LEHMANN, J.; MIANO, T. M.; MILTNER, A.; SCHROTH, G. Factors controlling humification and mineralization of soil organic matter in the tropics. Geoderma, v. 79, p. 117-161, 1997.

WANDRUSZKA, von $R$. The micellar model of humic acid: evidence from pyrene fluorescence measurements. Soil Science, v. 163, p. 921-930, 1998.

WESTAD, F.; SCHMIDT, A.; KERMIT, M. Incorporating band-assignment in near infrared spectroscopy regression models. Journal of Near Infrared Spectroscopy, v. 16, p. $265-273,2008$. 